\author{
INSTITUTO DE QUÍMICA
}

DEPARTAMENTO DE QUÍMICA FUNDAMENTAL

\title{
ESTUDO DO COMPORTAMENTO TÉRMICO DE ASFALTENOS DE UM PETRÓLEO BRASILEIRO
}

\author{
Maria Luisa Aleixo Gonçalves \\ Tese de Doutorado \\ Prof. Dr. Jivaldo do Rosário Matos \\ Orientador \\ Dr. Arthur de Lemos Scofield \\ Co-orientador
}

SẢO PAULO

27 de Fevereiro de 2002 


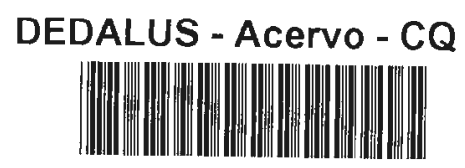

30100004686

Ficha Catalográfica

Elaborada pela Divisão de Biblioteca e

Documentação do Conjunto das Químicas da USP.

\begin{abstract}
Gonçalves, Maria Luisa Aleixo
G635e Estudo do comportamento térmico de asfaltenos de um petróleo brasileiro / Maria Luisa Aleixo Gonçalves. -- São Paulo, 2002.

$165 \mathrm{p}$.

Tese (doutorado) - Instituto de Química da Universidade de São Paulo. Departamento de Química Fundamental.

Orientador: Matos, Jivaldo do Rosário

Co-orientador : Scofield, Arthur de Lemos

1. Análise térmica : Química analítica 2. Termogravimetria Química analítica I. T. I1. Matos, Jivaldo do Rosário, orientador III. Scofield, Arthur de Lemos, co-orientador.
\end{abstract}




\section{"Estudo do Comportamento Térmico de Asfaltenos de um Petróleo Brasileiro"}

\section{MARIA LUISA ALEIXO GONÇALVES}

Tese de Doutorado submetida ao Instituto de Química da Universidade de São Paulo como parte dos requisitos necessários à obtenção do grau de Doutor em Química - Área: Química Analítica.

Aprovada por:

Prof.Dr. JIVALDO DO ROSÁRIO MATOS

$$
\text { IQ - USP }
$$

(Orientador e Presidente)

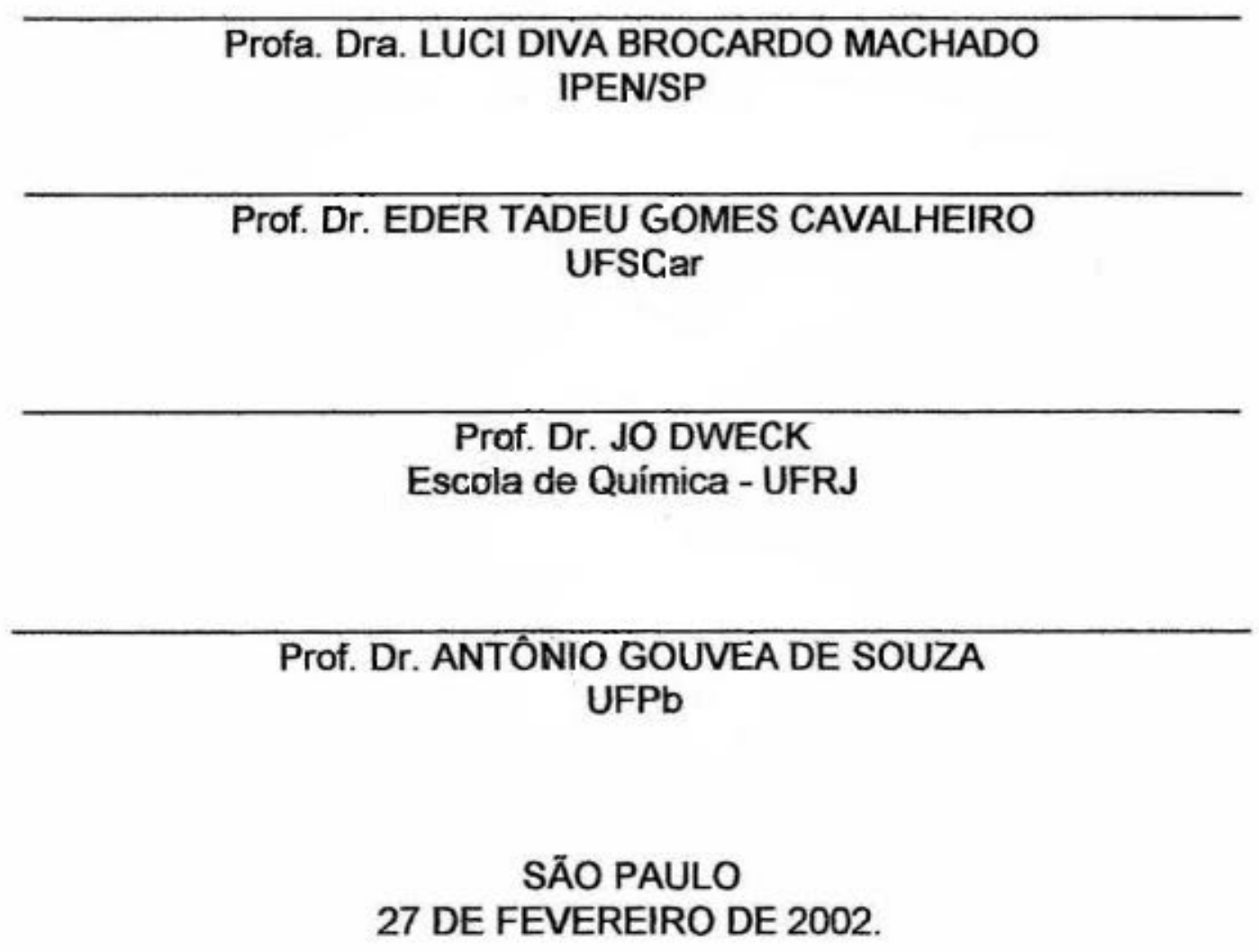


A meus pais - José e Laura,

A Lorena e Tassia, minhas filhas,

A meu marido - Hilton. 


\section{AGRADECIMENTOS}

Ao Prof. Dr. Jivaldo do Rosário Matos, pela orientação, amizade, confiança e oportunidade da realização deste trabalho.

Ao Dr. Arthur de Lemos Scofield, meu professor no Cenpes, pela co-orientação.

Ao Dr. Marco Antonio Gomes Teixeira, pela motivação, incentivo e valiosas discussões.

À Profa. Dra. Maria Encarnacion Vasquez Suarez Iha, pelo apoio no Instituto de Química da Universidade de São Paulo - USP.

Aos colegas do Laboratório de Análise Térmica Prof. Ivo Giolito - LATIG, pelo carinho, em especial à Lucildes Pita Mercuri e Maria Lurdes Felsner.

À Petrobras, por viabilizar a parte experimental do trabalho em seu Centro de Pesquisas - Cenpes.

À Rosana Kunert e Maria Cristina Saba, gerentes da Química no Cenpes durante o periodo desta pesquisa, pela confiança e apoio.

Aos engenheiros Francisco Carlos Costa, Claudia Alvarenga, Marcos de Freitas Sugaya e Roberto Lopes pelas informações sobre os processos de refino da Petrobras.

Às colegas do Cenpes, Rosana Cardoso Lopes Pereira, Sonia Cabral de Menezes e Naira Machado da Silva, pelos ensinamentos das técnicas de espectrometria de massa e ressonância magnética nuclear e discussões durante o desenvolvimento desse trabalho.

Às colegas Regina Célia Guimarães e Maria do Socorro J. Silva pelo fornecimento e preparo das amostras utilizadas na pesquisa.

Aos colegas do Cenpes que colaboraram na obtenção dos resultados, com destaque especial para Denise Dinis Filgueira, Ana Paula Nogueira Rego, Paula Alessandra, Bárbara Prestes de Castro, Manuel Joaquim Guimarães, Rosana Garrido, Claudia Maria Silva Braga, Aline Lopes Ferreira, Najla Maroun Estrada, Tereza Cristina Oliveira da Fonseca.

Às secretárias Telma Oliveira Ribeiro, Amanda dos Santos Lemos e Tatiene dos Santos Gama pela ajuda no preparo da documentação das muitas viagens a São Paulo.

À Universidade de São Paulo, que, no seu Instituto de Química, ofereceu a oportunidade de realização do trabalho.

E a todos que direta ou indiretamente contribuíram para esta realização. 


\section{RESUMO}

A decomposição térmica dos asfaltenos é a principal responsável pela formação de coque no processamento de petróleos. O fenômeno não é claramente entendido, pelas dificuldades ainda existentes na caracterização de tais componentes pesados do óleo.

Este trabalho apresenta informações sobre os produtos da decomposição térmica dos asfaltenos isolados de um petróleo da Bacia de Campos, maior bacia produtora de petróleo no Brasil. A abordagem envolveu: 1) estudos da decomposição térmica dos asfaltenos por termogravimetria (TG) em condições controladas; 2) caracterização dos produtos voláteis dessa decomposição por termogravimetria acoplada à cromatografia gasosa e espectrometria de massas (TG/DTA-CG-EM) e 3) caracterização dos produtos sólidos obtidos em diferentes temperaturas pela reação de oxidação catalisada pelo íon rutênio (RICO) que converte seletivamente alquil aromáticos em ácidos alcanóicos.

A decomposição térmica dos asfaltenos foi estudada por termogravimetria. Os asfaltenos se decompõem drasticamente entre 320 e $650^{\circ} \mathrm{C}$ produzindo $54 \%$ de produtos voláteis e $46 \%$ de coque.

O material volátil liberado dos asfaltenos a $700^{\circ} \mathrm{C}$ foi analisado por TG/DTA acoplado a CG-EM. Foi identificada uma série de alcanos contendo de $\mathrm{C}_{3}$ a $\mathrm{C}_{10}$. Esse resultado causou grande surpresa, pois na análise da pirólise de diferentes asfaltenos são observados alcanos com maior número de átomos de carbono. Outro experimento foi realizado, agora em duas etapas: coleta do material volátil e injeção desta no sistema GC-EM. Desta vez foi possível identificar a série homóloga de alcanos de $\mathrm{C}_{11}$ até $\mathrm{C}_{33}$.

Para o maior conhecimento da decomposição térmica dos asfaltenos, foram obtidos, em escala preparativa, produtos sólidos de decomposição térmica destes nas temperaturas de $320,380,400,440,480,550$ e $580^{\circ} \mathrm{C}$. As análises realizadas nesses produtos - elementar, espectroscopia na região do infravermelho, ressonância magnética nuclear de carbono 13 no estado sólido indicaram que quanto maior a temperatura de obtenção dos produtos sólidos, menor é o conteúdo de hidrogênio e carbono alifático. 
Os asfaltenos e os seus produtos de pirólise foram submetidos a reação de oxidação seletiva. Os ácidos gerados foram metilados para análise por CG-EM. Nos asfaltenos e nos produtos obtidos a $320,380,400$ e $440^{\circ} \mathrm{C}$ foram identificados ésteres metílicos lineares que indicaram a presença de hidrocarbonetos alifáticos contendo de 5 a 25 átomos de carbono, ésteres metílicos de ácidos dicarboxílicos que indicaram a presença de pontes alquilicas entre os grupamentos aromáticos contendo de 3 a 15 átomos de carbono e alguns ésteres metílicos de ácidos benzenodicarboxilicos. Comparando-se o teor total desses ésteres metílicos presentes em cada produto de reação, foi verificado que a concentração dos ésteres metílicos lineares diminui lentamente a 320, 380, $400^{\circ} \mathrm{C}$, e drasticamente a partir de $400^{\circ} \mathrm{C}$. O mesmo ocorrendo com os ésteres dos ácidos dicarboxílicos e benzeno dicarboxílicos, em menor concentração que os ésteres metílicos lineares. 


\section{ABSTRACT}

The thermal decomposition of asphaltenes is mainly responsible for the formation of coke in petroleum processing. The phenomena involved are not clearly understood, due to the difficulties in characterizing such heavy components.

This research reports the application of thermal analysis techniques to study the thermal behavior of asphaltenes from Brazilian oil (Campos Basin). The approach involves: 1) studies of the thermal decomposition of asphaltenes under controlled conditions by thermogravimetry (TG); 2) characterization of volatile fractions by thermogravimetry and differential thermal analysis coupled with gas chromatography and mass spectrometry (TG/DT-GC-MS); 3) solid products from the thermal decomposition of asfaltenes where subjected to ruthenium (VIII) ion catalyzed oxidation reaction (RICO) that converts selectively and efficiently, alkyl aromatics to alkanoic acids.

Thermogravimetry was used to study the asphaltenes thermal decomposition. The asphaltenes drastically decomposes from 320 to $650^{\circ} \mathrm{C}$ to produce $54 \%$ of volatile products and $46 \%$ of coke.

The volatile products of the asphaltenes at $700^{\circ} \mathrm{C}$ were done by TG/DTA coupled to GC-MS. The volatile material was identified as a series of straight chain of normal alkyl ranging from $\mathrm{C}_{3}$ to $\mathrm{C}_{10}$. This result indicated limitations of the apparatus employed n-alkyl chains longer than these were expected. However, it worked well for lighter components. Another experiment, in which gaseous products from pyrolysis procedure were recovered by bubbling in $\mathrm{CH}_{2} \mathrm{Cl}_{2}$, accounted for the heavier components. The solution obtained this time can be analyzed by syringe injection in a CG-MS. The majority of the volatile material is constituted of straight chain alkanes ranging from $\mathrm{C}_{13}$ to $\mathrm{C}_{33}$.

Knowing more about the thermal decomposition conversion of asphaltenes, the solid pyrolysis products of them were obtained in larger quantities at 320,380 , $400,440,480,550$ e $580^{\circ} \mathrm{C}$. They were characterized by elemental analysis and 
Os asfaltenos e os seus produtos de pirólise foram submetidos a reação de oxidação seletiva. Os ácidos gerados foram metilados para análise por CG-EM. Nos asfaltenos e nos produtos obtidos a $320,380,400$ e $440^{\circ} \mathrm{C}$ foram identificados ésteres metílicos lineares que indicaram a presença de hidrocarbonetos alifáticos contendo de 5 a 25 átomos de carbono, ésteres metílicos de ácidos dicarboxílicos que indicaram a presença de pontes alquilicas entre os grupamentos aromáticos contendo de 3 a 15 átomos de carbono e alguns ésteres metílicos de ácidos benzenodicarboxilicos. Comparando-se o teor total desses ésteres metílicos presentes em cada produto de reação, foi verificado que a concentração dos ésteres metílicos lineares diminui lentamente a 320, 380, $400^{\circ} \mathrm{C}$, e drasticamente a partir de $400^{\circ} \mathrm{C}$. O mesmo ocorrendo com os ésteres dos ácidos dicarboxílicos e benzeno dicarboxílicos, em menor concentração que os ésteres metílicos lineares. 


\section{ÍNDICE}

1. INTRODUÇÃO E OBJETIVOS ……............................................. 1

2. CONSIDERAÇÕES GERAIS ………….................................. 5

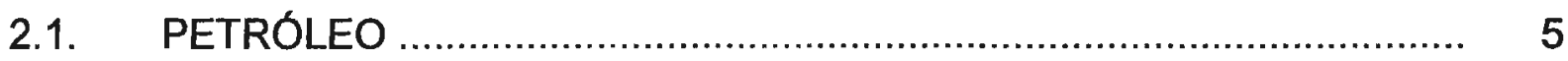

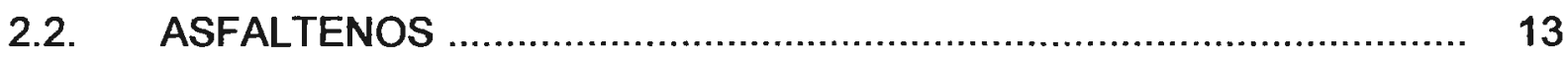

2.3. ANÁLISE TÉRMICA …................................................................... 16

2.3.1. Termogravimetria e a termogravimetria derivada ......................... 19

2.3.2. Análise térmica diferencial e a calorimetria exploratória diferencial .. 21

2.3.3. Aplicações da análise térmica em asfaltenos ................................. 25

2.4. REAÇÃO DE OXIDAÇĀO CATALISADA PELO ÍON RUTÊNIO VIII ...... 27

2.5. DESENVOLVIMENTO DO TRABALHO ……........................................ 30

3. PARTE EXPERIMENTAL ……………….............................................. $\quad 33$

3.1. MATERIAIS E REAGENTES ….................................................... 33

3.2. EXTRAÇÃO DOS ASFALTENOS ……….............................................. 33

3.3. CARACTERIZAÇĀO DOS ASFALTENOS ….......................................... 34

3.3.1. Análise elementar orgânica ................................................................. 34

3.3.2. Fluorescência de raios- $X$................................................................. 35

3.3.3. Espectrometria de massa com plasma indutivamente acoplado ...... 35

3.3.4. Calorimetria exploratória diférencial ........................................... $\quad 35$

3.3.5. Espectroscopia de absorção na região do infravermelho .............. 36

3.3.6. Termogravimetria .................................................................. 36

3.3.7. Ressonância magnética nuclear de carbono e de hidrogênio .......... 38

3.3.8. Osmometria de pressão de vapor ................................................ $\quad 38$

3.4. OBTENÇÃO DOS PRODUTOS SÓLIDOS DA DECOMPOSICCÃO
TÉRMICA DOS ASFALTENOS EM DIFERENTES TEMPERATURAS . 39

3.4.1. Formo tubular ..................................................................... 39

3.4.2. Termogravimetria .................................................................. 40

3.5. CARACTERIZAÇÃO DOS PRODUTOS SOLIDOS DA

DECOMPOSIÇA̋O TÉRMICA DOS ASFALTENOS EM DIFERENTES TEMPERATURAS

3.5.1. Análise elementar orgânica ................................................................ 42

3.5.2. Espectroscopia de absorção na região do infravermelho ..................... 42

3.5.3. Ressonância magnética nuclear do carbono ........................................ 42

3.5.4. Reação de oxidação catalisada pelo ín rutênio $(R / C O)$................. 43

3.5.5. Esterificação dos ácidos obtidos na reação RICO ......................... 45

3.5.6. Caracterização dos ácidos e ésteres metílicos por espectroscopia a regiấo do infravermelho 
3.5.7. Caracterização dos ésteres metilicos por cromatografia gasosa acoplada à espectrometria de massa

3.6. CARACTERIZAÇÃO DO MATERIAL VOLÁTIL PRODUZIDO DURANTE A DECOMPOSIÇÃO TÉRMICA DOS ASFALTENOS

3.6.1. Análise por termogravimetria e análise térmica diferencial simultâneas acopladas à cromatografia gasosa e espectrometria de massa

3.6.2. Análise por cromatografia gasosa acoplada à espectrometria de massas

4. RESULTADOS E DISCUSSŌES ........................................................... 50

4.1. ASFALTENOS DO ÓLEO DA BACIA DE CAMPOS ............................. 50

4.2. CARACTERIZAÇÃO DOS ASFALTENOS ISOLADOS DO PETRÓLEO DA BACIA DE CAMPOS

4.2.1. Análise por calorimetria exploratória diferencial ............................ 51

4.2.2. Análise elementar e osmometria por pressão de vapor ................... 52

4.2.3. Análise por espectroscopia de absorção na região do infravermelho 52

4.2.4. Ressonância magnética nuclear do carbono e hidrogênio ............... 54

4.3. COMPORTAMENTO TÉRMICO DOS ASFALTENOS ........................ 57

4.3.1. Termogravimetria .................................................................. 57

4.3.2. Cinética da decomposição térmica dos asfaltenos por

4.3.3. Termogravimetria isotérmica .................................................... 64

4.4. OBTENÇÃO E CARACTERIZAÇÃO DOS PRODUTOS DE
DECOMPOSIÇÃO TÉRMICA DOS ASFALTENOS ...................................6 65

4.4.1. Produtos sólidos da decomposição térmica (PSDT) dos asfaltenos 65

4.4.1.1. Preparo e caracterização dos PSDT dos asfaltenos utilizando forno tubular nas temperaturas de $320,380,450$ e $550^{\circ} \mathrm{C}$.

4.4.1.2. Preparo e caracterização dos PSDT dos asfaltenos utilizando equipamento TGA-951 nas temperaturas de 320,380, 400, 440, 480,550 e $550^{\circ} \mathrm{C}$

4.4.2. Produtos voláteis da decomposição térmica (PVDT) dos asfaltenos 97

4.4.2.1. $\quad$ PVDT dos asfaltenos liberados entre 30 e $250^{\circ} \mathrm{C} \mathrm{.....................} 98$

4.4.2.2. PVDT dos asfaltenos liberados entre 350 e $550^{\circ} \mathrm{C}$.................... 100

5. CONSIDERAÇÕES FINAIS ...................................................... 105

5.1. COMPORTAMENTO TÉRMICO DOS ASFALTENOS ......................... 105

5.2. GRUPAMENTOS ALQUILA LIGADOS AOS NÚCLEOS AROMATICOS DOS ASFALTENOS E EM SEUS PSDT 106

5.3. PONTES ALQUÍLICAS ENTRE NÚCLEOS AROMÁTICOS PRESENTES NOS ASFALTENOS E EM SEUS PSDT 106 
6. PERSPECTIVAS FUTURAS .................................................. 108

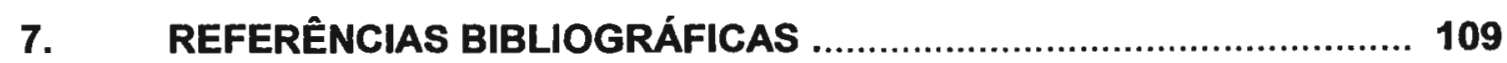

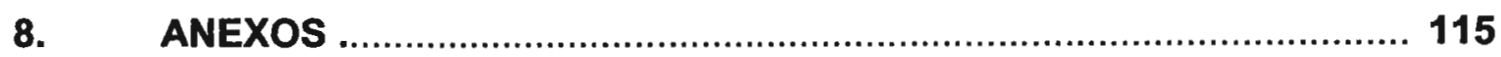

9. CURRICULUM VITAE ......................................................... 160 


\section{ÍNDICE DE FIGURAS}

Figura 2.1 - Esquema básico da unidade de destilação de uma refinaria ........ 6

Figura 2.2 - Esquema das unidades de craqueamento catalítico e coqueamento ......................................................................... 10

Figura 2.3 - Esquema para quantificação dos asfaltenos pelo método IP-143 . 13

Figura 2.4 - (a) Estrutura hipotética de asfaltenos proposta por Bestougeff e Byramjee (1994); (b) sugerida por Yen (1961) e por Watson (1994) .... 14

Figura 2.5 - Esquema de um sistema termoanalítico ............................... 17

Figura 2.6 - Curva típica de TG/DTG .................................................... 20

Figura 2.7 - Variações de massa detectáveis por termogravimetria .............. 21

Figura 2.8 - Curva típica de DTA (evento endotérmico)............................. 24

Figura 2.9 - Reação de aril-alcano e diaril-alcano com o íon Ru (VIII) ............ 28

Figura 2.10 - Reação de unidades de aromáticos condensados com o íon $\mathrm{Ru}$ (VIII)

Figura 2.11 - Reação com de tetróxido de rutênio em presença de agente oxidante

Figura 2.12 - Esquema analítico proposto para a avaliação da degradação térmica dos asfaltenos isolados do petróleo da Bacia de Campos

Figura 3.1- Esquema do forno tubular utilizado para a obtenção dos produtos sólidos nas emperaturas de $320,380,450$ e $550^{\circ} \mathrm{C}$

Figura 3.2 - Equipamento TGA-951 modificado para obtenção dos produtos sólidos da decomposição térmica dos asfaltenos nas temperaturas de $320,380,400,440,480,550,580^{\circ} \mathrm{C}$

Figura 3.3 - Esquema da reação RICO

Figura 3.4 - Esquema do equipamento para recolhimento dos voláteis produzidos durante a decomposição térmica dos asfaltenos e posterior análise por CG-EM

Figura 4.1 - Curva de DSC dos asfaltenos obtida na faixa de -100 a $+100^{\circ} \mathrm{C}$ a $5^{\circ} \mathrm{C} \mathrm{min}^{-1}$ em atmosfera de Hélio $\left(50 \mathrm{~mL} \mathrm{~min}^{-1}\right)$

Figura 4.2 - Espectro de absorção no IV dos asfaltenos isolados de um petróleo da Bacia de Campos

Figura 4.3 - Curva de termogravimetria dos asfaltenos (10 mg)de um óleo da Bacia de Campos a $10^{\circ} \mathrm{C} \mathrm{min}^{-1} \mathrm{sob}$ fluxo de $\mathrm{N}_{2}$ a $100 \mathrm{~mL} \mathrm{~min}^{-1}$

Figura 4.4 - Curva de termogravimetria em atmosfera de $\mathrm{N}_{2}\left(100 \mathrm{~mL} \mathrm{~min}^{-1}\right)$ entre 30 e $700^{\circ} \mathrm{C}$ e em AR $\left(100 \mathrm{~mL} \mathrm{~min}^{-1}\right)$ entre 700 e $1000^{\circ} \mathrm{C} \mathrm{min}^{-1} \ldots .$.

Figura 4.5- Fração residual $x$ temperaturas nas programações de aquecimento de $2,5,10$ e $20{ }^{\circ} \mathrm{C} \mathrm{min} \mathrm{m}^{-1}$

Figura 4.6 - Curvas de Log $b \times 1 / T$

Figura 4.7 - Decomposição térmica dos asfaltenos - Gráfico de conversão em produto sólido 
Figura 4.8 - Intensidade da banda de absorção dos ésteres $\left(1736 \mathrm{~cm}^{-1}\right)$ obtidos na reação RICO dos asfaltenos e PSDT- $320^{\circ} \mathrm{C}, \mathrm{PSDT}-380^{\circ} \mathrm{C}$ (célula de $1 \mathrm{~mm}$ de espessura); PSDT-450, PSDT $-550^{\circ} \mathrm{C}$ (célula de $0,2 \mathrm{~mm}$ de espessura)

Figura 4.9 - Tipos de carbonos quantificados por $\mathrm{RMN}^{13} \mathrm{C}$ 80

Figura 4.10 - Intensidade da absorção a $1710 \mathrm{~cm}^{-1}$ dos ácidos obtidos nos produtos da reação RICO com os asfaltenos e produtos de decomposição térmica (PSDTa- $320^{\circ} \mathrm{C}, \mathrm{PSDTa}-380^{\circ} \mathrm{C}, \mathrm{PSDTa}-400^{\circ} \mathrm{C}$, PSDTa $-440^{\circ} \mathrm{C}$, PSDTa $-480^{\circ} \mathrm{C}$, PSDTa $-550^{\circ} \mathrm{C}$ e PSDTa- $580^{\circ} \mathrm{C}$

Figura 4.11 - Cromatograma de íons: (a) ésteres metílicos isolados na reação RICO dos asfaltenos (b) ésteres metílicos isolados no ensaio em branco da reação RICO

Figura 4.12- (a)éster metílico de ácidos monocarboxílicos, (b) éster dimetílico de ácidos dicarboxílicos, (c)éster dimetílico de ácidos benzeno dicarboxílicos

Figura 4.13- Ésteres metílicos totais dos ácidos gerados na reação RICO com os asfaltenos e seus produtos de decomposição térmica

Figura 4.14 - Comparação das concentrações dos ésteres metílicos de ácidos monocarboxílicos gerados na reação RICO dos asfaltenos e produtos de decomposição térmica a 320, 380, 400, 440, 480, 550 e $580^{\circ} \mathrm{C}$

Figura 4.15- Comparação das concentrações dos ésteres metílicos de ácidos monocarboxílicos gerados na reação RICO dos asfaltenos e ,produtos de decomposição térmica a $320,380,400,440,480,550$ e $580^{\circ} \mathrm{C}$

Figura 4.16 - Comparação das concentrações dos ésteres metílicos de ácidos monocarboxílicos gerados na reação RICO dos asfaltenos e produtos de decomposição térmica a $440,480,550$ e $580^{\circ} \mathrm{C}$

Figura 4.17 - Quebra do grupamento alquila ligado ao anel aromático (n-pentadecilbenzeno ) proposto por Savage (1991)

Figura 4.18 - Comparação das concentração dos ésteres metílicos de ácidos dicarboxílicos gerados na reação RICO dos asfaltenos e produtos de decomposição térmica a $320,380,400,440,480,550$ e $580^{\circ} \mathrm{C}$

Figura 4.19 - Comparação das concentrações dos ésteres dimetílicos de ácidos benzodicarboxílicos gerados na reação RICO dos asfaltenos e produtos de decomposição térmica a 320, 380, 400, 440, 480, 550 e $580^{\circ} \mathrm{C}$

Figura 4.20 - Possíveis isômeros dos ésteres dimetílicos dos ácidos benzenodicarboxílicos $\left(\mathrm{C}_{8}\right)$ encontrado nos produtos da reação RICO dos asfaltenos e seus produtos de decomposição térmica

Figura 4.21 - Ésteres dimetílicos dos ácidos dimetil benzeno dicarboxílicos $\left(C_{9}\right.$ e $\left.C_{10}\right)$ encontrados nos produtos da reação RICO dos asfaltenos e seus produtos de decomposição térmica

Figura 4.22 - Compostos poliaromáticos que liberariam diácidos na reação RICO com 8 átomos de carbono 
Figura 4.23 - Estruturas aromáticas que geram poliácidos na reação RICO .. 96

Figura 4.24 - Representação esquemática do sistema DTG/CG-EM .............. 97

Figura 4.25 - Curva de TG/DTA dos asfaltenos entre 30 e $250^{\circ} \mathrm{C}$ no sistema acoplado DTG/CG-EM - $10^{\circ} \mathrm{C} \mathrm{min}^{-1} \mathrm{em} \mathrm{He}$ a uma vazão de $50 \mathrm{~mL}$ $\min ^{-1}$

Figura 4.26 - Cromatograma total de íons dos PVDT dos asfaltenos liberados entre 30 e $250^{\circ} \mathrm{C}$ no sistema DTG/CG-EM

Figura 4.27- Curva de TG/DTG/DTA dos asfaltenos entre 30 e $600^{\circ} \mathrm{C}$ no sistema acoplado DTG/CG-EM

Figura 4.28 - Cromatograma total de ions dos PVDT dos asfaltenos liberados entre 250 e $600^{\circ} \mathrm{C}$ no sistema DTG/CG-EM

Figura 4.29 - Esquema do equipamento TGA-951 para recolhimento dos PVDT dos asfaltenos e posterior análise por CG-EM

Figura 4.30 - Cromatogramas total de íons dos PVDT dos asfaltenos recuperados em $\mathrm{CH}_{2} \mathrm{Cl}_{2}$ :A-solução retirada do tubo de quartzo do equipamento TGA-951; B-solução contida no frasco coletor adaptado à saída do equipamento 


\section{ÍNDICE DE TABELAS}

Tabela 2.1 - Faixa de ebulição dos hidrocarbonetos obtidos na destilação atmosférica e vácuo do petróleo

Tabela 3. 1 - Origem dos reagentes utilizados

Tabela 3. 2 - Condições da DSC para determinação de parafinas em asfaltenos

Tabela 3. 3 - Condições analíticas da termogravimetria para análise do comportamento térmico dos asfaltenos

Tabela 3. 4 - Condições analíticas da termogravimetria isotérmica ( $T=320$, $380,430,438,450,480,550$ e $700^{\circ} \mathrm{C}$ )

Tabela 3. 5 - Condições analíticas para obtenção dos parâmetros cinéticos de decomposição térmica dos asfaltenos .

Tabela 3. 6 - Condições da análise de RMN ${ }^{1} \mathrm{H}$ e de $\mathrm{RMN}^{13} \mathrm{C}$

Tabela 3. 7 - Condições da análise para determinação do peso molecular dos asfaltenos

Tabela 3. 8 - Condiçס̃es do equipamento de TG para a obtenção dos coques nas temperaturas de $320,380,400,440,480,550,580$

Tabela 3. 9 - Condições analíticas para obtenção dos espectros de RMN ${ }^{13} \mathrm{C}$.

Tabela 3. 10 - Condiçōes da reação RICO com asfaltenos

Tabela 3. 11 - Condições analíticas utilizadas no sistema CG-EM para a caracterização dos ésteres metílicos procedentes da reação RICO ......

Tabela 3. 12 - Condições de análise para identificação dos voláteis no sistema acoplado TG/DTA-CG-EM

Tabela 3. 13 -Condições analíticas de CG-EM do material volátil recolhido durante a decomposição térmica dos asfaltenos no equipamento de TG

Tabela 4.1 - Características do Petróleo utilizado no estudo

Tabela 4.2 - Resultados de análise elementar dos asfaltenos isolados do óleo da Bacia de Campos

Tabela 4.3 - Comparação entre as absorções no IV da análise de asfaltenos de diferentes origens e o isolado da Bacia de Campos

Tabela 4.4 - Resultados da análise de RMN ${ }^{13} \mathrm{C}$ dos asfaltenos isolados do óleo da Bacia de Campos

Tabela 4.5 - Resultados da análise de $\mathrm{RMN}^{1} \mathrm{H}$ dos asfaltenos

Tabela 4.6 - Energia de ativação a diferentes niveis de conversão

Tabela 4.7 - Percentuais de resíduos em diferentes tempos obtidos a partir da TG isotérmica dos asfaltenos

Tabela 4.8 - Percentuais de PSDT dos asfaltenos obtidos em forno tubular após 20 min nas temperaturas de $320,380,450$ e $550^{\circ} \mathrm{C}$

Tabela 4.9 - Comparação dos percentuais de PSDT dos asfaltenos preparados no forno tubular e os medidos por TG

Tabela 4.10 - Análise elementar dos PSDT obtidos em forno tubular comparados com a análise dos asfaltenos

Tabela 4.11 - Resultados de ${ }^{13} \mathrm{C}$ RMN no estado sólido dos PSDT dos asfaltenos obtidos em forno tubular. 
Tabela 4.12 - Ésteres metílicos dos ácidos gerados na reação RICO com os asfaltenos e de seus produtos sólidos obtidos em forno tubular

Tabela 4.13 - Temperaturas do forno do TGA-951 durante a obtenção dos produtos sólidos da decomposição térmica dos asfaltenos

Tabela 4.14 - Quantidades de produtos sólidos obtidos a 320, 380,400,440, 480,550 e $580^{\circ} \mathrm{C}$ no equipamento TGA-951

Tabela 4.15 - Resultados da análise de TG dos produtos $\mathrm{PSDTa}-320^{\circ} \mathrm{C}$, PSDTa- $380^{\circ} \mathrm{C}$, PSDTa $-400^{\circ} \mathrm{C}$, PSDTa $-440^{\circ} \mathrm{C}$, PSDTa $-480^{\circ} \mathrm{C}$, PSDTa- $550^{\circ} \mathrm{C}$ e PSDTa- $580^{\circ} \mathrm{C}$

Tabela 4.16 - Análise elementar dos produtos PSDTa- $320^{\circ} \mathrm{C}, \mathrm{PSDTa}-380^{\circ} \mathrm{C}$, PSDTa- $400^{\circ} \mathrm{C}$, PSDTa- $440^{\circ} \mathrm{C}$, PSDTa- $480^{\circ} \mathrm{C}, \mathrm{PSDTa}-550^{\circ} \mathrm{C}$ e PSDTa- $580^{\circ} \mathrm{C}$

Tabela 4.17 - Análise de RMN $13 \mathrm{C}$ no estado sólido dos produtos PSDTa- $320^{\circ} \mathrm{C}$, PSDTa $-380^{\circ} \mathrm{C}$, PSDTa $-400^{\circ} \mathrm{C}$, PSDTa- $440^{\circ} \mathrm{C}$, PSDTa- $480^{\circ} \mathrm{C}$, PSDTa- $550^{\circ} \mathrm{C}$ e PSDTa- $580^{\circ} \mathrm{C}$

Tabela 4.18 - Séries de ésteres metílicos dos ácidos gerados na reação RICO com os asfaltenos e PSDTa- $320^{\circ} \mathrm{C}$, PSDTa- $380^{\circ} \mathrm{C}$, PSDTa $-400^{\circ} \mathrm{C}, \mathrm{PSDTa}-440^{\circ} \mathrm{C}, \mathrm{PSDTa}-480^{\circ} \mathrm{C}, \mathrm{PSDTa}-550^{\circ} \mathrm{C}$ e PSDTa- $580^{\circ} \mathrm{C}$

Tabela 4.19 - Temperatura de ebulição de ácidos e ésteres contendo de 2 a 7 átomos de carbono

Tabela 4.20 - Resultados da análise de CG-EM das soluções em $\mathrm{CHCl}_{2}$ dos PVDT coletados diretamente na saída do TGA-951 


\section{ÍNDICE DE ANEXOS}

Anexo 1 - Espectros de RMN ${ }^{13} \mathrm{C} \mathrm{e}{ }^{1} \mathrm{H}$ dos asfaltenos em solução de clorofórmio deuterado deuterado $\left(\mathrm{CDCL}_{3}\right)$

Anexo 2 - Curvas de TG dos asfaltenos em isotermas de 320, 380, 430, 480, $550,700^{\circ} \mathrm{C}$

Anexo 3 - Espectros de absorção no infravermelho dos produtos sólidos da decomposição térmica dos asfaltenos obtidos em forno tubular:

PSDT $-320^{\circ} \mathrm{C}, \mathrm{PSDT}-380^{\circ} \mathrm{C}, \mathrm{PSDT}-450^{\circ} \mathrm{C}$ e PSDT $-550^{\circ} \mathrm{C}$

Anexo 4 - Espectros de $\mathrm{RMN}^{13} \mathrm{C}$ no estado sólido dos asfaltenos e seus produtos sólidos de decomposição térmica gerados no forno tubular PSDT $-320^{\circ} \mathrm{C}, \mathrm{PSDT}-380^{\circ} \mathrm{C}$, PSDT $-450^{\circ} \mathrm{C}$ e PSDT $-550^{\circ} \mathrm{C}$

Anexo 5 - Espectros de absorção no IV dos ácidos gerados na reação RICO com os asfaltenos, PSDT $-320^{\circ} \mathrm{C}, \mathrm{PSDT}-380^{\circ} \mathrm{C}, \mathrm{PSDT}-450^{\circ} \mathrm{C}$ e PSDT $-550^{\circ} \mathrm{C}$

Anexo 6 - Espectros de absorção no IV dos ésteres metílicos dos ácidos gerados na reação RICO com os asfaltenos e seus produtos sólidos de decomposição térmica no forno tubular: PSDT $-320^{\circ} \mathrm{C}, \mathrm{PSDT}-380^{\circ} \mathrm{C}$, PSDT $-450^{\circ} \mathrm{C}$ e PSDT $-550^{\circ} \mathrm{C}$

Anexo 7 - Cromatogramas totais de íons da mistura de ésteres metílicos dos ácidos gerados na reação RICO com os asfaltenos e seus produtos sólidos de decomposição térmica obtidos no forno tubular: PSDT $-320^{\circ} \mathrm{C}$, PSDT $-380^{\circ} \mathrm{C}$, PSDT $-450^{\circ} \mathrm{C}$ e PSDT $-550^{\circ} \mathrm{C}$

Anexo 8 - Curvas de controle da temperatura do forno do TGA-951 na obtenção dos produtos sólidos da decomposição térmica dos asfaltenos: PSDTa- $320^{\circ} \mathrm{C}, \mathrm{PSDTa}-380^{\circ} \mathrm{C}, \mathrm{PSDTa}-400^{\circ} \mathrm{C}$, PSDTa- $440^{\circ} \mathrm{C}, \mathrm{PSDTa}-480^{\circ} \mathrm{C}$, PSDTa- $550^{\circ} \mathrm{C}$ e PSDTa- $580^{\circ} \mathrm{C}$

Anexo 9 - Curvas de TG/DTG dos produtos sólidos gerados na decomposição térmica dos asfaltenos em forno do TGA-951: PSDTa- $320^{\circ} \mathrm{C}$, PSDTa- $380^{\circ} \mathrm{C}, \mathrm{PSDTa}-400^{\circ} \mathrm{C}, \mathrm{PSDTa}-440^{\circ} \mathrm{C}, \mathrm{PSDTa}-480^{\circ} \mathrm{C}$, PSDTa- $550^{\circ} \mathrm{C}$ e PSDTa- $580^{\circ} \mathrm{C}$

Anexo 10 - Espectros de absorção no IV dos produtos sólidos gerados na decomposição térmica dos asfaltenos no forno do TGA-951:

PSDTa- $320^{\circ} \mathrm{C}$, PSDTa $-380^{\circ} \mathrm{C}$, PSDTa $-400^{\circ} \mathrm{C}$, PSDTa $-440^{\circ} \mathrm{C}$, PSDTa- $480^{\circ} \mathrm{C}$, PSDTa $-550^{\circ} \mathrm{C}$ e PSDTa- $580^{\circ} \mathrm{C}$

Anexo 11 - Espectros de $\mathrm{RMN}^{13} \mathrm{C}$ dos produtos sólidos da decomposição térmica dos asfaltenos no TGA-951: PSDT $-320^{\circ} \mathrm{C}, \mathrm{PSDT}-380^{\circ} \mathrm{C}$, PSDT $-400^{\circ} \mathrm{C}$, PSDT $-440^{\circ} \mathrm{C}$, PSDT- $480^{\circ} \mathrm{C}$, PSDT-550 $\mathrm{C}$ e PSDT-580 151

Anexo 12 - Cromatograma de íons relativos a cada classe de ésteres dimetílicos gerados na reação RICO com os asfaltenos PSDTa- $400^{\circ} \mathrm{C} .157$ 


\section{ABREVIATURAS}

\begin{tabular}{|c|c|}
\hline $\mathrm{C}_{\text {arom }} \cdot \ldots \ldots \ldots \ldots \ldots . . . . . . .$. & Carbono em cadeia aromático \\
\hline $\mathrm{C}_{\text {alif }} \ldots \ldots \ldots \ldots \ldots \ldots . . . . . . . .$. & Carbono em cadeia alifática \\
\hline CG-EM ............ & Cromatografia gasosa acoplada à espectrometria de massa \\
\hline CP/MAS .......... & Polarização cruzada com rotação no ângulo mágico \\
\hline DSC ................ & Calorimetria exploratória diferencial \\
\hline DTA . & Análise térmica diferencial (Differential Thermal analysis) \\
\hline DTG ................ & Termogravimetria derivada (Derivative thermogravimetry) \\
\hline DTG-CG-EM ... & $\begin{array}{l}\text { Termogravimetria e análise térmica diferencial simultâneas } \\
\text { acopladas à cromatografia gasosa e espectrometria de massa }\end{array}$ \\
\hline FCC .................. & Unidade de craqueamento catalítico (Fluid catalytic cracking) \\
\hline FTIR ................ & Infravermelho com transformada de Fourrier \\
\hline GLP ................ & Gás liquefeito de petróleo \\
\hline GOL .... & Gasóleo leve de petróleo \\
\hline GOP ........ & Gasóleo pesado de petróleo \\
\hline IV ............... & Espectroscopia de absorção na região do infravermelho \\
\hline MAS ... & Rotação do angulo mágico \\
\hline NQS .. & Non quaternary supression - técnica de $\mathrm{RMN}^{13} \mathrm{C}$ \\
\hline PSDT .............. & Produto sólido da decomposição térmica dos asfaltenos \\
\hline PVDT . & Produto volátil da decomposição térmica dos asfaltenos \\
\hline RAT . & Resíduo atmosférico de petróleo \\
\hline RICO .................. & $\begin{array}{l}\text { Reação de oxidação catalisada pelo íon rutênio (Rutenium ion } \\
\text { calalyzed oxidation reaction) }\end{array}$ \\
\hline $\mathrm{RMN}^{1} \mathrm{H} \ldots \ldots \ldots . . .$. & Ressonância magnética nuclear do hidrogênio \\
\hline $\mathrm{RMN}^{13} \mathrm{C} \ldots \ldots \ldots$ & Ressonância magnética nuclear do carbono 13 \\
\hline RV ..... & Resíduo de vácuo de petróleo \\
\hline .............. & Termogravimetria \\
\hline & Unidade de massa atômica \\
\hline
\end{tabular}




\section{INTRODUÇÃO E OBJETIVOS}

Asfaltenos são uma classe de substâncias presentes em óleos de xisto, carvões e petróleos, em concentrações, nesses últimos, que variam de $0,1 \% \mathrm{em}$ peso em óleos leves até $17 \%$ em óleos pesados, como o petróleo de Boscan (Tissot e Welte, 1984). De um modo geral, a definição mais aceita de asfaltenos é a de uma fração caracterizada por critérios de solubilidade, constituída de compostos insolúveis em hidrocarbonetos alifáticos e solúveis em hidrocarbonetos aromáticos (Speight, 1984).

Apesar de, muitas vezes, estarem presentes em baixa concentração nos óleos, os asfaltenos são, certamente, a fração de constituintes do petróleo que mais preocupa os pesquisadores, já que estão intrinsecamente relacionados com problemas de produção e refino de óleo.

$\mathrm{Na}$ produção, eles são os principais responsáveis pela formação de depósitos em colunas de escoamento de óleo, provocando paradas do poço produtor. A deposição não só afeta as colunas de escoamento como também pode causar redução da permeabilidade das rochas geradoras $e$, conseqüentemente, a queda de vazões de produção e até danos irreversiveis à formação rochosa (Leontaritis e Mansoori, 1988).

No refino, o problema agravou-se com o crescimento da demanda de combustiveis e destilados leves, acarretando a necessidade de conversão dos resíduos pesados de petróleo - antes utilizados apenas como combustiveis suplementares e impermeabilizadores - em produtos nobres. Os tratamentos térmicos e termocatalíticos para o processamento desses resíduos, onde se concentram os asfaltenos presentes no óleo, acarretam a formação de coque oriundo da degradação térmica das moléculas asfaltênicas. Esse material sólido carbonáceo acaba desativando o catalisador utilizado no processo (Speight, 1989), ou provocando deposição nos equipamentos da refinaria.

A conversão de resíduos pesados em produtos pode, segundo Speight (1992), ser classificada de duas maneiras: rejeição de carbono ou adição de 
hidrogênio. Independentemente de qual processo ocorra, a química envolvida é extremamente complexa e influencia enormemente a conversão. Sobre a conversão em produtos pesados de viabilidade comercial, Speight (1989) reconhece que a pouca química conhecida é absolutamente especulativa, e sustenta que a chave para o aumento da eficiência de conversão é o desenvolvimento de um melhor entendimento da química da formação de coque, principalmente através do conhecimento do comportamento térmico dos asfaltenos que seriam seus principais formadores.

Desta forma, torna-se relevante o estudo da degradação térmica e o maior aprofundamento no conhecimento da estrutura química dos asfaltenos de petróleo e de seu produto sólido de decomposição térmica, o coque. Na literatura verificase, entretanto, a concentração de esforços em melhorar a caracterização da estrutura macromolecular dos asfaltenos, sem o correspondente desenvolvimento de proposições de mecanismos para a decomposição térmica dos mesmos.

Os problemas de desativação de catalisadores e formação de borras que ocorrem durante os processamentos termocatalíticos e térmicos de residuos pesados de petróleo são fatos relevantes, que justificam uma avaliação mais profunda dos produtos oriundos da degradação térmica dos asfaltenos.

Em termos de estrutura molecular, os métodos físicos de análise têm sido muito utilizados para a obtenção de informações sobre a estrutura molecular dos asfaltenos (Christopher e colaboradores, 1996). A técnica de pirólise acoplada à cromatografia gasosa e espectrometria de massa (CG-EM) foi utilizada com o objetivo de transformar a estrutura complexa em frações menores, mais facilmente caracterizados (Wilhelms, 1993; Skjevrak, 1993; Eglinton, 1991; Jones e Douglas, 1987). Já a termogravimetria, foi utilizada (Bestougeff, 1962; Nicksic, 1968; Calderon e Cotte, 1983) unicamente com a intenção de avaliar a estabilidade térmica dos asfaltenos, sem a preocupação de identificar o material formado durante a sua decomposição térmica.

Na década de 80 , métodos seletivos de degradação química utilizando a reação de oxidação catalisada pelo ion rutênio (Strausz e colaboradores, 1985, 
1989) passaram a ser utilizados. Esse reagente converte núcleos aromáticos a ácidos carboxílicos, deixando os grupos alquila intactos (Courtney e Swansborough, 1972). Através da degradação química e degradação térmica, Strausz (1992) determinou, nos asfaltenos de Atabasca, os substituintes alquila do núcleo poliaromático e o tamanho dos mesmos.

Assim, a despeito dos esforços para o conhecimento químico dos asfaltenos, ainda se verificam alguns pontos na sua estrutura que não estão bem esclarecidos: 1) as ligações internucleares; 2) a distribuição dos heteroátomos nessa estrutura e 3 ) os mecanismos de remoção dos heteroátomos com a temperatura.

No Brasil, apesar do grande desenvolvimento no campo de pesquisa, a Petrobras ainda necessita de um conhecimento mais amplo sobre o comportamento térmico e características desses materiais.

Em vista disso, neste trabalho, propõe-se avaliar quimicamente os produtos da decomposição térmica dos asfaltenos de um petróleo brasileiro, tanto os produtos voláteis como o produto sólido, principalmente este último, pouco estudado, talvez pelas dificuldades de se encontrar metodologias analíticas para este tipo de material.

A proposta analítica apresentada neste trabalho engloba: 1) a utilização das técnicas de análise térmica - principalmente a termogravimetria - pouco explorada até o momento para a caracterização de asfaltenos de petróleo; 2) o acoplamento de técnicas termoanalíticas com técnicas de separação e identificação, como a cromatografia gasosa e a espectrometria de massa, como possibilidade para a caracterização dos produtos leves liberados na decomposição térmica dos asfaltenos; 3) a utilização da reação de oxidação catalisada pelo íon rutênio para caracterizar os produtos sólidos da decomposição térmica dos asfaltenos.

Acredita-se que um estudo mais detalhado do produto sólido da decomposição térmica e a avaliação de como a estrutura dos asfaltenos se 
comporta com a temperatura, podem gerar respostas para as questões ainda não resolvidas.

Os resultados da avaliação do efeito da temperatura no comportamento químico da fração de asfaltenos permitirão, a otimização das condições operacionais das unidades de craqueamento catalítico (FCC), principalmente de resíduos pesados de petróleo, fazendo com que haja um aumento na conversão desta fração em produtos. O conhecimento do comportamento térmico dos asfaltenos também será de grande valia para a unidade de tratamento térmico de resíduos pesados (coqueamento), em que, além dos produtos leves, o coque é um produto final. 


\section{CONSIDERAÇÕES GERAIS}

\subsection{PETRÓLEO}

O petróleo é constituído na sua maior parte de hidrocarbonetos parafínicos, naftênicos e aromáticos e, em menores quantidades, de compostos heteroatômicos e asfaltenos (Tissot e Welte, 1984). Os asfaltenos constituem a fração mais pesada do óleo e estão presentes em concentrações que variam de $0,1 \%$ a $17 \%$ em peso.

Para que se tenha o potencial energético do petróleo efetivamente aproveitado este deve ser desdobrado em cortes de faixas de ebulição características, denominadas frações.

A destilação é o método de separação que define o rendimento de cada fração fornecendo a composição do óleo e informando como será seu comportamento durante o refino. Os pontos de ebulição dos hidrocarbonetos aumentam com o aumento de suas massas molares. Desta forma, com a variação das condições de aquecimento de um petróleo, é possível a vaporização de compostos leves, intermediários e pesados, que, ao se condensarem, podem ser separados. Paralelamente, ocorre a formação de um resíduo bastante pesado, constituído principalmente de hidrocarbonetos de elevadas massas molares, que não vaporizam nas condições de temperatura e pressão nas quais a destilação é realizada.

Um fator importante no processo de destilação do óleo é a pressão a que ele está sendo submetido. Quanto maior for a pressão exercida, maior será a temperatura de ebulição do líquido. A conjugação destes dois parâmetros temperatura e pressão permite que o petróleo seja separado em suas diversas frações.

Uma unidade de destilação na refinaria é basicamente composta de três seções principais: 1) pré-aquecimento e dessalinização, 2) destilação atmosférica e 3) destilação a vácuo (Figura 2.1). 


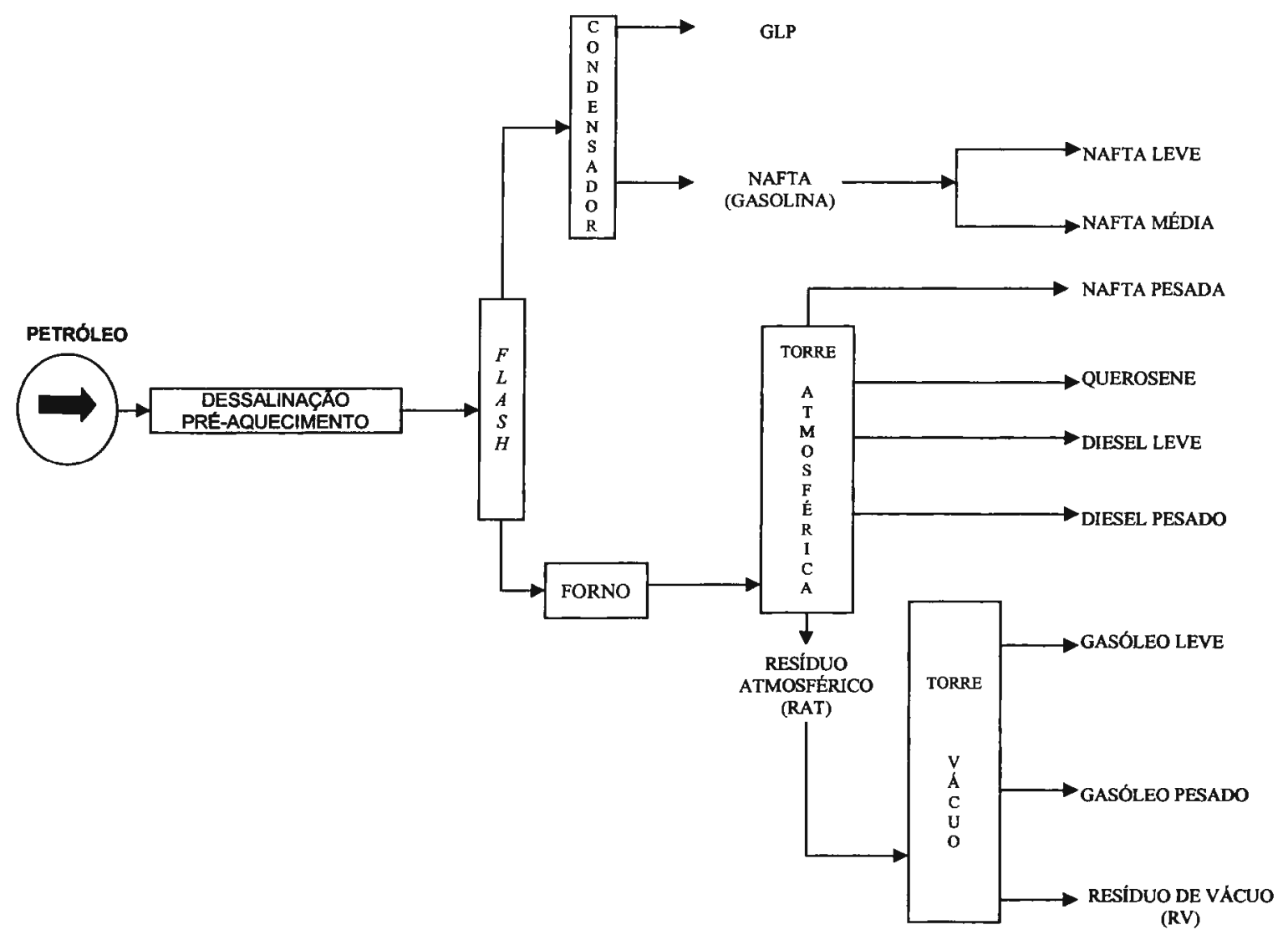

Figura 2. 1-Esquema básico da unidade de destilação de uma refinaria.

O processo de destilação tem início com o bombeamento do óleo frio através de vários trocadores de calor, onde é progressivamente aquecido ao mesmo tempo em que resfria os produtos que deixam a unidade de destilação.

Antes do óleo ser enviado à seção de fracionamento, passa por uma dessalgadora para remover os sais, água e partículas em suspensão. Esses contaminantes, se não forem retirados do petróleo causam sérios danos às unidades de destilação devido ao caráter corrosivo dos mesmos.

O petróleo dessalgado passa por uma torre de pré-fracionamento (flash) onde são recolhidas as frações mais leves: nafta leve e o gás liquefeito de petróleo (GLP). 
O petróleo pré-vaporizado deixa a torre de pré-fracionamento e é encaminhado para uma segunda bateria de fornos, onde a sua temperatura é elevada ao máximo valor possivel conseguida por troca térmica com as correntes quentes que deixam o processo. Quanto maior for a temperatura atingida no préaquecimento, menor será a quantidade de combustivel gasta nos fornos para o aquecimento final do óleo.

Ao sair do último trocador de pré-aquecimento, o petróleo está ainda com a temperatura muito abaixo da requerida para que ocorra o seu fracionamento óleo. Então, antes de entrar na unidade de destilação, passa por fornos tubulares onde recebe a energia térmica produzida pela queima do óleo ou mesmo do gás produzido na unidade atingindo a temperatura de $700^{\circ} \mathrm{F}\left(371^{\circ} \mathrm{C}\right)$. A partir dessa temperatura, tem início a decomposição térmica das frações pesadas presentes no óleo bruto. $O$ craqueamento térmico é uma ocorrência indesejável porque provoca a deposição de coque nos tubos dos fornos e nas regióes das torres, causando problemas operacionais.

À saída dos fornos, boa parte do petróleo já se encontra vaporizado e nestas condições é introduzido na torre de destilação à pressão atmosférica.

As torres de destilação à pressão atmosférica possuem, no seu interior, bandejas que permitem a separação do petróleo em cortes pelos seus pontos de ebulição. Os hidrocarbonetos cujos pontos de ebulição são maiores ou iguais à temperatura de uma determinada bandeja ficam retidos, enquanto que o restante prossegue em direção ao topo até encontrar outra bandeja, mais fria, onde o fenômeno se repete. Em determinados pontos da coluna os produtos são retirados da torre, segundo as temperaturas limites de destilação das frações. Os componentes mais leves, que não condensaram em nenhuma bandeja, saem pelo topo e são condensados em trocadores de calor fora da torre.

Uma torre de destilação de petróleo que trabalhe em condições atmosféricas tem como produtos o óleo diesel, o querosene e a nafta pesada. $O$ resíduo da destilação atmosférica que deixa o fundo da coluna é conhecido como 
Resíduo Atmosférico (RAT), e dele ainda podem ser retiradas frações importantes por destilação a vácuo, segundo estágio do refino de petróleo.

O RAT é um corte de alta massa molecular e nele já se concentram os asfaltenos presentes no óleo. O RAT tem baixo valor comercial, entretanto nele estão contidas frações de elevado potencial econômico, que não podem ser separadas na destilação atmosférica por causa dos seus altos pontos de ebulição. Assim, esse resíduo é encaminhado às torres de destilação que operam a vácuo.

Da mesma forma que na destilação atmosférica, o RAT é bombeado para os fornos da seção de vácuo para que sua temperatura seja aumentada. Nos fornos, ele não ultrapassa $371^{\circ} \mathrm{C}$, temperatura máxima para que não ocorra o craqueamento da carga.

É comum a injeção vapor d'água nos fornos de vácuo para aumentar a turbulência da carga que está sendo injetada e diminuir o tempo de residência da mesma nos fornos. O vapor d'água minimiza a deposição de coque nas fornalhas. O abaixamento da pressão é feito por intermédio de uma série de condensadores e ejetores que, por meio da condensação do vapor d'água e de alguns hidrocarbonetos, produzem o vácuo.

A carga aquecida, após deixar os fornos, vai para a torre de vácuo a uma pressão de $100 \mathrm{mmHg}$ o que já provoca a vaporização de boa parte da carga. Os hidrocarbonetos vaporizados, como na destilação atmosférica, atravessam as bandejas de fracionamento e são coletados em duas retiradas laterais: gasóleo leve (GOL) e gasóleo pesado (GOP). O GOL é um produto pouco mais pesado que o óleo diesel e pode ser a ele misturado quanto seu ponto inicial de ebulição não é elevado. O GOP é utilizado como carga da unidade de craqueamento catalítico (Figura 2.2).

O produto residual da destilação é conhecido como Residuo de Vácuo (RV). Ele é constituido de hidrocarbonetos de elevadíssima massa molar. Conforme suas especificações, pode ser vendido como óleo combustível ou asfalto. Em algumas refinarias, ele é carga da unidade de coqueamento. Nessa 
unidade, o RV é transformado em coque, um produto vendido para as siderúrgicas.

A Tabela 2.1 descreve as faixas de ebulição das frações de petróleo obtidas na destilação atmosférica e destilação a vácuo do óleo.

Tabela 2. 1 - Faixa de ebulição dos hidrocarbonetos obtidos na destilação atmosférica e vácuo do petróleo

\begin{tabular}{l|c}
\hline \multicolumn{1}{c|}{ FRAÇÕES } & FAIXA DE EBULIÇÃO $\left({ }^{\circ} \mathrm{C}\right)^{*}$ \\
\hline Nafta leve & $21-150$ \\
\hline Gasolina & $20-180$ \\
\hline Nafta pesada & $150-205$ \\
\hline Querosene & $205-260$ \\
\hline Gasóleo leve & $300-400$ \\
\hline Gasóleo pesado & $400-550$ \\
\hline Resíduo atmosférico & $>370$ \\
\hline Resíduo de vácuo & $>540$ \\
\hline
\end{tabular}

*Faixa de ebulição que depende da refinaria

Petróleos de diferentes origens contém concentrações diferentes de cada uma dessas frações. Assim, alguns óleos apresentam quantidades maiores de constituintes com baixo ponto de ebulição, enquanto outros têm elevadas proporções de componentes com alto ponto de ebulição. As frações mais pesadas do óleo - RAT e RV - obtidas durante o refino, apresentam maiores concentrações dos asfaltenos.

Com o processamento cada vez maior de óleos pesado e com o aumento da demanda de produtos nobres (gasolina e diesel), o RAT que é utilizado como carga da unidade de destilação a vácuo passou a ser utilizado, também, como carga da unidade de craqueamento catalítico (Figura 2.2).

Na unidade de craqueamento catalítico (FCC-Fluid Catalytic Cracking), o gasóleo pesado proveniente da destilação a vácuo e o RAT proveniente da destilação atmosférica saem das unidades de destilação aquecidos a $300^{\circ} \mathrm{C}$ e são encaminhados para a base do vaso de reação (riser). Neste ponto, recebem uma grande quantidade de catalisador à alta temperatura. A mistura carga-catalisador atinge temperaturas que vão de 550 a $580^{\circ} \mathrm{C}$, provocando instantânea 
vaporização da carga. A mistura carga-catalisador entra no vaso de reação de forma ascendente e as cadeias moleculares da carga, pela ação da temperatura e do catalisador, são quebradas, dando origem a hidrocarbonetos de cadeia menores. Este processo tem como finalidade principal a produção de GLP e gasolina. São produzidos também o óleo de reciclo leve e pesado. O produto de fundo da fracionadora é constituído de frações pesadas residuais de craqueamento e de partículas de catalisador que foram arrastadas pela corrente gasosa que deixou o reator.

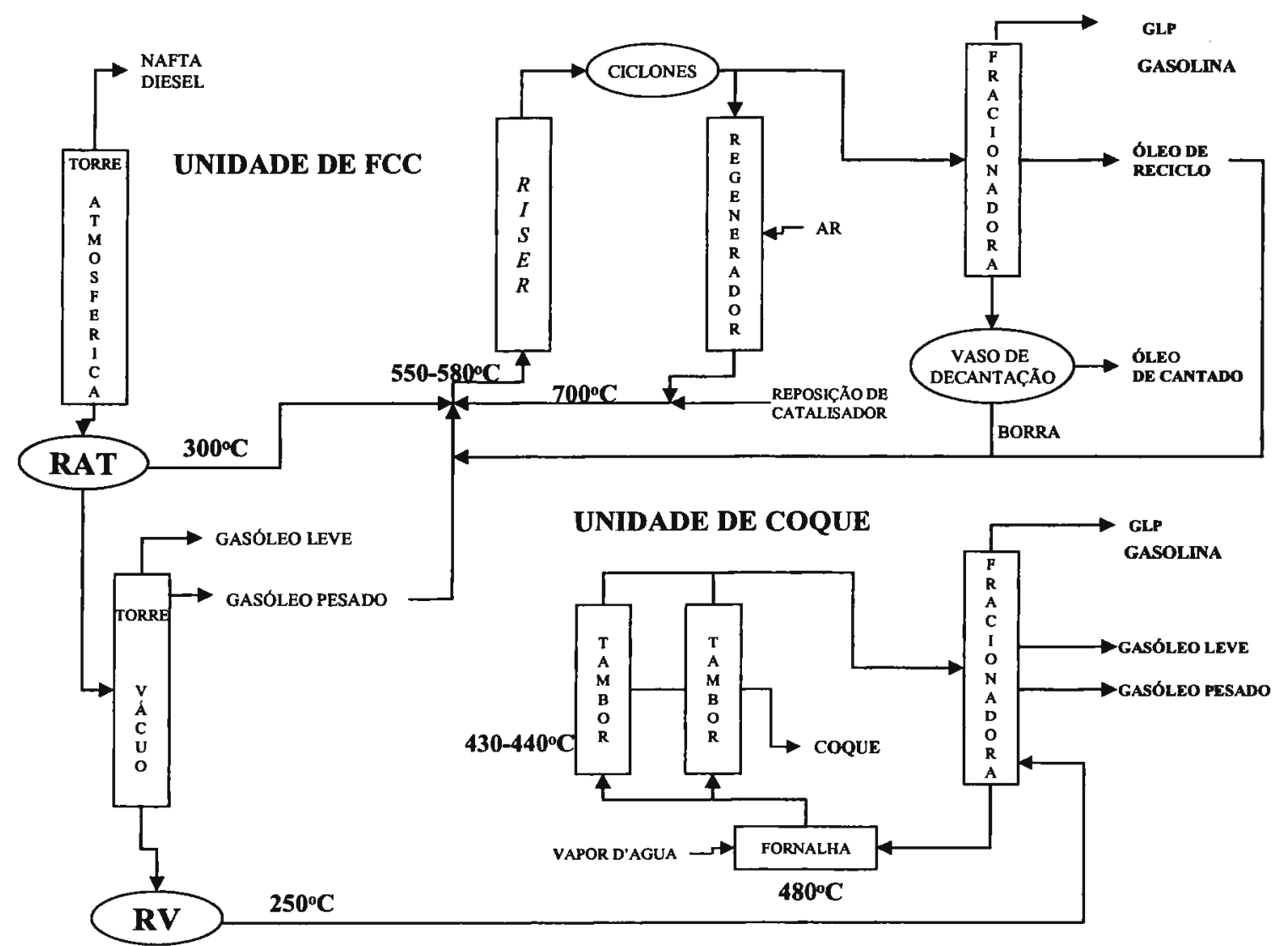

Figura 2. 2 - Esquema das unidades de craqueamento catalítico e coqueamento.

Este resíduo é enviado a um vaso de decantação, onde pelo topo sai o óleo decantado ou clarificado, isento de partículas sólidas. No vaso decantador, além do óleo decantado ou clarificado, é obtida uma borra de óleo e catalisador que é totalmente reciclada ao reator. 
Na unidade de FCC ocorre também a formação de coque - resíduo de alto teor de carbono - que se deposita na superfície do catalisador. Para que a ação catalítica não seja prejudicada, é necessária a remoção desse coque. $O$ catalisador desativado é então retirado do vaso de reação e enviado para o regenerador para que o coque seja removido por combustão. Durante esse processo, uma grande quantidade de calor é gerada e é totalmente aproveitada para o aquecimento da carga e do vaso de craqueamento.

Quando o RAT usado como carga para a unidade de FCC é proveniente de um óleo pesado - rico em asfaltenos - a quantidade de coque que se forma durante o processo é grande. A deposição de coque na unidade de FCC é desejável até um certo ponto. Excesso desse material, além de acarretar problemas no funcionamento da unidade, acarreta perdas na produção de produtos desejáveis. Neste ponto, já é percebida a necessidade do conhecimento do comportamento térmico dos asfaltenos frente às temperaturas aplicadas na unidade de FCC. Este conhecimento auxiliará os estudos de otimização do processamento de óleos pesados, melhorando o rendimento de produtos nobres e formação de coque suficiente para gerar a energia da unidade.

Além do craqueamento catalítico ( $F C C)$, existem outros processos térmicos para conversão de frações mais pesadas de petróleo. Nessas unidades, as frações pesadas são transformadas em produtos mais leves pela ação da temperatura e pressão. Nesses processos se enquadram o craqueamento térmico, a viscorredução e o coqueamento. Todos são baseados na decomposição de cadeias pesadas de hidrocarbonetos, gerando moléculas mais leves. Paralelamente, uma parte da carga é convertida em coque. Os três processos diferem fundamentalmente no interesse do produto final.

O craqueamento térmico, o mais antigo dos processos térmicos de refino, tem como finalidade a produção de gasolina e gases. A viscorredução tem a finalidade de diminuir a viscosidade de cargas pesadas de modo que sejam aproveitadas como óleo combustivel. Tanto um quanto o outro são considerados processos obsoletos, que foram substituidos pelo craqueamento catalítico, processo mais econômico. 
O coqueamento é um processo térmico um pouco mais moderno que o craqueamento térmico e a viscorredução (Barros, 1998). Tem como finalidade principal a de produzir gasóleo para carga de FCC. O coque formado nessa unidade é recuperado e vendido como produto. Além do GOL, GOP e do coque, essa unidade produz também GLP e gasolina.

O resíduo pesado proveniente da destilação a vácuo é, normalmente, a carga utilizada na unidade de coqueamento (Figura 2.2). $O$ processo tem início com o aquecimento e introdução desta carga diretamente no fundo da fracionadora. Os produtos leves saem pelo topo da unidade e o material pesado é transferido para uma fornalha onde é rapidamente aquecido a $480^{\circ} \mathrm{C}$. Ao sair da fornalha, passam aos tambores de coque para a formação do coque permanecendo entre $430-450^{\circ} \mathrm{C}$ por 24 horas.

A fornalha é o equipamento mais crítico da unidade de coqueamento, porque como a carga vai ser aquecida a uma temperatura maior que a da zona de craqueamento, é necessário evitar a deposição de coque nas paredes das serpentinas. Para desfavorecer a formação de coque, vapor d'água é injetado, o que provoca alta turbulência naquela região, evitando a deposição de coque. $O$ coqueamento não se dá na fornalha, mas é "retardado" para que ocorra nos tambores, e dai se originou o nome do processo - coqueamento retardado.

Como no craqueamento catalítico de resíduos, na unidade de coqueamento retardado, a carga passa por diferentes temperaturas. Sendo a carga um resíduo pesado terá uma elevada concentração de asfaltenos que são os principais geradores de coque (Speight, 1989). Neste ponto, é verificado que os resíduos pesados, ricos em asfaltenos, utilizados como cargas nas unidades de tratamento térmico da refinaria, são submetidos a temperaturas elevadas. 0 conhecimento do comportamento térmico dos asfaltenos nessas temperaturas $\left(440,480,550,580^{\circ} \mathrm{C}\right)$, seria de fundamental importância para a otimização dessas unidades. 


\subsection{ASFALTENOS}

Como já mencionado, os asfaltenos são os constituintes mais pesados do petróleo. Apesar de estarem presentes em pequenas quantidades nos óleos, se concentram nas frações mais pesadas e, por sua característica macromolecular, são os responsáveis por uma série de problemas durante o refino.

De um modo geral, a definição mais aceita de asfaltenos é a de uma fração caracterizada por critérios de solubilidade, constituída de materiais insolúveis em hidrocarbonetos alifáticos e solúveis em hidrocarbonetos aromáticos (Speight, 1984).

Os asfaltenos são quantificados no petróleo tomando-se como base a sua definição. A metodologia normalmente utilizada pelas indústrias de petróleo é um ensaio padronizado pelo Institute of Petroleum (Standard Methods for Analysis and Testing of Petroleum and Related Products - vol. 1 IP143) que consiste basicamente na precipitação de parte do óleo com heptano e, em seguida, solubilização do precipitado com tolueno. Os material solúveis em tolueno são, então, denominado de asfaltenos (Figura 2.3).

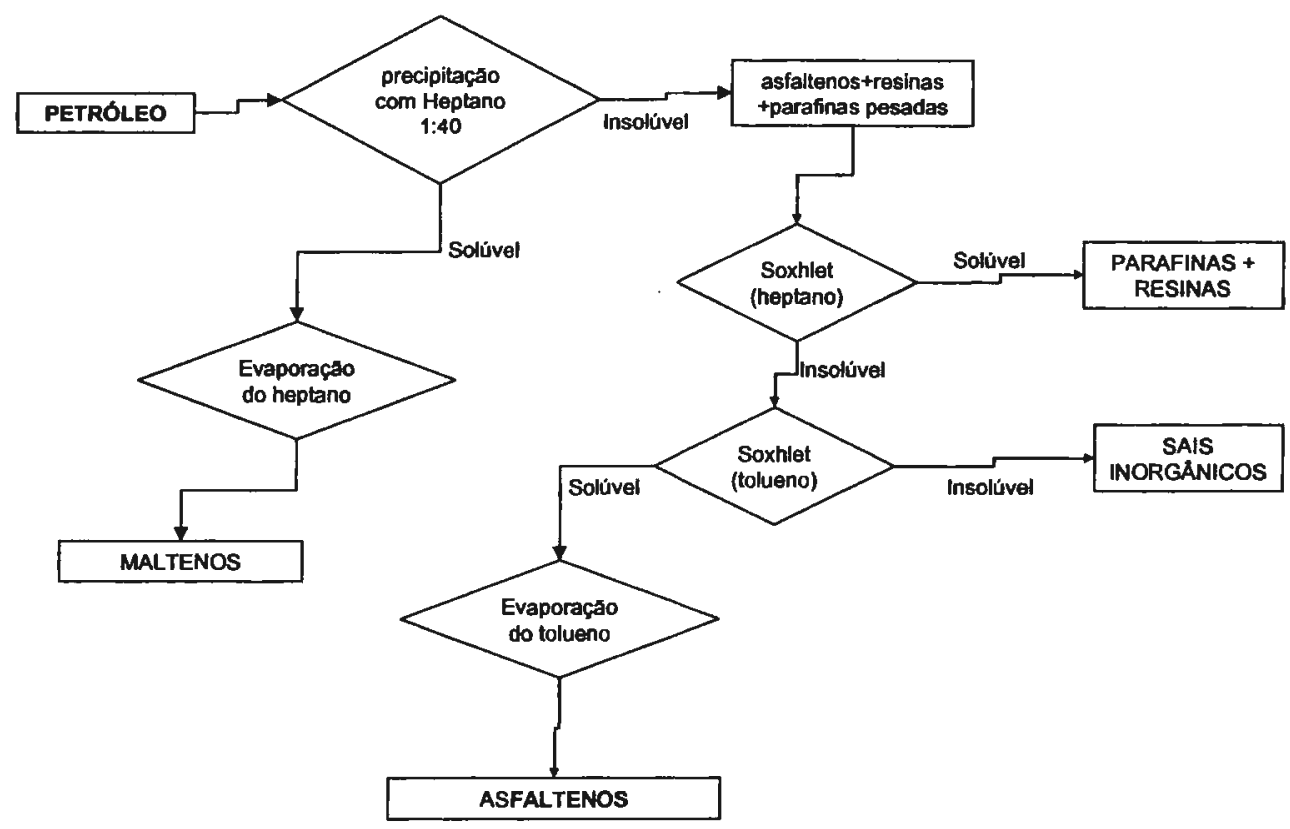

Figura 2. 3 - Esquema para quantificação dos asfaltenos pelo método IP. 143. 
Os pesquisadores postulam, como estrutura dos asfalteno, um núcleo poliaromático condensado que sustenta substituintes alquillicos e hidroaromáticos contendo heteroátomos. É uma estrutura com características macromoleculares, apresentando massa molar entre 1000 a 10000 u. A Figura 2.4a mostra uma estrutura hipotética proposta para um asfalteno de petróleo. Essa estrutura é baseada apenas no sistema poliaromático (Bestougeff e Byramjee, 1994).

Os estudos de difração de raios $X$ revelaram que os asfaltenos se agregam através do perfilamento dos núcleos poliaromáticos ligados pelos grupamentos alquila por pontes de hidrogênio, conferindo à molécula uma estrutura lamelar (Figura 2.4b) (Yen, 1961 e Watson e Barteau, 1994). Mais recentemente, pesquisas na área de modelagem molecular sugeriram agregados mais complexos (Murgich e colaboradores, 1995), viabilizando o entendimento de fenômenos físico-químicos dos asfaltenos - como estabilizações de emulsões e modificações da molhabilidade da rocha produtora - que não são explicados se for levada em consideração apenas a estrutura poliaromática.

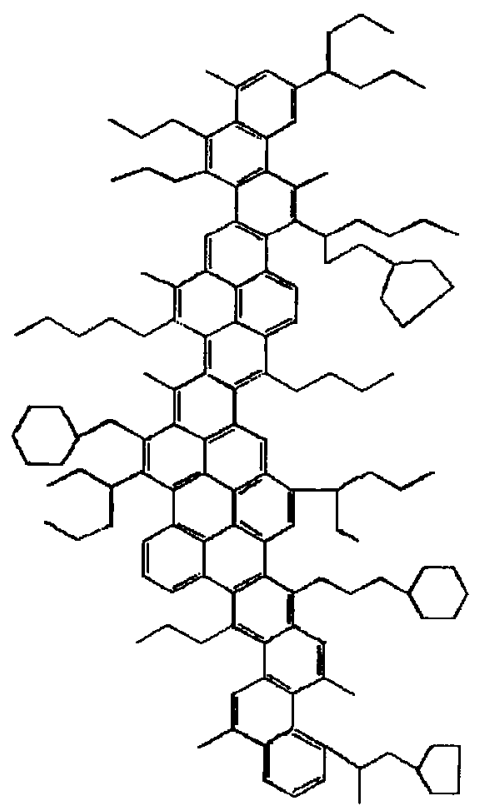

(a)

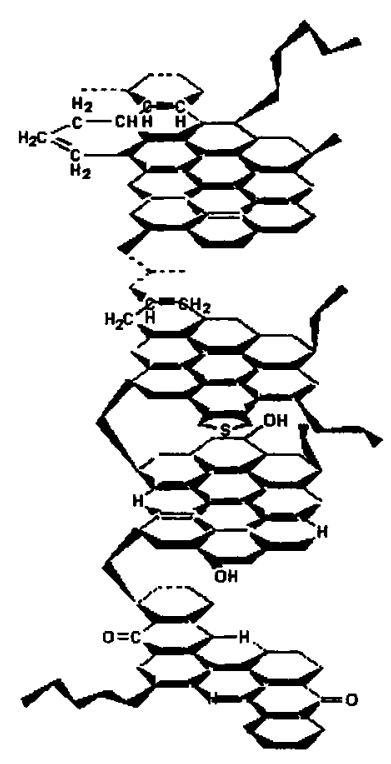

(b)

Figura 2. 4 - (a) Estrutura hipotética de asfaltenos proposta por Bestougeff e Byramjee (1994); (b) sugerida por Yen (1961) e por Watson (1994). 
Em termos de estrutura molecular, os métodos físicos de análise têm sido muito utilizados para a obtenção de informações sobre a molécula de asfaltenos, com destaque para a ressonância magnética nuclear do carbono $13\left(\mathrm{RMN}^{13} \mathrm{C}\right)$, que fornece parâmetros do sistema poliaromático sem, entretanto, apresentam informações sobre a disposição dos heteroátomos nessa estrutura (Christopher e colaboradores, 1996). Estes elementos estão presentes nos asfaltenos em concentrações que vão de 1 a 1,5\% de nitrogênio e oxigênio e 5 a $8 \%$ de enxofre (Speight, 1994).

Alguns pesquisadores lançaram mão dos ensaios térmicos com o objetivo de transformar a estrutura complexa em frações menores, mais facilmente caracterizados. A pirólise acoplada à cromatografia gasosa e à espectrometria de massa (Py-CG-EM) são as técnicas mais utilizadas (Wilhelms, 1993; Skjevrak,1993; Eglinton,1991; Jones e Douglas, 1987).

A termogravimetria, técnica termoanalítica, foi utilizada por alguns autores (Bestougeff, 1962; Nicksic, 1968; Calderon e Cotte, 1983), unicamente com a intenção de avaliar a estabilidade térmica dos asfaltenos, sem estender o estudo de identificação ao material de degradação térmica.

Speight (1989), avaliando termicamente um asfalteno na faixa de 300 a $900^{\circ} \mathrm{C}$, verificou a presença de materiais de baixa massa molecular nos produtos da decomposição térmica dos asfaltenos, deduzindo que o sistema poliaromático, mais complexo, deva permanecer como resíduo não volátil (coque). Verificou, também, que esse resíduo sólido representa $45 \%$ dos asfaltenos. Em investigações posteriores, Speight (1994) constatou que a maior parte do oxigênio e enxofre presentes nos asfaltenos é eliminada durante o tratamento térmico, enquanto o nitrogênio permanece quase em sua totalidade. Esta tendência é uma forte indicação de que este heteroátomo é estável na estrutura asfaltênica e está, portanto, distribuído no sistema poliaromático.

Outros autores dedicaram-se ao estudo da degradação térmica de asfaltenos de petróleo (Ekwenchi, 1984; Savage, 1985; Trauth, 1992; Christy, 1992), mas com atenção apenas na identificação dos produtos voláteis da sua 
decomposição térmica, talvez pela dificuldade de caracterização do resíduo sólido - coque - que se forma após essa degradação.

Strausz e colaboradores (1985, 1989), ainda com a intenção de conhecer melhor a estrutura dos asfaltenos, aplicaram métodos seletivos de degradação utilizando a reação de oxidação com tetróxido de rutênio, método conhecido como RICO (ruthenuim ion-catalyzed oxidation). Esse reagente converte núcleos aromáticos em ácidos carboxílicos, deixando os grupos alquila intactos (Courtney e Swansborough,1972). Por meio da degradação química e degradação térmica, Strausz (1992) determinou, nos asfaltenos de Atabasca, os substituintes alquila do núcleo poliaromático e o tamanho dos mesmos.

\subsection{ANÁLISE TÉRMICA}

Análise térmica é o termo utilizado para definir um grupo de técnicas em que uma propriedade física de uma substância ou de seus produtos de reação é medida em função da temperatura ou do tempo, enquanto esta substância é submetida a um programa controlado de temperatura (Mackenzie, 1984).

Os primeiros métodos termoanalíticos começaram a ser aplicados por volta de 1800. A evolução desta técnica se deu lentamente e os trabalhos iniciais resultaram de esforços isolados de alguns grupos de pesquisadores, empregando instrumentos rudimentares (Duval, 1963; Szabadvary e Buzagh-Gere, 1979 e Giolito, 1988).

Em um sistema de análise térmica genérico (Figura 2.5), a amostra é colocada em um ambiente no qual é possível observar, direta ou indiretamente, uma modificação em função da temperatura e do tempo. As mudanças ocorridas na amostra são monitoradas por um transdutor apropriado, que produz um sinal elétrico análogo à mudança física ou química. Este sinal é ampliado eletronicamente e aplicado ao dispositivo de leitura e registro (Matos, 1998). 


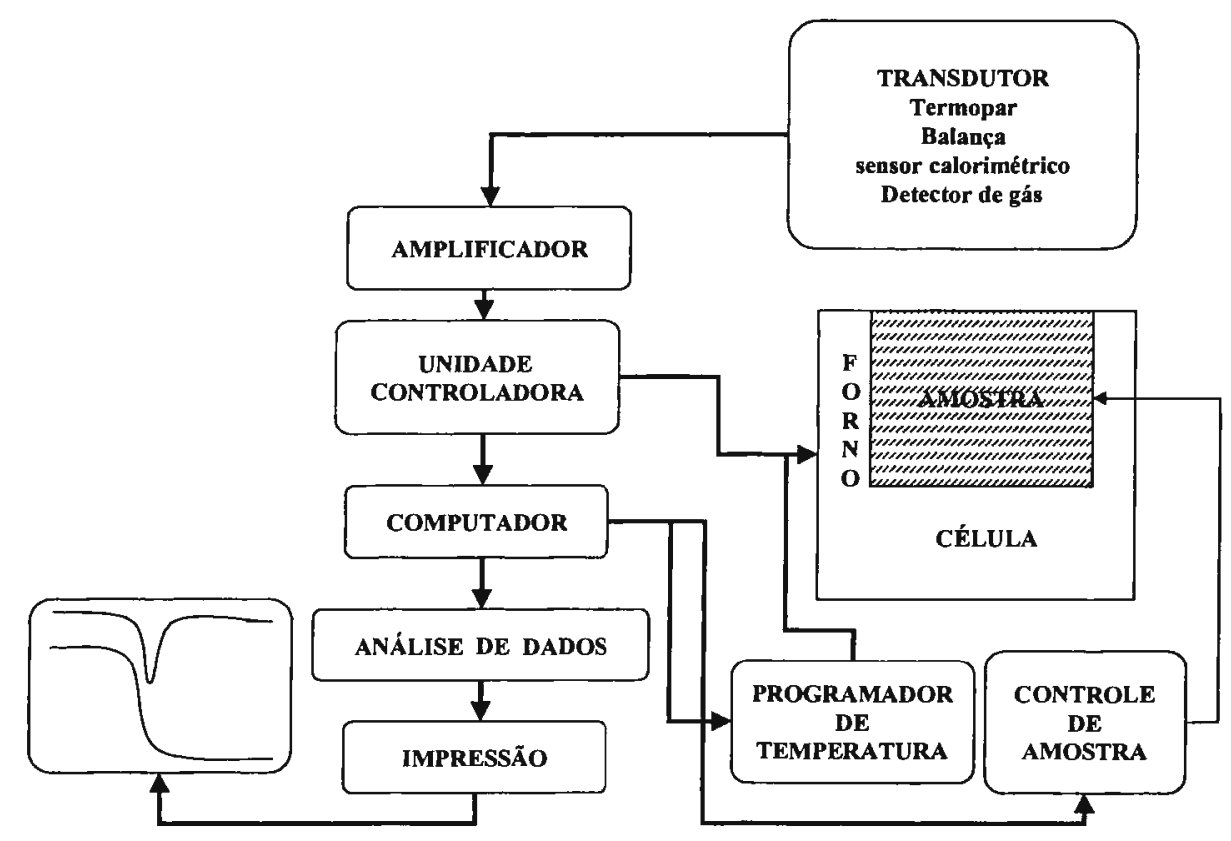

Figura 2. 5 - Esquema de um sistema termoanalítico.

Os diferentes tipos de técnicas de análise térmica são descritos na literatura por Wendlandt (1986) e Mackenzie (1986). As técnicas de análise térmica mais utilizadas são:

- termogravimetria (TG - Thermogravimetry), que mede a perda ou ganho de massa de uma substância em função da temperatura.

- calorimetria exploratória diferencial (DSC - Differential Scanning Calorimetry), que mede a quantidade de energia envolvida nos processos físicos ou químicos de uma amostra que é submetida a um programa de temperatura controlada juntamente com um material de referência termicamente inerte.

- análise térmica diferencial (DTA - Differential Thermal Analysis), que mede a variação de temperatura de uma amostra em relação a uma referência quando esta é submetida a uma programação de temperatura controlada.

A termogravimetria e a análise térmica diferencial são as mais antigas das técnicas de análise térmica. A comercialização de equipamentos permitiu a difusão dessas técnicas, que tiveram auge de aplicação na década de 70 , na 
caracterização de materiais poliméricos (Tury, 1981). Hoje em dia, as técnicas de análise térmica são utilizadas não só na área de polímeros e mineralogia como em análise de materiais cerâmicos, materiais eletrônicos, farmacêuticos, alimentícios, biológicos, etc.

Nos últimos trinta anos, a análise térmica apresentou um desenvolvimento surpreendente, e a quantidade de publicações na área contribuiu para a criação dos periódicos Journal of Thermal Analysis, em 1969, e Thermochimica Acta em 1970. A criação, em 1965, da International Confederation for Thermal Analysis (ICTA) é uma outra conseqüência deste crescimento. O Chemical Abstract resume, mensalmente, todas as publicações na área em seu CA Selects of Thermal Analysis. O avanço tecnológico permite discussões de grupos interessados nas técnicas termoanalíticas: Thermal (http://www.egr.msu.edu/mailman/listinfo/thermal) e o Thermal Methods Group (http://www.bkpublishing.com) são acessos que, após inscrição, permitem o intercâmbio direto e rápido com o mundo.

A aplicação da análise térmica em petróleos e seus derivados teve, segundo Weselowski (1981), sua primeira citação em 1958. Kopsch (1995) em seu livro - Thermal Methods in Petroleum Analysis - descreve a experiência de 20 anos de atividade no German Institute for Petroleum Research utilizando as técnicas de análise térmica na caracterização de petróleos e seus produtos.

Os métodos tradicionais de análise térmica, como descrito anteriormente, são usados para estudar a variação da massa do composto e os efeitos de variações entálpicas. No entanto, os gases libertados da decomposição térmica de um dado material não podem ser separados e nem tão pouco detectado por estes métodos.

O grande desenvolvimento na área de análise térmica foi o acoplamento das técnicas termoanalíticas às técnicas de separação e identificação. A termogravimetria foi acoplada à cromatografia gasosa - TG-CG - (Chiu, 1968), ao infravermelho com transformada de Fourier - TG-FTIR - (Wieboldt e Adams, 1987) e à espectrometria de massa - TG-EM - (Gibson e Johnson, 1972). Para a análise 
de misturas mais complexas o TG foi acoplado à espectrometria de massa precedida por separação na cromatografia gasosa - TG-CG-EM (Whiting e Langvardt, 1984).

O uso simultâneo e o acoplamento de duas técnicas têm crescido nos últimos 20 anos com a introdução de TG-EM, TG-FTIR e outras combinações de analisadores de gás liberados (Yuen e Mappes, 1983; Jansen, 1992; Mullens, 1992; Hutchinson, 1993 e McClennem, 1993). Sistemas de combinações com três técnicas ou mais também já foram usados, como, por exemplo, TG/DTA-FTIR, TG/DTA-EM e TG/DTA-CG-EM (Whitting, 1984; Chung e Aldridg, 1992 e McGhie, 1994).

\subsubsection{Termogravimetria e a termogravimetria derivada}

Na termogravimetria (TG), o parâmetro físico medido em função da temperatura ou do tempo é a perda ou ganho de massa durante o programa controlado de temperatura. O gráfico resultante da termogravimetria de uma substância está representado na Figura 2.6. O eixo de ordenada vertical descreve a perda de massa enquanto que a abscissa descreve a temperatura ou o tempo em que o evento está ocorrendo.

A termogravimetria derivada (DTG) é o registro da curva TG, na qual deriva-se a massa em relação ao tempo, dm/dt, em função da temperatura ou do tempo, ou seja:

$$
\mathrm{dm} / \mathrm{dt}=\mathrm{f}(\mathrm{T} \text { ou } \mathrm{t})
$$

Desta maneira, são obtidas curvas que correspondem à primeira derivada da curva TG e nas quais os degraus são substituidos por picos que delimitam áreas proporcionais às alterações de massa que ocorrem na amostra. A curva DTG apresenta as informações de uma forma visualmente mais acessivel (maior resolução), permite a determinação da temperatura inicial de decomposição e da temperatura do pico máximo ( $\left.T_{\text {máx. }}\right)$, onde a perda de massa ocorre mais rapidamente. 
A termogravimetria é basicamente quantitativa no que se refere à perda ou ganho de massa. Entretanto, a mudança de temperatura na qual ocorre o evento é qualitativa, pois dependerá do instrumento, das características da amostra e das condições em que foi analisada.

São variáveis que afetam os resultados da temperatura:

- taxa de aquecimento.

- gás de arraste e sua vazão.

- a geometria e o material dos cadinhos.

- a posição do termopar que mede a temperatura em que está sendo submetida a amostra.

- quantidade e tamanho das partículas da amostra.

- condutividade térmica da amostra.

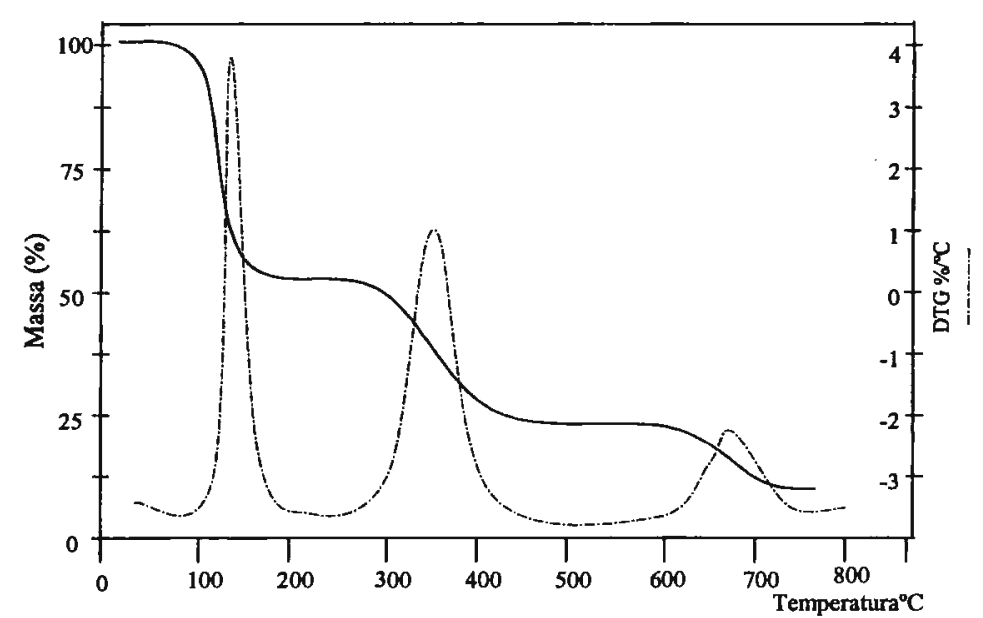

Figura 2. 6 - Curva típica de TG/DTG.

A geometria e o material do cadinho, aposição dos termopares, a quantidade de amostra irão interferir, basicamente, nas temperaturas inicial e final do evento, sendo que a taxa de aquecimento irá interferir também no formato da curva e, algumas vezes, no percentual de massa perdida (Cavalheiro e colaboradores, 1985 e Miyano e colaboradores, 2000). 
O tipo de atmosfera introduzida na célula de TG dependerá do processo a ser investigado. Assim, na avaliação da decomposição térmica deve ser utilizado um gás inerte, para que somente efeitos da temperatura sobre a amostra sejam verificados. Já em estudos de oxidação com a temperatura, a atmosfera deverá ser reativa, neste caso o oxigênio ou o ar são introduzidos no equipamento.

A Figura 2.7 ilustra as variações de massa detectáveis pela termogravimetria.

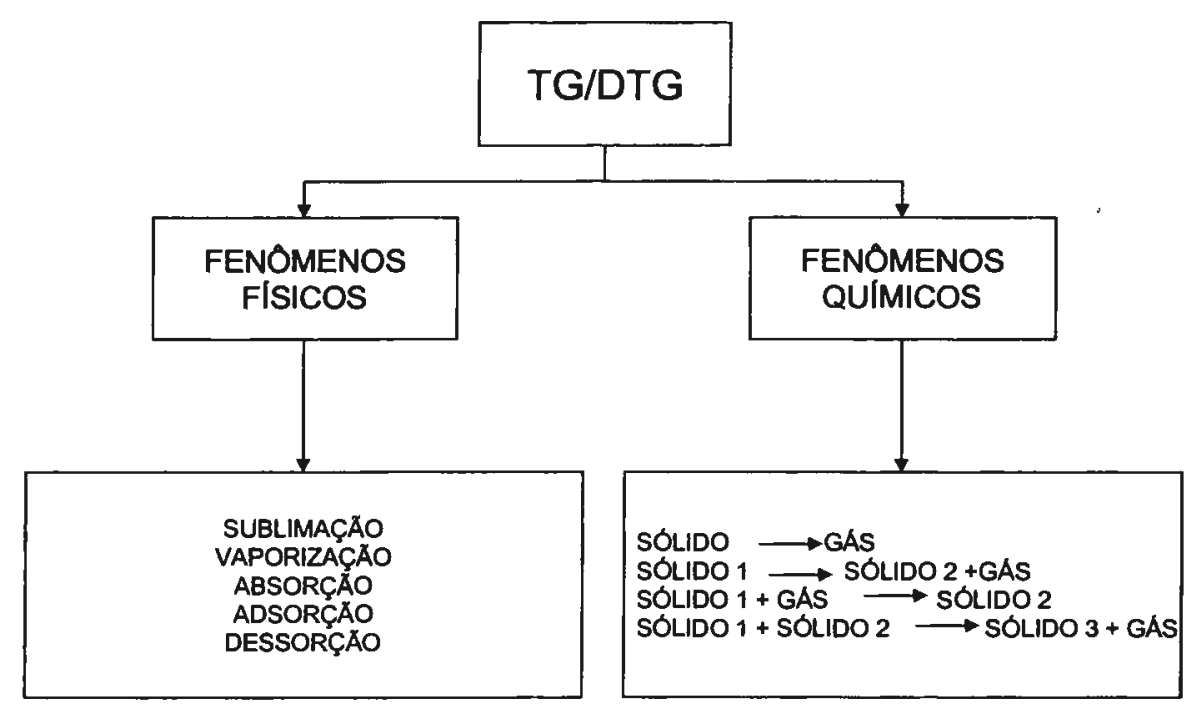

Figura 2. 7 - Variações de massa detectáveis por termogravimetria.

\subsubsection{Análise térmica diferencial e a calorimetria exploratória diferencial}

As técnicas de análise térmica diferencial (DTA) e calorimetria exploratória diferencial (DSC) têm o mesmo princípio, sendo atualmente consideradas como semelhantes e complementares. Ambas permitem avaliar as variações entálpicas que ocorrem com uma amostra durante o aquecimento ou resfriamento em programação controlada de temperatura. A palavra "diferencial" é usada porque a temperatura da amostra é medida em função de um material de referência termicamente estável.

A definição formal das duas técnicas aprovada pela IUPAC (Mackenzie, 1985 e Giolito, 1988): a análise térmica diferencial é a técnica na qual a diferença 
de temperatura entre a amostra e um material de referência é medida e registrada em função da temperatura, enquanto a amostra e a referência são submetidas a uma programação controlada de temperatura.

A calorimetria exploratória diferencial é uma técnica procedente do DTA, na qual é medida a diferença de energia fornecida à substância e a um material de referência em função da temperatura, enquanto estas são submetidas a uma programação controlada de temperatura.

De acordo com o método de medição utilizado, tem-se o DSC com compensação de potência e o DSC com fluxo de calor.

No DSC com compensação de potência, a amostra e a referência são aquecidas ou resfriadas em compartimentos separados, individualmente. Isto torna possível manter a amostra e a referência em condições isotérmicas, ao contrário da técnica DTA. Assim, se a amostra sofre alteração de temperatura devido a um evento endotérmico ou exotérmico em função do aquecimento ou resfriamento a que é submetida, ocorre uma modificação na potência de entrada do forno correspondente, de modo a anular essa diferença. Isto consiste no "balanço nulo" de temperatura.

O DSC com fluxo de calor tem desempenho equivalente ao DSC com compensação de potência (McNaughtan e Mortimer, 1975 e Brown, 1988) e foi desenvolvido a partir do DTA. A principal diferença em relação ao DTA consiste na execução de medidas quantitativas, uma vez que o DSC com fluxo de calor possui uma resistência térmica bem definida, sendo adequada para este tipo de medida.

No DSC com fluxo de calor, a amostra e a referência são colocadas em cadinhos idênticos, localizados sobre um disco termoelétrico de constantan e aquecidos por uma única fonte de calor. O calor é transferido através do disco para a amostra e a referência, e o fluxo de calor diferencial $(\Delta T)$ entre os dois é controlado por termopares conectados abaixo dos cadinhos. Desta forma, a 
diferença no fluxo de calor da amostra e da referência é diretamente proporcional à diferença de potência das junções dos dois termopares.

A diferença entre o DSC de compensação de potência, o DTA e DSC com fluxo de calor é a maneira como eles apresentam os resultados. No DSC com compensação de potência é adotada a convenção termodinâmica: eventos endotérmicos $(\Delta H>0)$ são caracterizados por um pico ascendente na curva, enquanto no DTA e no DSC com fluxo de calor esse mesmo evento é representado na curva DSC por um pico descendente Wendlandt, 1986). Além disso, tanto no DTA quanto no DSC com fluxo de calor, o sinal é originado da diferença da temperatura entre a amostra e a referência; enquanto que no DSC com compensação de potência o sinal é proveniente do calor diferencial fornecido pela amostra e pela referência.

Tanto a técnica de DTA quanto a de DSC envolvem o aquecimento ou resfriamento, em condições idênticas, de uma amostra e uma referência termicamente inerte registrando, em função da temperatura, qualquer diferença de temperatura que ocorra entre elas. Qualquer mudança física ou química que ocorra com a amostra teste e que envolva evolução ou absorção de calor causará uma diferença de temperatura temporária da amostra em relação à referência, originando um sinal que representa um evento exotérmico ou endotérmico (Figura 2.8).

Mudanças na temperatura da amostra podem ser causadas por transições físicas ou químicas, tais como:

- Mudança de fase.

- Reações de decomposição térmica.

- Reações de oxidação ou redução. 


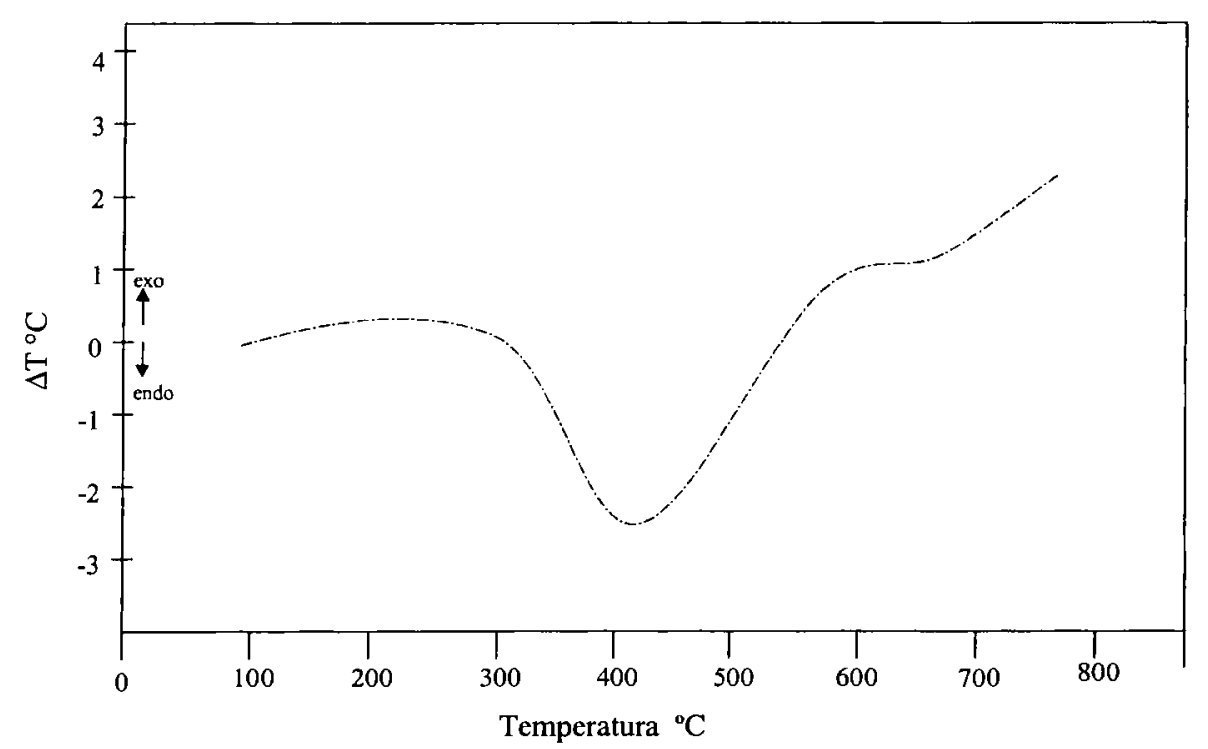

Figura 2. 8 - Curva tipica de DTA (evento endotérmico).

Muitas vezes não ocorre nenhum processo físico e, mesmo assim, é registrada uma mudança na linha base indicando haver ocorrido uma diferença de temperatura entre a amostra e a referência. Isto é relacionado com a diferença de capacidade calorífica e condutividade térmica dos dois materiais.

Com a introdução de equipamentos microprocessados no mercado, foi possivel a inversão de sinais endotérmicos e exotérmicos; e a representação do sentido termodinâmico verdadeiro passou a ser irrelevante.

Como na TG, tanto fatores instrumentais quanto a característica da amostra afetarão o formato da curva resultante das análises de DTA e DSC. Se o resultado destas análises é utilizado para uma avaliação qualitativa, a forma, posição e número de sinais endotérmicos e exotérmicos serão importantes. Uma simples mudança nas condições analíticas, isto é, na taxa de aquecimento, na atmosfera introduzida ou mesmo na forma e no material do cadinho, acarretará mudança no resultado.

A escolha das condições para análise, tanto de DTA ou DSC, dependerá da investigação que se está fazendo. Em geral, a escolha da atmosfera deve ser compatível com o processo a ser investigado: quando um processo de 
decomposição térmica está sendo avaliado, será necessário usar uma atmosfera inerte para que se possam observar, no registro da análise, apenas as transições causadas pela ação da temperatura; no caso do estudo da oxidação com a temperatura, a atmosfera deverá ser o oxigênio ou o ar.

\subsubsection{Aplicaçōes da análise térmica em asfaltenos}

Poucas referências relatam a utilização das técnicas de análise térmica como ferramenta para a avaliação de asfaltenos. Dentre as técnicas termoanalíticas, a termogravimetria tem sido a mais explorada.

Bestougeff (1962) foi o primeiro a estudar o comportamento térmico de asfaltenos. Analisou, utilizando uma balança de Chévenard, amostras de asfaltenos de três petróleos de diferentes procedências. Verificou que a transformação dos asfaltenos, em atmosfera de argônio, tem início em $325^{\circ} \mathrm{C}$ e, a $600^{\circ} \mathrm{C}$, apresenta um percentual de residuo estável. Mais tarde, em 1968, Nicksic verificou que as curvas integrais são similares em forma e posição para todos os asfaltenos estudados.

Calderón e Cotte (1983) estudaram o comportamento térmico dos asfaltenos de um óleo venezuelano (Boscan) entre 25 e $550^{\circ} \mathrm{C}$, verificando que o comportamento térmico deste correspondia aos dos asfaltenos em geral. Enfatizaram, neste trabalho, a importância da termogravimetria para a elucidação dos mecanismos de decomposição térmica desta fração pesada do óleo. Já Khulbe e colaboradores (1984), também por termogravimetria, determinaram a energia de ativação aparente e a constante de Arrhenius do betumem canadense Cold Lake.

Karacan e Kok (1997) analisaram, por DSC e TG, frações de saturados, aromáticos, resinas e asfaltenos (SARA) de dois petróleos procedentes da Turquia. Aplicando o modelo cinético de Arrhenius, determinaram a energia de ativação do craqueamento de cada fração, verificando que os asfaltenos apresentavam a maior energia de ativação dentre todas. Observaram que a perda 
de massa das frações era aditiva, sugerindo que cada fração, no óleo cru, seguisse um mecanismo de decomposição independente.

A utilização do DTA ou do DSC na avaliação de asfaltenos foi ainda menos explorada pelos pesquisadores da área. Apenas a partir dos anos 90 é que são encontradas algumas referências sobre o assunto.

Kopsch (1994) avaliou asfaltenos de 16 petróleos de origens diferentes (Venezuela, Arábia, Irã, Rússia e Inglaterra) por DSC, determinando a temperatura de transição vitrea $\left(T_{g}\right)$ dos mesmos e estabelecendo uma correlação entre as $T_{g}$ e a temperatura de fusão $\left(T_{m}\right)$ dos asfaltenos.

A calorimetria exploratória diferencial foi utilizada recentemente para acompanhar um processo de extração de parafinas de diferentes resíduos de petróleo (Teixeira e Gonçalves, 2000). A metodologia foi proposta por Albert e colaboradores (1985) para a determinação de parafinas em amostras de asfaltos. Os autores verificaram que a fração de saturados isolados de asfaltos - parafinas contendo de 30 a 40 átomos de carbono - apresentava evento endotérmico entre 0 e $100^{\circ} \mathrm{C}$.

Mais tarde Claudy e Letoffé (1988) verificaram que a entalpia média de fusão destes compostos na matriz de petróleo era de 200 $\mathrm{Jg}^{-1}$ (1988). Em 1991 os mesmos autores propuseram uma metodologia utilizando a técnica de DSC para quantificar essa fração cristalizável em asfaltos aplicando a fórmula:

$$
\% \text { parafinas }=\frac{\Delta_{s}^{\ell} H}{2}
$$

Mais recentemente, com a possibilidade de acoplamento de técnicas analíticas, outras informações sobre a decomposição térmica dos asfaltenos puderam ser obtidas. Calemma e Rausa (1997) avaliaram termicamente asfaltenos de sete diferentes óleos. Além das análises por $T G$ e $\mathrm{RMN}^{13} \mathrm{C}$, 
obtiveram algumas informações com o acoplamento da TG com o equipamento de infravermelho com transformada de Fourier (TG-FTIR), completando a avaliação pelo acoplamento das técnicas de pirólise, cromatografia gasosa e espectrometria de massa (Pirólise/CG-EM). Por meio de avaliações não isotérmicas, usando diferentes programas de aquecimento, determinaram parâmetros cinéticos da decomposição térmica dos asfaltenos. Em cada caso, os dados apresentaram um aumento da $E_{\text {ativ }}$ durante a reação, particularmente em altos graus de conversão. As evidências experimentais sugeriram que a decomposição térmica dos asfaltenos ocorre em três rotas diferentes: 1) quebra das cadeias alquílicas ligadas aos anéis aromáticos policondensados 2) quebra das pontes entre as unidades aromáticas, hidroaromáticas e naftênicas e 3) aromatização das estruturas hidroaromáticas.

\subsection{REAÇÃO DE OXIDAÇÃO CATALISADA PELO ÍON RUTÊNIO VIII}

O reagente tetróxido de rutênio $\left(\mathrm{RuO}_{4}\right)$ - íon rutênio VIII - foi preparado pela primeira vez em 1860 por Claus (Lee, 1973). Em 1953, Djerassi, investigando a oxidação de compostos orgânicos, verificou que era um reagente muito vigoroso, pois, em seu relato, diz que "pequeníssima quantidade do íon rutênio VIII reage com éter anidro e benzeno causando explosão com chama intensa amarela, e com piridina apenas uma chama forte". Entretanto, outros pesquisadores relatam que essas reações com o ion rutênio são controladas e usadas para uma variedade de oxidações sem o risco de explosão (Courtney, 1972).

Este reagente é conhecido por apresentar a propriedade de reagir seletivamente com os carbonos $\mathrm{sp}^{2}$ de substratos orgânicos: por exemplo, um arilalcano ou diaril-alcanos podem ser convertidos em ácidos mono e dicarboxílicos respectivamente convertendo a cadeia aromática restante em $\mathrm{CO}_{2}$ (Figura 2.9). Reagindo com carbonos $\mathrm{sp}^{2}$ também oxidam unidades de aromáticos condensados a ácidos benzeno policarboxílicos (2. 10) (Strausz, 1989).

O rutênio e o ósmio pertencem ao mesmo grupo da tabela periódica e é esperado que os óxidos destes metais sejam similares. Entretanto o tetróxido de rutênio tem algumas vantagens sobre o tetróxido de ósmio: é menos volátil e é 
menos tóxico, apesar de que quando inalado causar irritações da mucosa, mas não é um veneno para os olhos como o tetróxido de ósmio. Além disso, é um oxidante mais eficaz que o tetróxido de ósmio. O vigor deste oxidante, apresentado por Djerassi, pode ser controlado dissolvendo-o em água ou em tetracloreto de carbono, solvente em que é bem estável (Lee e Engh, 1973).<smiles>Cc1ccccc1</smiles><smiles>CC(=O)O[C+]C=CCCC(=O)O</smiles><smiles>c1ccc(Cc2ccccc2)cc1</smiles>

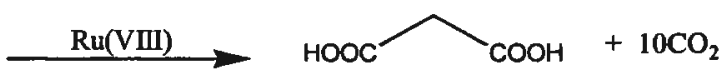

Figura 2. 9 - Reação de aril-alcano e diaril-alcano com o íon Ru (VIII).<smiles>CC(C)CC(=O)c1ccccc1C(=O)O</smiles><smiles>O=C(O)c1cc(C(=O)O)c(C(=O)O)cc1C(=O)O</smiles>

\section{10 - Reação de unidades de aromáticos condensados com o íon rutênio} (VIII).

O ion Ru (VIII) é bastante instável e, normalmente, é preparado pela oxidação de compostos de rutênio em menor estado de oxidação como, por exemplo, o tricloreto de rutênio, o rutenato de sódio ou o dióxido de rutênio. Algumas reações de preparo do tetróxido de rutênio utilizam agentes de oxidação como hipoclorito de sódio (Wolf e colaboradores, 1970), bromatos (Berkowitz e 
Rylander, 1958), periodato de sódio (Martin, 1952) entre outros. O tetróxido assim formado é isolado em tetracloreto de carbono.

Os procedimentos reacionais descritos na literatura ocorrem com a utilização de quantidades pequenas de tetróxido de rutênio em conjunto com um outro oxidante - periodato de sódio, por exemplo. Tipicamente, o sistema bifásico de tetracloreto de carbono e água é usado com o substrato orgânico a ser oxidado. O tricloreto de rutênio, rutenato de sódio ou o dióxido de rutênio são misturados vigorosamente por algumas horas nesse sistema bifásico. $O$ tetróxido de rutênio - substância de cor amarelada - se forma e é solubilizado no tetracloreto de carbono. O periodato de sódio restante se mantém na fase aquosa. Quando o tetróxido de rutênio oxida o substrato orgânico, ele é reduzido a dióxido de rutênio que é insolúvel nos dois solventes, migrando para a interface onde é novamente oxidado pelo periodato de sódio solubilizando, posteriormente, na fase não aquosa. Assim o processo opera continuamente até que todo substrato tenha sido oxidado (Figura 2.11).

$\mathrm{RuO}_{2} \cdot 2 \mathrm{H}_{2} \mathrm{O}$ (interface) $+2 \mathrm{NalO}_{4}$ (fase aquosa) $\rightarrow \mathrm{RuO}_{4}$ (fase orgânica) $+2 \mathrm{NalO}_{3}+2 \mathrm{H} 2 \mathrm{O}$
Substrato orgânico $+\mathrm{RuO}_{4}$ (fase orgânica) $\rightarrow \mathrm{RuO}_{2} \cdot 2 \mathrm{H}_{2} \mathrm{O}$ (interface) + Produto de oxidação

Figura 2. 11 - Reação com de tetróxido de rutênio em presença de agente oxidante.

Ashhy e Goel (1981) verificaram que a adição de acetonitrila a esse meio reacional bifásico, além de acelerar a reação de oxidação, causava um aumento no rendimento do produto de oxidação. O autor explicou o fenômeno pela formação de um complexo $\left[\left(\mathrm{Ru}_{3} \mathrm{O}(\mathrm{OAc})_{6}(\mathrm{H} 2 \mathrm{O})_{3}{ }^{{ }^{-}-\mathrm{OAc}}\right]\right.$, que se apresentou inativo quando testado como catalisador no sistema $\left[\mathrm{CCl}_{4} / \mathrm{H}_{2} \mathrm{O} / \mathrm{OO}_{4}{ }^{-}\right]$; entretanto, com a adição de acetonitrila a este sistema, a reação ocorreu prontamente. A acetonitrila foi um dos primeiros co-solventes a ser utilizado na reação RICO. Mais tarde, outros autores testaram co-solventes para esta reação com intenção de 
quantificar melhor os produtos de oxidação formados (Murata e colaboradores, 1994).

A oxidação catalisada pelo íon rutênio (RICO) foi introduzida no campo da química de combustíveis por Stock e colaboradores em 1983. Stock (1985, 1986, $1987,1988)$ verificou que o método não só fornecia informações sobre as cadeias alifáticas e pontes metilências como também fornecia informações sobre a cadeia aromática presente em carvões.

Outros pesquisadores também usaram a mesma técnica para caracterizar as cadeias alifáticas de carvões de várias origens (Mallya e Zingaro, 1986, Standen e colaboradores, 1992, Murata e colaboradores, 1994).

Strausz e colaboradores em 1985 iniciaram um estudo sobre a estrutura dos asfaltenos utilizando a reação RICO. Desde então, inúmeros trabalhos foram publicados por ele e colaboradores (1989, 1992, 1999). A contribuição deste grupo no entendimento da estrutura de asfaltenos é muito grande.

\subsection{DESENVOLVIMENTO DO TRABALHO}

$\mathrm{Na}$ literatura, foi encontrado um número relevante de trabalhos com o objetivo de caracterizar os asfaltenos, poucos com a preocupação de relatar a estabilidade térmica dos mesmos, mas nenhum contendo uma avaliação química dos produtos sólidos formados quando submetidos a diferentes temperaturas.

A partir dessa observação, foi proposto, para esse trabalho de pesquisa, um esquema analítico que proporcionasse a avaliação do produto sólido da decomposição térmica dos asfaltenos, em diferentes temperaturas (Figura 2.12). Para complementação, os produtos voláteis da decomposição térmica são avaliados por técnicas de análise térmica acopladas às técnicas de identificação, ainda não exploradas na área de petróleo.

Para o estudo, foi escolhido um óleo brasileiro da Bacia de Campos, região conhecida por produzir óleos ricos em asfaltenos. A extração dos asfaltenos deste óleo foi a primeira etapa do trabalho. Uma vez isolados, foram caracterizados por 
métodos físicos de análise. O material volátil procedente da decomposição térmica destes asfaltenos foi caracterizado, em parte, por técnicas simultâneas de termogravimetria e análise térmica diferencial acopladas à cromatografia gasosa e espectrometria de massa não utilizadas, até o momento, para esse tipo de fração de petróleo. O material sólido, formado em diferentes temperaturas, foi caracterizado por métodos físicos e submetido à reação de oxidação seletiva catalisada pelo íon rutênio VIII (RICO). As moléculas de ácidos geradas nessa reação foram caracterizadas por cromatografia gasosa acoplada com espectrometria de massa após esterificação.

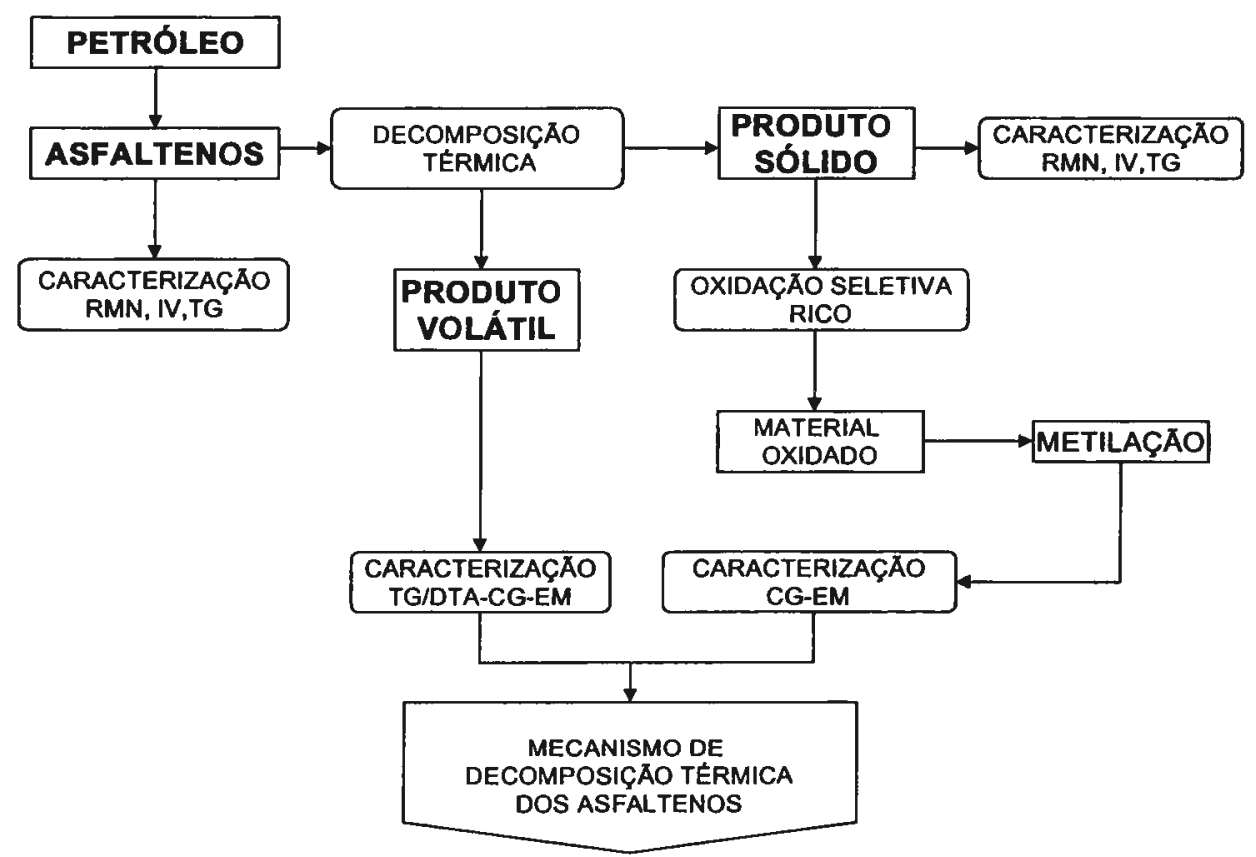

Figura 2. 12 - Esquema analítico proposto para a avaliação da degradação térmica dos asfaltenos isolados do petróleo da Bacia de Campos.

O conjunto de informações fornecerá subsídios para a área de engenharia de processamento de petróleo da Petrobras ainda carente de informações sobre o mecanismo da decomposição térmica dessa classe de substância.

As temperaturas selecionadas para a obtenção dos produtos sólidos da decomposição térmica dos asfaltenos foram algumas das utilizadas nas unidades de craqueamento catalítico e coqueamento retardado das refinarias: 580,550 , 
$480,440,400,380$ e $320^{\circ} \mathrm{C}$. As três últimas foram adicionadas ao estudo visando a obtenção de mais informações sobre a decomposição térmica dos asfaltenos e proposição de um mecanismo de degradação. 


\section{PARTE EXPERIMENTAL}

\subsection{MATERIAIS E REAGENTES}

Os solventes e reagentes foram utilizados diretamente como recebidos, não sendo realizados processos de purificação. Quando possivel, foram utilizados grau UV/HPLC. A origem dos mesmos está descrita na Tabela 3. 1.

Tabela 3. 1 - Origem dos reagentes utilizados

\begin{tabular}{l|l}
\hline REAGENTE & ORIGEM \\
\hline Água & Deionizada purificada por resinas \\
\hline Diclorometano & Grau Pesticida -MALLINCKRODT \\
\hline Clorofórmio & Grau PA -CONTROL \\
\hline Acetonitrila & Grau UV/HPLC -VETEC \\
\hline Cloreto de rutênio (III) & ALDRICH \\
\hline Tetracloreto de carbono & Grau PA - GRUPO QUÍMICA \\
\hline Metaperiodato de sódio & Grau PA - REAGEN \\
\hline Hidróxido de sódio & Grau PA - GRUPO QUÍMICA \\
\hline Brometo de potássio anidro & ALDRICH \\
\hline Diazald & ALDRICH \\
\hline Tolueno & Grau PA - GRUPO QUÍMICA \\
\hline n-heptano & Grau PA - GRUPO QUÍMICA \\
\hline Éter & Grau PA - ISOFAR \\
\hline
\end{tabular}

A vidraria utilizada foi lavada com água e detergente específico para laboratório, seguindo-se uma limpeza com solução de ácido sulfúrico e dicromato de potássio $1: 1 \mathrm{~m} / \mathrm{m}$, solução $1 \%$ de bicarbonato de potássio e água deionizada e secagem em estufa a $100^{\circ} \mathrm{C}$.

\subsection{EXTRAÇÃO DOS ASFALTENOS}

A extração dos asfaltenos, foi baseada no ensaio padronizado pelo Institute of Petroleum - (Standard Methods for Analysis and Testing of Petroleum and 
Related Products - vol. 1 IP143). O método consistiu em misturar $3 \mathrm{~g}$ do petróleo com n-heptano na razão $1: 40 \mathrm{~m} / \mathrm{v}$. A solução foi mantida sob refluxo, a $60^{\circ} \mathrm{C}$, por 1 hora. Após este, tempo foi mantida em repouso, no escuro, por 1 hora e meia. Em seguida filtrada, e o sólido retido no filtro submetido a lavagens com $n$ heptano por extração em Soxhlet, até que o solvente voltasse a sua cor original. Neste ponto, o solvente foi substituído por tolueno para extração dos asfaltenos. O processo de extração foi finalizado quando este voltou a sua cor original. Em seguida o tolueno foi evaporado por destilação em evaporador rotatório sob vácuo, a uma temperatura de $40^{\circ} \mathrm{C}$.

O equipamento Soxhlet utilizado para as extrações possuia as mesmas dimensões descritas no ensaio IP-143. Uma única modificação ocorreu, já no final do procedimento: o tolueno, solvente que solubiliza os asfaltenos, que no ensaio padrão é evaporado em recipiente aberto em placa de aquecimento e sem muito controle de temperatura, aqui foi evaporado sob vácuo, minimizando qualquer tipo de decomposição da amostra.

Após cerca de 180 extrações, foram obtidas $34 \mathrm{~g}$ de asfaltenos do petróleo utilizado.

\subsection{CARACTERIZAÇÃO DOS ASFALTENOS}

\subsubsection{Análise elementar orgânica}

Para a determinação dos elementos carbono, hidrogênio e nitrogênio, foi utilizado o analisador elementar marca Perkin Elmer modelo 2400. Para esta análise foi seguida a metodologia descrita no ensaio ASTM 5291-95 (Determination of carbon, hidrogen and nitrogen in oil fractions), para análise elementar de produtos de petróleo.

Para as determinações do teor de oxigênio, foi utilizado um analisador marca Fisons modelo 1108, tomando-se como base a metodologia descrita no ensaio ASTM 5122-98 (Determination of oxigen in gasolines). 


\subsubsection{Fluorescência de raios- $X$}

As determinações de enxofre foram realizadas em um espectrômetro de fluorescência de raios-x, marca Philips, modelo PW 2400, equipado com tubo de ródio. Para a determinação do elemento enxofre na matriz orgânica (asfaltenos), a amostra foi pulverizada a 325 mesh e $1 \mathrm{mg}$ aplicado em uma lâmina para análise. Por esse método são obtidos resultados semiquantitativos. A calibração do espectrômetro foi feita com a utilização de sais puros do respectivo elemento.

\subsubsection{Espectrometria de massa com plasma indutivamente acoplado}

Foi utilizado um espectrômetro da Perkin Elmer, modelo ELAN-6000, para a determinação dos elementos $\mathrm{Fe}, \mathrm{Ni}, \mathrm{V}$, Co e $\mathrm{Ga}$. A amostra de asfaltenos foi devidamente mineralizada em ácido nítrico em forno de micro ondas e tiveram seus volumes ajustados adequadamente para a análise.

\subsubsection{Calorimetria exploratória diferencial}

O ensaio foi realizado para verificar se durante a extração dos asfaltenos haveria coprecipitação de parafinas, fenômeno, anteriormente, observado durante a extração desta fração de resíduos pesados de petróleo (Gonçalves e Teixeira, 1997).

Foi utilizado um DSC-30, marca Mettler, nas condições descritas na Tabela 3.2 (Claudy e colaboradores, 1991). O sinal endotérmico entre 0 e $100^{\circ} \mathrm{C}$ correspondente à fusão das parafinas presentes nos asfaltenos foi integrado e o valor da entalpia comparada com a entalpia média de fusão de parafinas puras. As parafinas foram quantificadas utilizando-se a fórmula apresntada no item 2.3.3. 
Tabela 3. 2 - Condições da DSC para determinação de parafinas em asfaltenos

\begin{tabular}{l|l}
\hline Massa de amostra & $20 \mathrm{mg}$ \\
\hline Cadinho & Alumínio $40 \mu \mathrm{L}$ \\
\hline Gás de arraste/Vazão & Hélio a $50 \mathrm{~mL} \mathrm{~min}$ \\
\hline Faixa de temperatura & -100 a $+100^{\circ} \mathrm{C}$ \\
\hline Taxa de resfriamento & $5^{\circ} \mathrm{C} \mathrm{min}^{-1}$ \\
\hline Taxa de aquecimento & $10^{\circ} \mathrm{C} \mathrm{m^{-1 }}$ \\
\hline Calibração da temperatura & Mercúrio, gálio, e índio (fusão) \\
\hline Calibração do sinal em $\mathrm{J} / \mathrm{g}$ & Índio (fusão) \\
\hline
\end{tabular}

\subsubsection{Espectroscopia de absorção na região do infravermelho}

Foi utilizado um espectrômetro de infravermelho, marca Nicolet, modelo Magna 760. Os espectros de absorção na região do infravermelho foram obtidos preparando-se a amostra pela técnica de disco prensado (Silverstein, 2000): 10 $\mathrm{mg}$ dos asfaltenos foram misturados com $100 \mathrm{mg}$ de brometo de potássio seco; a mistura foi pulverizada em um gral de ágata e, em seguida, prensada sob pressão de 10.000 psi, formando um disco transparente; cada disco foi, então, analisado na faixa de número de onda de 4.000 a $400 \mathrm{~cm}^{-1}$.

\subsubsection{Termogravimetria}

Fōi utilizada para a avaliação térmica dos asfaltenos uma termobalança marca DuPont, modelo TGA-951, acoplada ao sistema de controle e aquisição de dados modelo TA-2100 da TA-Instruments. Estas análises foram realizadas nas condições descritas na Tabela 3.3 .

Os estudos isotérmicos utilizaram o mesmo equipamento nas condições descritas na Tabela 3.4 .

O estudo cinético da decomposição térmica dos asfaltenos foi realizado pelo programa TGA Decomposition Kinetics Data Analysis Program - version 4.0 fornecido pela TA-Instruments. Esse programa tem como base a determinação de cinética de decomposição de materiais poliméricos proposta por Fllyn e Wall (1996). Para a utilização do programa, foi necessária a realização de quatro 
análises em taxas de aquecimento diferentes. Na Tabela 3.5 são apresentadas as condições destas análises.

Tabela 3. 3 - Condições analíticas TG para análise do comportamento térmico dos asfaltenos

ANÁLISE EM ATMOSFERA INERTE

\begin{tabular}{l|l}
\hline Massa de amostra & $10 \mathrm{mg}$ \\
\hline Cadinho & Platina de $40 \mu \mathrm{L}$ \\
\hline Taxa de aquecimento & $10^{\circ} \mathrm{C} \mathrm{min}{ }^{-1}$ \\
\hline Gás de arraste/Vazão & Nitrogênio a $100 \mathrm{~mL} \mathrm{~min}^{-1}$ \\
\hline \multicolumn{1}{c}{ ANÁLISE EM ATMOSFERA DE $\mathrm{N}_{2}$ E AR } \\
\hline Massa de amostra & $10 \mathrm{mg}$ \\
\hline Cadínho & Platina de $40 \mu \mathrm{L}$ \\
\hline Taxa de aquecimento & $10^{\circ} \mathrm{C} \mathrm{min}^{-1}$ \\
\hline Gás de arraste entre 30 e $700^{\circ} \mathrm{C} /$ Vazão & Nitrogênio a $100 \mathrm{~mL} \mathrm{~min}^{-1}$ \\
\hline Gás de arraste entre 700 a $1000^{\circ} \mathrm{C} /$ Vazão & Ar a $100 \mathrm{~mL} \mathrm{~min}^{-1}$ \\
\hline
\end{tabular}

Tabela 3. 4 - Condições analíticas da termogravimetria isotérmica ( $T=320$, $380,430,438,450,480,550$ e $700^{\circ} \mathrm{C}$ )

\begin{tabular}{l|l}
\hline Massa de amostra & $10 \mathrm{mg}$ \\
\hline Cadinho & Platina de $40 \mu \mathrm{L}$ \\
\hline Taxa de aquecimento & $10^{\circ} \mathrm{C} \mathrm{\text {min } ^ { - 1 }}$ \\
\hline Faixa de temperatura & 30 até a T de isoterma \\
\hline Isoterma em T'C & 60 min \\
\hline Gás de arraste $N$ Vazão & Nitrogênio a $100 \mathrm{~mL} \mathrm{~min}^{-1}$ \\
\hline
\end{tabular}

Tabela 3. 5 - Condições analíticas para obtenção dos parâmetros cinéticos de decomposição térmica dos asfaltenos

\begin{tabular}{l|l}
\hline Massa de amostra & $10 \mathrm{mg}$ \\
\hline Cadinho & Platina de $40 \mu \mathrm{L}$ \\
\hline Taxas de aquecimento & $2-5-7,5-10^{\circ} \mathrm{C} \mathrm{min}-1$ \\
\hline Faixa de temperatura & 30 até $1000^{\circ} \mathrm{C}$ \\
\hline Gás de arraste/Vazão & Nitrogênio a $100 \mathrm{~mL} \mathrm{~min}^{-1}$ \\
\hline
\end{tabular}




\subsubsection{Ressonância magnética nuclear de carbono e de hidrogênio}

Para análise por ressonância magnética nuclear do ${ }^{13} \mathrm{C}$ e ${ }^{1} \mathrm{H}$ da amostra dos asfaltenos em solução foi utilizado o equipamento GEMINI-300 nas condições descritas na Tabela 3.6.

Tabela 3. 6 - Condições da análise de $\operatorname{RMN}^{1} \mathrm{H}$ e de $\mathrm{RMN}^{13} \mathrm{C}$

\begin{tabular}{l|c}
\hline \multicolumn{1}{c}{ RMN $^{1} \mathrm{H}$} & $300,075 \mathrm{MHz}$ \\
\hline Freqüência & $4500,5 \mathrm{~Hz}$ \\
\hline Janela espectral & $3.335 \mathrm{~s}$ \\
\hline Tempo de aquisição & $25^{\circ}(5,0 \mu \mathrm{s})$ \\
\hline Pulso & 600 \\
\hline Número de transientes & $\mathrm{CDCl}_{3}$ \\
\hline Solvente & $5 \%$ \\
\hline Concentração & \\
\hline \multicolumn{1}{c}{ RMN $^{13} \mathrm{C}$} & $75,4 \mathrm{MHz}$ \\
\hline Freqüência & $20000 \mathrm{~Hz}$ \\
\hline Janela espectral & $0,755 \mathrm{~s}$ \\
\hline Tempo de aquisição & $90^{\circ}(26,0 \mu \mathrm{s})$ \\
\hline Pulso & $20 \mathrm{~s}$ \\
\hline Intervalo entre pulsos & $\mathrm{Gated}$ \\
\hline Modo do desacoplador & 3700 \\
\hline Número de transientes & $\mathrm{CDCl}_{3} \mathrm{Com} 0,05 \mathrm{M} \mathrm{Cr}(\mathrm{acac})_{3}$ \\
\hline Solvente & $40 \%$ \\
\hline Concentração &
\end{tabular}

\subsubsection{Osmometria de pressão de vapor}

Para a determinação da massa molar dos asfaltenos foi utilizado um osmômetro de pressão de vapor, marca Wescan, modelo 233A. As condições desta análise estão descritas na Tabela 3. 7. 
Tabela 3. 7 - Condições da análise para determinação da massa molecular dos asfaltenos

\begin{tabular}{l|l}
\hline Solvente & Tolueno \\
\hline Solução & $0,2 \mathrm{~g}$ de asfaltenos em $25 \mathrm{~mL}$ \\
\hline Diluições & $1,2,3$ e $4 \mathrm{~mL}$ por $25 \mathrm{~mL}$ \\
\hline Temperatura da câmara & $80^{\circ} \mathrm{C}$ \\
\hline Temperatura da câmara de soluções & $40^{\circ} \mathrm{C}$ \\
\hline Corrente & $20 \mathrm{~mA}$ \\
\hline
\end{tabular}

\subsection{OBTENÇÃO DOS PRODUTOS SÓLIDOS DA DECOMPOSIÇÃO TÉRMICA DOS ASFALTENOS EM DIFERENTES TEMPERATURAS}

Após conhecer o comportamento térmico dos asfaltenos a partir das curvas de TG/DTG, foram realizados testes para a obtenção dos produtos sólidos da decomposição térmica dos asfaltenos (PSDT). Os primeiros testes foram realizados em forno tubular. Entretanto os resultados obtidos com os produtos sólidos gerados nesse forno, não foram satisfatórios. Em uma Segunda experiência foi utilizado o equipamento de termogravimetria (TGA-951), com modificações.

Os itens a seguir descrevem detalhadamente as condições experimentais em cada caso.

\subsubsection{Forno tubular}

Foi utilizado um forno tubular de grafite, conforme apresentado na Figura 3.1. A amostra de asfaltenos (cerca de $1 \mathrm{~g}$ ), pesada em cadinhos de alumina, foi colocada no interior do tubo de quartzo, que estava, inicialmente, externo ao forno. Em seguida, uma corrente de gás inerte, nitrogênio a $100 \mathrm{~mL} \mathrm{~min}^{-1}$, foi introduzida e o sistema purgado por pelo menos 15 minutos antes do inicio do aquecimento. $O$ forno foi programado para aquecer em incrementos de $50^{\circ} \mathrm{C}$ até a temperatura de isoterma desejada. Ao atingir a temperatura desejada o tubo de quartzo foi introduzido no forno e o conjunto, cadinho e amostra, mantido em seu 
interior no interior por 20 minutos. Ao final desse tempo, o tubo de quartzo foi retirado do interior do forno e mantido em atmosfera inerte até até atingir a temperatura ambıente. Ù conjunto caainnho e amostra, foi então retírado do interior do tubo de quartzo e pesado para quantificação do produto sólido gerado. Foram obtidōs produtos sólidos da decomposição térmica dos asfaltenos nas temperaturas de $320,380,450$ e $550^{\circ} \mathrm{C}$.

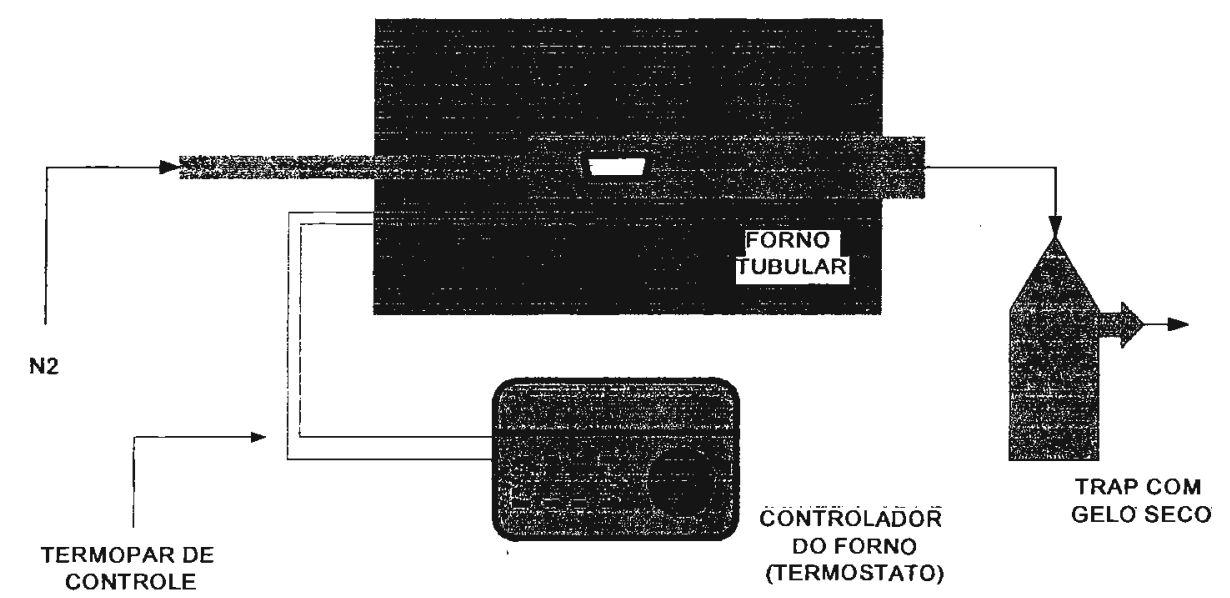

Figura 3. 1- Esquema do forno tubular utilizado para a obtenção dos produtos sólidos nas temperaturas de $320,380,450$ e $550^{\circ} \mathrm{C}$.

\section{4:2. Termogravimetria}

A termobalança, TGA-951, foi adaptada para ser utilizada apenas como forno visando a obtenção dos produtos sólidos (Figura 3.2). Nessas condiçōes foi possível realizar os testes utilizando massa de asfaltenos de aproximadamente $500 \mathrm{mg}$, além de se conseguir melhor controle da temperatura e atmosfera no interior do forno. Os testes foram realizados empregando-se cápsula de alumina. O conjunto de cápsula e amostra foi colocado no centro do forno, ainda frio, com vazão de nitrogênio de $100 \mathrm{mLmin}^{-1}$. Antes de iniciar o aquecimento, foi feita uma purga com esse gás inerte durante 15 minutos, com o objetivo de se retirar todo o ar do interior do sistema antes de iniciar o aquecimento.

Ass condiçōes adotadas para o aquecimento dos asfaltenos estão resumidas na Tabela 3.8. Inicialmente, o forno foi aquecido rapidamente $\left(100^{\circ} \mathrm{C}\right.$ $\min ^{-1}$ ) até uma temperatura $50^{\circ} \mathrm{C}$ abaixo daquela desejada. A seguir, a uma taxa 
de $20^{\circ} \mathrm{C} \mathrm{min}{ }^{-1}$, foi aquecido até a temperatura da isoterma desejada e mantido, nesta temperatura, por $10 \mathrm{~min}$. Após esse tempo, o forno foi resfriado externamente com ar frio a $50^{\circ} \mathrm{Cmin}^{-1}$ até $100^{\circ} \mathrm{C}$. Nesta temperatura foi aberto para retirada do produto formado após a decomposição térmica dos asfaltenos. $O$ produto sólido obtido foi, então, acondicionado em dessecador contendo sílica gel e pesado quando totalmente frio.

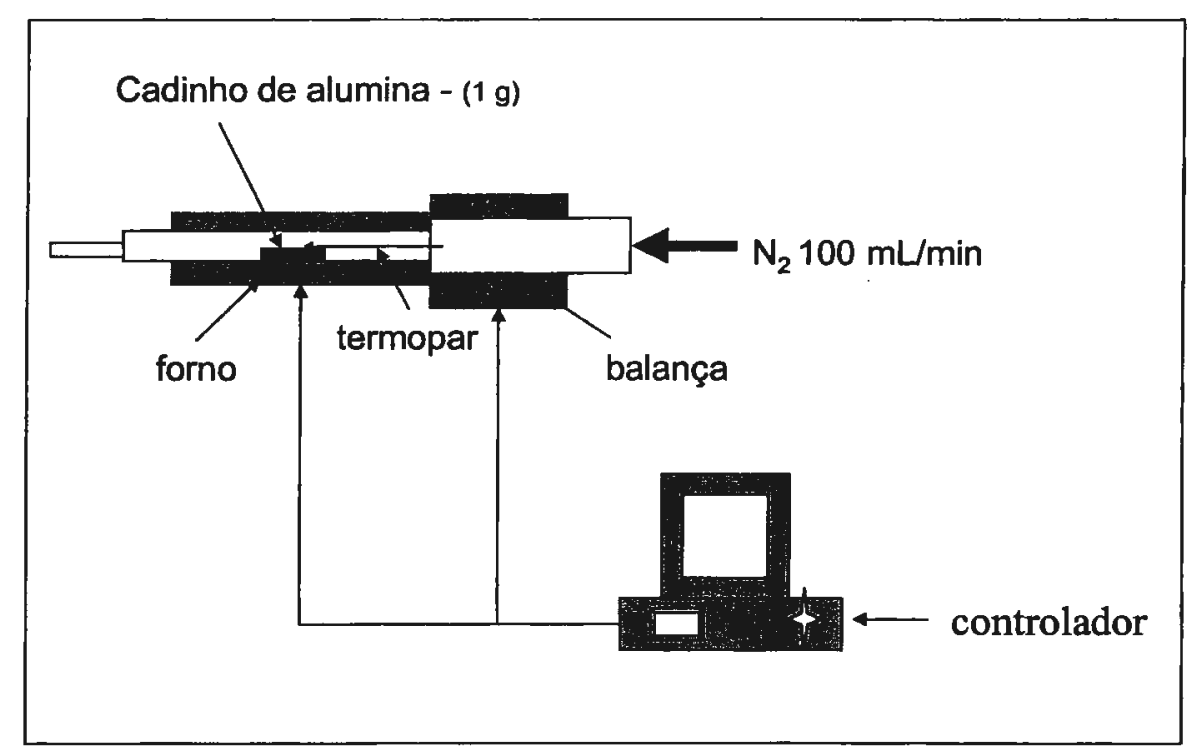

Figura 3. 2 - Equipamento TGA-951 modificado para obtenção dos produtos sólidos da decomposição térmica dos asfaltenos nas temperaturas de 320 , $380,400,440,480,550,580^{\circ} \mathrm{C}$.

Tabela 3. 8 - Condições do equipamento de TG para a obtenção dos coques nas temperaturas de 320, 380, 400, 440, 480, 550, 580

\begin{tabular}{|c|c|c|c|c|c|c|c|}
\hline & \multicolumn{7}{|c|}{ TEMPERATURAS $\left({ }^{\circ} \mathrm{C}\right)$} \\
\hline Aquecimento a $10^{\circ} \mathrm{C} \mathrm{min}^{-1}$ de $30^{\circ} \mathrm{C}$ até & 270 & 330 & 350 & 390 & 430 & 500 & 530 \\
\hline Em seguida a $20^{\circ} \mathrm{C} \mathrm{min}{ }^{-1}$ até & 320 & 380 & 400 & 440 & 480 & 550 & 580 \\
\hline Temperatura das Isotermas & 320 & 380 & 400 & 440 & 480 & 550 & 580 \\
\hline Tempo em cada isoterma & \multicolumn{7}{|c|}{$10 \mathrm{~min}$} \\
\hline Taxa de resfriamento até $100^{\circ} \mathrm{C}$ & \multicolumn{7}{|c|}{$100^{\circ} \mathrm{C} \mathrm{min}^{-1}$} \\
\hline
\end{tabular}




\subsection{CARACTERIZAÇÃO DOS PRODUTOS SÓLIDOS DA DECOMPOSIÇÃO TÉRMICA DOS ASFALTENOS EM DIFERENTES TEMPERATURAS}

\subsubsection{Análise elementar orgânica}

A determinação de carbono, hidrogênio, nitrogênio e oxigênio nos resíduos da decomposição térmica dos asfaltenos foi realizada como descrito no item 3.3.1, para a caracterização dos asfaltenos. A determinação do teor de enxofre foi realizada por Fluorescencia de raios $\mathrm{X}$, como já descrito no item 3.3.2.

\subsubsection{Espectroscopia de absorção na região do infravermelho}

Foi utilizado um espectrômetro de infravermelho, marca Nicolet, modelo Magna 760. Os espectros de absorção na região infravermelho foram obtidos usando-se a metodologia já descrita em 3.3.5.

\subsubsection{Ressonância magnética nuclear do carbono}

Os resíduos obtidos em cada uma das temperaturas são pouco ou totalmente insolúveis em clorofórmio. $A$ análise por $\mathrm{RMN}^{13} \mathrm{C}$ só se tornou possível em fase sólida. Desta forma, os asfaltenos e os resíduos da decomposição dos asfaltenos em diferentes temperaturas foram analisados seguindo a metodologia descrita a seguir.

Para a análise de amostras no estado sólido, foi utilizado um equipamento Varian INOVA-300, equipado com sonda RT CP/MAS de $7 \mathrm{~mm}$ (constituída de nitreto de silício com tampa de Kel-F), apropriada para análise de amostras sólidas. Foram utilizadas três condições experimentais: a primeira, de forma quantitativa, empregou a técnica de pulso simples; a segunda, a técnica de polarização cruzada com rotação no ângulo mágico (CP/MAS) e varredura de tempo de contato, que mesmo não sendo uma técnica quantitativa, pode ser utilizada comparativamente quando os materiais são semelhantes; e a terceira utilizou a seqüência de pulsos chamada non-quaternary supression (NQS), que 
mostra somente os carbonos quaternários presentes na amostra. A título de comparação, os asfaltenos também foram analisados da mesma forma.

Os espectros foram obtidos pelas três metodologias, aplicando-se uma freqüência de 75,4 MHz; janela espectral de $50000 \mathrm{~Hz}$; tempo de aquisição de $0,05 \mu \mathrm{s}$; pulso de $90^{\circ}$; velocidade de rotação do MAS de $5600 \mathrm{~Hz}$ e a referência de HMB (hexa metil benzeno - picos de metilas em 17,3 ppm). O processamento dos dados foi realizado em Line Broadening (lb) de $50 \mathrm{~Hz}$ e função gaussiana (gf) de 0,008s. As demais variáveis para a obtenção de espectros pelas três metodologias estão descritas na Tabela 3. 9.

Tabela 3. 9 - Condições analíticas para obtenção dos espectros de $\mathrm{RMN}^{13} \mathrm{C}$

\begin{tabular}{l|l}
\hline \multicolumn{2}{c}{${ }^{13} \mathrm{C}$ MAS } \\
\hline Intervalos entre pulsos & $100 \mathrm{~s}$ \\
\hline Número de transientes & 400 (equivale a uma noite de aquisição) \\
\hline Intervalos entre pulsos & \multicolumn{1}{|c}{${ }^{13} \mathrm{C}$ CP/MAS } \\
\hline Seqüência & Polarização cruzada com rotação do ângulo mágico \\
\hline Tempo de contato & $20-4000 \mu \mathrm{s}$ \\
\hline Número de transientes & 400 \\
\hline & ${ }^{13} \mathrm{C} \mathrm{CP/MAS} \mathrm{-} \mathrm{NQS}$ \\
\hline Intervalos entre pulsos & $4 \mathrm{~s}$ \\
\hline Seqüência & $\mathrm{NQS}$ \\
\hline Tempo de contato & $4000 \mu \mathrm{s}$ \\
\hline Janela do desaclopador & $60 \mu \mathrm{s}$ \\
\hline Número de transientes & 400 \\
\hline
\end{tabular}

\subsubsection{Reação de oxidação catalisada pelo íon rutênio (RICO)}

Os produtos da decomposição térmica dos asfaltenos nas diferentes temperaturas e os asfaltenos foram submetidos à reação RICO. Strausz (1985) foi o primeiro pesquisador a usar a reação RICO como ferramenta de caracterização da estrutura dos asfaltenos. Nesse trabalho, as proporções entre a amostra e reagentes (Tabela 3.10 ) foram as mesmas descritas por Strausz (1985). 
Entretanto, algumas modificações foram introduzidas uma vez que o material de decomposição térmica apresenta características diferentes da dos asfaltenos de origem. Assim, a reação RICO foi feita a uma temperatura de $40^{\circ} \mathrm{C}$ por 24 horas com agitação intensa, condição mais drástica, seguida por pesquisadores que aplicaram a reação RICO em carvões (Murata e colaboradores, 1994).

\section{Tabela 3. 10 - Condições da reação RICO com asfaltenos}

\begin{tabular}{l|c}
\hline Massa de amostra & $150 \mathrm{mg}$ \\
\hline Periodato de sódio $\left(\mathrm{NalO}_{4}\right)$ & $1,7 \mathrm{mg}$ \\
\hline Tetracloreto de carbono $\left(\mathrm{CCl}_{4}\right)$ & $10 \mathrm{ml}$ \\
\hline Água deionizada $\left(\mathrm{H}_{2} \mathrm{O}\right)$ & $10 \mathrm{ml}$ \\
\hline Acetonitrila $\left(\mathrm{CH}_{3} \mathrm{CN}\right)$ & $10 \mathrm{ml}$ \\
\hline Cloreto de rutênio $\left(\mathrm{RuCl}_{3}\right)$ & $7,5 \mathrm{mg}$ \\
\hline
\end{tabular}

Após as $\mathbf{2 4}$ horas de reação, o meio reacional foi filtrado e a fase orgânica separada de acordo com o esquema apresentado na Figura 3.3. A fase aquosa foi acidificada e extraída com pequenas quantidades de diclorometano $(2 \mathrm{~mL})$ para retirada total dos ácidos. Foi realizada também uma reação em branco seguindose o mesmo esquema de extração.

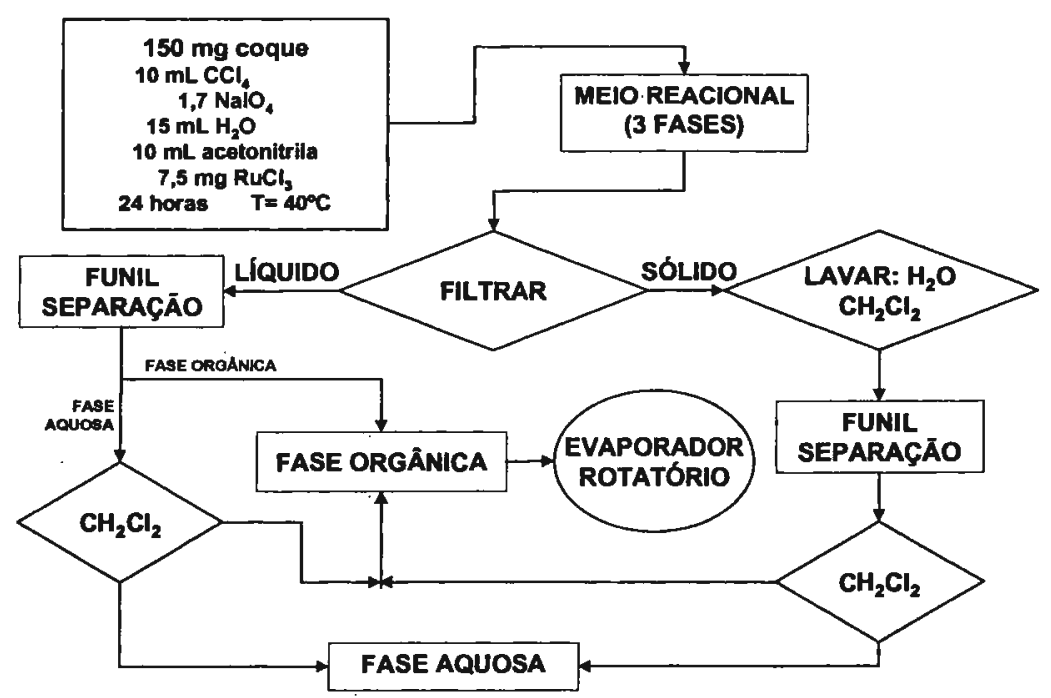

Figura 3. 3 - Esquema da reação RICO. 
A fase orgânica, onde se concentram os produtos de interesse de cada reação, foi analisada por infravermelho para constatação da presença de ácidos e, em seguida, esterificada com diazometano para análise por cromatografia gasosa acoplada à espectrometria de massa.

\subsubsection{Esterificação dos ácidos obtidos na reação RICO}

Os ácidos formados na reação RICO com resíduos e os asfaltenos foram esterificados com diazometano. Este reagente de metilação foi obtido através do produto Diazald - N-metil-N-nitroso-p-toluenossulfonamida - segundo a metodologia descrita por Boer e Baker (1963): uma solução contendo 0,05 moles $(11,0 \mathrm{~g})$ do reagente em éter $(75 \mathrm{~mL})$ foi lentamente adicionada a uma solução, aquecida a $70^{\circ} \mathrm{C}$, de hidróxido de sódio $(5 \mathrm{mg})$ em álcool etílico $(30 \mathrm{~mL})$ e água (8mL). O destilado, amarelo, foi recolhido em balão imerso em gelo seco. Toda a reação ocorreu em vidraria própria para geração do gás diazometano, fornecida pela Aldrich (Diazald®Kit - Diazomethane Generator - $\mathrm{n}^{\circ} \mathrm{cat}$. Z10, 025-0). O diazometano obtido em solução etérea foi armazenado em freezer, até o momento da reação de metilação.

\subsubsection{Caracterização dos ácidos e ésteres metílicos por espectroscopia na região do infravermelho}

Foi utilizado um equipamento de infravermelho, marca Perkin, Elmer Spectrum-2000. As amostras de ácidos e ésteres metílicos por serem viscosas foram diluídas com algumas gotas de $\mathrm{CH}_{2} \mathrm{Cl}_{2}$. Uma pequena quantidade de cada solução foi espalhada sobre uma célula de $\mathrm{NaCl}$. Após a evaporação do $\mathrm{CH}_{2} \mathrm{Cl}_{2}$, outra célula de $\mathrm{NaCl}$ foi apoiada sobre a primeira formando um filme de amostra com espessura aproximada de $0,01 \mathrm{~mm}$. Em seguida, foram analisadas na faixa de comprimento de onda de 4.000 a $400 \mathrm{~cm}^{-1}$.

Para análise semiquantitativa, as amostras de ácidos tiveram seus volumes ajustados em $5 \mathrm{~mL}$. As soluções, assim diluídas, foram analisadas em células de espessura ótica constante de 0,2 ou $1 \mathrm{~mm}$. Como referência foi utilizado o próprio solvente de diluição $\left(\mathrm{CH}_{2} \mathrm{Cl}_{2}\right)$. Foi medida, para cada uma das soluções, a 
intensidade da absorção a $1710 \mathrm{~cm}^{-1}$, característica do grupamento carbonila de ácido. Para os produtos de metilação, foi utilizada a mesma metodologia, sendo que os ésteres foram avolumados em balões volumétricos de $2 \mathrm{~mL}$ e analisados em células de espessura ótica de $1 \mathrm{~mm}$ e medida a intensidade da absorção a $1736 \mathrm{~cm}^{-1}$, característica de carbonila de ésteres.

\subsubsection{Caracterização dos ésteres metílicos por cromatografia gasosa acoplada à espectrometria de massa}

Para análise dos ésteres metílicos, foi utilizado o sistema de cromatografia gasosa acoplada à espectrometria de massa (CG-EM), modelo HP 5988, nas condições descritas na Tabela 3. 11.

Numa segunda etapa, com o objetivo de comparar relativamente as classes de ésteres metílicos identificados, cada produto da reação de metilação teve seu volume ajustado em $2 \mathrm{~mL}$ com diclorometano. Em cada uma das soluções, foram adicionados $5,0 \mu \mathrm{L}$ de um padrão interno. Por disponibilidade do laboratório, foi utilizada uma substância aromática deuterada - fenantreno $d_{10}$. A área de cada éster metílico identificado foi comparada com a área do fenantreno $d_{10}$. $A$ integração das áreas dos picos cromatográficos foi realizada a partir dos seguintes cromatogramas de íons:

- Padrão interno-fenantreno $d_{10}: m / z=188$.

- Ésteres metílicos de ácidos carboxílicos: $\mathrm{m} / \mathrm{z}=74+87$.

- Ésteres dimetílicos de ácidos dicarboxílicos: $\mathrm{m} / \mathrm{z}=55+59$.

- Ésteres dimetílicos de ácidos benzeno dicarboxillicos: $\mathrm{m} / \mathrm{z}=$ $163+177+191$.

$$
R_{\alpha i}=A_{\alpha i} / A_{p i}
$$

$R_{\alpha i}=$ razão de área do composto i pertencente à classe $\alpha$.

$A_{\alpha i}=$ área do composto i pertencente à classe $\alpha$.

$A_{p i}=$ área do padrão interno - fenantreno $d_{10}$. 
Tabela 3. 11 - Condições analíticas utilizadas no sistema CG-EM para a caracterização dos ésteres metílicos procedentes da reação RICO

\begin{tabular}{l|l}
\hline Coluna: & Fenil Metil silicone (DB-5) $(30 \mathrm{~m} \times 0.25 \mathrm{~mm} \times 0.25 \mu \mathrm{m})$ \\
\hline Injetor: & Splitless $(0.5 \mathrm{~min})$ \\
\hline $\mathrm{T}_{\text {INJETOR }}:$ & $280^{\circ} \mathrm{C}$ \\
\hline Gás de arraste: & Hélio $(12 \mathrm{psi})$ \\
\hline Volume injetado: & $1.0 \mathrm{uL}$ \\
\hline$T_{\text {FORNO }}:$ & $50^{\circ} \mathrm{C}-4^{\circ} \mathrm{Cmin}^{-1}-280^{\circ} \mathrm{C}(30 \mathrm{~min})-30^{\circ} \mathrm{C} \mathrm{min}^{-1}-300^{\circ} \mathrm{C}(5 \mathrm{~min})$ \\
\hline$T_{\text {FONTE DE lons }}$ & $200^{\circ} \mathrm{C}$ \\
\hline$T_{\text {INTERFACE }}:$ & $280^{\circ} \mathrm{C}$ \\
\hline Faixa de massa: & $(15-450)$ u.m.a \\
\hline Energia dos elétrons: & $70 \mathrm{eV}$ \\
\hline Corrente de emissão: & $300 \mu \mathrm{A}$ \\
\hline
\end{tabular}

\subsection{CARACTERIZAÇÃO DO MATERIAL VOLÁTIL PRODUZIDO DURANTE A DECOMPOSIÇÃO TÉRMICA DOS ASFALTENOS}

\subsubsection{Análise por termogravimetria e análise térmica diferencial simultâneas} acopladas à cromatografia gasosa e espectrometria de massa

Foi utilizado o sistema, marca Shimadzu, que acopla as técnicas termoanalíticas e simultâneas TG/DTG/DTA, modelo DTG-50 H com cromatografia gasosa e espectrometria de massa (CG-EM), modelo CG14BC QP-5000.

Uma pequena quantidade dos asfaltenos $(0,7 \mathrm{mg})$ é colocada no sistema TG-DTA onde ocorre a decomposição térmica em atmosfera de hélio ultrapuro $(99,999 \%)$. Os voláteis liberados são transferidos através de uma interface $\left(250^{\circ} \mathrm{C}\right)$ e retidos em um concentrador resfriado com gelo seco. Ao término do processo de decomposição térmica, o sistema concentrador é aquecido $\left(300^{\circ} \mathrm{C}\right)$, e os voláteis desorvidos e carreados para o cromatógrafo onde são separados por ordem crescente de polaridade. Após a separação os compostos voláteis são conduzidos para uma fonte de impacto de elétrons de alta energia (70 eV). Os 
íns formados são separados por um analisador do tipo quadrupolo e, a seguir, chegam ao detetor de massa, obtendo-se como resultado os respectivos espectros de massa. As condições de análise estão resumidas na Tabela 3.12.

Tabela 3. 12 - Condições de análise para identificação dos voláteis no sistema acoplado TG/DTA-CG-EM

\begin{tabular}{l|l}
\hline \multicolumn{1}{c|}{ SISTEMAS } & \multicolumn{1}{c}{ CONDIÇÕES } \\
\hline TG/DTA & $\begin{array}{l}\text { Massa: } 0,7 \mathrm{mg} \\
\text { Taxa de aquecimento: } 10^{\circ} \mathrm{C} \mathrm{min}{ }^{-1} \\
\text { Vazão de gás: } \mathrm{N}_{2} \text { a } 50 \mathrm{~mL} \mathrm{~min}^{-1}\end{array}$ \\
\hline INTERFACE & Temperatura: $250^{\circ} \mathrm{C}$ \\
\hline TRAP & $\begin{array}{l}\text { Recheio: Tenax } \\
\text { Temperatura de adsorção: }-50^{\circ} \mathrm{C} \\
\text { Temperatura de dessorção: } 300^{\circ} \mathrm{C}\end{array}$ \\
\hline \multirow{2}{*}{ CG-EM } & $\begin{array}{l}\text { Coluna: } 1 \mathrm{~m} \text { empacotada com Tenax } 60 \text { mesh } \\
\text { Programação: } 80^{\circ} \mathrm{C}(2 \mathrm{~min})-20^{\circ} \mathrm{C} \mathrm{min} \mathrm{mi}^{-1}-300^{\circ} \mathrm{C}(4 \mathrm{~min}) \\
\text { Energia dos elétrons: } 70 \mathrm{eV}\end{array}$ \\
\hline
\end{tabular}

\subsubsection{Análise por cromatografia gasosa acoplada à espectrometria de massas}

Neste experimento, o material volátil liberado durante a decomposição térmica dos asfaltenos foi recolhido e analisado em seguida por cromatografia gasosa acoplada a espectrometria de massa. Para este experimento, a saída do equipamento de TGA-951 foi conectada, por meio de um tubo de tygon $(3 \mathrm{~cm})$, a um frasco contendo $5 \mathrm{~mL}$ de diclorometano. $O$ conjunto foi imerso em banho de gelo para minimizar a saída do material mais leve. A Figura 3.4 mostra esquematicamente essa montagem. 


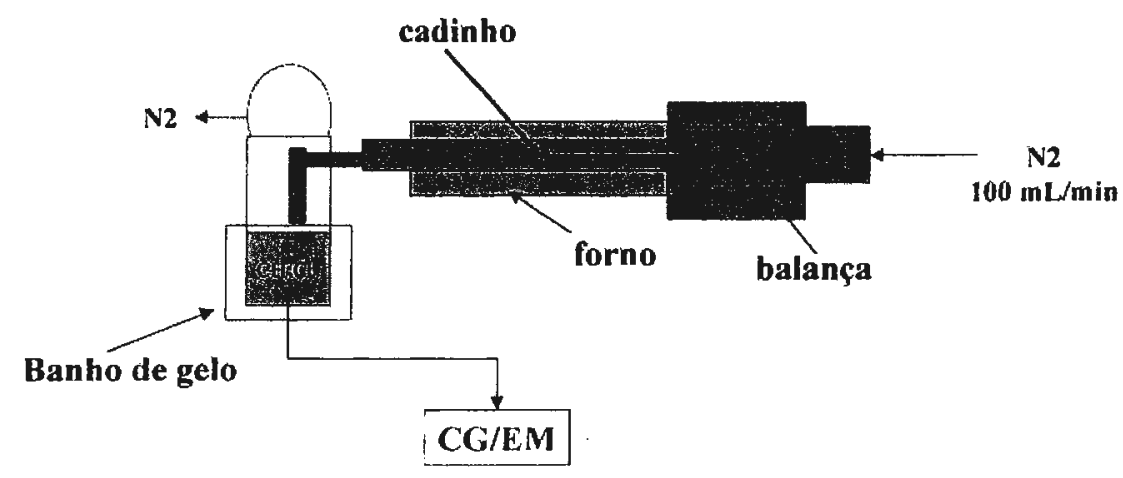

Figura 3. 4 - Esquema do equipamento para recolhimento dos voláteis produzidos durante a decomposição térmica dos asfaltenos e posterior análise por CG-EM.

Uma massa de $10 \mathrm{mg}$ de asfaltenos foi decomposta termicamente na termobalança em atmosfera de $\mathrm{N}_{2}\left(100 \mathrm{mLmin}^{-1}\right)$, da temperatura ambiente até $700^{\circ} \mathrm{C}$, a uma taxa de $10^{\circ} \mathrm{Cmin}^{-1}$. Durante a decomposição, parte do material volátil se condensou na área fria do tubo de quartzo do equipamento, não alcançando o solvente no frasco gelado. No final da reação de decomposição, o analisador termogravimétrico foi resfriado e somente aberto à temperatura ambiente. O material condensado foi, então, retirado do tubo de quartzo, através de lavagem do mesmo com $\mathrm{CH}_{2} \mathrm{Cl}_{2}$, e transferido para o frasco contendo diclorometano.

As condições analíticas para recolher e identificar o material volátil são apresentadas de forma resumida no Tabela 3.13

Tabela 3. 13 -Condiçōes analíticas de CG-EM do material volátil recolhido durante a decomposição térmica dos asfaltenos no equipamento de TG

\begin{tabular}{l|l}
\hline Coluna & fenil metil silicone (DB-5) $(30 \mathrm{~m} \times 0.25 \mathrm{~mm} \times 0.25 \mu \mathrm{m})$ \\
\hline Injetor & Splitless $(1.0 \mathrm{~min})$ \\
\hline $\mathbf{T}_{\text {INJETOR }}$ & $280^{\circ} \mathrm{C}$ \\
\hline Gás de arraste & Hélio $(10 \mathrm{psi})$ \\
\hline Volume injetado & $1.0 \mu \mathrm{L}$ \\
\hline $\mathbf{T}_{\text {FORNO }}$ & $80^{\circ} \mathrm{C}-4^{\circ} \mathrm{C} \mathrm{min}^{-1}-290^{\circ} \mathrm{C}(30 \mathrm{~min})$ \\
\hline $\mathbf{T}_{\text {FONTE DE IONS }}$ & $200^{\circ} \mathrm{C} \mathrm{T}$ INTERFACE $: 280^{\circ} \mathrm{C}$ \\
\hline Faixa de massa & $(15-450)$ u.m.a \\
\hline Energia dos elétrons & $70 \mathrm{eV}$ \\
\hline Corrente de emissão & $300 \mu \mathrm{A}$ \\
\hline
\end{tabular}




\section{RESULTADOS E DISCUSSÕES}

\subsection{ASFALTENOS DO ÓLEO DA BACIA DE CAMPOS}

Para a obtenção dos asfaltenos, foi selecionado um óleo da Bacia de Campos (Rio de Janeiro) contendo um teor elevado de asfaltenos. A Tabela 4.1 apresenta algumas características do óleo selecionado.

Tabela 4. 1 - Características do Petróleo utilizado no estudo

\begin{tabular}{l|c}
\hline Densidade ${ }^{\circ} \mathrm{API}$ & 16,1 \\
\hline Densidade relativa a20/4 & 0,9550 \\
\hline Viscosidade a $20^{\circ} \mathrm{C} \mathrm{mm} / \mathrm{s}$ & 2854 \\
\hline Asfaltenos \%m/m & 6,1 \\
\hline Enxofre total \%m/m & 0,77 \\
\hline Nitrogênio total \%m/m & 0,55 \\
\hline
\end{tabular}

Os asfaltenos foram isolados seguindo procedimento IP-143 apresentado no item 3.2 e caracterizados pelas técnicas físico-químicas de análise, com objetivo de se conhecer o material em estudo.

\subsection{CARACTERIZAÇÃO DOS ASFALTENOS ISOLADOS DO PETRÓLEO DA BACIA DE CAMPOS}

Durante a precipitação dos asfaltenos, hidrocarbonetos parafínicos pesados costumam ser arrastados (Teixeira e Gonçalves, 1999). Como neste trabalho pretende-se caracterizar os componentes oriundos da decomposição térmica dos asfaltenos e sabendo-se que os produtos leves gerados são constituídos basicamente de hidrocarbonetos parafínicos, foi necessário saber a grandeza de co-precipitação de parafinas nos asfaltenos isolados. Usou-se a calorimetria exploratória diferencial, metodologia descrita por Claudy e colaboradores (1991) para quantificação desta fração em asfaltos.

Para a caracterização química destes asfaltenos, foram utilizadas a análise elementar, a espectroscopia na região do infravermelho (IV) e a ressonância 
magnética nuclear (RMN). A osmometria de pressão de vapor foi a técnica utilizada para determinação da massa molecular.

\subsubsection{Análise por calorimetria exploratória diferencial}

A determinação do conteúdo de parafinas que co-precipitaram durante a extração dos asfaltenos utilizando a técnica de DSC consiste em medir a entalpia de fusão desta fração fundida entre 0 e $100^{\circ} \mathrm{C}$ e compará-la com a entalpia de parafinas puras $\left(200 \mathrm{~J} \mathrm{~g}^{-1}\right)$.

A curva de DSC resultante do ensaio está apresentada na Figura 4.1. Foi observado um sinal endotérmico muito pequeno entre 0 e $100^{\circ} \mathrm{C}$. Associando-se esse resultado ao trabalho de Caudy e colaboradores (1991), pode-se atribuir que esse evento corresponde à fusão das parafinas. Comparando-se o valor de entalpia encontrado ( $4 \mathrm{~J} \mathrm{~g}^{-1}$ ) com aquele inferido pelos autores para fusão de parafinas puras (200 $\left.\mathrm{J} \mathrm{g}^{-1}\right)$, verificou-se que co-precipitaram com os asfaltenos cerca de $2 \%$ de material parafínico.

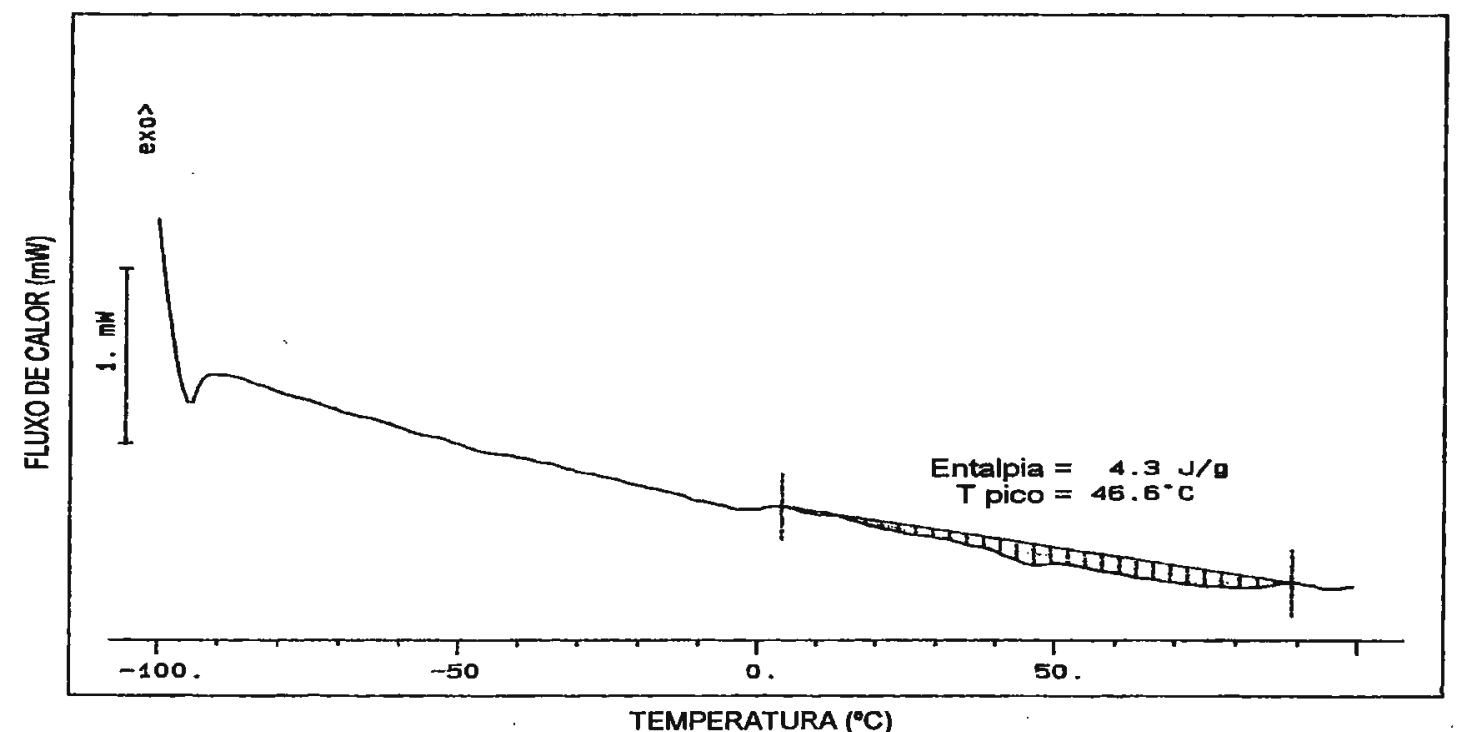

Figura 4. 1 - Curva de DSC dos asfaltenos obtida a $5^{\circ} \mathrm{C} \mathrm{J} \mathrm{g}^{-1}$ entre $-100 \mathrm{e}$ $+100^{\circ} \mathrm{C}$ em atmosfera dinâmica de Hélio $\left(50 \mathrm{mLmin}^{-1}\right)$. 


\subsubsection{Análise elementar e osmometria por pressão de vapor}

Os resultados de análise elementar dos asfaltenos isolados estão listados na Tabela 4.2. São valores característicos de uma fração pesada (Speight, 1994), uma vez que apresentou relação $\mathrm{C} / \mathrm{H}=0,9$, concentração baixa de $\mathrm{Ni}, \mathrm{V}$ e $\mathrm{Fe}$ e elevados teores de $\mathrm{N}, \mathrm{S}$ e $\mathrm{O}$. Considerando-se os teores de $\mathrm{C}, \mathrm{H}, \mathrm{N}, \mathrm{S}$ e O, podese estimar a fórmula mínima: $\mathrm{C}_{369} \mathrm{H}_{437} \mathrm{~N}_{7} \mathrm{O}_{4} \mathrm{~S}_{2}$. Esse dado se aproxima do valor encontrado para o peso molecular médio destes asfaltenos - 5100 u.m. determinado por osmometria de pressão de vapor.

Tabela 4. 2 - Resultados de análise elementar dos asfaltenos isolados do óleo da Bacia de Campos

\begin{tabular}{l|c}
\hline \multicolumn{1}{c|}{ ELEMENTO } & RESULTADO \\
\hline Carbono \%m & 85,8 \\
\hline Hidrogênio \%m & 8,4 \\
\hline Nitrogênio \%m & 1,8 \\
\hline Oxigênio \%m & 1,3 \\
\hline Enxofre \%m & 0,93 \\
\hline Níquel ppm & 26 \\
\hline Vanádio ppm & 28 \\
\hline Ferro ppm & 4,2 \\
\hline Cobalto ppm & 1,9 \\
\hline Gálio ppm & $<0,5$ \\
\hline
\end{tabular}

\subsubsection{Análise por espectroscopia de absorção na região do infravermelho}

A espectroscopia de absorção na região do infravermelho é uma técnica de análise em que a amostra é submetida a uma radiação de comprimento de onda na região do infravermelho. A faixa de radiação utilizada na química orgânica é a que vai de 0,6 a $2,5 \mu\left(4000\right.$ a $\left.666 \mathrm{~cm}^{-1}\right)$. Um espectro de infravermelho apresenta grande quantidades de sinais, chamados de bandas e é característico de uma molécula como um todo, porém os grupamentos e ligações apresentam absorções que geram bandas de formato característico da estrutura da molécula. Isto se torna extremamente útil, pois num rápido exame do espectro, pode-se obter informações importantes sobre o composto a ser analisado, assim como a função e algumas características estruturais da molécula. 
A análise por espectroscopia no IV (Figura 4.2) dos asfaltenos extraídos do óleo da Bacia de Campos forneceu informações sobre os grupos funcionais presentes na molécula. De maneira geral, são observadas bandas características de grupamentos hidroxilas $\left(3500 \mathrm{~cm}^{-1}\right)$, estiramento de grupamento aromático (1603 $\mathrm{cm}^{-1}$ ) vibração $\mathrm{C}-\mathrm{H}$ fora do plano do aromático $\left(871,809\right.$ e $758 \mathrm{~cm}^{-1}$ ), estiramento de grupamento $\mathrm{CH}$ e $\mathrm{CH}_{2}\left(2990\right.$ e $\left.2850 \mathrm{~cm}^{-1}\right)$ e vibrações rotacionais de grupamentos $\mathrm{CH}_{3}$ e $\mathrm{CH}_{2}\left(1460\right.$ e $\left.1378 \mathrm{~cm}^{-1}\right)$.

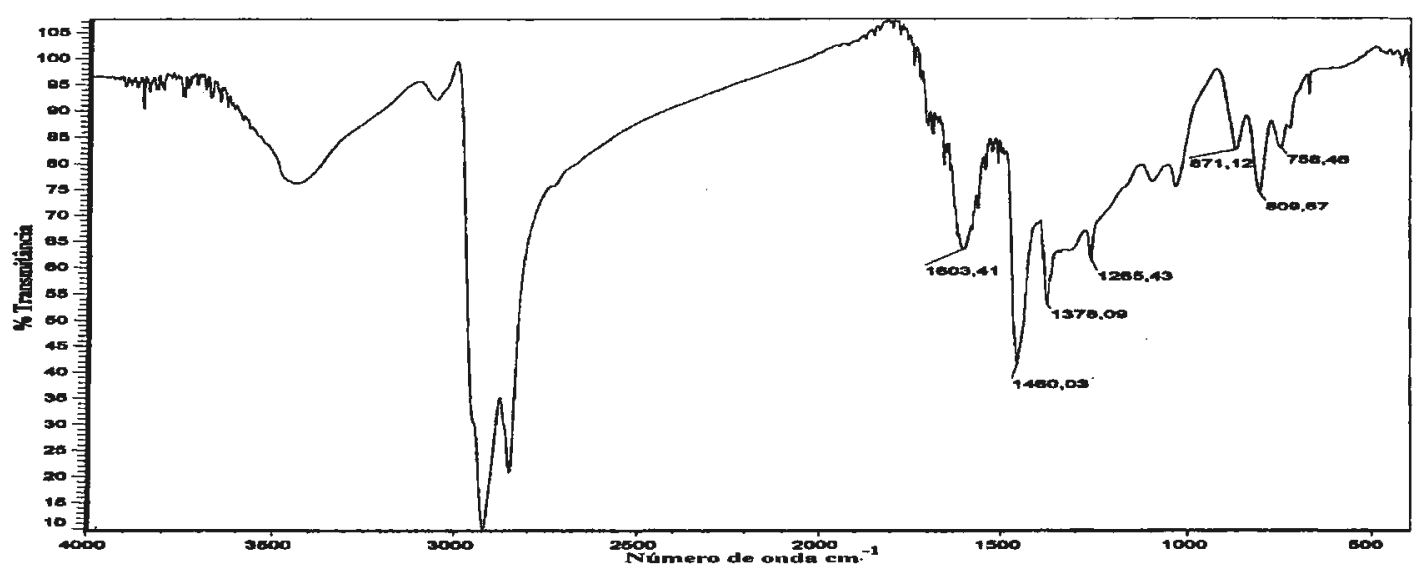

Figura 4. 2 - Espectro de absorção no IV dos asfaltenos isolados de um petróleo da Bacia de Campos.

O espectro obtido para a amostra de asfaltenos tem perfil similar ao dos espectros dos asfaltenos isolados de diferentes petróleos e citados na literatura (Calemma, 1995; Jain, 1991). A Tabela 4.3 compara as absorções encontradas na análise por espectroscopia no IV de asfaltenos de diferentes origens geológicas com os obtidos para esse estudo.

Tabela 4. 3 - Comparação entre as absorções no IV da análise de asfaltenos de diferentes origens e o isolado da Bacia de Campos

\begin{tabular}{|c|c|c|c|}
\hline Absorções no IV & $\begin{array}{c}\text { Calemma } \\
(1995)^{\star} \\
\text { cm }^{-1}\end{array}$ & $\begin{array}{c}\text { Jain } \\
(1991)^{\star \star \star} \\
\text { cm }^{-1}\end{array}$ & $\begin{array}{l}\text { Asfaltenos } \\
\qquad \mathrm{cm}^{-1}\end{array}$ \\
\hline $\mathrm{O}-\mathrm{H}$ estiramento & $3100-3640$ & 3668 & 3500 \\
\hline $\mathrm{C}-\mathrm{H}$ arom. estiramento & $3000-3100$ & 3053 & 3100 \\
\hline $\mathrm{C}-\mathrm{H}$ alifático estiramento & $2780-3000$ & 2924,2851 & 2980 \\
\hline $\mathrm{C}-\mathrm{H}$ & & 1458,1377 & 1460 e 1378 \\
\hline $\mathrm{C}=\mathrm{O}$ estiramento & $1640-1800$ & & \\
\hline $\mathrm{C}=\mathrm{C}$ arom. estiramento & $1620-1590$ & 1592 & 1603 \\
\hline $\mathrm{C}-\mathrm{H}$ arom. def. fora do plano $(1 \mathrm{H})$ & $915-730$ & $863,807,723$ & $871,809,758$ \\
\hline
\end{tabular}




\subsubsection{Ressonância magnética nuclear do carbono e hidrogênio}

A espectrometria de ressonância magnética nuclear (RMN) é basicamente uma espectrometria de absorção semelhante à absorção no infravermelho (Silverstein e Webster, 2000). A técnica se baseia na medida da energia absorvida por certos elementos em uma determinada região de radiofreqüência.

Na RMN, a amostra é submetida, em condições apropriadas, a um campo magnético, absorvendo radiação eletromagnética na região de radiofrequeências, em uma freqüência que dependerá de sua estrutura. A absorção é uma função dos núcleos da molécula.

Todos os núcleos apresentam carga. Em alguns casos, a carga gira em torno do eixo nuclear, gerando um dipolo magnético ao longo do eixo. $O$ momento angular da carga em movimento é descrito em "número de spin" (I), que pode assumir valores de $0,1 / 2,1,3 / 2$ etc. Os núcleos que têm $I=0$ não possuem momento angular e núcleos que possuem $I \neq 0$, e que, portanto, giram em torno de seu eixo, geram um dipolo magnético em torno desse eixo.

Na ausência de um campo magnético, os núcleos estão orientados ao acaso e os dipolos magnéticos podem estar apontados em qualquer direção com igual probabilidade. Se, entretanto, um campo magnético é aplicado, este núcleo se orienta em função do seu "número de spin", de acordo com a fórmula $2 \mid+1$. Núcleos que possuem $\mathrm{I}=1 / 2\left({ }^{1} \mathrm{H},{ }^{3} \mathrm{H},{ }^{13} \mathrm{C},{ }^{15} \mathrm{~N},{ }^{19} \mathrm{~F},{ }^{15} \mathrm{P}\right)$ apresentam duas orientações em relação a um campo magnético: paralelamente (a favor do campo) ou antiparalelamente (contra o campo). Se, agora, é introduzida uma radiação eletromagnética de determinada freqüência, o excesso de população de núcleos alinhados a favor do campo magnético irá absorver energia e se orientar contra o campo magnético. Essa quantidade de energia absorvida é medida e registrada em um gráfico, originando o espectro de RMN.

O campo magnético em um núcleo não é exatamente igual ao campo magnético aplicado. Se isto ocorresse, o espectro de RMN apresentaria somente um pico de absorção para núcleos de uma mesma espécie, independente do 
ambiente químico em que se encontram. Os núcleos encontram-se blindados por uma nuvem de elétrons circulantes que estão envolvidos na formação de ligações com outros átomos na molécula. O grau de blindagem depende da densidade dos elétrons em movimento e o grau de blindagem de um próton dependerá do efeito indutivo dos outros grupos ligados ao átomo em questão. Essa diferença é que permite a observação, no espectro de RMN, dos diferentes tipos de hidrogênios e carbonos presentes em uma molécula orgânica.

Para um químico orgânico, o espectro de $\mathrm{RMN}$ de ${ }^{13} \mathrm{C}$ é mais importante que o de ${ }^{1} \mathrm{H}$, já que os esqueletos de cadeias carbônicas são a base da química orgânica. Entretanto, esqueletos de carbono são quase que exclusivamente constituídos de átomos de ${ }^{12} \mathrm{C}$ que não apresentam espectro de RMN. Somente o ${ }^{13} \mathrm{C}$, isótopo presente em quantidade muito pequena nos esqueletos - abundância de $1,1 \%$ do ${ }^{12} \mathrm{C}$-, apresenta número de spin igual a $1 / 2 \mathrm{e}$, portanto, gera espectro de RMN.

O desenvolvimento de equipamentos pulsados com transformada de Fourier e com campos magnéticos elevados deram o impulso que a técnica de RMN ${ }^{13} \mathrm{C}$ necessitava. O tempo de aquisição de um espectro diminuiu e a possibilidade do desacoplamento de outros núcleos de carbono, principalmente do ${ }^{1} \mathrm{H}$, tornaram os espectros mais simples e com melhor resolução.

Nas últimas décadas, a ressonância magnética nuclear do ${ }^{13} \mathrm{C}$ tem sido muito utilizada como ferramenta para caracterização de sistemas complexos como os asfaltenos (Artok, 1999; Calemma, 1998, Calemma, 1995), fornecendo informações relevantes sobre a estrutura desses sistemas. O uso simultâneo da ressonância magnética de ${ }^{1} \mathrm{H}$ e ${ }^{13} \mathrm{C}$ permite a determinação de uma série de parâmetros estruturais, tais como a fração de carbono aromático, o número médio de carbonos em um grupamento alquila ligado a sistemas aromáticos e o percentual de substituição desse sistema (Hasan, 1983, Dickinson, 1980).

Os asfaltenos extraídos do petróleo da Bacia de Campos foram analisados por $\mathrm{RMN}^{13} \mathrm{C}$ e por $\mathrm{RMN}^{1} \mathrm{H}$ em clorofórmio deuterado. Pela análise do espectro de $\mathrm{RMN}^{13} \mathrm{C}$ (Anexo 1), foram obtidas informações sobre as frações de carbonos 
aromáticos e alifáticos presentes nos asfaltenos, bem como a forma de substituição dos mesmos na molécula (Tabela 4.4). Praticamente a metade dos carbonos presentes é de cadeia aromática e a outra metade de cadeias alifáticas. Dos carbonos aromáticos, a maior parte $(30,8 \%)$, é composta por carbonos não substituídos e o restante é dividido em carbonos tetra-substituído - ou em junção de anel $(12,7 \%)$ - ou por grupamentos alquila $(11,5 \%)$.

Tabela 4. 4 - Resultados da análise de $\mathrm{RMN}^{13} \mathrm{C}$ dos asfaltenos isolados do óleo da Bacia de Campos

\begin{tabular}{l|c|c}
\hline Tipos de carbono & $\begin{array}{c}\text { Deslocamento } \\
\text { Quimico (ppm) }\end{array}$ & $\% \mathrm{C}$ \\
\hline $\mathrm{C}_{\text {aromáticos totais }}$ & $115-165$ & 55,0 \\
\hline $\mathrm{C}$ aromáticos não substituídos, & $115-129$ & 30,8 \\
\hline $\mathrm{C}_{\text {aromáticos em junçáo de anel }}$ & $129-137$ & 12,7 \\
\hline $\mathrm{C}_{\text {aromático substituídos por alquila ou }}$ & $137-165$ & 11,5 \\
heteroátomos & & \\
\hline $\mathrm{C}_{\text {alifáticos totais }}$ & & \\
\hline
\end{tabular}

A tabela 4.5 apresenta o resultado da análise de $\mathrm{RMN}^{1} \mathrm{H}$. Os percentuais dos tipos de hidrogênios encontrados são coerentes com os tipos de carbonos determinados por $\mathrm{RMN}^{13} \mathrm{C}$. A presença de $23 \%$ de hidrogênios na posição beta em relação a anéis aromáticos nas estruturas parafínicas e de $32 \%$ de hidrogênios metilênicos confirmam a existência de cadeias alquílicas ligadas à estrutura aromática. 
Tabela 4. 5 - Resultados da análise de $\mathrm{RMN}{ }^{\dagger} \mathrm{H}$ dos asfaltenos

\begin{tabular}{l|c|c}
\hline \multicolumn{1}{c|}{ Tipos de Hidrogênios } & $\begin{array}{c}\text { Desiocamento } \\
\text { Químico } \\
\text { (ppm) }\end{array}$ & $\%$ H \\
\hline$H_{\text {em anéis diaromáticos ou maiores }}$ & $9,2-7,1$ & 7,2 \\
\hline$H_{\text {monoaromático }}$ & $7,1-6,0$ & 2,5 \\
\hline$H_{\text {alfa a anéis aromáticos }}$ & $4,0-2,0$ & 15,1 \\
\hline$H_{\text {beta a anéis aromáticos e metínicos em estruturas naftênicas e parafinicas }}$ & $2,0-1,5$ & 23,0 \\
\hline$H_{\text {metilênicos em estruturas parafínicas, metilas beta e metilenos gama ou maior a }}$ & $1,5-1,05$ & 32,5 \\
\hline anéis aromáticos & $1,05-0,5$ & 19,7 \\
\hline aromáticos metilas em estruturas parafínicas ou metilas gama ou maior a anéis
\end{tabular}

\subsection{COMPORTAMENTO TÉRMICO DOS ASFALTENOS}

\subsubsection{Termogravimetria}

A avaliação inicial do comportamento térmico da amostra de asfaltenos foi realizada pela técnica de termogravimetria em atmosfera dinâmica de nitrogênio. As curvas de TG/DTG apresentadas na (Figura 4.3) são semelhantes às de asfaltenos de diversas procedências (Calemma e Rausa, 1997).

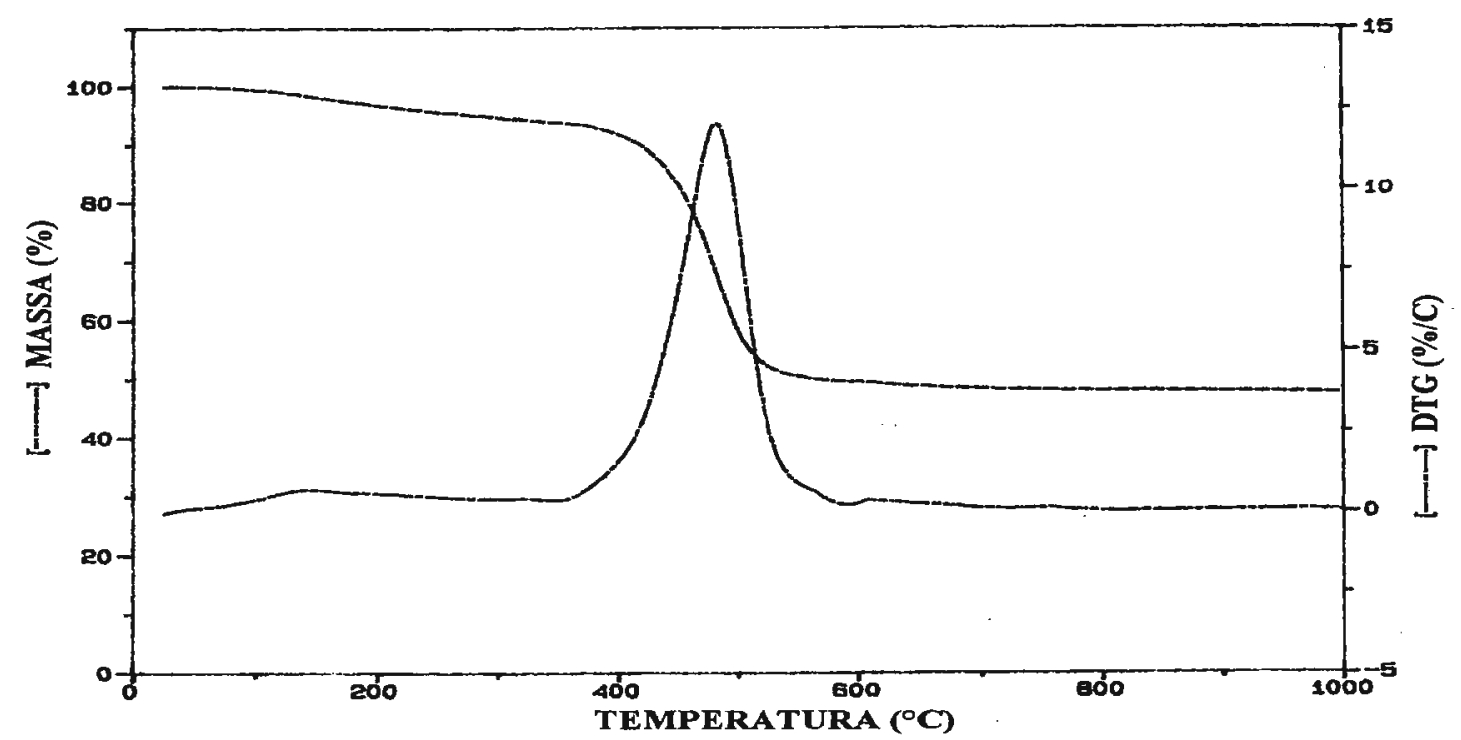

Figura 4. 3 - Curvas de TG/DTG dos asfaltenos (10 mg) do um óleo da Bacia de Campos a $10^{\circ} \mathrm{C} \mathrm{min}{ }^{-1}$ em $N_{2}$ na vazão de $100 \mathrm{~mL} \mathrm{~min}^{-1}$. 
A primeira etapa de perda de massa $(\Delta \mathrm{m}=8 \%)$ observada entre as temperaturas de 30 e $300^{\circ} \mathrm{C}$ pode estar relacionada, em parte, com a presença de parafinas que co-precipitaram com os asfaltenos (item 4.2), ou mesmo com a eliminação de tolueno remanescente da sua extração. Moschopedis e Speight (1978) comentam que, entre 190 e $200^{\circ} \mathrm{C}$, os asfaltenos da região de Athabasca apresentam o início de uma dissociação moderada liberando metano, etano, CO e $\mathrm{CO}_{2}$ proveniente da decomposição de ácidos carboxílicos e grupamentos alquila presentes na estrutura de asfaltenos. Afirmam, entretanto que a decomposição térmica ocorre realmente acima de $350^{\circ} \mathrm{C}$.

Uma segunda perda de massa $\left(\Delta \mathrm{m}=45 \%\right.$ ) ocorre entre 350 e $650^{\circ} \mathrm{C}$ devido à degradação térmica dos asfaltenos, conforme relatado por Moschopedis e Speight (1978) e mais tarde por Calemma e Rausa (1997). Não ocorrem outros eventos térmicos em atmosfera de nitrogênio e o produto final à $700^{\circ} \mathrm{C}$ equivale a $47 \%$ da amostra inicial - resíduo carbonáceo.

Um segundo experimento foi realizado em duas etapas, utilizando a mesma taxa de aquecimento (Figura 4.4). Na primeira etapa, a amostra foi aquecida até $700^{\circ} \mathrm{C}$ sob atmosfera de $\mathrm{N}_{2} \mathrm{e}$, a partir dessa temperatura, a atmosfera do forno foi trocada para ar sintético. Pode ser observado que, com a entrada de ar sintético, o resíduo a $700^{\circ} \mathrm{C}$ queima rapidamente em aproximadamente $800^{\circ} \mathrm{C}$ deixando cerca de $1 \%$ de cinzas (Teixeira e Gonçalves, 1999).

Como já mencionado anteriormente, a Petrobras tem interesse em conhecer o comportamento térmico dos asfaltenos nas temperaturas de operação de suas unidades de coqueamento e craqueamento catalítico de cargas pesadas de petróleo. São de interesse, portanto, os resíduos gerados nas temperaturas de $440,450,480,550$ e $580^{\circ} \mathrm{C}$.

Para avaliação dos produtos sólidos da decomposição térmica dos asfaltenos nessas temperaturas, seria necessária a obtenção de quantidades suficientes para a sua caracterização. Nesse momento surgiram algumas dúvidas:

- Como seria possivel a obtenção de resíduos da decomposição térmica dos asfaltenos em quantidades suficientes? 
- Como obtê-los de forma semelhante a aqueles das unidades de FCC e de coqueamento de uma refinaria?

- Como adaptar as condições analíticas para isolar os resíduos nas mesmas condições das unidades das refinarias, dado que - conforme apresentado no capítulo anterior - nas unidades de FCC as cargas são mantidas à temperaturas elevadas por frações de segundo, enquanto que na unidade de coqueamento esse tempo é de cerca de 24 horas.

Numa tentativa de subsidiar uma resposta para esses questionamentos a foi realizada uma avaliação cinética da decomposição térmica dos mesmos.

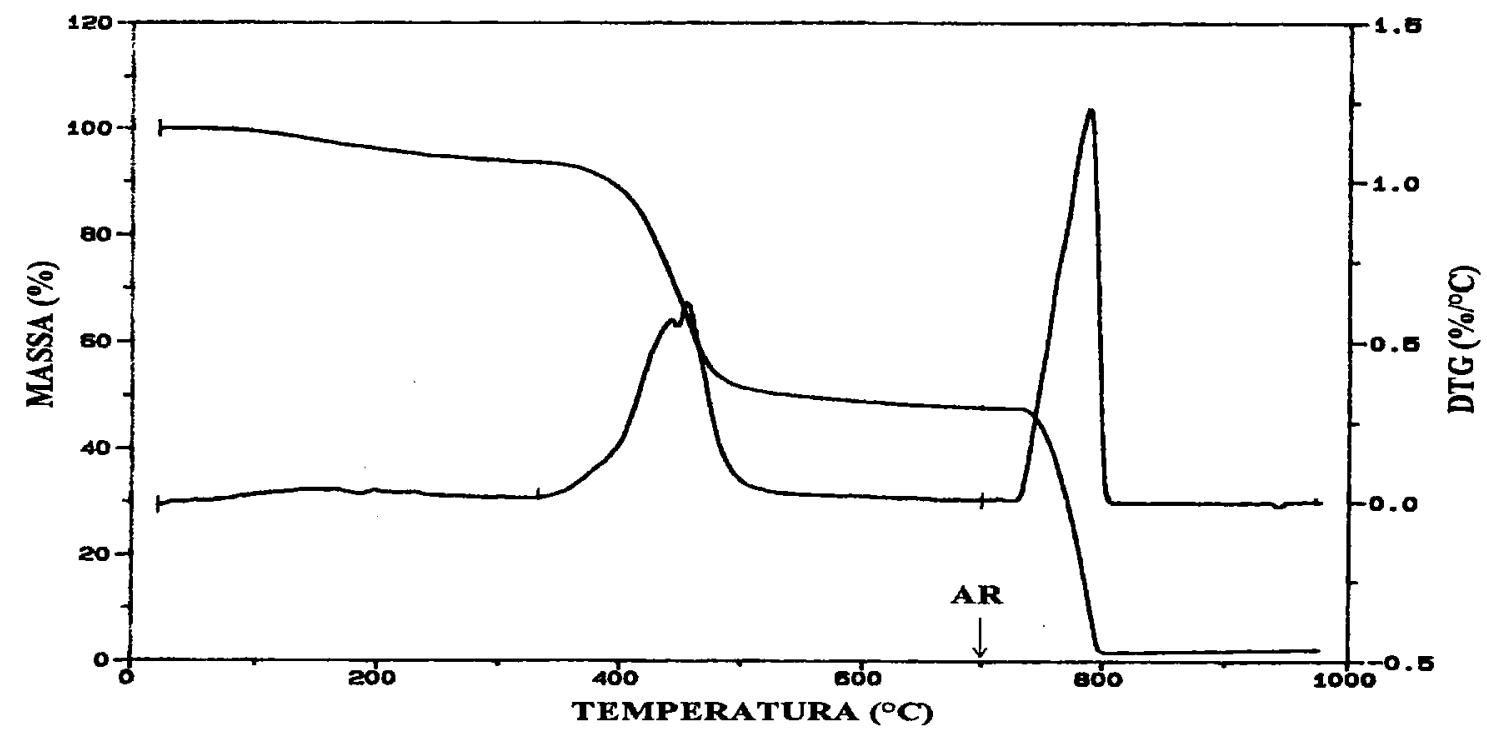

Figura 4. 4 - Curvas de TG/DTG na taxa de $10^{\circ} \mathrm{C} \mathrm{min}^{-1}$ sob atmosfera dinâmica de $\mathrm{N}_{2}\left(100 \mathrm{~mL} \mathrm{~min}^{-1}\right)$ entre $30 \mathrm{e} 700^{\circ} \mathrm{C}$ e em ar sintético $(100 \mathrm{~mL}$ $\mathrm{min}^{-1}$ ) entre 700 e $1000^{\circ} \mathrm{C} \mathrm{min}^{-1}$.

\subsubsection{Cinética da decomposição térmica dos asfaltenos por termogravimetria}

Foi utilizado o programa de cinética fornecido pelo fabricante do analisador TGA-951. Esse programa é baseado no método desenvolvido por Flynn e Wall (1966), que determina de forma rápida e fácil a energia de ativação da decomposição térmica de amostra diretamente das curvas de perda de massa $x$ 
temperatura obtidas em diferentes taxas de aquecimento. $\mathrm{O}$ método parte da equação que define a cinética de primeira ordem:

$$
\frac{d C}{d t}=f(C)
$$

Como o experimento é feito a uma taxa linear de aquecimento $(\beta)$ tem-se $T=\beta t+a, \operatorname{logo:}$

$$
\begin{gathered}
\frac{d T}{d t}=\beta \\
\frac{d C}{d T} \frac{d T}{d t}=K_{0} \exp \left(-E_{a} / R T\right) C \therefore \\
\frac{d C}{d T} \beta=k_{0} \exp \left(-E_{a} / R T\right) C
\end{gathered}
$$

onde:

$C=$ fração reagida

$\mathrm{t}=$ tempo

$K_{0}=$ freqüência ou fator pré exponencial $(1 / \mathrm{min})$

$E_{a}=$ energia de ativação $(\mathrm{J} / \mathrm{mol})$

$\mathrm{R}=$ constante dos gases

$\mathrm{T}=$ temperatura

Resolvendo a equação diferencial e fazendo uma série de aproximações, os autores determinam a energia de ativação através do coeficiente angular da reta obtida no gráfico de $\log \beta$ versus $1 / \mathrm{T}$.

A partir das curvas de perda de massa em função da temperatura, obtidas nas diferentes taxas de aquecimento, iniciando em $300^{\circ} \mathrm{C}$ e finalizando em $500^{\circ} \mathrm{C}$, são introduzidas no programa, as informações dos percentuais de conversão em que se deseja realizar a avaliação. No presente estudo foram 10 , 
$20,30,40,50,60,70,80,90$ e $95 \%$ de conversão em residuo. A partir dessa informação, são determinadas as curvas de fração residual em função da temperatura nas diferentes taxas de aquecimento (Figura 4.5).

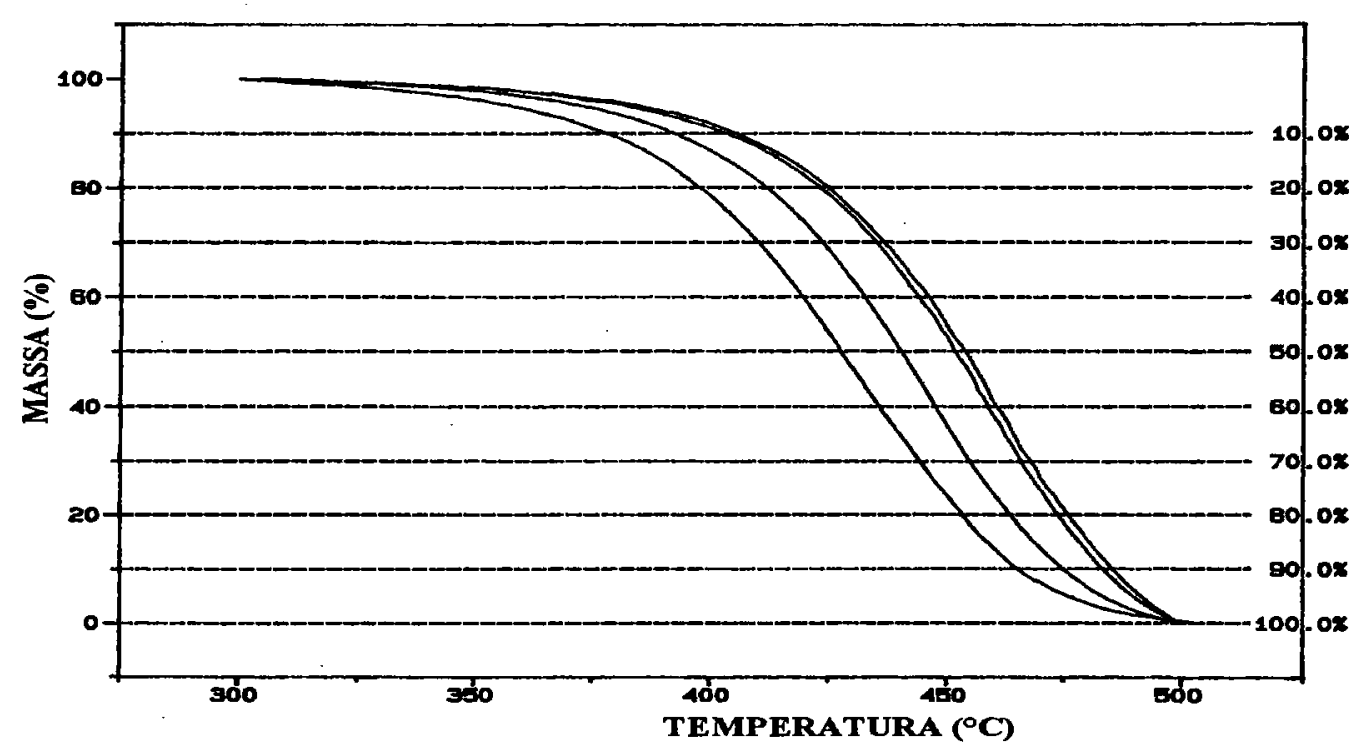

Figura 4. 5- Fração residual $x$ temperaturas nas taxas de aquecimento de 2 - 5 - 7,5 - $10^{\circ} \mathrm{Cmin}^{-1}$.

A seguir, o programa determinou as temperaturas em cada programação de aquecimento $\beta$ para os diferentes niveis de conversão solicitados, sendo obtido o gráfico de $\log \beta$ versus $1 / T$ a uma conversão constante (Figura 4.6). As retas, aparentemente, apresentam a mesma inclinação indicando que o mecanismo de decomposição é independente do nivel de conversão e, portanto, corresponde a uma reação de primeira ordem. Entretanto a energia de ativação $\left(E_{a}\right)$, definida pelo coeficente angular das retas (Tabela 4.6) parece aumentar considerávelmente com a temperatura sugerindo diferentes inclinações para as retas. Khulbe e colaboradores (1984), quando avaliaram a cinética da decomposição térmica de asfaltenos de petróleos de diferentes origens, verificaram reação de primeira ordem. Não é objetivo deste trabalho definir a ordem da reação de decomposição térmica dos asfaltenos, mas essa informação sugere um estudo mais apurado sobre o assunto.

Um resultado interessante foi obtido a partir da curva de conversão dos asfaltenos em resíduo versus tempo (Figura 4.7). Pode-se observar que a $320 \mathrm{e}$ $380^{\circ} \mathrm{C}$ são necessárias horas para que ocorra a conversão total dos asfaltenos 
em resíduo sólido (coque). Na temperatura de $400^{\circ} \mathrm{C}$ esse tempo é de 130 minutos. Enquanto que a $440^{\circ} \mathrm{C}$ são necessários 20 minutos e, à temperaturas maiores que $480^{\circ} \mathrm{C}$, os asfaltenos são totalmente convertidos em coque em menos de 1 minuto.

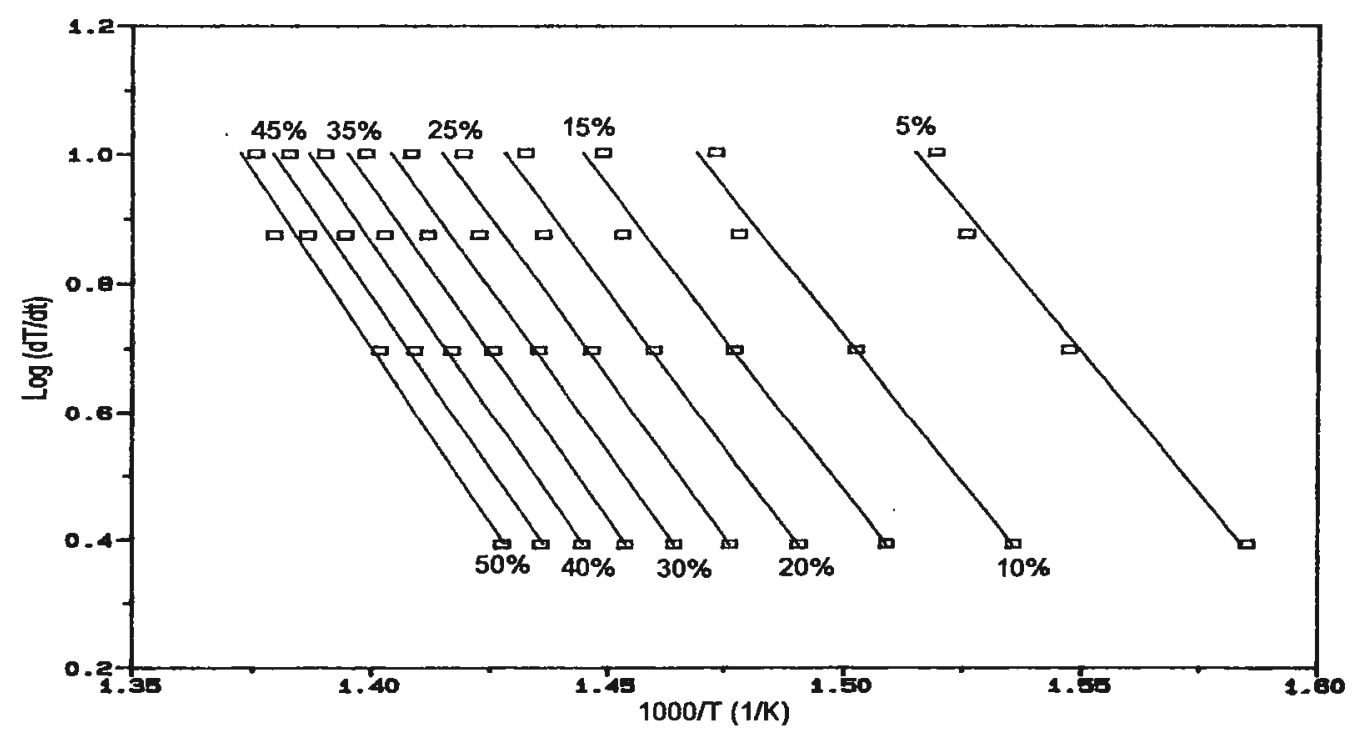

Figura 4. 6 - Curvas de $\log \beta \times 1 /$ T.

Tabela 4. 6 - E de ativação a diferentes niveis de conversão entre as temperaturas de 300 e $500^{\circ} \mathrm{C}$

\begin{tabular}{c|c|c}
\hline$\%$ CONVERSÃO & $\begin{array}{c}\mathrm{E}_{\mathrm{a}} \\
\mathrm{kJ} / \mathrm{mol}\end{array}$ & $\begin{array}{c}\text { Log (Fator preexp.) } \\
1 / \mathrm{min}\end{array}$ \\
\hline 5,0 & 175,5 & 12,33 \\
\hline 10,0 & 175,2 & 12,16 \\
\hline 15,0 & 179,1 & 12,41 \\
\hline 20,0 & 182,6 & 12,66 \\
\hline 25,0 & 185,2 & 12,83 \\
\hline 30,0 & 189,1 & 13,10 \\
\hline 35,0 & 192,8 & 13,37 \\
\hline 40,0 & 195,6 & 13,56 \\
\hline 45,0 & 198,0 & 13,73 \\
\hline 50,0 & 198,9 & 13,80 \\
\hline 60,0 & 199,0 & 13,90 \\
\hline 70,0 & 202,7 & 13,88 \\
\hline 80,0 & 207,5 & 14,26 \\
\hline 90,0 & 231,0 & 15,82 \\
\hline
\end{tabular}



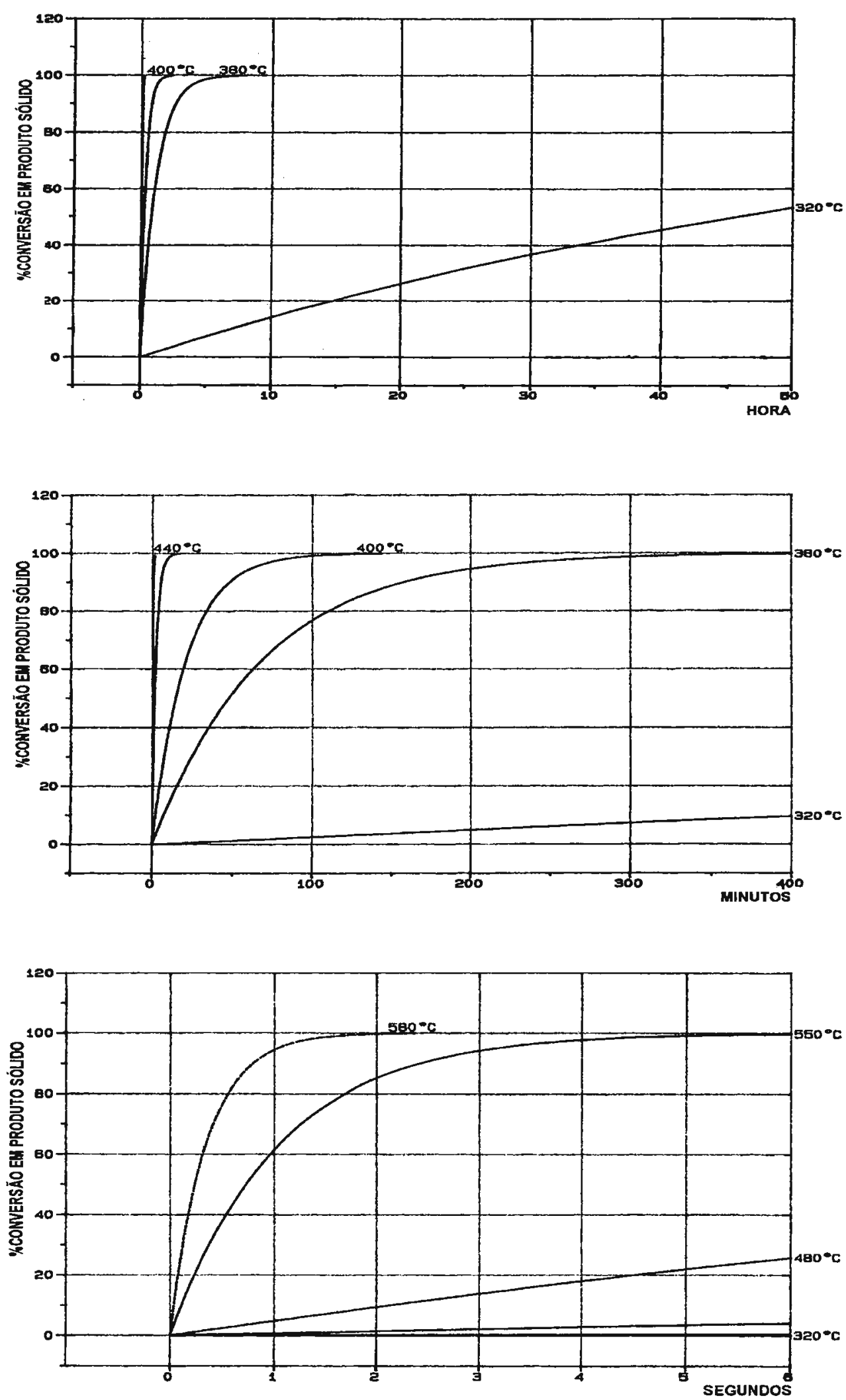

Figura 4. 7 - Decomposição térmica dos asfaltenos - Gráfico de conversão em produto sólido. 
Nas unidades de craqueamento de RV e RAT das refinarias, os tempos de contato das cargas e, portanto, dos asfaltenos, é da ordem de segundos. Já na unidade de coqueamento retardado, é de até 24 horas. Nestas condições não seria fácil a obtenção dos resíduos de decomposição térmica dos asfaltenos. Foi então resolvido que, neste trabalho, seria fixado um tempo único em cada temperatura, para que fosse possivel realizar estudos comparativos dos produtos sólidos obtidos nas diferentes temperaturas.

Algumas simulações foram realizadas por termogravimetria isotérmica, com o objetivo de se conhecer o teor de residuo formado em cada temperatura.

\subsubsection{Termogravimetria isotérmica}

Esse experimento consistiu em tratar a amostra de asfaltenos (10 mg), em atmosfera de nitrogênio, nas temperaturas de interesse e em mais algumas que poderiam complementar o estudo. As curvas de termogravimetria isotérmica obtidas nesse ensaio estão apresentadas no Anexo 2. Os percentuais de resíduo formado em diferentes tempos em cada temperatura estão apresentados na Tabela 4.7. Definiu-se como tempo zero $\left(t_{0}\right)$ o primeiro instante em que o forno atingiu a temperatura da isoterma desejada.

Tabela 4. 7 - Percentuais de resíduos em diferentes tempos obtidos a partir da TG isotérmica dos asfaltenos

\begin{tabular}{l|c|c|c|c|c|c|c|c}
\hline \multirow{2}{*}{$\begin{array}{l}\left.{ }^{\circ} \mathrm{C}\right) \\
\mathrm{t}(\mathrm{min})\end{array}$} & $\mathrm{t}_{0}$ & 2 & 4 & 6 & 10 & 20 & 35 & 60 \\
\hline 320 & 95,0 & 94,5 & 94,2 & 94,1 & 93,8 & 93,3 & 92,9 & 92,4 \\
\hline 380 & 92,3 & 91,4 & 90,5 & 89,8 & 88,8 & 86,6 & 84,3 & 82,1 \\
\hline 430 & 82,9 & 78,4 & 74,6 & 71,6 & 66,9 & 60,0 & 55,6 & 52,8 \\
\hline 438 & 78,9 & 72,9 & 68,5 & 65,2 & 62,9 & 56,9 & 54,7 & 53,4 \\
\hline 450 & 73,7 & 64,0 & 59,5 & 57,1 & 54,6 & 52,5 & 51,3 & 50,6 \\
\hline 480 & 64,8 & 58,4 & 56,9 & 56,1 & 55,3 & 54,5 & 54,1 & 53,8 \\
\hline 550 & 53,0 & 52,7 & 52,5 & 52,4 & 52,2 & 52,0 & 51,8 & 51,8 \\
\hline 700 & 48,7 & 48,6 & 48,5 & 48,4 & 48,3 & 47,8 & 47,6 & 47,4 \\
\hline
\end{tabular}


Foi observado que, nestas condições de análise, em vinte minutos os percentuais de resíduos obtidos nas temperaturas a 450,480 e $550{ }^{\circ} \mathrm{C}$ são bastante semelhantes; e que a $700^{\circ} \mathrm{C}$ é atingindo o percentual máximo de resíduo de decomposição térmica (aproximadamente 48\%). Esse teste, em diferentes isotermas, está coerente com a conversão em residuo observada no estudo cinético da decomposição (item 4.1.2): a conversão total dos asfaltenos em coque ocorre muito rapidamente a partir de $450^{\circ} \mathrm{C}$ o que também está de acordo com a temperatura de pico na curva de DTG (Figura 4.3).

Ao final da avaliação do comportamento térmico dos asfaltenos extraídos do óleo da Bacia de Campos por TG, conclui-se que os produtos sólidos procedentes da decomposição térmica dos asfaltenos nas temperaturas de interesse da refinaria deveriam ser obtidos em cada uma das temperaturas de interesse após um único tempo de contato nas mesmas. Foi escolhido, para efeitos comparativos, o tempo de 20 minutos.

\subsection{OBTENÇÃo E caracterização dos PRODUTOS dE DECOMPOSIÇÃO TÉRMICA DOS ASFALTENOS}

\subsubsection{Produtos sólidos da decomposição térmica (PSDT) dos asfaltenos}

Para caracterizar quimicamente os produtos sólidos da decomposição térmica (PSDT) dos asfaltenos, nas diferentes temperaturas, foi necessário pelo menos $200 \mathrm{mg}$ de cada um deles. Para obtenção de cada um desses produtos sólidos, inicialmente, foi utilizado um forno tubular como descrito no item 3.4.1. Os produtos sólidos, assim obtidos, foram estudados pelas técnicas físico-químicas de análise e submetidos à reação de degradação promovida pelo íon rutênio. Ao final da avaliação, os resultados indicaram poucas diferenças entre os sólidos. Novos produtos sóidos deveriam ser obtidos. Foi utilizado como forno o próprio equipamento de termogravimetria com pequenas modificações, para que se pudesse isolar uma maior quantidade de amostra. 


\subsubsection{Preparo e caracterização dos PSDT dos asfaltenos utilizando forno tubular nas temperaturas de $320,380,450$ e $550^{\circ} \mathrm{C}$}

Os ensaios para obtenção dos PSDT dos asfaltenos em forno tubular podem ser considerados como testes exploratórios, que objetivaram definir melhores condições de obtenção desses materiais em quantidades suficientes para sua avaliação química. Portanto, cerca de $1 \mathrm{~g}$ de asfaltenos foi submetido às temperaturas de $320,380,450$ e $550^{\circ} \mathrm{C}$ por 20 minutos, tempo mínimo para que a temperatura do forno se estabilizasse. Ao final deste tempo as massa dos produtos agora denominados de PSDT-320, PSDT-380, PSDT-450 e PS-550 foram medidas. A Tabela 4.8 apresenta os percentuais de PSDT obtidos nestas condições. Era esperada uma diminuição no percentual de sólido formado com o aumento da temperatura devido à maior quantidade de voláteis gerados. Essa tendência foi observada, entretanto com uma inversão nas temperaturas de 450 e $550^{\circ} \mathrm{C}$, causada provavelmente pelas dificuldades de controle do forno encontradas durante o experimento assim como pela possivel perda de material durante a decomposição térmica.

Tabela 4. 8 - Percentuais de PSDT dos asfaltenos obtidos em forno tubular após 20 min nas temperaturas de $320,380,450$ e $550^{\circ} \mathrm{C}$

\begin{tabular}{c|c|c|c}
\hline $\mathrm{T}^{\circ} \mathrm{C}$ & $\begin{array}{c}\text { Massa de } \\
\text { asfaltenos }(\mathrm{mg})\end{array}$ & $\begin{array}{c}\text { Massa de PSDT } \\
(\mathrm{mg})\end{array}$ & $\begin{array}{c}\mathrm{PSDT} \\
(\%)\end{array}$ \\
\hline 320 & 1,17357 & 0,71791 & 61 \\
\hline 380 & 1,72102 & 0,93280 & 54 \\
\hline 450 & 1,75856 & 0,61477 & 35 \\
\hline 550 & 2,34892 & 1,06942 & 46 \\
\hline
\end{tabular}

Os percentuais de PSDT obtidos pelo forno tubular foram comparados com os percentuais obtidos nos estudos isotérmicos no tempo de 20 minutos descritos no item 4.1.3 (Tabela 4.9). Foi verificada uma diferença acentuada entre eles. Embora os experimentos sejam diferentes, era esperada alguma similaridade nos percentuais de produtos sólidos gerados. Tal diferença está, provavelmente, relacionada com as dificuldades encontradas no controle do experimento. 
Tabela 4. 9 - Comparação dos percentuais de PSDT dos asfaltenos preparados no forno tubular e os medidos por TG

\begin{tabular}{c|c|c}
\hline Temperatura $\left({ }^{\circ} \mathrm{C}\right)$ & $\begin{array}{c}\text { \% PSDT obtido no } \\
\text { forno tubular } \\
(\mathrm{t}=20 \mathrm{~min})\end{array}$ & $\begin{array}{c}\text { \% PSDT medido na TG } \\
\text { ( } \mathrm{t}=20 \mathrm{~min})\end{array}$ \\
\hline 320 & 61 & 93,3 \\
\hline 380 & 54 & 86,6 \\
\hline 450 & 35 & 52,5 \\
\hline 550 & 46 & 52,0 \\
\hline
\end{tabular}

A Tabela 4.10 apresenta os resultados obtidos pela de análise elementar dos PSDT e compara com os valores encontrados anteriormente para os asfaltenos.

Foi observado um aumento na relação $\mathrm{C} / \mathrm{H}$ com o aumento da temperatura de decomposição térmica dos asfaltenos. Essa tendência já era esperada, pois durante a decomposição térmica ocorrem quebras dos grupamentos alquila ligados ao núcleo poliaromático dos asfaltenos diminuindo a concentração de hidrogênio (Moschopedis, S., Parkash, S. e Speiht, 1978). A relação C/N diminuiu, indicando, a princípio, que parte do nitrogênio presente nos asfaltenos fica retido no resíduo de decomposição. A relação $\mathrm{C} / \mathrm{O}$ apresentou, inicialmente um aumento e, em seguida, uma diminuição drástica. Não se tem, a princípio, uma explicação para este fato. É possível que a falta de controle da atmosfera inerte no interior do forno tubular durante a obtenção dos produtos possa ter acarretado a entrada de ar causando uma parcial oxidação dos asfaltenos.

Tabela 4. 10 - Análise elementar dos PSDT obtidos em forno tubular comparados com a análise dos asfaltenos

\begin{tabular}{|c|c|c|c|c|c|c|c|}
\hline \multirow[t]{2}{*}{ AMOSTRAS } & \multirow[t]{2}{*}{ C \% } & \multirow[t]{2}{*}{$H \%$} & \multirow[t]{2}{*}{$\mathrm{N} \%$} & \multirow[t]{2}{*}{$0 \%$} & \multicolumn{3}{|c|}{ Relação } \\
\hline & & & & & $\mathrm{C} / \mathrm{H}$ & $\mathrm{C} / \mathrm{N}$ & $\mathrm{C} / \mathrm{O}$ \\
\hline Asfaltenos & 85,8 & 8,4 & 1,8 & 1,3 & 0,9 & 55,6 & 88,0 \\
\hline PSDT $-320^{\circ} \mathrm{C}$ & 88,1 & 7,6 & 2,2 & 0,8 & 1,0 & 46,7 & 146,8 \\
\hline PSDT $-380^{\circ} \mathrm{C}$ & 89,6 & 5,0 & 2,7 & 1,0 & 1,5 & 38,7 & 119,5 \\
\hline PSDT $-450^{\circ} \mathrm{C}$ & 87,1 & 3,4 & 2,8 & 2,8 & 2,1 & 36,3 & 41,5 \\
\hline PSDT $-550^{\circ} \mathrm{C}$ & 86,4 & 2,7 & 2,8 & 7,1 & 2,7 & 36,0 & 16,2 \\
\hline
\end{tabular}

Os espectros de absorção no IV dos produtos foram pouco elucidativos (Anexo 3), mas foi possivel verificar que ocorre uma diminuição nas absorções 
características de ligações $\mathrm{CH}, \mathrm{CH}_{2}, \mathrm{CH}_{3}\left(1430\right.$ e $\left.1380 \mathrm{~cm}^{-1}\right)$ e um aumento considerável nas intensidades das absorções a $3300 \mathrm{~cm}^{-1}$ e $1100 \mathrm{~cm}^{-1}$ relativas a grupamentos -OH e $\mathrm{C}-\mathrm{O}$ respectivamente, confirmando as suspeitas quanto à oxidação parcial já descrita no parágrafo anterior.

Os produtos da decomposição térmica dos asfaltenos foram, também, avaliados por $\mathrm{RMN}^{13} \mathrm{C}$. Como apresentavam baixa solubilidade em solventes orgânicos, só foi possivel a realização dessa análise em estado sólido. Para efeitos comparativos, os asfaltenos antes analisados por RMN em solução (item 4.2.4), foram também analisados pela mesma técnica.

A técnica de $\mathrm{RMN}^{13} \mathrm{C}$ no estado sólido é amplamente utilizada para caracterização de materiais não solúveis em solventes orgânicos, como materiais poliméricos e catalisadores (Fyfe, 1983). Tem sido utilizada também na caracterização de combustíveis sólidos (Solum, 1989), assim como na caracterização de asfaltenos de diferentes origens (Callema, 1995 e 1998).

A obtenção de um espectro de $\mathrm{RMN}^{13} \mathrm{C}$ no estado sólido requer a utilização de técnicas especiais que anulem ou diminuem as interações nucleares fortes causadas pela rigidez molecular e pela proximidade das cadeias, fenômenos que não ocorrem quando da análise em solução - no estado líquido as moléculas se movimentam rapidamente anulando essas interações (Fyfe, 1983). As interações causam o alargamento do sinal de RMN acarretando espectros com pouca resolução.

As interações entre os núcleos de ${ }^{1} \mathrm{H}$ e ${ }^{13} \mathrm{C}$ são eliminadas quando a análise de sólidos é realizada pela técnica denominada de rotação no ângulo mágico (magic angle spinning - MAS) desenvolvida por Andrew e colaboradores (1958). Esta técnica consiste em colocar a amostra no interior de uma sonda que gira no ângulo de $54^{\circ} 44^{\prime}$, condição que permite simular, para as moléculas no estado sólido, os movimentos de moléculas em solução. Nesta condição, é possivel a análise quantitativa das diferentes configurações de carbonos presentes na amostra. 
A polarização cruzada (CP) com rotação do ângulo mágico (CP/MAS) e varredura do tempo de contato é outra técnica utilizada na análise de RMN de sólidos. Não é uma metodologia quantitativa, mas pode ser utilizada comparativamente quando os materiais analisados são semelhantes. A polarização cruzada (CP) é aplicada em compostos rígidos contendo núcleos de spin abundantes como ${ }^{1}{ }^{1} \mathrm{H}$.

Uma outra técnica a chamada de Non-Quaternary Supression (NQS) promove uma seqüência de pulsos que elimina algumas interações entre os diferentes tipos de carbonos mostrando apenas os carbonos totalmente substituídos presentes na molécula em análise (Opella e Frey, 1979).

Os asfaltenos e os produtos sólidos da decomposição térmica destes nas temperaturas de $320,380,450$ e $550^{\circ} \mathrm{C}$ foram então analisados por $\mathrm{RMN}^{13} \mathrm{C}$ utilizando as técnicas acima citadas. Os espectros resultantes estão apresentados no Anexo 4.

No espectro de $\mathrm{RMN}^{13} \mathrm{C}$ utilizando a metodologia de CP/MAS com variação de tempo de contato, foi observado que o máximo de transferência de polarização ocorreu a $200 \mu \mathrm{s}$, tempo característico de uma estrutura rígida. Para os produtos de decomposição térmica, foi observado que os tempos de contato diminuiam com o aumento da temperatura de obtenção dos mesmos. Assim, os máximos de transferência de polarização ocorreram a $200 \mu \mathrm{s}$ para o $\mathrm{PSDT}-320^{\circ} \mathrm{C}, 100 \mu \mathrm{s}$ para o PSDT $-380^{\circ} \mathrm{C}$ e entre 50 e $100 \mu$ s para o PSDT $-450^{\circ} \mathrm{C}$. Essa observação indicou que as estruturas desses produtos foram tornando-se mais rígidas à medida que a temperatura de obtenção aumentou. 0 mesmo não foi observado para o produto obtido a $550^{\circ} \mathrm{C}$, talvez pela pequena quantidade de amostra fornecida para análise.

Pelos espectros de $\mathrm{RMN}^{13} \mathrm{C}$ quantitativos usando a técnica de MAS e NQS, foi possivel obter os parâmetros apresentados na Tabela 4.11. Foi observada uma diminuição no percentual de carbonos alifáticos à medida que a temperatura de obtenção dos produtos aumentava, assim como os percentuais de carbonos metilênicos, metínicos e naftênicos. No $\mathrm{PSDT}-450^{\circ} \mathrm{C}$, os únicos carbonos 
alifáticos encontrados são metilas, provavelmente como substituintes de anéis aromáticos. Já no PSDT $-550^{\circ} \mathrm{C}$, o percentual de carbonos aromáticos substituídos pode ser atribuído à substituição por heteroátomos, uma vez que não há carbonos alifáticos nesta amostra. Os percentuais de carbonos aromáticos não substituídos e em junção de anéis aumentam com o aumento da temperatura de obtenção dos produtos, o que já era esperado, uma vez que com o aumento da temperatura ocorre uma diminuição no percentual de carbonos alifáticos e aumento na rigidez das estruturas médias.

Tabela 4. 11 - Resultados de RMN $^{13} \mathrm{C}$ no estado sólido dos PSDT dos asfaltenos obtidos em forno tubular

\begin{tabular}{l|c|c|c|c|c}
\hline \multicolumn{1}{c|}{ TIPOS DE CARBONO } & Asfaltenos & PSDT-320 & PSDT-380 & PSDT-450 & PSDT-550 $^{\circ} \mathrm{C}$ \\
\hline Carom,total & 55,5 & 64,9 & 86,7 & 95,0 & 100,0 \\
\hline C arom,não subst. + Junçåo & 38,9 & 48,0 & 58,4 & 72,5 & 73,1 \\
\hline Carom,subst. por alquila & 16,6 & 16,9 & 28,3 & 23,3 & 26,9 \\
\hline Califático, total & 44,5 & 35,1 & 13,3 & 4,2 & - \\
\hline C alifático (Me em final de cadeia) & & 9,6 & 6,9 & 4,2 & - \\
\hline Califático (CH,CH, nafténico) & & 25,5 & 6,4 & - & - \\
\hline Carom. totalmente subst. ${ }^{\star *}$ & & 40,0 & 54,8 & 51,1 & 43,8 \\
\hline
\end{tabular}

(") Valores dificeis de serem determinados; não há definição nítida desta região do espectro

("*) Obtidos pelo espectro de NQS- Non quaternary supression

Com o objetivo de conhecer mais sobre os produtos sólidos formados nas diferentes temperaturas, estes e os asfaltenos foram submetidos à reação de oxidação catalisada pelo ion rutênio - RICO (item 3.5.4).

Segundo Strausz (1989), na reação RICO com os asfaltenos, os carbonos aromáticos ligados a grupamento alquila são seletivamente oxidados a ácidos monocarboxílicos e a ácidos dicarboxílicos quando esses grupamentos ligados ao anel aromático são de origem naftênica ou pertencente a pontes alquílicas de ligação entre os núcleos poliaromáticos (Figura 2.9). Já os anéis aromáticos são oxidados por esse reagente para dar origem a ácidos benzeno dicarboxilicos (Figura 2.10).

Os ácidos gerados na reação RICO com os asfaltenos e cada um dos produtos sólidos foram analisados por espectroscopia de absorção no IV. Foi 
observada, em todos os produtos, uma banda intensa a $1710 \mathrm{~cm}^{-1}$, característica de absorção de grupamento $\mathrm{C}=\mathrm{O}$ de ácido (Anexo 5). Em seguida esses ácidos foram metilados com diazometano para facilitar a identificação por cromatografia gasosa acoplada a espectrometria de massa (CG-EM) e novamente analisados por espectroscopia de absorção no IV (Anexo 6). Verificou-se a presença da banda de absorção característica de éster $\left(1736 \mathrm{~cm}^{-1}\right)$ e o desaparecimento da banda de absorção de ácido $\left(1710 \mathrm{~cm}^{-1}\right)$.

Para a quantificação relativa dos ésteres formados, cada um dos produtos de reação teve o volume ajustado em $5 \mathrm{~mL}$ com diclorometano e medida a intensidade da banda de ésteres a $1736 \mathrm{~cm}^{-1}$ (Figura 4.8). Pode-se observar que a concentração de ésteres diminui com o aumento da temperatura de obtenção dos produtos, confirmando a eliminação dos grupamentos alquila com o aumento da temperatura.

Em seguida cada solução em diclorometano foi analisada por cromatografia gasosa acoplada a espectrometria de massa (CG-EM) para identificação dos ésteres formados.
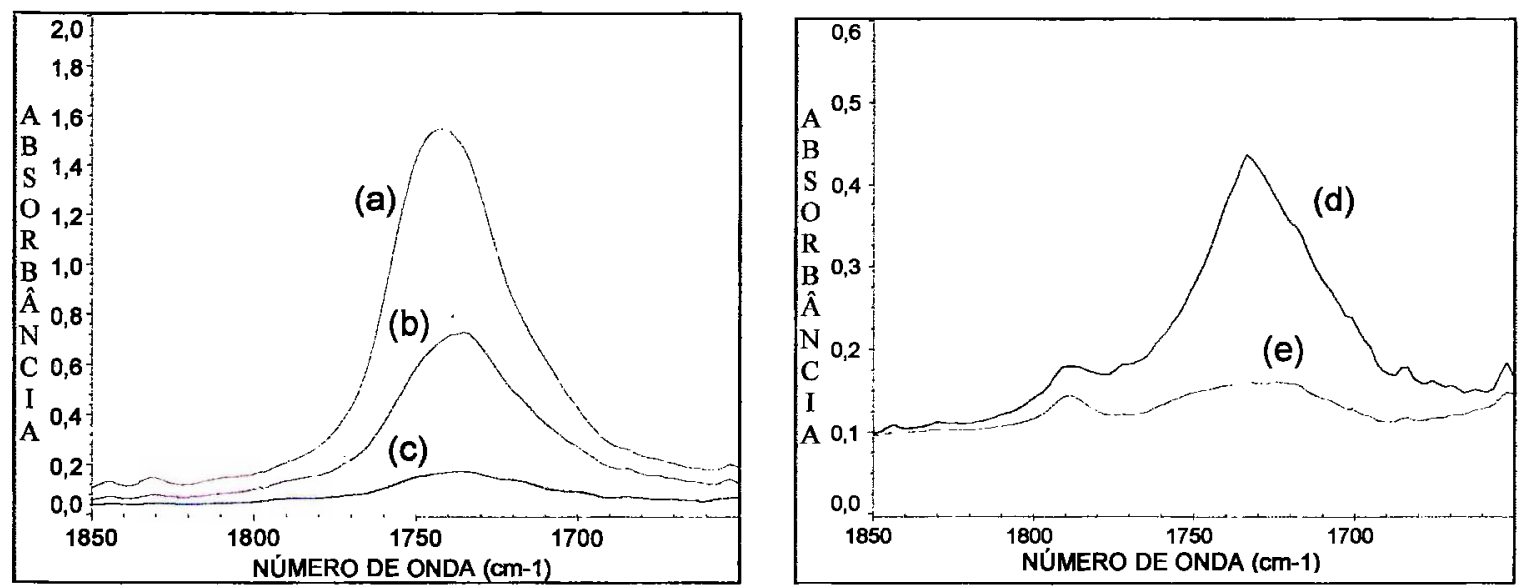

Figura 4. 8 - Intensidade da banda de absorção dos ésteres $\left(1736 \mathrm{~cm}^{-1}\right)$ obtidos na reação RICO dos (a) asfaltenos, (b) PSDT-320 $\mathrm{C}$, (c) PSDT-380 $0^{\circ} \mathrm{C}$ (célula de $1 \mathrm{~mm}$ de espessura), (d) PSDT $-450^{\circ} \mathrm{C}$, (e)PSDT-550 $\mathrm{C}$ (célula de $0,2 \mathrm{~mm}$ de espessura).

Na espectrometria de massa (EM) as moléculas são ionizadas sob vácuo e, de acordo com a energia envolvida no processo, são fragmentadas ou não. 
Dentre as diversas formas de ionização, a mais utilizada é impacto eletrônico. Neste caso, as moléculas são ionizadas através da colisão com um feixe de elétrons e o excesso de energia leva à fragmentação posterior. Os íons formados são separados através de um analisador de massa de acordo com a relação massa sobre carga $(\mathrm{m} / \mathrm{z})$ e detectados através de uma eletromultiplicadora. $O$ espectro de massa obtido poder ser utilizado como uma impressão digital da molécula em estudo e contém muitas informações sobre a sua estrutura. No caso da espectrometria de massa de alta resolução, os íons são separados através de um analisador de setor magnético, e, dependendo da resolução de massa alcançada e do tipo de aplicação, não é necessária a separação prévia dos componentes de uma mistura.

O acoplamento da técnica de cromatografia gasosa com a espectrometria de massa (CG-EM), permite que os componentes de uma mistura sejam separados e identificados. O grau de detalhamento obtido é limitado pela resolução obtida na etapa de separação. A medida que os componentes são separados na coluna cromatográfica, eles alcançam o detetor de massa, onde as moléculas são ionizadas e fragmentadas. O registro obtido é denominado de cromatograma total de íons (Total ion chromatogram - TIC) e a cada pico cromatográfico corresponde um espectro de massa que pode ser de um componente ou de mais de um, dependendo da separação obtida.

No Anexo 7, são apresentados os cromatogramas totais de íons da análise de CG-EM dos ésteres metílicos gerados na reação RICO com os asfaltenos e seus produtos de decomposição térmica.

Tanto os asfaltenos quanto o PSDT- $320^{\circ} \mathrm{C}$ geraram, na reação $\mathrm{RICO}$, os mesmos ésteres majoritários. Foi verificada, a partir da análise dos espectros de massa obtidos nessas duas amostras, a presença de ésteres metílicos graxos com cadeia alquílica entre $\mathrm{C}_{6}$ e $\mathrm{C}_{24}$ e séries homólogas de ésteres dimetílicos de ácidos dicarboxílicos com cadeia de $\mathrm{C}_{4}$ até $\mathrm{C}_{13}$. Foi detectada também a presença de ésteres dimetílicos dos ácidos benzodicarboxílicos entre $C_{8}$ a $C_{10}$. 
As mesmas séries homólogas de ésteres metílicos e dimetílicos de cadeias alquílicas foram encontradas no produto da reação $\mathrm{RICO}$ com o PSDT- $380^{\circ} \mathrm{C}$, não sendo encontrada, entretanto, a série de ésteres de ácidos dicarboxílicos.

Já na reação com as amostras de PSDT- $450^{\circ} \mathrm{C}$ e PSDT $-550^{\circ} \mathrm{C}$, não foram observados os fragmentos característicos de ésteres metílicos. Foi observado apenas um sinal intenso com espectro de massa idêntico ao ftalato de dioctila, substância encontrada em alguns solventes orgânicos, sendo atribuido à contaminação do solvente.

A Tabela 4.12 apresenta de forma resumida as séries de ésteres metílicos identificadas nos produtos da reação RICO com as amostras em questão.

Tabela 4. 12 - Ésteres metílicos dos ácidos gerados na reação RICO com os asfaltenos e de seus produtos sólidos obtidos em forno tubular

\begin{tabular}{c|c|c|c|c|c}
\hline \multirow{2}{*}{$\begin{array}{c}\text { AMOSTRAS } \\
\text { ÉSTERES }\end{array}$} & \multicolumn{5}{|c}{ Séries homólogas } \\
\cline { 2 - 6 } & Asfaltenos & $\begin{array}{c}\text { PSDT- } \\
320^{\circ} \mathrm{C}\end{array}$ & $\begin{array}{c}\text { PSDT- } \\
380^{\circ} \mathrm{C}\end{array}$ & $\begin{array}{c}\text { PSDT- } \\
450^{\circ} \mathrm{C}\end{array}$ & PSDT-550 ${ }^{\circ} \mathrm{C}$ \\
\hline $\begin{array}{c}\text { Metílicos de } \\
\text { ácidos graxos }\end{array}$ & $\left(\mathrm{C}_{6}-\mathrm{C}_{24}\right)$ & $\left(\mathrm{C}_{6}-\mathrm{C}_{24}\right)$ & $\left(\mathrm{C}_{6}-\mathrm{C}_{24}\right)$ & - & - \\
\hline $\begin{array}{c}\text { Dimetílicos de } \\
\text { ácidos } \\
\text { dicarboxílicos }\end{array}$ & $\left(\mathrm{C}_{4}-\mathrm{C}_{13}\right)$ & $\left(\mathrm{C}_{4}-\mathrm{C}_{13}\right)$ & - & - & - \\
\hline $\begin{array}{c}\text { Dimetílicos de } \\
\text { ácidos benzeno } \\
\text { dicarboxílicos }\end{array}$ & $\left(\mathrm{C}_{8}-\mathrm{C}_{10}\right)$ & $\left(\mathrm{C}_{8}-\mathrm{C}_{10}\right)$ & - & - & - \\
\hline
\end{tabular}

Poucas informações foram obtidas sobre a constituição química dos produtos sólidos da decomposição térmica dos asfaltenos nas temperaturas estudadas. Talvez este fato, possa ser explicado pelas dificuldades encontradas no controle do forno tubular utilizado para obtenção dessas amostras o que não permitiu a obtenção de produtos de decomposição térmica dos asfaltenos diferenciados. Entretanto, foram adquiridas experiências no que diz respeito à obtenção do material sólido da decomposição térmica dos asfaltenos, assim como na realização da reação RICO, de que não se encontrou registros de ter sido aplicada a produtos sólidos deste tipo.

Para melhores informações sobre os produtos sólidos da decomposição térmica dos asfaltenos em diferentes temperaturas se fez necessário gerar novos 
materiais, empregando uma metodologia que proporcionasse maior controle da temperatura e atmosfera do forno. Uma sugestão foi a utilização do próprio equipamento de termogravimetria (TGA-951) que, por ter um forno menor que o tubular e ser automatizado, forneceu melhor controle da temperatura e atmosfera interna ao forno.

Para a utilização do TGA-951 com esse objetivo, algumas modificações foram introduzidas para facilitar a obtenção de maior quantidade de produto sólido (item 3.4.2).

\subsubsection{Preparo e caracterização dos PSDT dos asfaltenos utilizando equipamento TGA-951 nas temperaturas de 320,380,400,440, 480, 550 e $550^{\circ} \mathrm{C}$}

Como mencionado no item anterior, o equipamento de TG teve que ser modificado para que fosse possível a obtenção dos produtos sólidos da decomposição térmica dos asfaltenos em quantidades suficientes para realização dos ensaios de caracterização. O cadinho original empregado no sistema TGA951 foi então substituído por um cadinho de alumina com capacidade para massa de amostras maiores. Esse cadinho foi posicionado na parte central do forno e não conectado ao sistema da balança (Figura 3.2). Desta forma, não foi possivel acompanhar as perdas de massa durante os experimentos, mas somente a temperatura a que a amostra estava sendo submetida. Por outro lado, as amostras foram pesadas antes e após o processo de aquecimento.

Para os ensaios em cada isoterma, os asfaltenos foram pesados no cadinho de alumina e colocados no interior do forno ainda frio. Após a purga de 15 min., com gás inerte, foram submetidos, como descrito no item 3.4.2, às temperaturas de $320,380,400,440,480,550$, e $580^{\circ} \mathrm{C}$ por 10 minutos, tempo mínimo observado, para garantir estabilização do forno em todas as temperaturas avaliadas. Após os 10 minutos em cada temperatura, o forno foi resfriado externamente com ar frio a $50^{\circ} \mathrm{C} \mathrm{min} ~^{-1}$ até $100^{\circ} \mathrm{C}$ e aberto. Em seguida, o cadinho, contendo o produto sólido da decomposição térmica, foi retirado de seu interior e acondicionado em dessecador. O conjunto cadinho de alumina e produto da 
decomposição térmica foi pesado após totalmente frio. Os produtos gerados nessa etapa foram denominados de PSDTa- $320^{\circ} \mathrm{C}, \mathrm{PSDTa}-380^{\circ} \mathrm{C}, \mathrm{PSDTa}-400^{\circ} \mathrm{C}$, PSDTa- $440^{\circ} \mathrm{C}, \mathrm{PSDTa}-480^{\circ} \mathrm{C}, \mathrm{PSDTa}-550^{\circ} \mathrm{C}$ e PSDTa- $580^{\circ} \mathrm{C}$.

As curvas de aquecimento estão apresentadas no Anexo 8. A Tabela 4.13 lista as temperaturas máximas que o forno do sistema TGA-951 atingiu em cada experimento $\mathrm{e}$ as temperaturas de estabilização para cada isoterma préestabelecida. Pode-se observar que não houve uma discrepância muito grande entre essas temperaturas e isso, de certa forma, representa um bom controle de temperatura para obtenção dos produtos de decomposição térmica.

Tabela 4. 13 - Temperaturas do forno do TGA-951 durante a obtenção dos produtos sólidos da decomposição térmica dos asfaltenos

\begin{tabular}{c|c|c}
\hline $\begin{array}{c}\mathrm{T} \\
\text { de Isoterma } \\
\left({ }^{\circ} \mathrm{C}\right)\end{array}$ & $\begin{array}{c}T_{\text {máx }} \\
\text { atingida no forno } \\
\left({ }^{\circ} \mathrm{C}\right)\end{array}$ & $\begin{array}{c}T \\
\text { de estabilização } \\
\text { do forno }\left({ }^{\circ} \mathrm{C}\right)\end{array}$ \\
\hline 320 & 324 & 320 \\
\hline 380 & 387 & 383 \\
\hline 400 & 408 & 403 \\
\hline 440 & 447 & 443 \\
\hline 480 & 490 & 480 \\
\hline 550 & 560 & 550 \\
\hline 580 & 593 & 580 \\
\hline
\end{tabular}

A Tabela 4.14 apresenta os percentuais de produtos sólidos isolados em cada uma das temperaturas. Agora, diferente da experiência realizada no forno tubular (item 4.4.1.1), os percentuais diminuem com o aumento de temperatura, tendência esperada.

Os produtos sólidos obtidos a partir das isotermas foram, inicialmente, submetidos à termogravimetria sob atmosfera dinâmica de nitrogênio. As curvas TG/DTG estão apresentadas no Anexo 9. A Tabela 4.15 compara as perdas de massa dos asfaltenos e dos seus produtos isolados a $320,380,400,440,480$, 550 e $580^{\circ} \mathrm{C}$. Foi observado que, na faixa de temperatura entre 350 e $550^{\circ} \mathrm{C}$, os percentuais de perda massa das amostras de PSDTa- $320^{\circ} \mathrm{C}$ e PSDTa- $380^{\circ} \mathrm{C}$, são semelhantes aos dos asfaltenos. Por outro lado, as curvas TG/DTG evidenciaram 
que entre 350 e $550^{\circ} \mathrm{C}$ as perdas de massa foram cada vez menores quanto maior a temperatura de obtenção do produto. Essa informação está coerente com o estudo cinético apresentado no item 4.3.2 em que, para essas temperaturas, a conversão em coque ocorre muito rapidamente. No caso do produto isolado a $580^{\circ} \mathrm{C}$, observou-se uma perda de massa de $2 \%$ entre 25 e $300^{\circ} \mathrm{C}$, que pode ser atribuída à adsorção de água superficial após resfriamento do produto.

Tabela 4. 14 - Quantidades de produtos sólidos obtidos a 320, 380, 400, $440,480,550$ e $580^{\circ} \mathrm{C}$ no equipamento TGA-951

\begin{tabular}{c|c|c|c}
\hline $\begin{array}{c}\mathrm{T} \\
\text { de Isoterma } \\
\left({ }^{\circ} \mathrm{C}\right)\end{array}$ & $\begin{array}{c}\text { Asfaltenos } \\
(\mathrm{mg})\end{array}$ & $\begin{array}{c}\text { Produto sólido } \\
(\mathrm{mg})\end{array}$ & $\begin{array}{c}\text { Produto sólido } \\
(\%)\end{array}$ \\
\hline 320 & 325 & 305 & 94 \\
\hline 380 & 301 & 271 & 90 \\
\hline 400 & 309 & 268 & 87 \\
\hline 440 & 491 & 320 & 65 \\
\hline 480 & 229 & 121 & 53 \\
\hline 550 & 298 & 151 & 51 \\
\hline 580 & 251 & 124 & 49 \\
\hline
\end{tabular}

Tabela 4. 15 - Resultados da análise de TG dos produtos PSDTa- $320^{\circ} \mathrm{C}$, PSDTa $-380^{\circ} \mathrm{C}$, PSDTa $-400^{\circ} \mathrm{C}$, PSDTa $-440^{\circ} \mathrm{C}$, PSDTa $-480^{\circ} \mathrm{C}, \mathrm{PSDTa}-550^{\circ} \mathrm{C} \mathrm{e}$ PSDTa $-580^{\circ} \mathrm{C}$

\begin{tabular}{|c|c|c|c|}
\hline \multirow[t]{2}{*}{ AMOSTRAS } & \multicolumn{2}{|c|}{ Massa perdida (\%) } & \multirow{2}{*}{$\frac{\text { Resíduo (\%) }}{700}$} \\
\hline & $30-300$ & $350-550$ & \\
\hline Asfaltenos & 8 & 45 & 47 \\
\hline PSDTa-320 ${ }^{\circ} \mathrm{C}$ & No & 45 & 54 \\
\hline PSDTa- $380^{\circ} \mathrm{C}$ & No & 43 & 57 \\
\hline PSDTa $-400^{\circ} \mathrm{C}$ & No & 38 & 62 \\
\hline PSDTa- $440^{\circ} \mathrm{C}$ & No & 29 & 71 \\
\hline PSDTa $-480^{\circ} \mathrm{C}$ & No & 21 & 79 \\
\hline PSDTa- $550^{\circ} \mathrm{C}$ & No & 5 & 95 \\
\hline PSDTa- $580^{\circ} \mathrm{C}$ & 2 & 3 & 95 \\
\hline
\end{tabular}

No-não observado

Esses produtos, também, foram caracterizados da mesma forma que aqueles gerados no forno tubular (item 3.1.1) por: análise elementar, espectroscopia no IV, $\mathrm{RMN}^{13} \mathrm{C}$ e aplicação da reação RICO. 
Os espectros de absorção no IV estão ilustrados no Anexo 10. O produto obtido a $320^{\circ} \mathrm{C}$ apresentou espectro muito semelhante ao dos asfaltenos, porém com um aumento significativo na intensidade da absorção a $3443 \mathrm{~cm}^{-1}$, atribuída ao estiramento do $-\mathrm{OH}$. Para os espectros dos produtos obtidos nas outras temperaturas, observou-se, como esperado, a diminuição das absorções caracteristicas das ligações $\mathrm{CH}, \mathrm{CH}_{2}, \mathrm{CH}_{3}\left(3100,2900,1460\right.$ e $\left.1378 \mathrm{~cm}^{-1}\right)$ e um aumento daquelas características de grupamentos aromáticos $\left(1622 \mathrm{~cm}^{-1}\right)$. Verificou-se, também, um aumento na intensidade da banda de absorção dos grupamentos $-\mathrm{OH}\left(3440 \mathrm{~cm}^{-1}\right)$ e $\mathrm{C}-\mathrm{O}\left(1100 \mathrm{~cm}^{-1}\right)$. Ou seja, as mesmas observações encontradas nos estudos preliminares com os produtos de decomposição obtidos em forno tubular (item 4.3.2).

Os resultados da análise elementar de cada produto de decomposição térmica dos asfaltenos estão listados na Tabela 4.16. Foram verificadas as mesmas tendências apresentadas quando da avaliação dos produtos sólidos obtidos em forno tubular, ou seja, observou-se:

(a) de maneira geral, um aumento da relação molar $\mathrm{C} / \mathrm{H}$ com a elevação da temperatura de obtenção dos produtos, indicando que o rompimento das cadeias alifáticas ligadas ao núcleo poliaromático torna-se mais pronunciado com o aumento da temperatura;

(b) um aumento relativo do teor de nitrogênio com a elevação da temperatura de obtenção do produto, indicando que esse elemento não é eliminado com o aquecimento, fato já descrito por Speight e colaboradores (1987).

(c) que para o elemento oxigênio o percentual de massa variou entre 1,3 e $2,7 \%$ de forma irregular, porém na maioria dos produtos foi maior do que para os asfaltenos de partida. Essas flutuações nos valores podem estar relacionadas à facilidade de adsorção de $\mathrm{H}_{2} \mathrm{O}$ ou $\mathrm{CO}_{2}$ sobre a superfície dos produtos de decomposição após o resfriamento. Esta observação é coerente com os espectros de absorção no infravermelho, 
em que se verifica um aumento de intensidade nas absorções características dos grupos $-\mathrm{OH}$ e $-\mathrm{CO}$.

(d) que o teor de enxofre diminui com o aumento da temperatura de obtenção dos produtos. Isso indica que esse elemento é parcialmente liberado na forma de alguns compostos gerados durante o processo de aquecimento ou já existentes nos asfaltenos de partida.

Tabela 4. 16 - Análise elementar dos produtos PSDTa- $320^{\circ} \mathrm{C}, \mathrm{PSDTa}-380^{\circ} \mathrm{C}$, PSDTa $-400^{\circ} \mathrm{C}$, PSDTa $-440^{\circ} \mathrm{C}$, PSDTa $-480^{\circ} \mathrm{C}$, PSDTa- $550^{\circ} \mathrm{C}$ e PSDTa $-580^{\circ} \mathrm{C}$

\begin{tabular}{|c|c|c|c|c|c|c|c|c|c|}
\hline \multirow[b]{2}{*}{ AMOSTRA } & \multicolumn{5}{|c|}{$\%$} & \multirow[b]{2}{*}{$\mathrm{C} / \mathrm{H}$} & \multirow[b]{2}{*}{$\mathrm{C} / \mathrm{N}$} & \multirow[b]{2}{*}{$\mathrm{C} / \mathrm{O}$} & \multirow[b]{2}{*}{$\mathrm{C} / \mathrm{S}$} \\
\hline & C & $\bar{H}$ & $\mathbf{N}$ & 0 & $\mathrm{~s}$ & & & & \\
\hline ASFALTENOS & 85,8 & $\overline{8,4}$ & 1,8 & 1,3 & 2,6 & 0,9 & 55,6 & 88,0 & 88,0 \\
\hline PSDTa- $320^{\circ} \mathrm{C}$ & 85,9 & 7,8 & 2,3 & 1,3 & 1,8 & 0,9 & 43,6 & 88,1 & 127,3 \\
\hline PSDTa- $380^{\circ} \mathrm{C}$ & 86,2 & 7,6 & 2,5 & 0,9 & 1,9 & 0,9 & 40,2 & 127,7 & 121,0 \\
\hline PSDTa- $400^{\circ} \mathrm{C}$ & 86,3 & 7,2 & 2,5 & 1,2 & 1,8 & 1,0 & 40,3 & 95,9 & 127,9 \\
\hline PSDTa- $440^{\circ} \mathrm{C}$ & 85,7 & 6,2 & 2,7 & 1,5 & 1,7 & 1,2 & 37,0 & 76,2 & 134,4 \\
\hline PSDTa- $480^{\circ} \mathrm{C}$ & 88,7 & 4,1 & 2,8 & 1,9 & 1,8 & 1,8 & 37,0 & 62,2 & 131,4 \\
\hline PSDTa-550 $0^{\circ} \mathrm{C}$ & 87,0 & 3,3 & 2,9 & 2,7 & 1,4 & 2,2 & 35,0 & 43,0 & 165,7 \\
\hline PSDTa- $580^{\circ} \mathrm{C}$ & 86,4 & 2,7 & 3,3 & 1,9 & 1,0 & 2,7 & 30,5 & 60,6 & 230,4 \\
\hline
\end{tabular}

Em seguida os produtos foram analisados por $\mathrm{RMN}^{13} \mathrm{C}$ utilizando as técnicas para o estado sólido. Os espectros resultantes da aplicação da técnica CP/MAS com variação do tempo de contato estão apresentados no Anexo 11. A Tabela 4.17 resume os resultados encontrados. Algumas considerações foram feitas:

Tabela 4. 17 - Análise de RMN ${ }^{13} \mathrm{C}$ no estado sólido dos produtos PSDTa$320^{\circ} \mathrm{C}$, PSDTa- $380^{\circ} \mathrm{C}$, PSDTa $-400^{\circ} \mathrm{C}$, PSDTa $-440^{\circ} \mathrm{C}$, PSDTa $-480^{\circ} \mathrm{C}$, PSDTa$550^{\circ} \mathrm{C}$ e PSDTa- $580^{\circ} \mathrm{C}$

\begin{tabular}{c|c|c|c|c}
\hline AMOSTRAS & $\begin{array}{c}\mathrm{C}_{\text {arom. total }} \\
(\%)\end{array}$ & $\begin{array}{c}\mathrm{C}_{\text {alifatico }} \\
(\%)\end{array}$ & $\begin{array}{c}\mathrm{C}_{\text {arom. tri-substitudo }} \\
(\%)\end{array}$ & $\begin{array}{c}\mathrm{C}_{\text {arom. subst. por } \mathrm{H}} \\
(\%)\end{array}$ \\
\hline ASFALTENOS & 55,5 & 44,5 & 27,7 & 27,8 \\
\hline PSDTa-320 0 & 60,9 & 39,1 & 36,4 & 24,5 \\
\hline PSDTa-380 $\mathrm{C}$ & 66,8 & 33,2 & 31,6 & 35,2 \\
\hline PSDTa-400 $\mathrm{C}$ & 67,8 & 32,2 & 40,6 & 27,2 \\
\hline PSDTa-440 $\mathrm{C}$ & 75,5 & 24,5 & 42,1 & 33,4 \\
\hline PSDTa-480 $40^{\circ} \mathrm{C}$ & 82,3 & 17,7 & 44,1 & 38,2 \\
\hline PSDTa-550 $\mathrm{C}$ & 97,8 & 2,2 & 33,1 & 64,7 \\
\hline PSDTa-580 5 & 99,0 & 1,0 & 31,3 & 67,7 \\
\hline
\end{tabular}


(a) Para os produtos isolados entre 320 e $480^{\circ} \mathrm{C}$ os máximos de transferência de polarização ocorreram a tempos de contato cada vez mais curtos à medida em que a temperatura de obtenção aumentou. Assim, este máximo ocorreu entre $100 \mu$ s para o PSDTa- $320^{\circ} \mathrm{C}$ e foi deslocando-se para $50 \mu \mathrm{s}$ até o PSDTa- $480^{\circ} \mathrm{C}$. Este fato indica, como já mencionado, que as estruturas médias destes produtos foram se tornando mais rígidas com o aumento da temperatura.

(b) Para os produtos isolados a 550 e $580^{\circ} \mathrm{C}$, apesar do teor de carbono aromático aumentar muito, o máximo de transferência de polarização volta a ser $100 \mu \mathrm{s}$, indicando uma espécie mais flexivel.

Essa última observação também pode ser explicada pela diminuição do teor de carbonos aromáticos tri-substituídos (Figura 4.9) verificado nas amostras de PSDTa-550 e PSDTa- $580^{\circ} \mathrm{C}$. Como o tempo de contato depende da distância entre os hidrogênios e os carbonos e como nessas amostras os carbonos totalmente substituídos devem estar, em sua maioria, em junção de anel, a distância entre esses núcleos de hidrogênio e carbono deve aumentar e, portanto, o tempo de contato para que a polarização ocorra, também aumentaria. Os dois fenômenos rigidez da estrutura e distância entre carbonos e prótons estão presentes simultaneamente e, em cada caso, dependerá de qual fenômeno está interferindo mais ou menos para cada amostra.

Os espectros de $\mathrm{RMN}^{13} \mathrm{C}$ quantitativos estão apresentados no Anexo 11. Usando a técnica de MAS e NQS foi possível obter os percentuais de carbonos alifáticos, carbonos aromáticos totais, e ainda dividir os carbonos aromáticos totais em tri-substituídos e substituídos apenas por hidrogênio (Figura 4.9).

A partir dos parâmetros obtidos, verificou-se: a) um aumento no teor de carbono aromático e diminuição de carbonos alifáticos com o aumento de temperatura de obtenção dos produtos sólidos e b) um aumento drástico dos carbonos aromáticos substituídos por hidrogênio com o aumento da temperatura. 
As duas observações confirmam que a eliminação dos grupamentos alquila ligados ao núcleo aromático dos asfaltenos aumenta com o aumento da temperatura a que estão sendo submetidos e que, a partir de $550^{\circ} \mathrm{C}$, essas cadeias alquílicas estão presentes em pequenas quantidade.

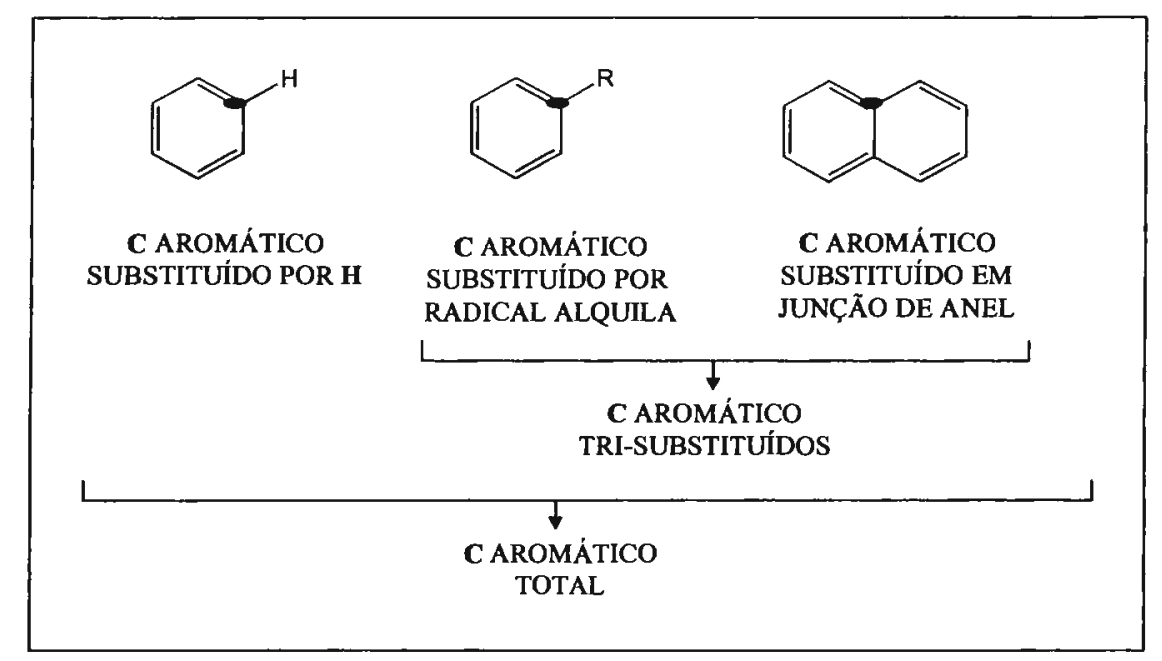

Figura 4. 9 - Tipos de carbonos quantificados por $R M N^{13} \mathrm{C}$.

A seguir, para identificar os tipos de grupamentos alquila ligados ao núcleo poliaromático dos asfaltenos, foi realizada a reação RICO com cada um dos produtos sólidos obtidos (item 3.5.4).

Nos primeiros testes desta reação (item 4.4.1.1), foi verificada a presença de ftalato de dioctila, contaminante proveniente dos solventes utilizados. Então, realizou-se uma reação em branco para conhecer sua interferência nas soluções a serem analisadas.

Os volumes das fases orgânicas, contendo os ácidos gerados nas reações RICO de cada produto foram ajustados em $2 \mathrm{~mL}$ com $\mathrm{CH}_{2} \mathrm{Cl}_{2}$ e analisados por espectroscopia de absorção no IV em células de $1,0 \mathrm{~mm}$ de espessura. Foi medida a intensidade da banda de absorção a $1710 \mathrm{~cm}^{-1}$ relativa ao grupamento $\mathrm{C}=\mathrm{O}$ de ácido (Figura 4.10).

Observou-se uma semelhança nas intensidades de absorção dos ácidos gerados na reação RICO das amostras de asfaltenos e PSDTa- $320^{\circ} \mathrm{C}$, confirmando, que nesta temperatura, ocorreu a perda de poucas cadeias laterais 
por quebra térmica. As intensidades da absorção dos ácidos gerados a partir da reação do $\mathrm{PSDTa}-380^{\circ} \mathrm{C}$ e $\mathrm{PSDTa}-400^{\circ} \mathrm{C}$ são semelhantes entre si, entretanto cerca de $40 \%$ menores em relação aquelas observadas nos dois primeiros casos. Já as intensidades de absorção dos ácidos gerados na reação do $\mathrm{PSDTa}-440^{\circ} \mathrm{C}$, $\mathrm{PSDTa}-480^{\circ} \mathrm{C}, \mathrm{PSDTa}-550^{\circ} \mathrm{C}$ e $\mathrm{PSDTa}-580^{\circ} \mathrm{C}$, são muito menores do que as encontradas para os asfaltenos (98\%). Essa observação indica que nestas temperaturas, a quebra das cadeias laterais ocorreu de forma pronunciada.

Para identificação de cada ácido gerado na reação RICO, as soluções, incluindo aquela do ensaio em branco, foram metiladas com diazometano (item 3.5.5). As soluções dos ésteres metílicos formados tiveram seus volumes ajustados a $2 \mathrm{~mL}$ com $\mathrm{CH}_{2} \mathrm{Cl}_{2}$ e a cada uma delas foram adicionados $5 \mu \mathrm{L}$ de uma solução contendo concentração conhecida do padrão de fenantreno deuterado para que fosse possível uma quantificação relativa desses ésteres. Em seguida, foram analisados por CG-EM, conforme descrito no item 4.4.1.1.

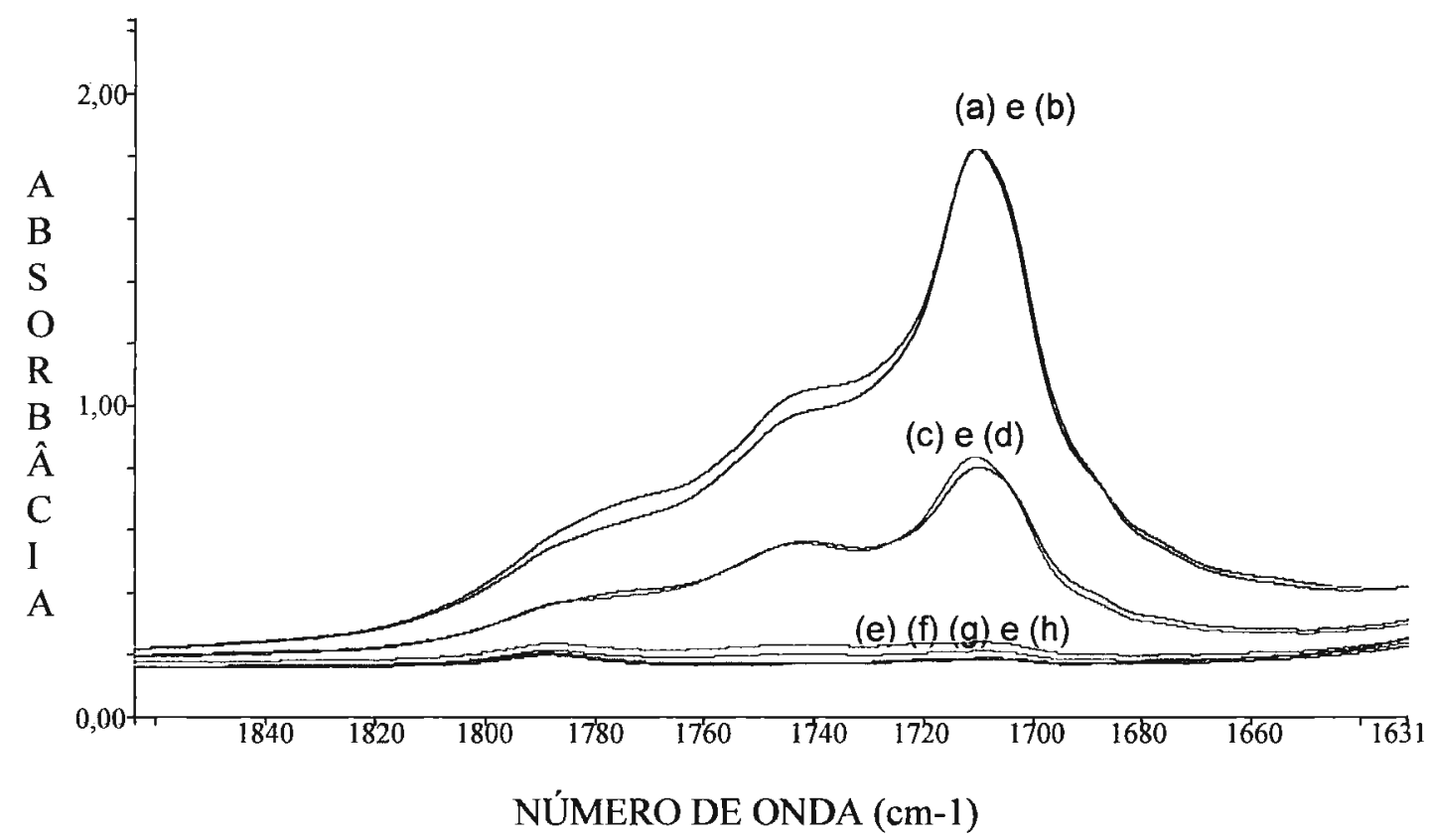

Figura 4. 10 - Intensidade da absorção a $1710 \mathrm{~cm}^{-1}$ dos ácidos obtidos nos produtos da reação RICO com os (a) asfaltenos, (b) PSDTa-320 ${ }^{\circ} \mathrm{C}$,

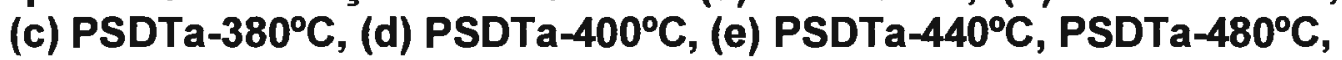
(g) PSDTa-550 $\mathrm{C}$ e (h) PSDTa-580 $\mathrm{C}$.

O cromatograma de íons relativos aos ésteres metílicos lineares gerados a partir da reação em branco foi comparado com o obtido da reação dos asfaltenos 
(Figura 4.11). No ensaio em branco foram detectados, em concentração muito pequena, ésteres metílicos contendo 16 e 18 átomos de carbono.
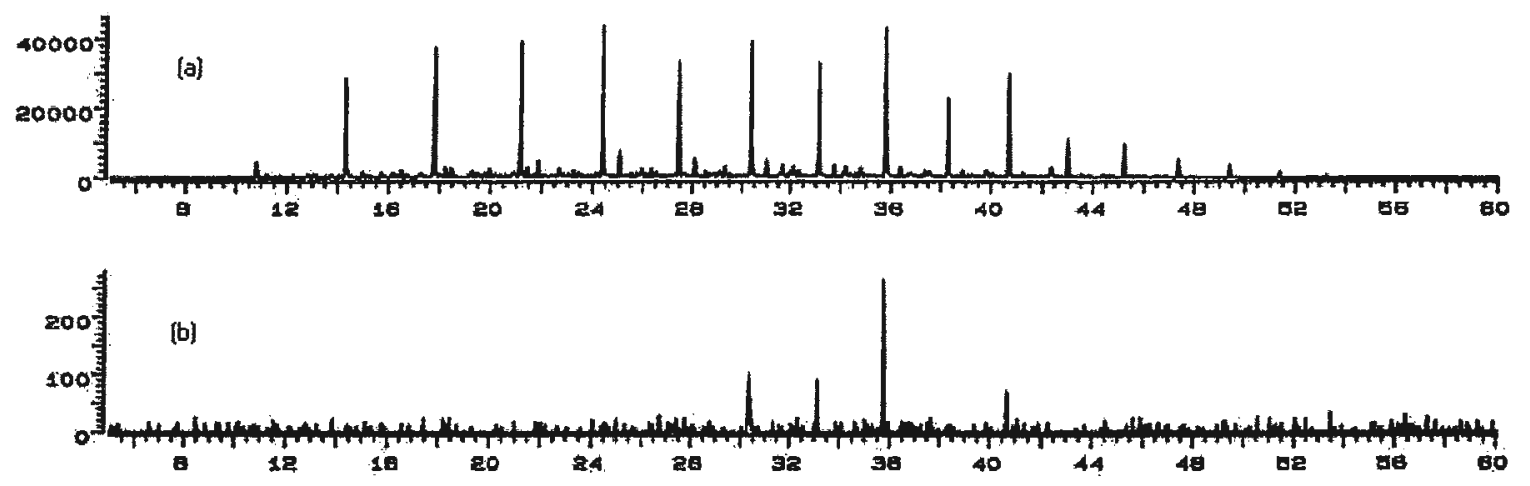

Figura 4. 11 - Cromatograma de íons: (a) ésteres metílicos isolados na reação RICO dos asfaltenos (b) ésteres metílicos isolados no ensaio em branco da reação RICO.

No Anexo 12 estão apresentados os cromatogramas ions dos ésteres encontrados em cada solução. A avaliação dos espectros de massa indicou, em todos elas, a presença das mesmas séries homólogas de ésteres metílicos: ésteres metilicos de ácidos monocarboxílicos, ésteres dimetílicos de ácidos dicarboxílicos e ésteres dimetílicos de ácidos benzeno dicarboxílicos (Figura 4.12).

$\mathrm{R}-\mathrm{COOMe}$

(a)
MeOOC- $\mathrm{R}-$ COOMe

(b)<smiles>CC(=O)c1ccccc1C(C)=O</smiles>

(c)

Figura 4. 12- (a)éster metílico de ácidos monocarboxílicos, (b) éster dimetílico de ácidos dicarboxílicos, (c)éster dimetílico de ácidos benzeno dicarboxílicos.

A Tabela 4.18 resume, de forma qualitativa, os resultados encontrados. Observou-se que a série de ésteres metílicos de ácido monocarboxílico é aquela de cadeia carbônica contendo de 7 a 24 átomos de carbono. Nos ésteres gerados a partir dos produtos isolados entre 400 e $580^{\circ} \mathrm{C}$ não foram encontrados ésteres metílicos de cadeias carbônicas com mais do que 20 átomos de carbono. Os 
ésteres dimetílicos de ácidos dicarboxilicos foram encontrados em todas as amostras e apresentam cadeia alifática contendo de 5 a 17 átomos de carbono em todas elas. Os ésteres dimetílicos de ácidos benzeno dicarboxílicos identificados apresentam de 8 até 10 átomos de carbono.

Tabela 4. 18 - Séries de ésteres metílicos dos ácidos gerados na reação RICO com os asfaltenos e PSDTa- $320^{\circ} \mathrm{C}$, PSDTa- $380^{\circ} \mathrm{C}$, PSDTa $-400^{\circ} \mathrm{C}$, PSDTa $-440^{\circ} \mathrm{C}, \mathrm{PSDTa}-480^{\circ} \mathrm{C}$, PSDTa $-550^{\circ} \mathrm{C}$ e PSDTa $-580^{\circ} \mathrm{C}$

\begin{tabular}{|c|c|c|c|c|c|c|c|c|}
\hline \multirow[b]{2}{*}{ ÉSTERES } & \multicolumn{8}{|c|}{ PSDTa } \\
\hline & asfaltenos & 320 & 380 & 400 & 440 & 480 & 550 & 580 \\
\hline $\begin{array}{l}\text { metílicos de ácidos } \\
\text { monocarboxílicos }\end{array}$ & $\begin{array}{c}\mathrm{Me} \\
\left(\mathrm{C}_{7}-\mathrm{C}_{24}\right)\end{array}$ & $\begin{array}{c}\mathrm{Me} \\
\left(\mathrm{C}_{7}-\mathrm{C}_{24}\right)\end{array}$ & $\begin{array}{c}\mathrm{Me} \\
\left(\mathrm{C}_{7}-\mathrm{C}_{24}\right)\end{array}$ & $\begin{array}{c}\mathrm{Me} \\
\left(\mathrm{C}_{7}-\mathrm{C}_{24}\right)\end{array}$ & $\begin{array}{c}\mathrm{Me} \\
\left(\mathrm{C}_{T}-\mathrm{C}_{20}\right)\end{array}$ & $\begin{array}{c}\mathrm{Me} \\
\left(\mathrm{C}_{7}-\mathrm{C}_{20}\right)\end{array}$ & $\begin{array}{c}\mathrm{Me} \\
\left(\mathrm{C}_{7}-\mathrm{C}_{20}\right)\end{array}$ & $\begin{array}{c}\mathrm{Me} \\
\left(\mathrm{C}_{7}-\mathrm{C}_{18}\right)\end{array}$ \\
\hline $\begin{array}{l}\text { dimetilicos de ácidos } \\
\text { dicarboxílicos }\end{array}$ & $\begin{array}{c}\mathrm{Me}_{2} \\
\left(\mathrm{C}_{5}-\mathrm{C}_{17}\right)\end{array}$ & $\begin{array}{c}\mathrm{Me}_{2} \\
\left(\mathrm{C}_{5}-\mathrm{C}_{17}\right)\end{array}$ & $\begin{array}{c}\mathrm{Me}_{2} \\
\left(\mathrm{C}_{5}-\mathrm{C}_{17}\right)\end{array}$ & $\begin{array}{c}\mathrm{Me}_{2} \\
\left(\mathrm{C}_{5}-\mathrm{C}_{17}\right)\end{array}$ & $\begin{array}{c}\mathrm{Me}_{2} \\
\left(\mathrm{C}_{5}-\mathrm{C}_{17}\right)\end{array}$ & $\begin{array}{c}\mathrm{Me}_{2} \\
\left(\mathrm{C}_{5}-\mathrm{C}_{17}\right)\end{array}$ & $\begin{array}{c}\mathrm{Me}_{2} \\
\left(\mathrm{C}_{5}-\mathrm{C}_{17}\right)\end{array}$ & $\begin{array}{c}\mathrm{Me}_{2} \\
\left(\mathrm{C}_{5}-\mathrm{C}_{17}\right)\end{array}$ \\
\hline $\begin{array}{c}\text { metílicos de ácidos } \\
\text { benzeno } \\
\text { dicarboxílicos }\end{array}$ & $\begin{array}{c}\mathrm{Me}_{2} \\
\mathrm{C}_{8}-\mathrm{C}_{10}\end{array}$ & $\begin{array}{c}\mathrm{Me}_{2} \\
\mathrm{C}_{8}-\mathrm{C}_{10}\end{array}$ & $\begin{array}{c}\mathrm{Me}_{2} \\
\mathrm{C}_{8}-\mathrm{C}_{10}\end{array}$ & $\begin{array}{c}\mathrm{Me}_{2} \\
\mathrm{C}_{\theta}-\mathrm{C}_{10}\end{array}$ & $\begin{array}{c}\mathrm{Me}_{2} \\
\mathrm{C}_{8}-\mathrm{C}_{10}\end{array}$ & $\begin{array}{c}\mathrm{Me}_{2} \\
\mathrm{C}_{\theta}-\mathrm{C}_{10}\end{array}$ & $\begin{array}{c}\mathrm{Me}_{2} \\
\mathrm{C}_{8}-\mathrm{C}_{10}\end{array}$ & $\begin{array}{c}\mathrm{Me}_{2} \\
\mathrm{C}_{8}-\mathrm{C}_{10}\end{array}$ \\
\hline
\end{tabular}

Como todas as soluções apresentaram os mesmos ésteres, se tornou necessário quantificá-los para que se pudesse fazer uma diferenciação entre as amostras estudadas. A introdução de um volume conhecido do padrão de fenantreno deuterado em cada uma das soluções dos ésteres permitiu medir a relação de áreas entre cada um dos componentes identificados e este padrão.

A figura 4.13 compara a concentração total de cada série homóloga de ésteres nas soluções geradas. Verificou-se que os ésteres metílicos de ácidos monocarboxílicos foram predominantes. E ainda que a concentração dos ésteres metílicos lineares diminui lentamente com o aumento da temperatura de obtenção dos produtos de decomposição térmica até $400^{\circ} \mathrm{C}$ e drasticamente a partir dessa temperatura. O mesmo ocorre com os ésteres dimetílicos de ácidos dicarboxílicos e benzeno dicarboxílicos. 


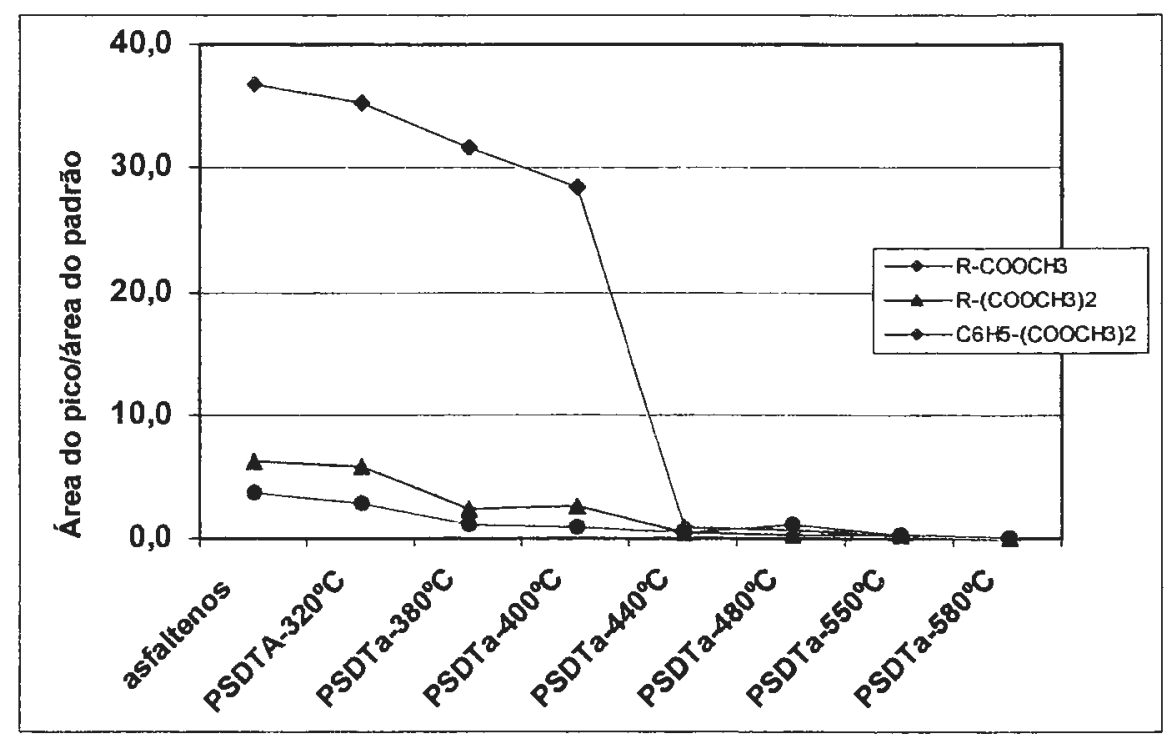

Figura 4. 13- Ésteres metílicos totais dos ácidos gerados na reação RICO com os asfaltenos e seus produtos de decomposição térmica.

A seguir serão apresentados e discutidos os resultados da quantificação relativa dos ésteres metilicos de cada uma das séries homólogas identificadas para cada amostra submetida à reação RICO.

\section{(i) ésteres metílicos dos ácidos monocarboxílicos}

As Figuras 4.14, 4.15 e 4.16 comparam, de forma relativa, a concentração dos diferentes ésteres metílicos de ácidos monocarboxílicos. Nestes gráficos pode-se observar que:

(a) A concentração de todos os ésteres metílicos diminui com o aumento da temperatura de obtenção do produto de decomposição térmica.

(b) Os ésteres metílicos de menor número de carbono estão em maior concentração em todos os produtos analisados.

(c) Os ésteres com cadeias $>C_{20}$ estão em menor quantidade mesmo nos asfaltenos que deram origem aos produtos.

(d) Os ésteres em $\mathrm{C}_{7}, \mathrm{C}_{8}, \mathrm{C}_{9}$ estão em concentrações maiores nas amostras do PSDTa-380 e PSDTa- $400^{\circ} \mathrm{C}$ do que nos asfaltenos. 
Strausz (1999) cita a facilidade de perda destes ácidos pequenos durante o procedimento de evaporação do solvente, além da parcial solubilidade na fase aquosa durante a reação RICO. Acredita-se que isso tenha contribuído para o ocorrido.

(e) Os ésteres metilicos de ácidos monocarboxilicos isolados dos asfaltenos e do PSDTa- $320^{\circ} \mathrm{C}$ apresentam série homóloga com máximo em $\mathrm{C}_{12}$ enquanto que o PSDTa- 380 e PSDTa- $400^{\circ} \mathrm{C}$ geraram série homóloga com máximo entre $\mathrm{C}_{8}$ e $\mathrm{C}_{10}$. Esse fato pode ser um indício de que grupamentos maiores sejam mais facilmente clivados durante a decomposição térmica.

(f) Os ésteres metílicos em $\mathrm{C}_{16}$ e $\mathrm{C}_{18}$ estão em concentrações maiores que fogem da tendência de diminuição. Strausz e colaboradores (1999) que usaram a reação RICO para caracterização de asfaltenos, sugerem como explicação que esses ácidos correspondentes estejam presentes nos asfaltenos de forma livre. Entretanto, é sabido que os ácidos palmítico $\left(C_{16}\right)$ e esteárico $\left(C_{18}\right)$ entram em ebulição a 256 e $287^{\circ} \mathrm{C}$, respectivamente. Se estivessem presentes de forma livre nos asfaltenos, tenderiam a desaparecer rapidamente durante a obtenção do PSDTa- $320^{\circ} \mathrm{C}$ e PSDTa- $380^{\circ} \mathrm{C}$ e não seriam observados, como estão sendo, nos produtos da reação RICO dos produtos acima de $320^{\circ} \mathrm{C}$. A explicação, mais plausível, seria a contaminação pelos solventes de extração, pois estes ésteres foram encontrados nos produtos da reação em branco, em pequena quantidade, mas 0 suficiente para acarretar o aumento observado. 


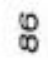

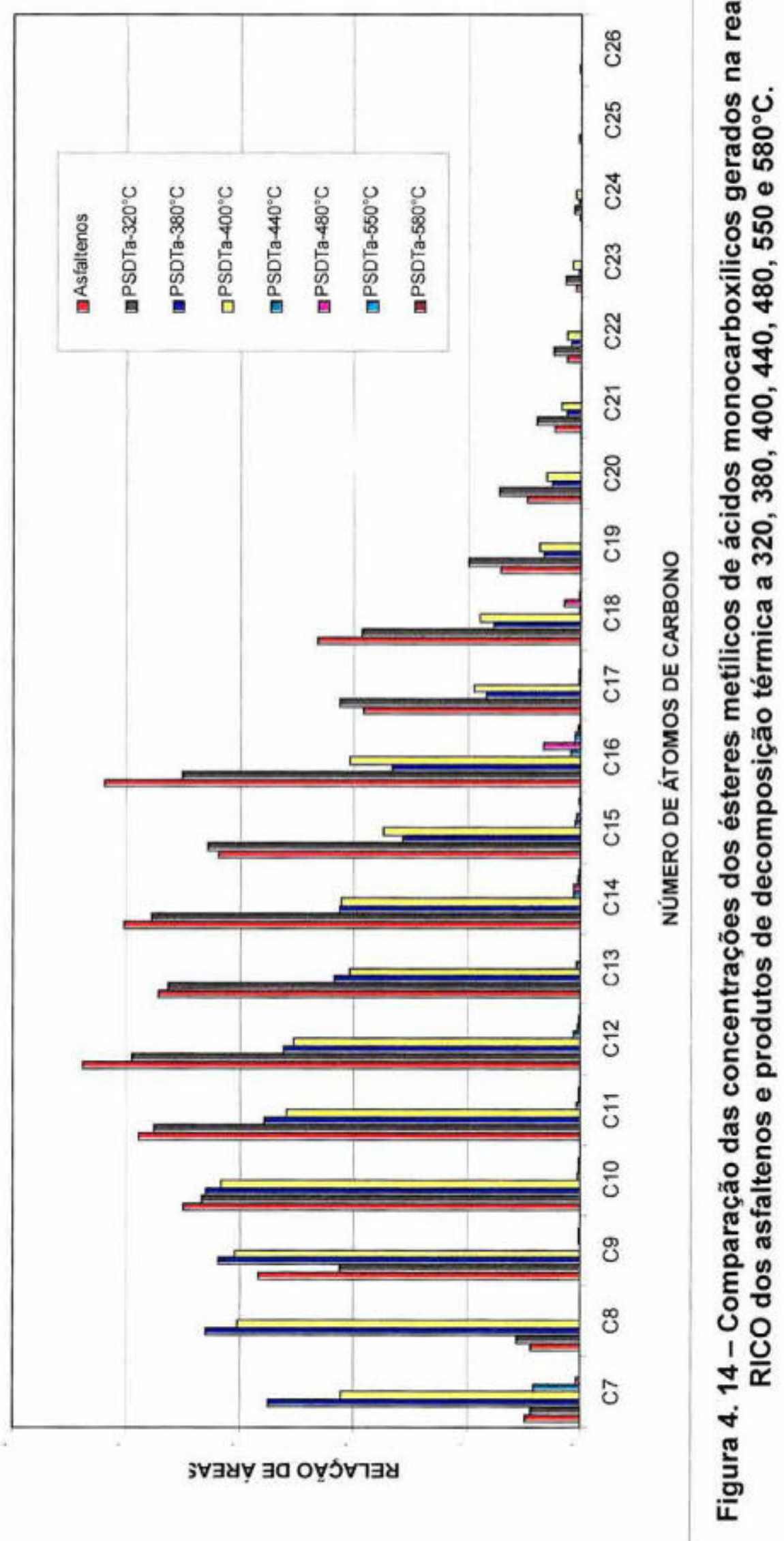


ญ్

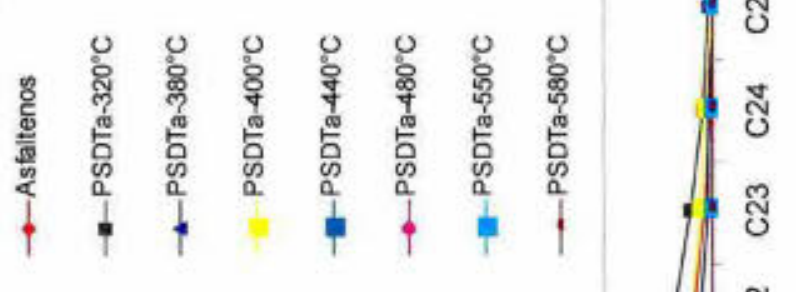

음

꾼

ㅎํㅇ

응 융

을

ํำ

는 웡

응 웅

๑

을

음

\%

ำ

옹ำ

을 흥

E

"․․․

\$

s

o

등

os

웜

한

동 홍

등

용

종

원

एक⿻

을 웅

ن

เ่

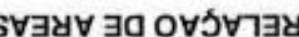


A partir de $440^{\circ} \mathrm{C}$ os ésteres metílicos gerados são quase que imperceptíveis, apresentando um máximo em $\mathrm{C}_{16}$ e $\mathrm{C}_{18}$, mas no mesmo nível encontrado no ensaio em branco.

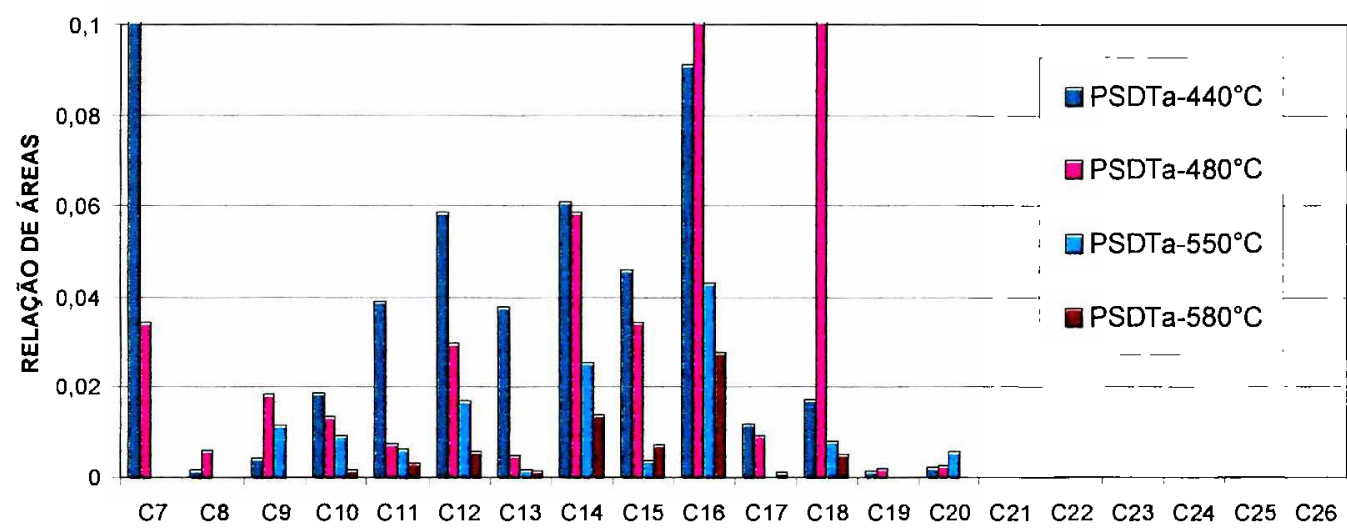

NÚMERO DE ÁTOMOS DE CARBONO

Figura 4. 16 - Comparação das concentrações dos ésteres metílicos de ácidos monocarboxílicos gerados na reação RICO dos asfaltenos e produtos de decomposição térmica a $440,480,550$ e $580^{\circ} \mathrm{C}$.

Savage e colaboradores (1988), em estudos sobre avaliação dos produtos de decomposição do n-pentadecilbenzeno, concluíram que o mecanismo de decomposição térmica de um alquil aromático é via radical livre ocorrendo a quebra do grupamento alquila no carbono beta ao anel aromático (Figura 4.17). Mais recentemente, Smith e Savage (1991) avaliaram a decomposição térmica, entre 350 e $425^{\circ} \mathrm{C}$, de uma família de alquil aromáticos verificando a possibilidade de ocorrência de três possiveis caminhos: o primeiro deles, e majoritário, resultava em produtos procedentes da quebra da ligação entre os carbonos $\alpha$ e $\beta$ ao anel aromático, via radical livre; o segundo, em menor escala, conduzia a produtos da quebra da ligação C-C alquil-aril; e um terceiro, que apresentava pequenas quantidades de produtos de degradação térmica, fazia supor reações de ciclização e condensação. 


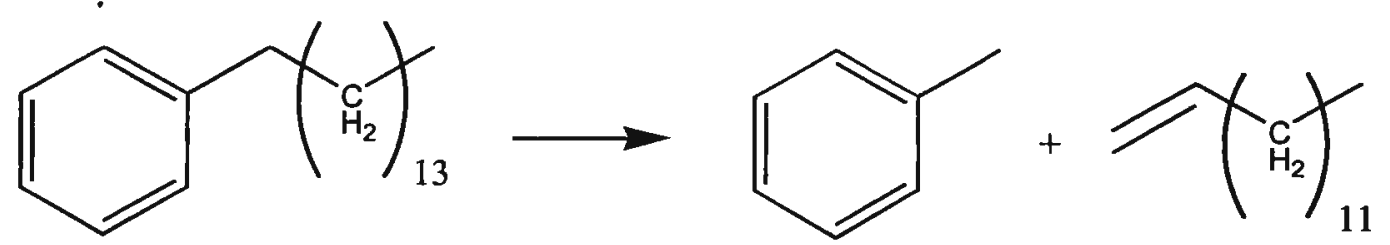

Figura 4. 17 - Quebra do grupamento alquila ligado ao anel aromático (n-pentadecilbenzeno ) proposto por Savage (1991).

O mecanismo via radical livre leva à formação de anéis aromáticos contendo pelo menos grupamentos metila. Com bases nessas observações, era esperado, nesse trabalho, que na reação RICO dos PSDT isolados à temperaturas acima de $440^{\circ} \mathrm{C}$, ocorresse a formação de ésteres metílicos contendo dois átomos de carbono. Entretanto, não foi observada a presença de acetato de metila em nenhum dos produtos após serem submetidos à reação RICO.

Uma explicação para esse fato pode ser a baixa temperatura de ebulição de ácidos e ésteres contendo pequenos números de carbono (Tabela 4.19). 0 acetato de metila que tem ponto de ebulição relativamente baixo pode ter sido arrastado durante a evaporação dos solventes utilizados para a recuperação dos mesmos do meio reacional. Um outro fato, citado por Strausz (1999), é que os ácidos contendo um número menor do que 14 átomos de carbono $\left(C_{14}\right)$ tenderiam a ficar na fase aquosa do meio reacional.

Tabela 4. 19 - Temperatura de ebulição de ácidos e ésteres contendo de 2 a 7 átomos de carbono

\begin{tabular}{c|c|c|c|c}
\hline $\begin{array}{c}N^{\circ} \\
\text { CARBONO }\end{array}$ & ÁCIDOS & $\begin{array}{c}\text { PONTO DE } \\
\text { EBULIÇÃO } \\
\left({ }^{\circ} \mathrm{C}\right)\end{array}$ & $\begin{array}{c}\text { ÉSTERES } \\
\text { METÍLICOS }\end{array}$ & $\begin{array}{c}\text { PONTO DE } \\
\text { EBULIÇÃO } \\
\left({ }^{\circ} \mathrm{C}\right)\end{array}$ \\
\hline $\mathrm{C} 2$ & acético & 118 & acetato & 57 \\
\hline $\mathrm{C} 3$ & propiônico & 141 & Propionato & 79 \\
\hline $\mathrm{C} 4$ & butírico & 162 & Butirato & 102 \\
\hline $\mathrm{C} 5$ & $\begin{array}{c}\text { Pentanóico } \\
\text { (valérico) }\end{array}$ & 185 & $\begin{array}{c}\text { Pentanoato } \\
\text { (valerato) }\end{array}$ & 128 \\
\hline $\mathrm{C} 6$ & hexanóico & 202 & $\begin{array}{c}\text { Hexanoato } \\
\text { (caproato) }\end{array}$ & 151 \\
\hline $\mathrm{C} 7$ & heptanóico & 223 & $\begin{array}{c}\text { Heptanoato } \\
\text { (enantato) }\end{array}$ & 172 \\
\hline
\end{tabular}


Sabendo-se que os ésteres metílicos de ácidos carboxílicos gerados na reação RICO dos asfaltenos e seus produtos de decomposição térmica em diferentes temperaturas caracterizam as cadeias laterais ligadas ao núcleo aromático (Figura 2.9) já se pode concluir que:

(a) Os asfaltenos isolados do óleo da Bacia de Campos apresentam em sua estrutura cadeias laterais alquílicas ligadas ao núcleo aromático contendo de 6 a pelo menos 23 átomos de carbono. Grupamentos alquila contendo mais de 20 átomos de carbono estão presentes em menor quantidade.

(b) Os grupamentos alquila ligados ao núcleo aromático dos asfaltenos são clivados quando os asfaltenos são submetidos ao aquecimento a partir de $320^{\circ} \mathrm{C}$, o que ocorre em maior escala a partir de $380^{\circ} \mathrm{C}$.

(c) A partir de $400^{\circ} \mathrm{C}$ os grupamentos alquila diminuem desaparecendo quase que totalmente nos produtos gerados a $580^{\circ} \mathrm{C}$.

(ii) ésteres dimetílicos dos ácidos dicarboxílicos.

A Figura 4.18 compara de forma relativa a concentração dos diferentes ésteres metílicos de ácido dicarboxílicos identificados. Nestes gráficos pode-se observar que:

(a) A concentração de todos os ésteres dimetílicos diminui com o aumento da temperatura de obtenção do produto de decomposição térmica.

(b) Os ésteres dimetílicos de ácidos dicarboxílicos isolados dos asfaltenos e produtos isolados nas temperaturas em estudo, apresentam série homóloga com máximo entre $C_{9}$ e $C_{10}$.

(c) Ocorre um decréscimo de toda a série de ésteres dimetílicos com o aumento da temperatura de obtenção dos produtos sólidos. 
ธ

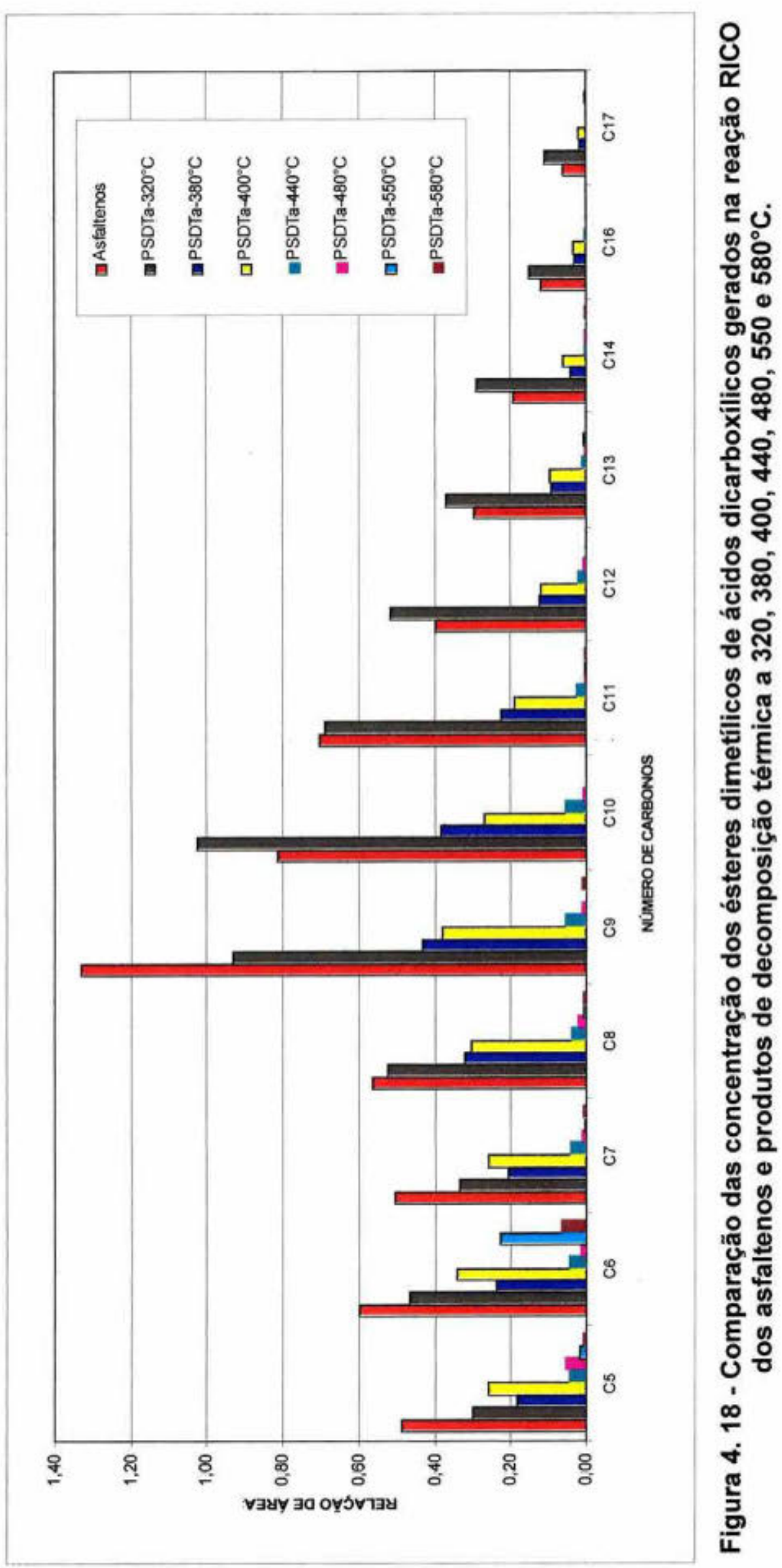


(c) Na reação RICO com o PSDTa- $320^{\circ} \mathrm{C}$, ocorre um decréscimo de cerca de $35 \%$ da concentração da série de ésteres dimetílicos.

(d) Na reação RICO com o PSDTa- $380^{\circ} \mathrm{C}$, ocorre um decréscimo de cerca de $70 \%$ da concentração da série de ésteres dimetílicos.

Sabendo-se que os ésteres dimetílicos de ácidos dicarboxilicos gerados na reação RICO dos asfaltenos e seus produtos de decomposição térmica em diferentes temperaturas caracterizam as pontes que ligam os núcleos aromáticos na estrutura dos asfaltenos (Fig.2.9) pode-se concluir que:

(a) Na estrutura dos asfaltenos isolados do óleo da Bacia de Campos foram identificadas pontes alquílicas entre os núcleos aromáticos contendo de 3 a 15.

(b) As pontes alquilicas são facilmente clivadas com a temperatura, pois a PSDTa- $320^{\circ} \mathrm{C}$ estes grupamentos apresentam um decréscimo de cerca de $35 \%$ e no PSDTa- $380^{\circ} \mathrm{C}$ um decréscimo de cerca de $70 \%$ quando comparados com os asfaltenos de origem.

(d) A partir de $400^{\circ} \mathrm{C}$ as pontes alquílicas desaparecem quase que totalmente nos produtos gerados à $580^{\circ} \mathrm{C}$.

(iii) ésteres dimetílicos de ácidos benzeno dicarboxílicos

A outra série de ésteres encontrados foi a dos dimetílicos de ácidos benzeno dicarboxílicos.

A Figura 4.19 apresenta a distribuição destes ésteres encontrados nos asfaltenos e seus produtos de degradação térmica. Como dito anteriormente, esses ésteres estão relacionados com a oxidação direta do núcleo aromático policondensado presente na estrutura avaliada pela reação RICO.

Foram encontrados dois isômeros do éster contendo 8 átomos de carbono que poderiam ser representados pelas fórmulas descritas na Figura 4.20. Entretanto não foi possivel, definir quais eram eles. 


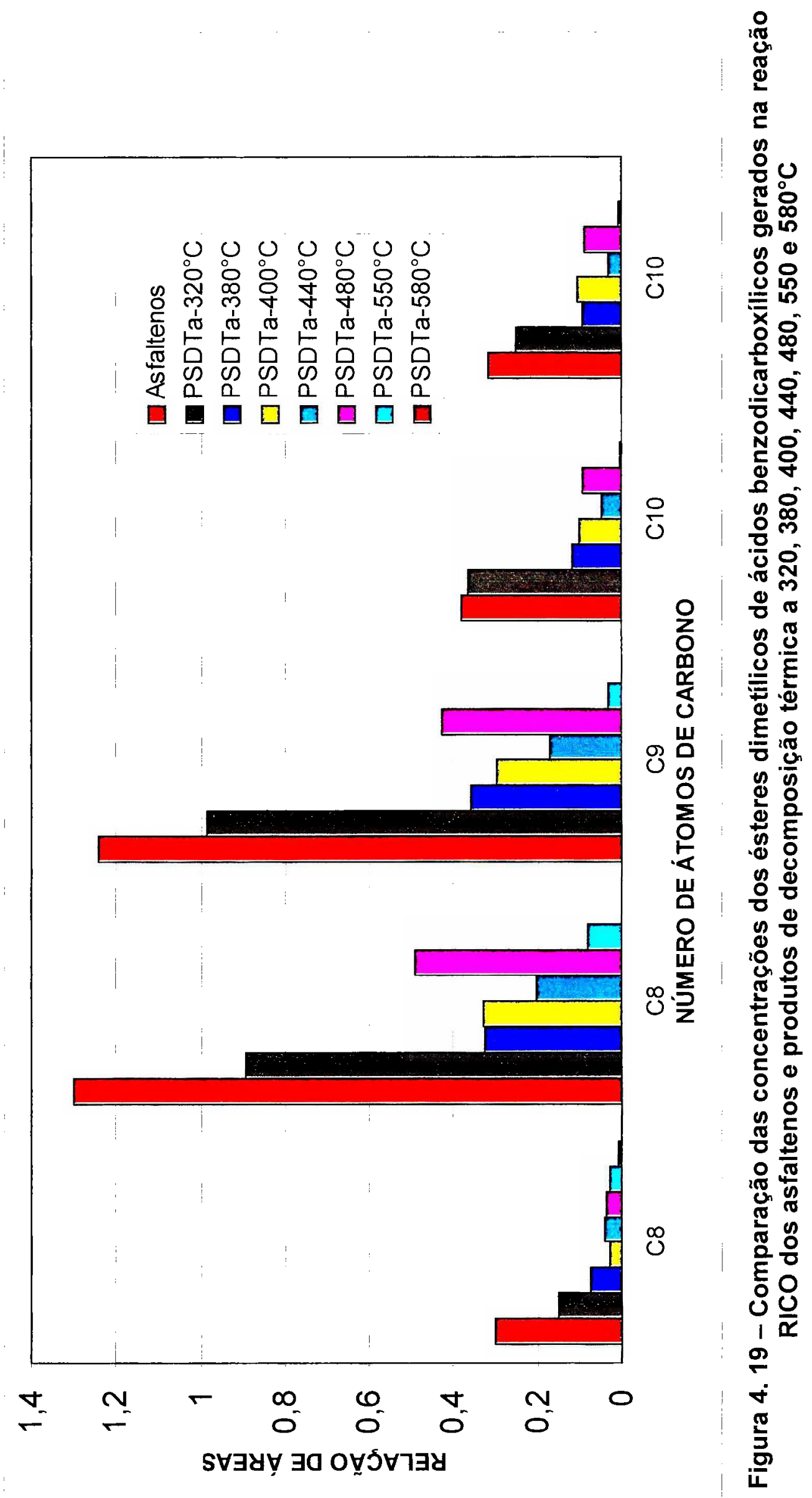


<smiles>CC(=O)c1ccccc1C(C)=O</smiles><smiles>CC(=O)c1cccc(C(C)=O)c1</smiles><smiles>CC(=O)c1ccc(C(C)=O)cc1</smiles>

Figura 4. 20 - Possíveis isômeros dos ésteres dimetílicos dos ácidos benzeno dicarboxílicos $\left(C_{8}\right)$ encontrado nos produtos da reação $R I C O$ dos asfaltenos e seus produtos de decomposição térmica.

O éster dimetílico do ácido benzeno dicarboxílico contendo nove átomos de carbono foi identificado como sendo o ftalato de metilia, contendo um substituinte metila no anel aromático. A sua posição no anel não pode ser determinada, o mesmo ocorrendo para os ésteres em $C_{10}$, neste caso apresentando dois grupamentos metilas ligados ao anel aromático (Figura 4.21).<smiles>CC(=O)c1ccccc1C(C)=O</smiles><smiles>CC(=O)c1cccc(C(C)=O)c1C(C)=O</smiles>

Figura 4. 21 - Ésteres dimetílicos dos ácidos dimetil benzeno dicarboxílicos $\left(C_{9}\right.$ e $\left.C_{10}\right)$ encontrados nos produtos da reação RICO dos asfaltenos e seus produtos de decomposição térmica.

Como já mencionado anteriormente, os ésteres dimetílicos procedentes de ácidos benzeno dicarboxílicos são produtos da oxidação do núcleo poliaromático presente na estrutura que está sendo avaliada pela reação RICO. As moléculas de poliaromáticos do tipo apresentados na Figura 4.22 geram esses tipos de ácidos benzeno dicarboxílicos. 
<smiles>O=C(O)c1ccc([IH]c2ccc3ccccc3c2)cc1C(=O)O</smiles><smiles>CC(C)CCCCCCCCC(=O)c1ccc(C(=O)O)cc1</smiles>

Figura 4. 22 - Compostos poliaromáticos que liberariam diácidos na reação RICO com 8 átomos de carbono.

Com essa observação é possivel inferir que os produtos sólidos obtidos da decomposição térmica dos asfaltenos isolados do óleo da Bacia de Campos apresentam estruturas do tipo sugeridos na Figura 4.22.

$\mathrm{Na}$ análise de $\mathrm{RMN}^{13} \mathrm{C}$ dos produtos obtidos a temperaturas acima de $400^{\circ} \mathrm{C}$ foi verificado um elevado percentual de carbono aromático. Nas amostras de PSDTa-550 e PSDTa-580 $\mathrm{C}$, havia a sugestão de que o núcleo aromático fosse bastante condensado. Com isso, era esperada, nos produtos da reação RICO destes sólidos, a presença de ésteres metílicos provenientes de poliácidos aromáticos (Figura 4.23), entretanto esses compostos não foram identificados.

É sabido que poliácidos aromáticos apresentam baixa solubilidade em solventes orgânicos (Strausz, 1999) e, neste trabalho, só foram avaliados os produtos da reação RICO presentes em diclorometano. $\dot{E}$ possivel que esses poliácidos estejam presentes nos ésteres formados na reação RICO com os produtos isolados a 550 e $580^{\circ} \mathrm{C}$. Entretanto, só seria possivel essa afirmação se a fase aquosa da reação RICO fosse avaliada. 
<smiles>c1ccc(-c2ccc3ccccc3c2)cc1</smiles><smiles>c1ccc(-c2cccc3ccccc23)cc1</smiles><smiles>c1cc2ccc3cccc4ccc(c1)c2c34</smiles><smiles>c1cc2c3c(cccc3c1)CC2</smiles>

$1,2,3$<smiles>c1ccc2cc3ccccc3cc2c1</smiles>

$1,2,4,5$

$1,2,3,4$

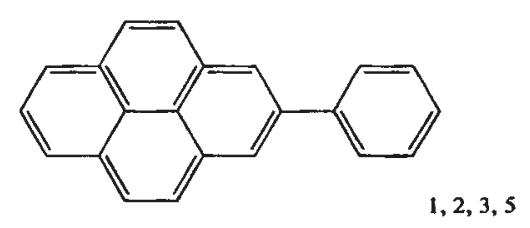<smiles>c1ccc(-c2c3ccccc3cc3ccccc23)cc1</smiles><smiles>c1ccc2c(c1)c1ccccc1c1ccccc21</smiles><smiles>c1cc2ccc3ccc4ccc5ccc6ccc1c1c2c3c4c5c61</smiles><smiles>c1cc2ccc3ccc4ccc5ccc6ccc7ccc8ccc1c1c2c3c4c5c6c7c81</smiles>

Figura 4. 23 - Estruturas aromáticas que geram poliácidos na reação RICO. 


\subsubsection{Produtos voláteis da decomposição térmica (PVDT) dos asfaltenos}

O sistema empregado na detecção e análise dos produtos voláteis liberados na decomposição térmica dos asfaltenos (PVDT) corresponde ao acoplamento das técnicas de análise térmica simultâneas TG/DTA (abreviatura definida pela Shimadzu como DTG) com a cromatografia gasosa e espectrometria de massa (CG-EM). Na literatura não foi verificada a utilização deste sistema acoplado para avaliação de frações de petróleo.

Este sistema permite que a análise seja realizada pelos modos DTG-EM e DTG-CG-EM, conforme ilustrado na Figura 4.24. No primeiro modo, durante o processo de decomposição térmica, os voláteis liberados são levados diretamente para o detector de massa, enquanto que no segundo os voláteis vão para uma unidade concentradora, onde serão adsorvidos, antes de serem separados por uma coluna cromatográfica e detectados pelo espectrômetro de massa. No presente estudo, estabeleceu-se o modo DTG-CG-EM, tendo em vista que o processo de decomposição térmica dos asfaltenos libera uma mistura de voláteis relativamente complexa, sendo necessária uma separação prévia na coluna cromatográfica.

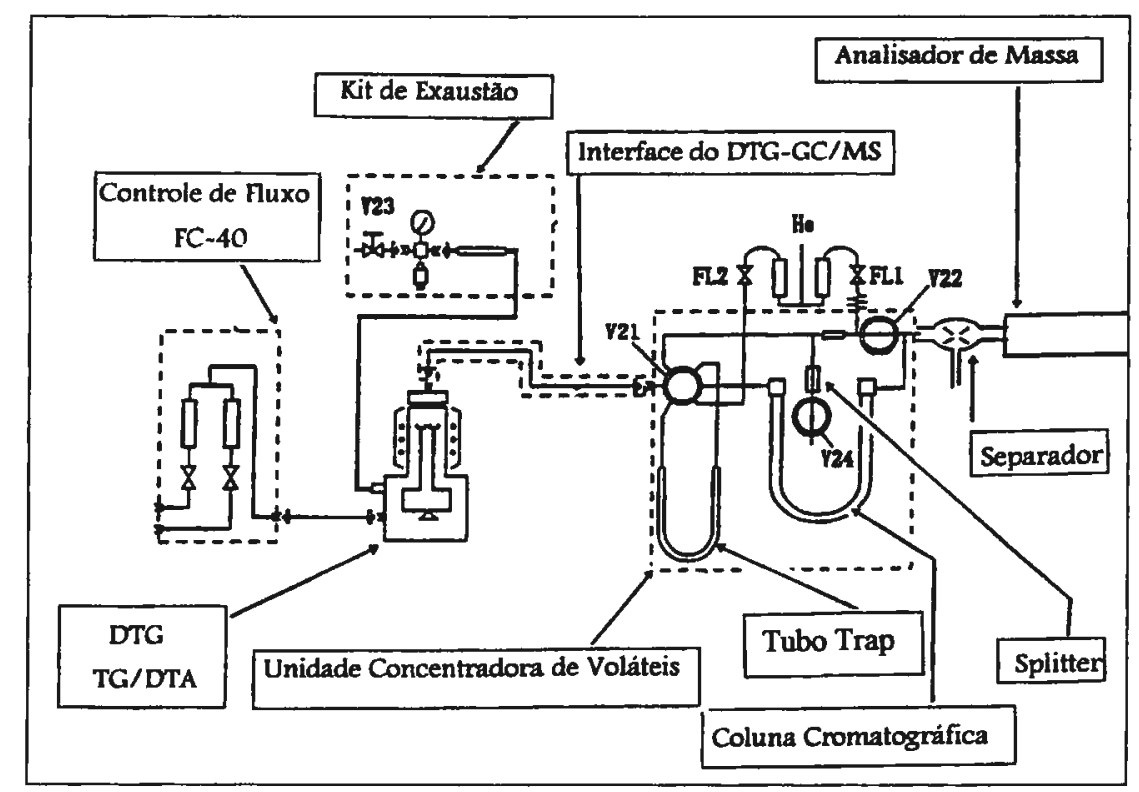

Figura 4. 24 - Representação esquemática do sistema DTG-CG-EM. 
Como já foi observado anteriormente (Figura 4.3), os asfaltenos apresentam dois eventos de perda de massa sob atmosfera de nitrogênio: o primeiro ocorre entre 30 e $300^{\circ} \mathrm{C}$ e segundo entre 350 e $550^{\circ} \mathrm{C}$. Foram, então, realizados dois ensaios distintos visando isolar e caracterizar, separadamente, os voláteis gerados em cada um dos eventos.

\subsubsection{PVDT dos asfaltenos liberados entre 30 e $250^{\circ} \mathrm{C}$}

Os asfaltenos com massa inicial em torno de 0,8 e $0,4 \mathrm{mg}$, respectivamente, foram submetidos a um processo de decomposição térmica no sistema DTG-50H no intervalo de temperatura de 30 a $250^{\circ} \mathrm{C}$. A Figura 4.25 apresenta as curvas de DTA e TG obtidas nesta condição.

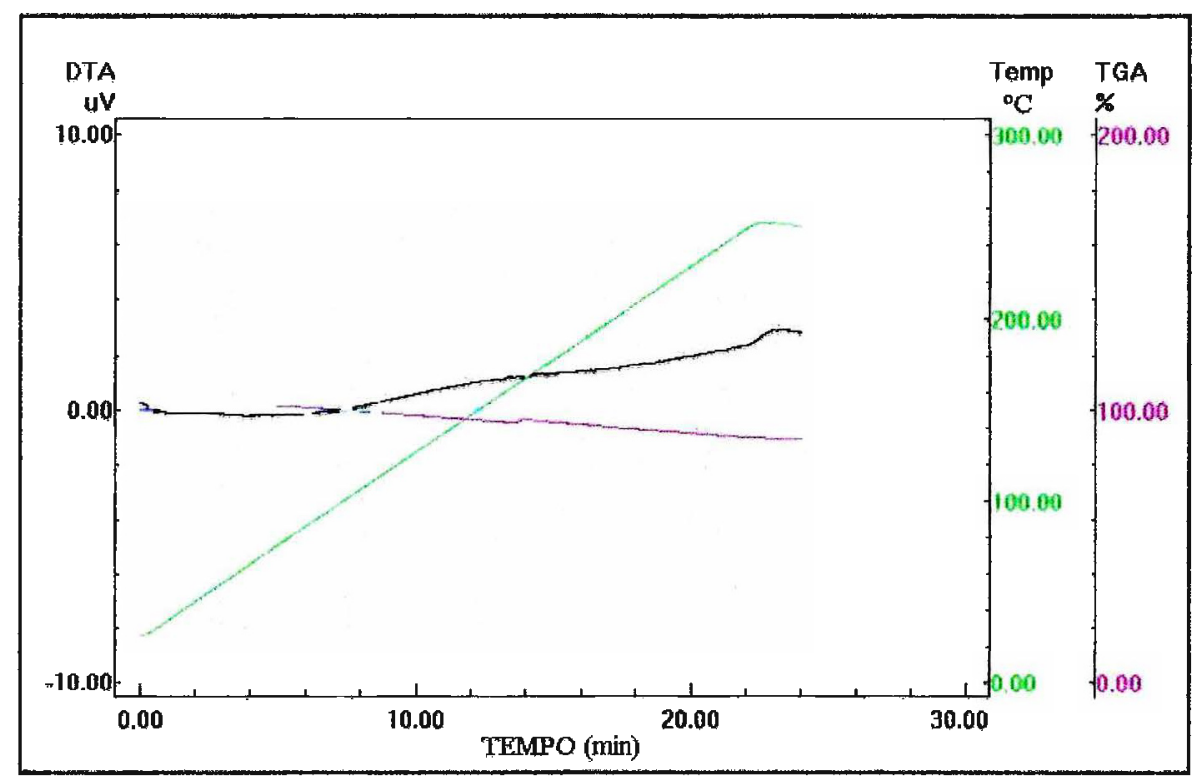

Figura 4. 25 - Curvas de TG/DTA dos asfaltenos entre 30 e $250^{\circ} \mathrm{C}$ no sistema acoplado DTG-CG-EM $-10^{\circ} \mathrm{C} \mathrm{min}^{-1} \mathrm{em}$ He a uma vazão de $50 \mathrm{~mL} \mathrm{~min}^{-1}$.

Na curva TG foi observada uma perda de massa de $10 \%$, coerente com a avaliação termogravimétrica realizada anteriormente. A curva de DTA, pouco definida, indica variação de linha base no sentido endotérmico. Os voláteis liberados foram conduzidos por uma interface, mantida a $250^{\circ} \mathrm{C}$, até a unidade concentradora. Esta unidade, que contém um adsorvente do tipo Tenax é mantida em um sistema de refrigeração com gelo seco, o que facilita a adsorção dos 
voláteis, vistos que estes são condensados. Ao término do processo térmico, a unidade de resfriamento foi substituída por uma de aquecimento mantida a $300^{\circ} \mathrm{C}$, a qual provoca a dessorção dos PVDT que são, imediatamente, levados para a coluna cromatográfica. A coluna utilizada, do tipo empacotada com Tenax (60/80 mesh), separou os compostos por ordem crescente do ponto de ebulição. Após separação os voláteis foram conduzidos para uma fonte de íons onde, através de um processo de impacto com elétrons de alta energia $(70 \mathrm{eV})$, são gerados íons positivos e negativos. Os íons formados são acelerados em direção ao analisador de massa, nesse caso um filtro quadrupolar, no qual as partículas carregadas são separadas de acordo com a relação $\mathrm{m} / \mathrm{z}$ e direcionadas para um sistema de deteç̧ão de íons. Utilizando um programa de computação, instalado na estação de tratamento dados dessa instrumentação, obteve-se como resultado os respectivos espectros de massa das substâncias liberadas entre 30 e $250^{\circ} \mathrm{C}$.

No cromatograma total de íons resultante do ensaio entre as temperaturas de 30 e $250^{\circ} \mathrm{C}$ (Figura 4.26) foram assinalados quatro picos que apresentaram, respectivamente, espectro de massa do tolueno, etil-benzeno e hidrocarbonetos parafínicos contendo 11 e 12 átomos de carbono. O tolueno e o etil-benzeno foram atribuídos ao solvente utilizado para extração dos asfaltenos do petróleo e os hidrocarbonetos provavelmente são procedentes da parafinas que copreciptaram com os asfaltenos (item 4.2.1) durante a sua extração do óleo.

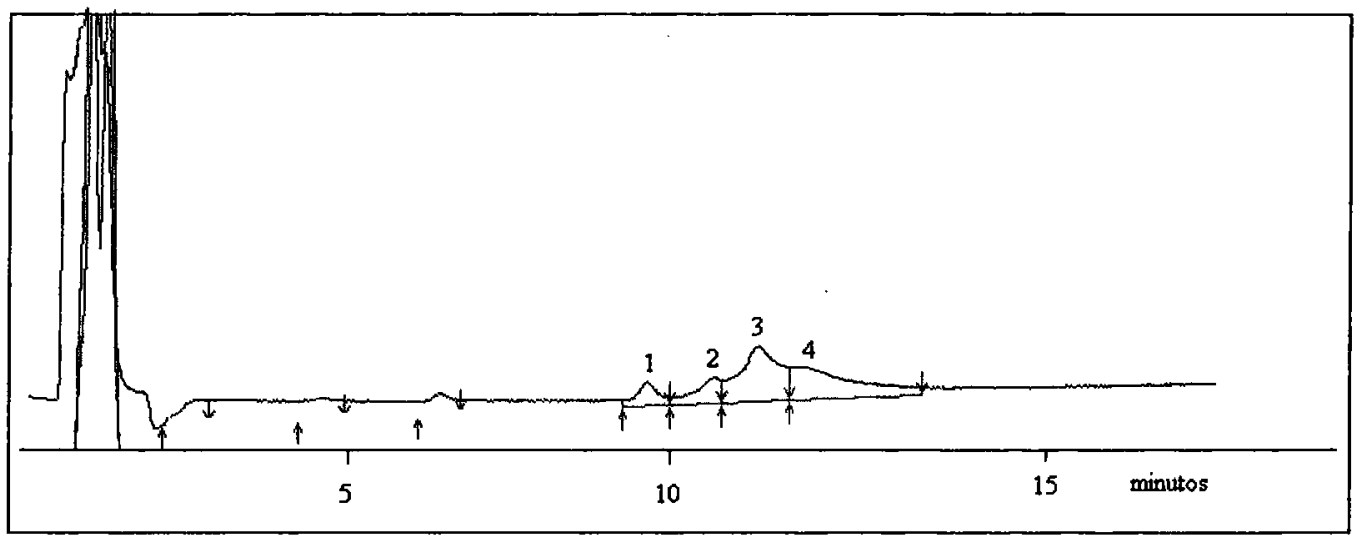

Figura 4. 26 - Cromatograma total de íons dos PVDT dos asfaltenos liberados entre 30 e $250^{\circ} \mathrm{C}$ no sistema DTG/CG-EM: 1) tolueno, 2) etil-benzeno, 3) undecano e 4) dodecano. 


\subsubsection{PVDT dos asfaltenos liberados entre 350 e $550^{\circ} \mathrm{C}$}

A amostra dos asfaltenos, após ter sido aquecida até $250^{\circ} \mathrm{C}$ no experimento anterior, foi resfriada até a temperatura ambiente e novamente aquecida até $600^{\circ} \mathrm{C}$. As curvas de TG/DTG/DTA desse segundo experimento estão apresentada na Figura 4.27.

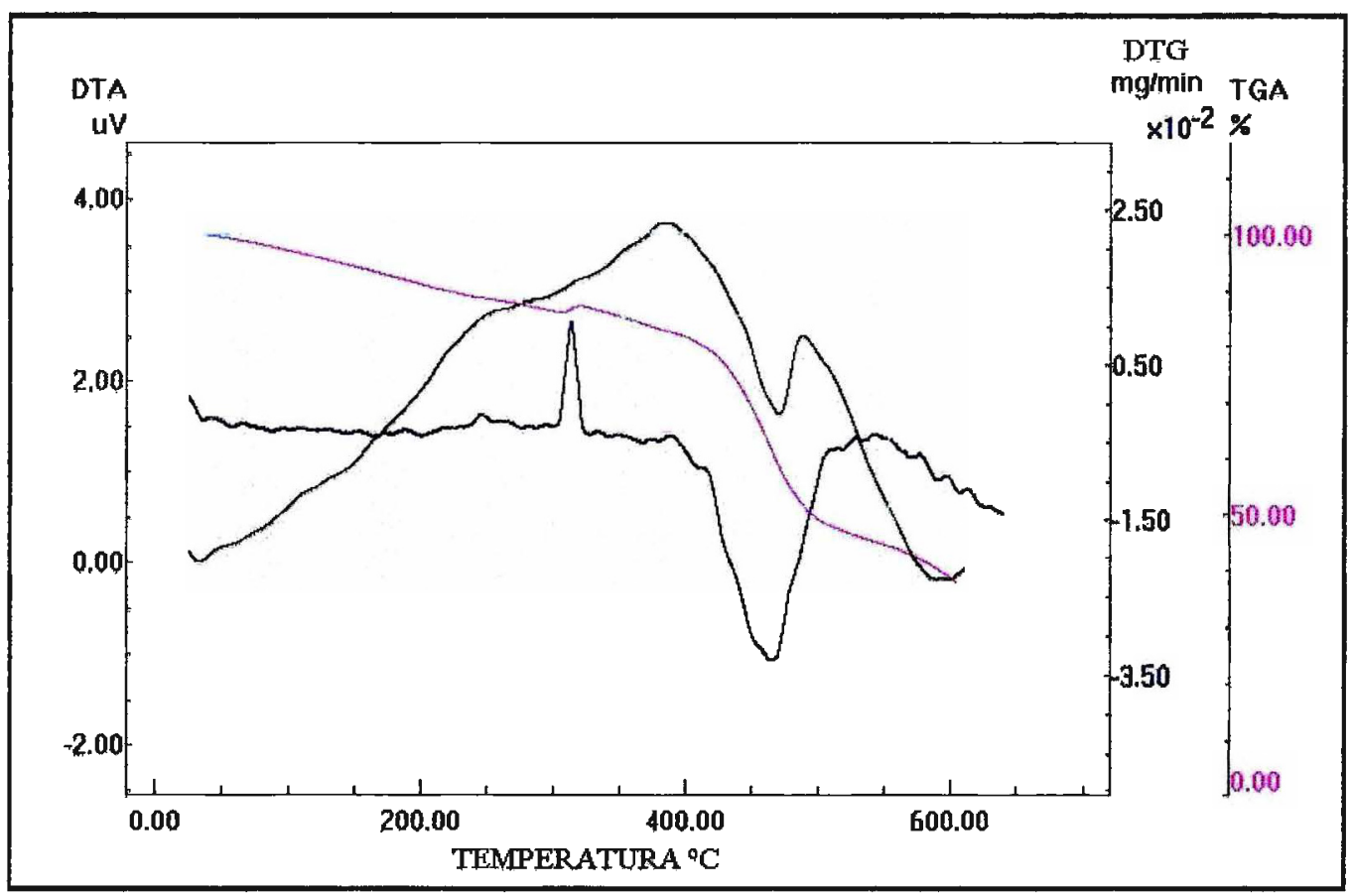

Figura 4. 27- Curva de TG/DTG/DTA dos asfaltenos entre 30 e $600^{\circ} \mathrm{C}$ no sistema acoplado DTG-CG-EM.

As curvas de TG/DTG indicaram a perda de massa pronunciada entre 350 e $550^{\circ} \mathrm{C}$ e a curva de DTA mostrou que este evento é endotermico. Como no primeiro experimento, os voláteis liberados foram conduzidos pela interface até a unidade concentradora de voláteis. Ao término do processo de decomposição térmica a unidade foi aquecida e o material nela retido foi levado para coluna cromatográfica. Após separação, os voláteis foram conduzidos para o espectrômetro de massa onde foram ionizados.

Foi observado um cromatograma total de íons (Figura 4.28) muito simples com picos com espectro de massa característicos de hidrocarbonetos lineares 
contendo de 3 até 12 átomos de carbono. Esse resultado causou uma grande surpresa, pois como já foi mencionado na literatura por diversos autores, são observados como PVDT de asfaltenos, compostos parafínicos com maiores número de átomos de carbono (Strausz, 1985).

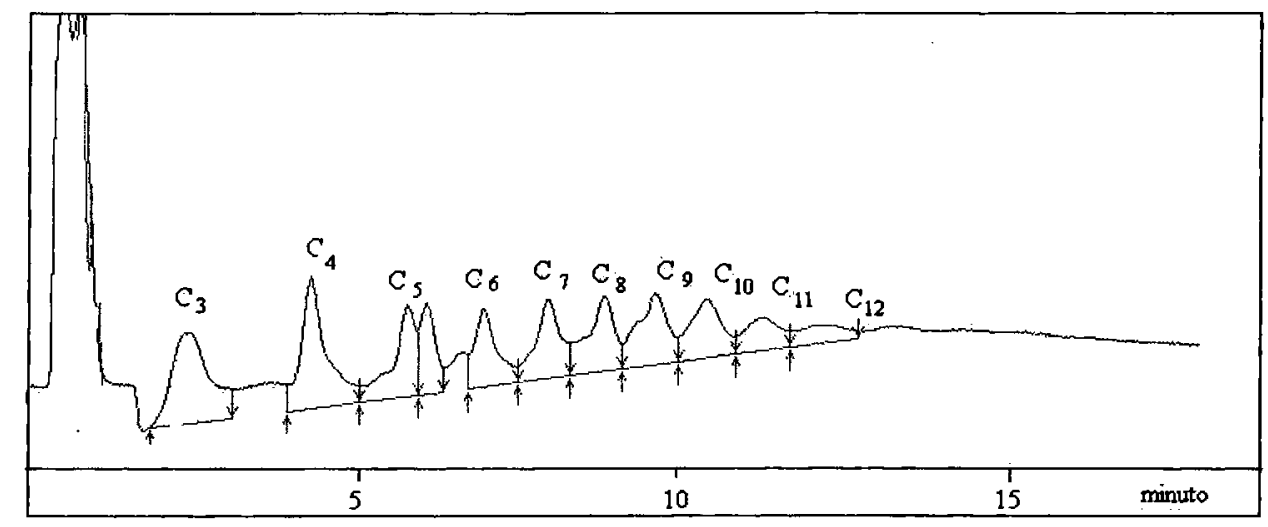

Figura 4. 28 - Cromatograma total de íons dos PVDT dos asfaltenos liberados entre 250 e $600^{\circ} \mathrm{C}$ no sistema DTG-CG-EM.

Algumas considerações foram feitas para explicar a não observação de hidrocarbonetos maiores que $C_{12}$ neste ensaio:

- Ocorre retenção dos hidrocarbonetos pesados na interface que liga o equipamento de TG/DTA ao CG-EM; o ponto de ebulição da parafina contendo 13 átomos de carbono é $235^{\circ} \mathrm{C}$, temperatura próxima daquela empregada no aquecimento da interface que liga o sistema. Então, os hidrocarbonetos que contm mais do que doze átomos de carbono na cadeia são liberados e podem ficar totalmente ou parcialmente retidos nessa interface.

- Ocorre retenção dos hidrocarbonetos pesados na unidade concentradora de voláteis;

- A coluna empacotada utilizada não apresenta comprimento não ideal para a separação de hidrocarbonetos com elevado número de carbono (Philp, 1994).

Em seguida, foi realizado um outro experimento utilizando um sistema em que fosse possivel eliminar a interface e a unidade concentradora de voláteis com 
adsorvente e que utilizasse, na separação do material liberado na decomposição térmica, um cromatógrafo equipado com coluna do tipo capilar (30 m).

O experimento consistiu em acoplar um frasco contendo diclorometano à saída do equipamento de TGA-951 (Figura 4.29).

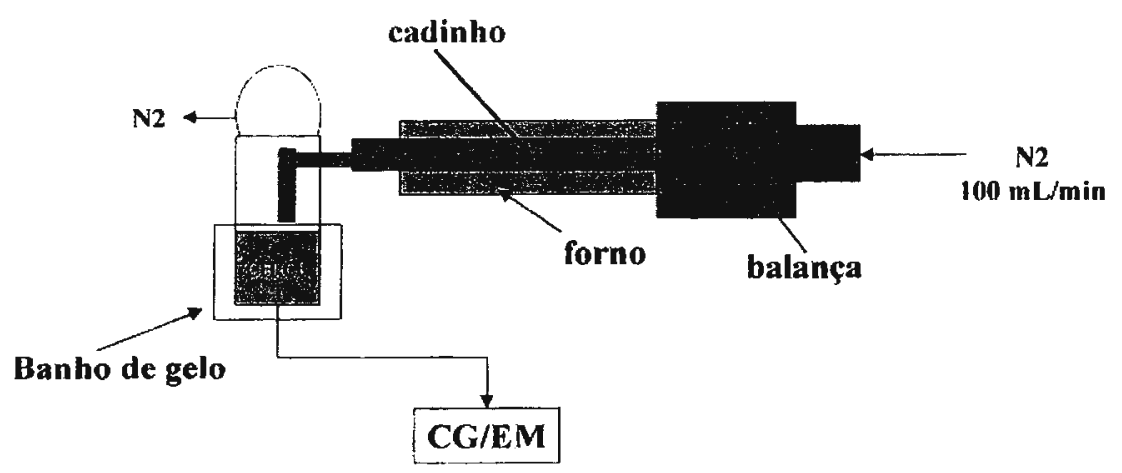

Figura 4. 29 - Esquema do equipamento TGA-951 para recolhimento dos PVDT dos asfaltenos e posterior análise por CG-EM

Foram colocados no analisador termogravimétrico (TGA-951) $10 \mathrm{mg}$ de asfaltenos. $\mathrm{O}$ sistema foi aquecido da temperatura ambiente até $700^{\circ} \mathrm{C} \mathrm{em}$ uma taxa de aquecimento de $10^{\circ} \mathrm{Cmin}^{-1}$ sob atmosfera dinâmica $\mathrm{N}_{2}\left(100 \mathrm{mLmin}^{-1}\right)$. No final do ensaio, o frasco contendo os produtos da decomposição térmica dos asfaltenos solubilizados em $\mathrm{CH}_{2} \mathrm{Cl}_{2}$ foi desacoplado do TGA-951 e o material, condensado no tubo de quartzo do equipamento, foi retirado por lavagens sucessivas com pequenas porções de $\mathrm{CH}_{2} \mathrm{Cl}_{2}$. As duas soluções foram concentradas até $2 \mathrm{~mL}$ para análise por CG-EM nas condições descritas na Tabela 3.13.

Os cromatogramas de íons de ambas as soluções, obtidos após separação dos compostos em uma coluna capilar de 30 metros, estão apresentados na Figura 4.30 A e B. Foi observado agora, um número maior de picos que se referem aos produtos da decomposição térmica, os quais correspondem a compostos que apresentam tamanho de cadeias carbônicas maiores que os identificados nos ensaios de DTG-CG-EM. 

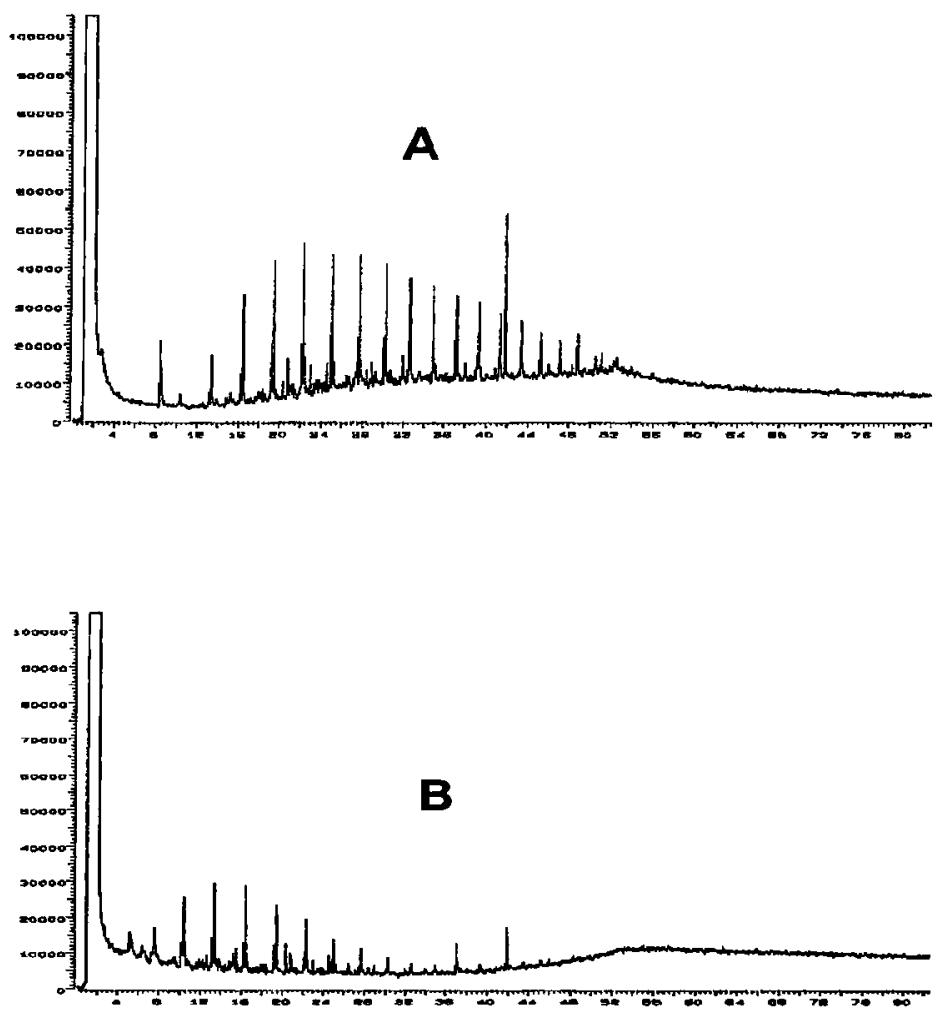

Figura 4. 30 - Cromatogramas total de íons dos PVDT dos asfaltenos recuperados em $\mathrm{CH}_{2} \mathrm{Cl}_{2}$ : A - solução retirada do tubo de quartzo do equipamento TGA-951; B - solução contida no frasco coletor adaptado à saída do equipamento.

Pela análise dos espectros de massa obtidos, foi possível verificar que as amostras são constituídas majoritariamente de parafinas $\left(C_{11}\right.$ e $\left.C_{33}\right)$ e olefinas $\left(\mathrm{C}_{14}\right.$ e $\left.\mathrm{C}_{21}\right)$, apresentando naftalenos e fenantrenos em níveis bem inferiores (Tabela 4.20). Foram encontrados os mesmos componentes nas duas soluções.

Em vista desses resultados, pode-se concluir dos experimentos utilizados para identificar os PVDT dos asfaltenos que:

- No sistema de técnicas acopladas (DTG-CG-EM) ocorre a retenção das espécies mais pesadas na interface.

- No sistema de recolhimento por borbulhamento, há a retenção de espécies mais pesadas, porém os hidrocarbonetos menores $\left(C_{3}\right.$ e $\left.C_{10}\right)$ são perdidos por volatilização. 
O importante é que as duas técnicas se complementaram, informando que os asfaltenos deste óleo da Bacia de Campos liberam hidrocarbonetos contendo compostos que apresentam de 3 a 33 átomos de carbono.

Tabela 4. 20 - Resultados da análise de CG-EM das soluções em $\mathrm{CHCl}_{2}$ dos PVDT coletados diretamente na saída do TGA-951

\begin{tabular}{|c|c|}
\hline SOLUÇÃO EM CHCl ${ }_{2}$ DOS PVDT & $\begin{array}{l}\text { COMPOSTOS } \\
\text { IDENTIFICADOS }\end{array}$ \\
\hline Recolhida no frasco com $\mathrm{CH}_{2} \mathrm{Cl}_{2}$ & $\begin{array}{l}\text { Parafinas }\left(C_{11}-C_{26}\right) \\
\alpha \text {-olefinas }\left(C_{14}-C_{21}\right) \\
\text { naftalenos }\left(C_{0}-C_{4}\right)_{4} \\
\text { fenantrenos }\left(C_{1}-C_{3}\right)\end{array}$ \\
\hline $\begin{array}{c}\text { Condensado do tubo de quartzo } \\
\text { do TGA-951 }\end{array}$ & $\begin{array}{l}\text { Parafinas }\left(C_{13}-C_{33}\right) \\
\alpha \text {-olefinas }\left(C_{14}-C_{24}\right) \\
\text { naftalenos }\left(C O-C_{4}\right) \\
\text { fenantrenos }\left(C_{1}-C_{3}\right) \\
\text { pirenos }\end{array}$ \\
\hline
\end{tabular}

Comparando esses resultados com aqueles obtidos pela reação RICO temse que:

- Pela avaliação da reação RICO com os asfaltenos, estão presentes em seu núcleo aromático grupos alquila contendo no máximo 24 átomos de carbono.

- Na avaliação dos PVDT destes mesmos asfaltenos, estão presentes grupamentos alquila contendo até 33 átomos de carbono.

$\mathrm{Na}$ reação RICO a amostra de asfaltenos passa por vária etapas de manipulação e pode ocorrer perda dos produtos gerados. E além disso, foi observado que alquila de maior número de carbonos estão presentes em menor quantidade. 


\section{CONSIDERAÇÕES FINAIS}

Após a avaliação dos produtos da decomposição térmica dos asfaltenos extraídos do petróleo da Bacia de Campos, algumas considerações podem ser feitas quanto:

\subsection{COMPORTAMENTO TÉRMICO DOS ASFALTENOS}

Nas condições operacionais da termogravimetria foram feitas algumas observações sobre o comportamento térmico da amostra de asfaltenos avaliada nesse estudo:

i. Na temperatura de $320^{\circ} \mathrm{C}$, a mais baixa desse estudo, já ocorre a decomposição térmica dos asfaltenos.

ii. A velocidade máxima de decomposição térmica ocorreu na temperatura de $425^{\circ} \mathrm{C}$.

iii. A avaliação da cinética de decomposição térmica dos asfaltenos indicou que a reação é de primeira ordem.

iv. Sob atmosfera dinâmica de $\mathrm{N}_{2}$ a $700^{\circ} \mathrm{C}$, os asfaltenos são convertidos totalmente a resíduo carbonáceo (coque) equivalente a cerca de $47 \%$ de sua massa inicial. Porém sob atmosfera de ar são decompostos completamente.

v. Nas condições operacionais foi verificado que nas temperatura de 320 e $380^{\circ} \mathrm{C}$, o tempo estimado a partir do grau de conversão extraido das curvasTG com diferentes taxas de aquecimentopara que os asfaltenos sejam convertidos totalmente a coque é de 24 horas. Na temperatura de $400^{\circ} \mathrm{C}$ esse tempo é de $150 \mathrm{~min}$. A $440^{\circ} \mathrm{C}$ é estimado em apenas 20 minutos. A temperaturas maiores que $480^{\circ} \mathrm{C}$, os asfaltenos são totalmente convertidos em coque em menos de 1 minuto. 


\subsection{GRUPAMENTOS ALQUILA. LIGADOS AOS NÚCLEOS AROMÁTICOS DOS ASFALTENOS E EM SEUS PSDT}

Nas condições analíticas do estudo, foi verificado que:

i. Os asfaltenos extraídos do petróleo brasileiro apresentam, em sua estrutura $45 \%$ de carbonos alifáticos.

ii. A concentração de grupamentos alquila ligados ao núcleo aromático é maior que a concentração de grupamentos alquila que ligam os núcleos aromáticos (pontes).

iii. A concentração dos grupamentos alquila ligados aos núcleos aromáticos diminui lentamente nos PSDT com o aumento da temperatura de obtenção até $400^{\circ} \mathrm{C}$.

iv. A concentração dos grupamentos alquila ligado aos núcleos aromáticos diminui drasticamente nos PSDT obtidos em temperaturas maiores que $440^{\circ} \mathrm{C}$.

$v$. Os grupamentos alquila de menor número de carbono estão em maior concentração em todos os produtos analisados.

vi. Os grupamentos alquila estão presentes na estrutura dos produtos sólidos gerados em temperaturas maiores que $440^{\circ} \mathrm{C}$, mas em quantidades 40 vezes menores que as presentes nos asfaltenos de origem.

\subsection{PONTES ALQUILICAS ENTRE NÚCLEOS AROMÁTICOS PRESENTES NOS ASFALTENOS E EM SEUS PSDT}

Nas condições do estudo, foi verificado que as pontes alquílicas que ligam os núcleos aromáticos :

i. São facilmente clivadas com o aumento da temperatura de obtenção dos PSDT dos asfaltenos. 
ii. A partir de $320^{\circ} \mathrm{C}$, ocorre um decréscimo de cerca de $35 \%$ destes grupamentos.

iii. A partir de $380^{\circ} \mathrm{C}$, ocorre um decréscimo de cerca de $70 \%$. 


\section{PERSPECTIVAS FUTURAS}

Este trabalho foi o início de uma pesquisa sobre o comportamento térmico dos asfaltenos presentes em petróleos Brasileiro. A abordagem, que envolveu estudos cinéticos da decomposição térmica dos asfaltenos e caracterização dos produtos voláteis e sólidos gerados da sua decomposição térmica, forneceu informações relevantes para o processamento dos resíduos pesados do petróleo (RV e RAT). A partir desses estudos outros tópicos de pesquisas poderão ser desenvolvidos, como por exemplo:

- A reação de oxidação seletiva aplicada aos asfaltenos e produtos sólidos de sua decomposição térmica revelou ser uma ferramenta poderosa na caracterização química dos mesmos. Entretanto não foi totalmente explorada. Neste trabalho, somente a fase orgânica desta reação foi contemplada. A fase aquosa deve conter produtos da reação que melhor caracterizam os produtos formados por condensados de aromáticos.

- Tanto a reação RICO, quanto a análise térmica, devem ser aplicadas a outros asfaltenos extraídos de diferentes petróleos Brasileiros para complementação do estudo.

- A termogravimetria mostrou grande potencialidade na avaliação térmica de frações pesadas de petróleo e, a partir dessas informações, pode-se propor sua utilização na avaliação das diferentes cargas que alimentam as unidades de craqueamento e coqueamento. 


\section{REFERÊNCIAS BIBLIOGRÁFICAS}

Albert, M., Brosselet, F., Claudy, P., Letoffé, J.M., Lopez, E., Damin, B. e Neff, B. (1985). Thermochim. Acta, 84, 101

Ashby, E. C. E., Goel, A B. A. (1981). J.Org. Chem., 46, 3936

Artok, L., Su, Y., Hirose, Y., Hosokawa, M., Murata, S., Nomura, M. (1999). Energy and Fuel, 13, 287

Barros, F.C., Bernardo, F.C.A., Chan, A., Bria, M. (1998). A/ChE, Spring Meeting, New Orleans

Berkowitz, L.M. E., Rylander, P.N. (1958). J.Amer. Chem. Soc. 80, 6682

Bestougeff, M.A., Byramjee, R.J. (1994). Asphaltenes and asphalts, pag. 67, Yen, T.F., Chilingarian, G.V. (Ed), Amsterdan, Elsivier

Bestougeff, M.A., Guiochon, G., Jaqueé J. (1962). Compt. Rend. 254, (2), 266

Boer, T. J., Baker, H. J. (1963). Organic Synthesis, Coll. Vol 4, John Willey and Soons, NY, 250

Brown, M. E. (1988). Introduction to Thermal Analysis - Techniques and Applications. Chapman and Hall. London.

Calderon, J.L., Cotte, E. (1983). Rev. Tec. INTEVEP, 3, (1), 69

Calemma, V., Iwanski, P., Nali, M., Scotti, R. e Montanari, L. (1995). Energy and Fuel, 9, 225

Calemma, V., Rausa, P. (1997). J. of Anal. and Appl. Pyr., 40-41, 569

Calemma, V., Rausa, P., D'antona, P., Montanari, L. (1998). Energy and Fuel, 12, 422

Cavalheiro, E., lanoshiro, M. (1995). Quim. Nova, 18, (3), 305 
Chiu, J. (1968). Anal. Chem.,40, 1516

Christopher, J., Sarpal, A.S., Kapur, G. (1996). Fuel, 75,(8), 999

Christy, A.A., Liang, Y.Z., Kavalheim, O.M. (1992). Fuel, 71, 125

Chung, H. L., Aldridg, J. C. (1992). Anal. Chem., 20, 123

Claudy, P., Letoffé, J.M., Changué, B. E., Orrit, J. (1988). Fuel, 67, 58

Claudy, P., Letoffé, J.M., King, G.N, Planché, J.P. e Brulle, B. (1991). Fuel Scien. and Technol. INTL, 9, (1), 71

Courtney, J.L., Swansborough, K.F.(1972). Rev. Pure and Appl. Chem. 22, 47

Dickinson, E.M. (1980). Fuel, 59, 290-294

Djerassi, C., Engle, R.R., (1953). J. Amer. Chem. Soc. 75, 3838

Duval, C. (1963). Inorganic Thermogravimetric Analysis. 2nd Edition. Elsevier, New York

Eglinton,T.I., Larter, S.R., Boonmj, J.(1991). J. Anal. Appl. Pyrolysis., 20, 25

Ekwenchi, M.M., Low, E.M., Montgomery, D.S., Strausz, O.P. (1984). Aostra J. Res., 1, (2), 127

Fyfe, C. A. (1983). Solid State NMR for Chemists, C.F.C. Press, Gueph

Flynn, J.H., Wall, L.A. (1966). Polym. Lett.., 4, 323

Gibson, E.K., Johnson, S.M. (1972). Thermochim. Acta, 4, 49

Giolito, I., lonashiro, M. (1988). Cerâmica, 34, 163

Giolito, I. (1988). Rev. Quím. Ind. 663, 12,

Hasan, M. U., Ali, M.F., Bukhari, A. (1983). Fuel, 62, 518

Hutchinson, E. J., Bowley, B., Pan, W-P. (1993). Thermochim.Acta, 223, 259 
Jain, P. K., Sangita, Maheshwari, R. K. (1991). Indian. J. Technol., 29, 259

Jansen, J. A. J., Van Der Maas, J. H., Posthuma De Boer, A. (1992). Appl. Spectrosc., 46,88

Jones, D.M., Douglas, A.G. (1987). Energy and Fuels, 1, 468

Karacan, O. e Kok, M.V. (1997). Energy and Fuel, 11, 385

Khulbe, K.C., Sachdev, A K., Mann, R.S., Davis, S. (1984). Fuel Process. Technol., 8, 259

Kopsch, H., (1994). Thermochim.Acta, 235, 271

Kopsch, H. (1995). Thermal Methods in Petroleum Analysis, VCH, Weinheim

Lee, D.G., Van Den Eng, M. (1973). Oxidation in organic chemistry, Part B Capitulo IV, pag. 177, Trahanovsky, W.S. (Ed), London, Academic Press Inc.

Leontaritis, K., Manssori, G. A. (1988), J. Pet. Sci. Eng., 1, 229

Mackenzie, R. C. (1984). Thermochim. Acta, 73, 251

Mackenzie, R. C. (1985). Pure Appl. Chem.,57, 1738

Mallya, N., Zingaro, R.A. (1984). Fuel, 63, 423,

Martim, F. S. (1952). J. Chem. Soc., 3055

Matos, J. R. (1988). Texto Crítico de Livre docência, Análise Térmica Potencialidades e Versatilidades (IQ-USP), São Paulo

McClennen, W. H. (1993). Anal. Chem., 65, 2819

McGhie, A. R. (1994). Thermochim.Acta, 234, 21.

Mcnaughtan, J. L. e Mortimer, C. T. (1975). IRS, Physical Chemistry, Series 2, Vol. 10. Butherworths. London. 
Miyano, M. H., Moura, M. F. V., Siqueira, L., Luiz, J. M. E Matos, J.R. (2000). Quím. Nova, 23, (1), 113

Moschopedis, S., Parkash, S. e Speiht, J.G. (1978). Fuel, 55 (10) 431

Mullens, J., Carleer; R., Reggers, G.; Yperman, J., Van Poucke, L. C. (1992). Thermochim.Acta, 212

Murata, S., U-Esaka, K., Ino-Eu, H., Nomura, M., (1994). Energy and Fuels, 8, 1379

Murgich, J., Rodrigues, J., Array, Y. (1995). International Symposium on Colloid Chemistry in Oil Production: Asphaltenes and Wax Deposition, 1, Rio de Janeiro.

Nicksic, S. W., Jeffries-Harris, M. J. (1968). J. Inst. Petrol., 54, (532), 107

Opella, S.J., Frey, M.H. (1979). J. Amer. Chem. Soc., 101, 5854

Ozawa, T. (2000). Thermochim. Acta, 355, 35

Philp, R.P. (1994). J. High Resolut. Chromatogr., 17, 398

Savage, P.E., Klein, M.T. (1985). Ind. Eng. Process. Des. Dev., 24, 1169

Savage, P.E., Klein, M.T. (1998). Ind. Eng. Chem.. Res., 27, 1348

Silverstein, R.M.E., Webster, F., X. (2000). Identificação espectrométrica de compostos orgânicos, Livros técnicos e Científicos, Brasil

Skjevrak, I., Larter, S., Graas, G.V., Jones, M. Berger, E. (1993). Org. Geochem., $22,(3 / 5), 873$

Smith, C. M., Savage, P.E., (1991). AlChE J., 37, (11), 1613

Speight, J.G. (1970). Fuel, 49, 134, 
Speight, J.G. (1989). Latest thoughts on the molecular nature of petroleum asphaltens, In: Symposium on Analytical Chemistry of Heavy Oils/Resids, Dallas, $T x$

Speight, J.G. (1992). Oil Shale Symposium Proceedings, 177, Kentucky University Speight, J.G. (1994). Characterization of heavy crude oil and petroleum residue. Paris:Technip, 29-32

Speight, J.G. (1994). Asphaltenes and asphalts, pag. 7-61, Yen, T.F., Chilingarian, G.V. (Ed), Amsterdan, Elsivier

Speight, J.G., Long, R.B., Trowbridge, D. (1984). Fuel, 33, 616

Stock, L. M., E Wang, S-H. (1985). Fuel, 64, 1713

Stock, L. M., E Wang, S-H. (1986). Fuel, 65, 1552

Stock, L. M. E Wang, S-H. (1987). Fuel, 66, 921

Stock, L. M., E Tse, K-T. (1983). Fuel, 62, 974,

Stock, L. M., E Wang, S-H. (1989). Energy and Fuel, 3, 533

Strausz, O.P. (1989). Am. Chem. Soc. Div. Petrol. Chem., 34, 395

Strausz, O.P., Mojelsky, T.W., Montgomery, D.S. (1985). Aostra J. Res., 2,(2), 131

Strausz, O.P., Mojelsky, T.W.,Lown, E.M. (1992). Fuel, 71, 1355

Strausz, O.P., Mojelsky, T.W., Lown, E.M. (1999). Energy and Fuel, 13, 228

Szabadvary, F., Buzágh-Gere, E., (1979). J. Therm. Anal.,15, 389

Teixeira, M. A. G., Gonçalves, M.L.A. (1999). Petrol. Sci. Technol., 17 (1\&2), 1

Teixeira, M.A G., Gonçalves, M.L.A. (2000). Petrol. Sci. Technol., 18, 3\&4, 273 
Tissot, B., Welte, D. H. (1984). Petroleum formation and ocurrence, 2nd Edition, Springer, Berlim.

Trauth, D.M., Yasar, M., Neurock, M., Nigam, A., Klein, T., Kukes, G. (1992). Fuel Sci. Technol. Int', 10, (7), 1161

Tury, E. A. (1981). Thermal Characterization of Polymeric Materials. Academic Press, INC, New York

Watson, B. A., Barteau, M.A. (1994). Ind. Eng. Chem. Res., 33, 2358-63

Wendlandt, W. W. (1986). Thermal Analysis. 3nd edition. Wiley. New York.

Weselowski , M. (1981), Thermochim.Acta, 46,21

Whiting, L. F., Langvardt, P. W. (1984). Anal. Chem., 56, 1755

Wieboldt, D., Adams, G. (1987). Spectroscopy, 2, 46

Wilhems, A., Larter, S.R. E., Schulten, H.R. (1993). Org. Geochem, 20, (7),1049

Wolf,S., Hasam, S. K. , Campbell, J. R. (1970). J. Chem. Soc., 1420

Yen, T.F., Erdman, J.G., Pollack, S.S. (1961). Anal. Chem., 33, 1587

Yuen, H. K., Mappes, G. W. (1983). Thermochim.Acta, 70, 269 
Anexo 1 - Espectros de RMN ${ }^{13} \mathrm{C} \mathrm{e}{ }^{1} \mathrm{H}$ dos asfaltenos em solução de Clorofórmio deuterado deuterado $\left(\mathrm{CDCl}_{3}\right)$ 


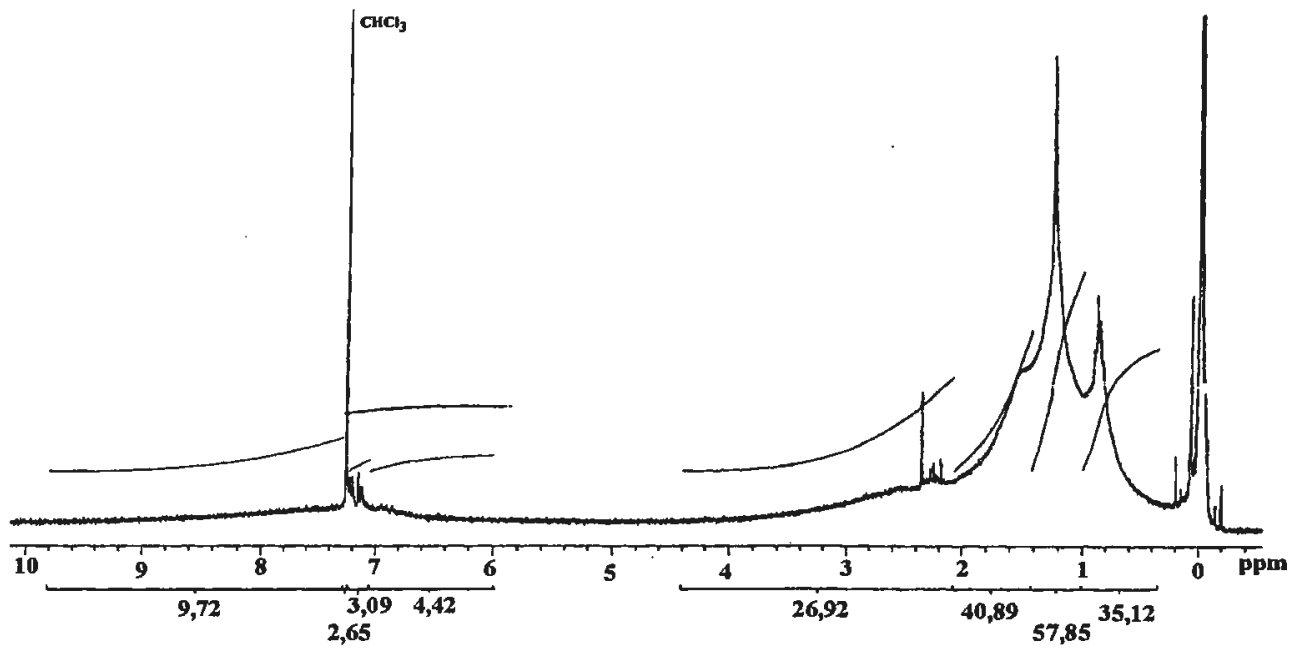

Figura A1 - Espectro de $\mathrm{RMN}^{1} \mathrm{H}$ em $\mathrm{CDCl}_{3}$ dos asfaltenos

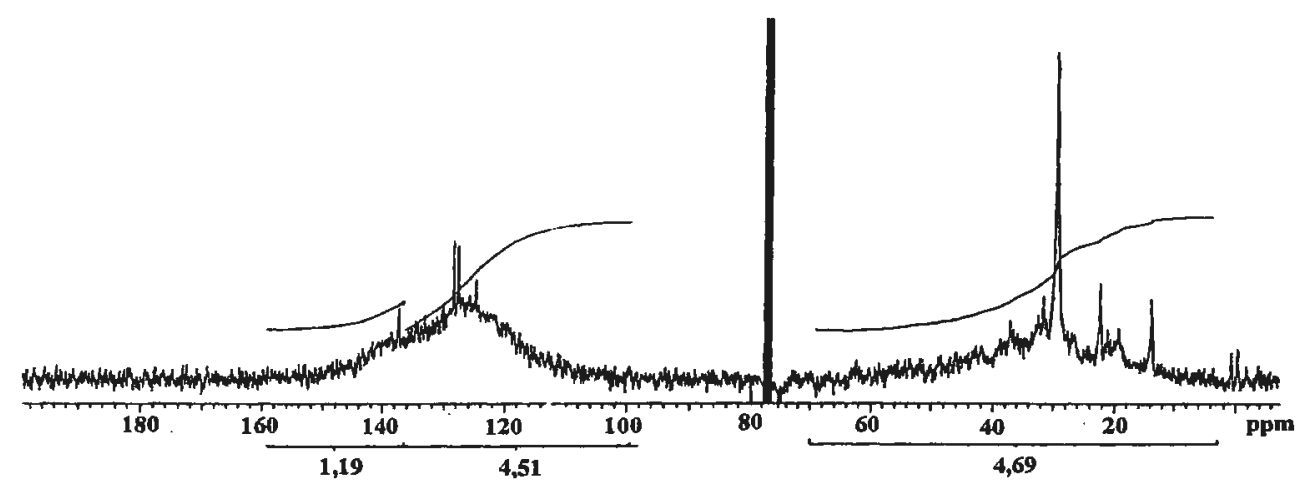

Figura A 2 - Espectro de $\mathrm{RMN}^{13} \mathrm{C}$ em $\mathrm{CDCl}_{3}$ dos asfaltenos 
Anexo 2 - Curvas de TG dos asfaltenos em isotermas de 320, 380, $430,480,550,700^{\circ} \mathrm{C}$ 


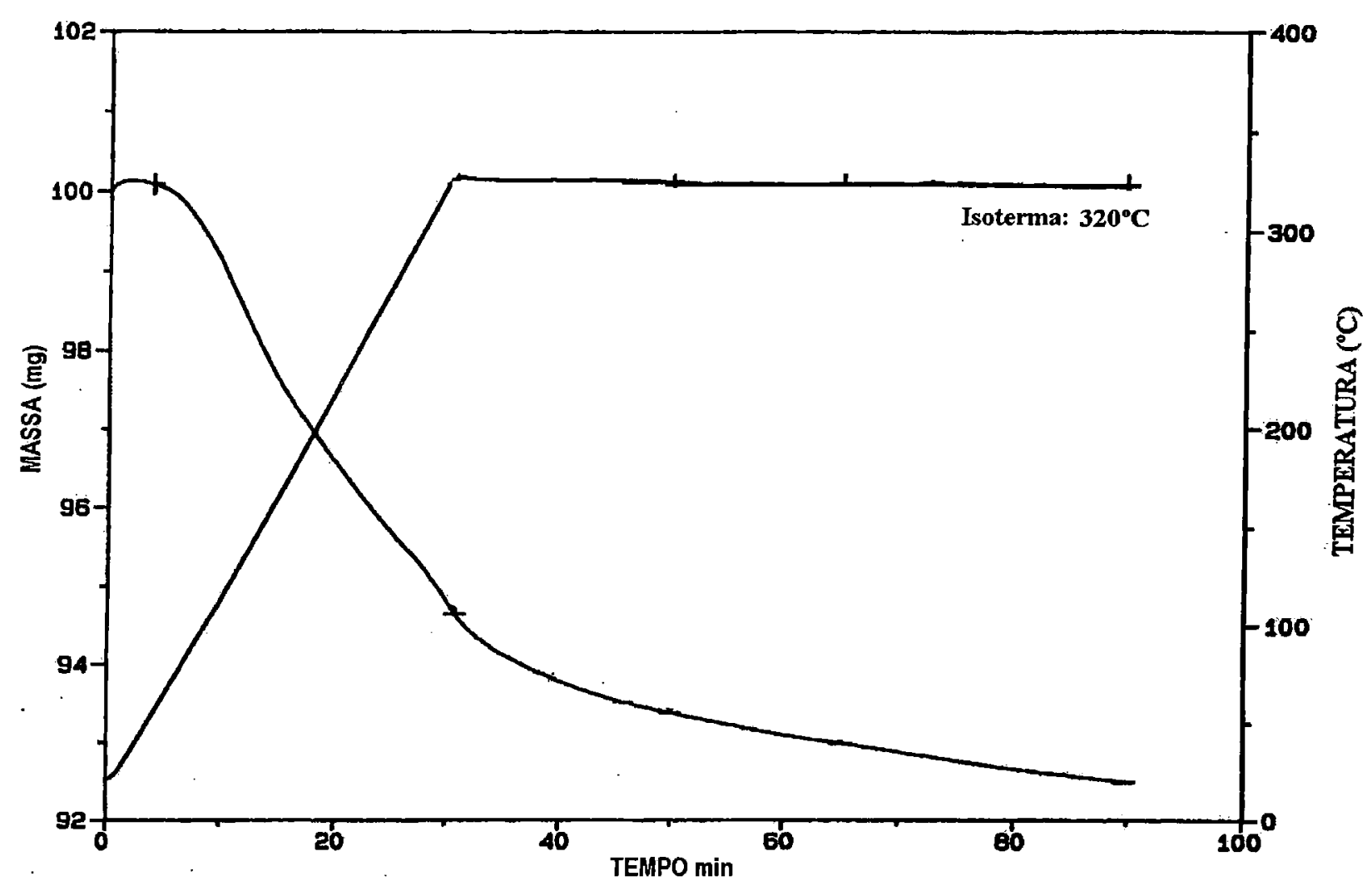

Figura A 3 - Curva de TG na isoterma de $320^{\circ} \mathrm{C}$

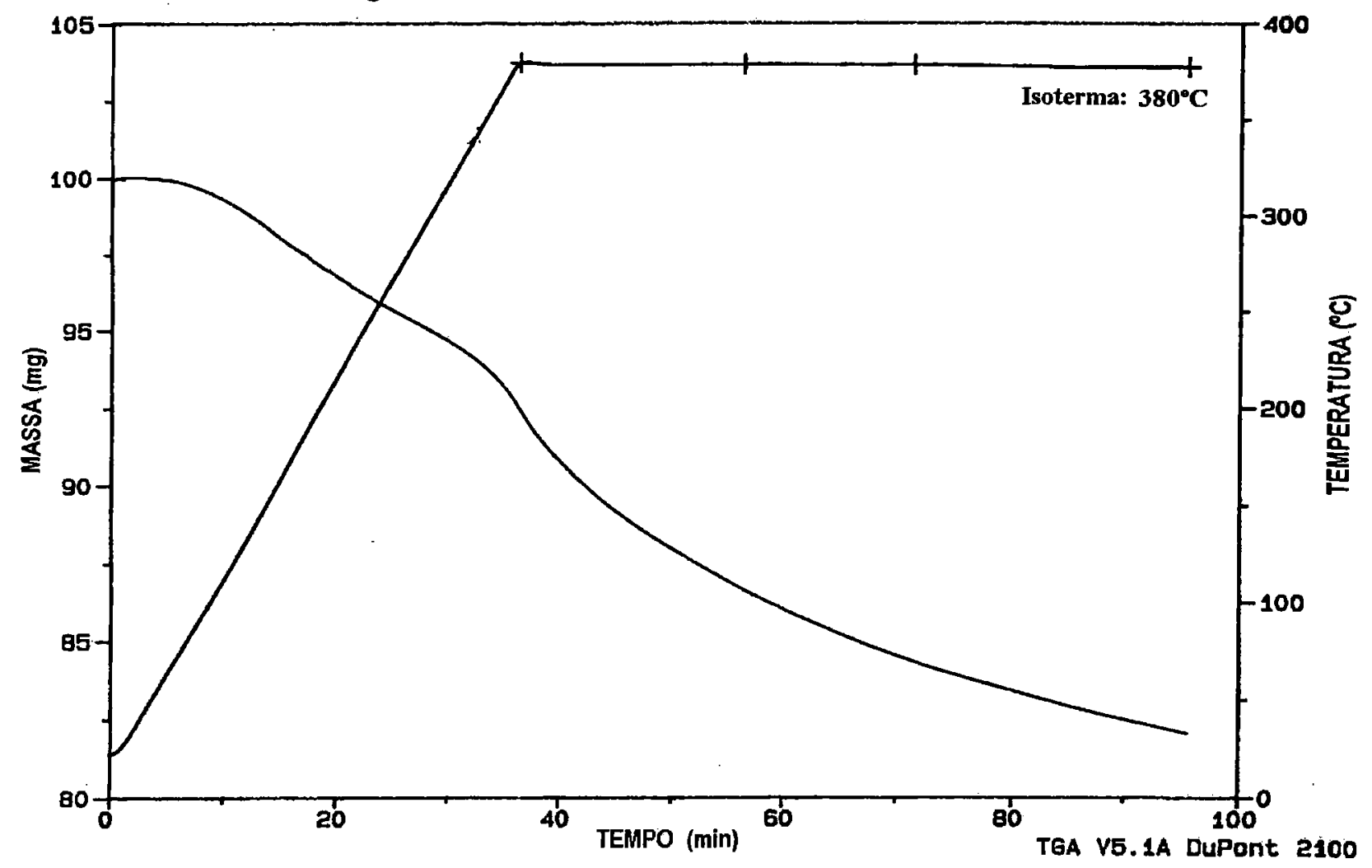

Figura A 4 - Curva de TG na isoterma de $380^{\circ} \mathrm{C}$ 


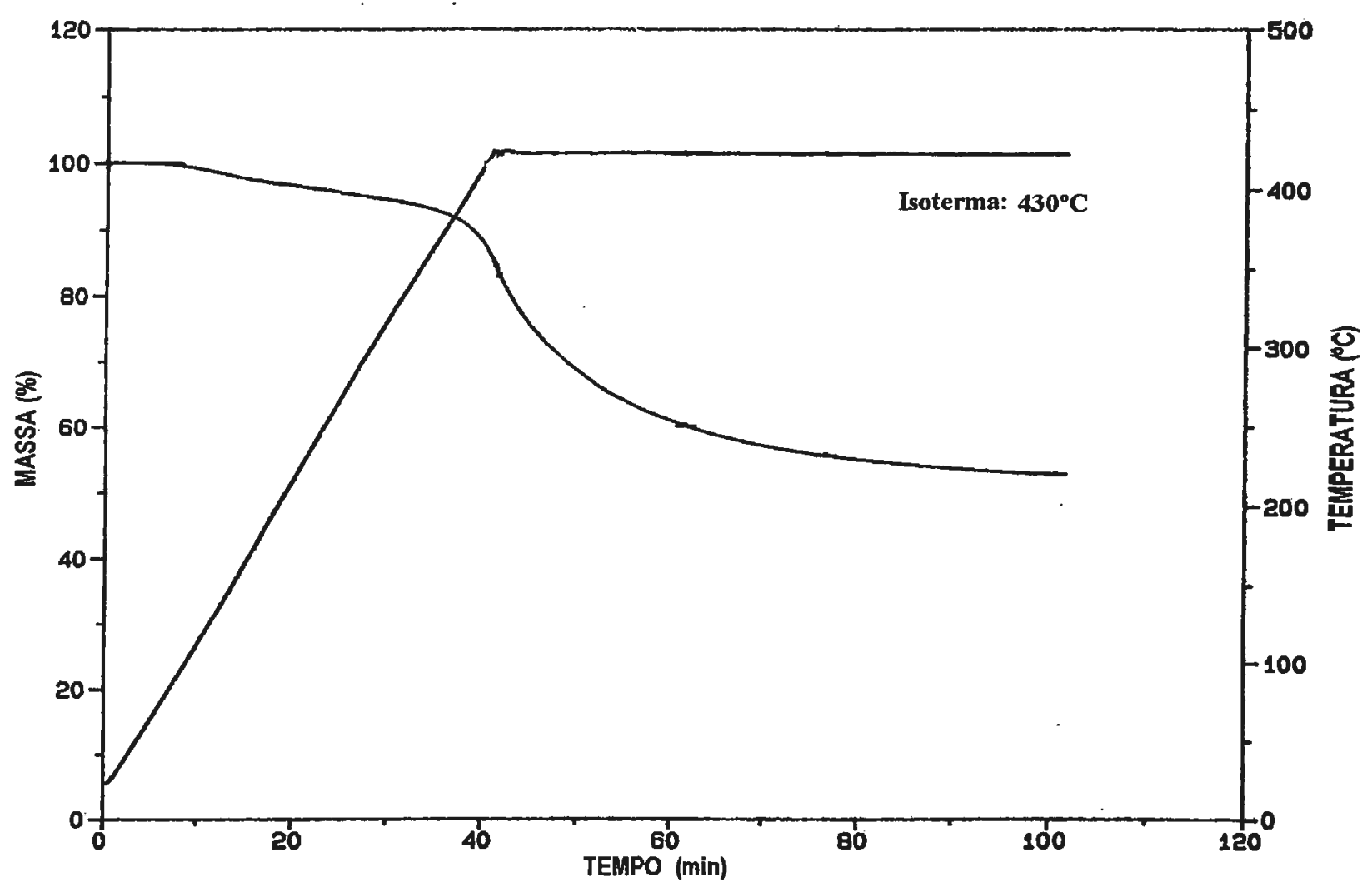

Figura A 5 - Curva de TG na isoterma de $430^{\circ} \mathrm{C}$

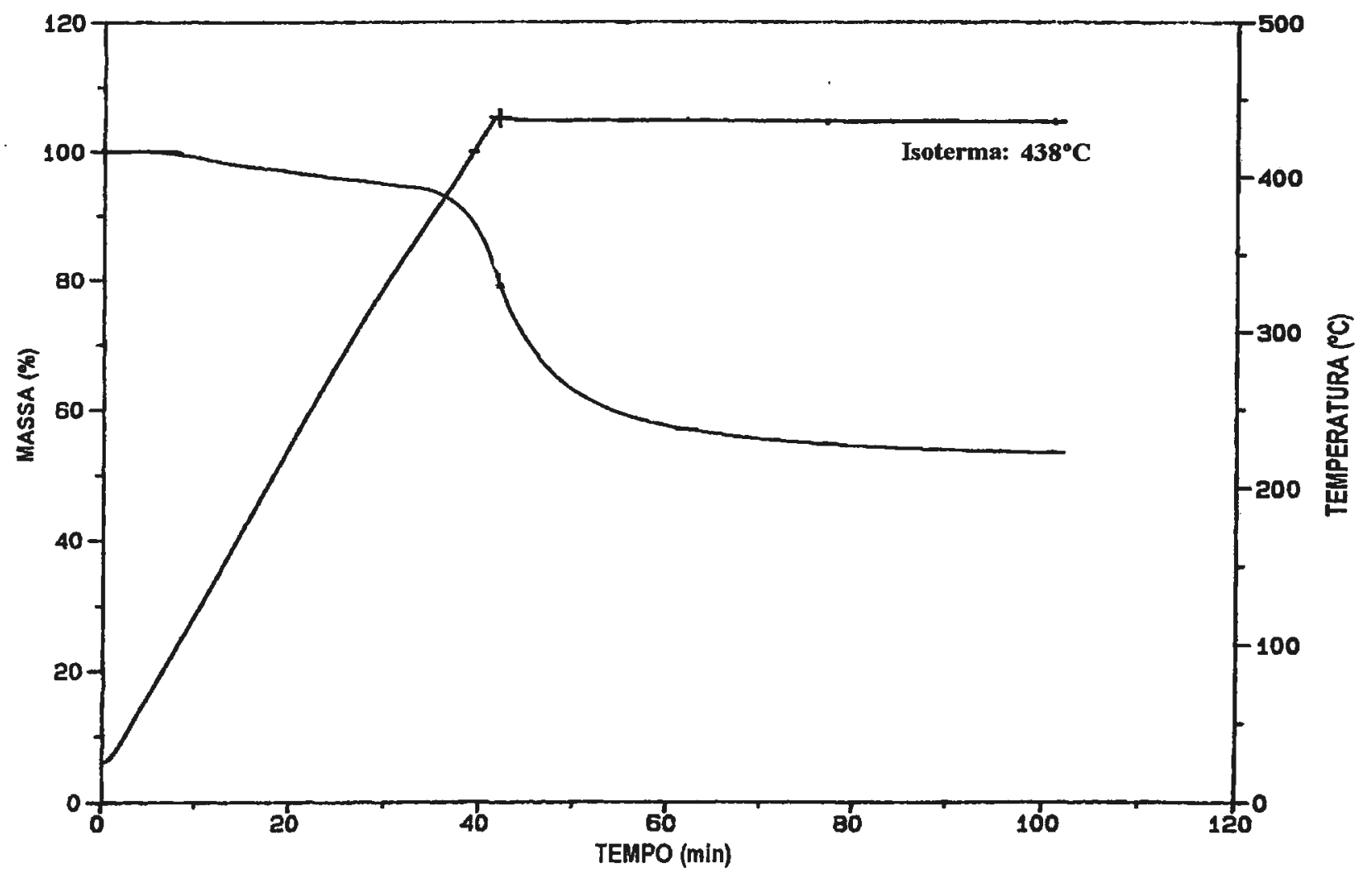

Figura A 6 - Curva de TG na isoterma de $438^{\circ} \mathrm{C}$ 


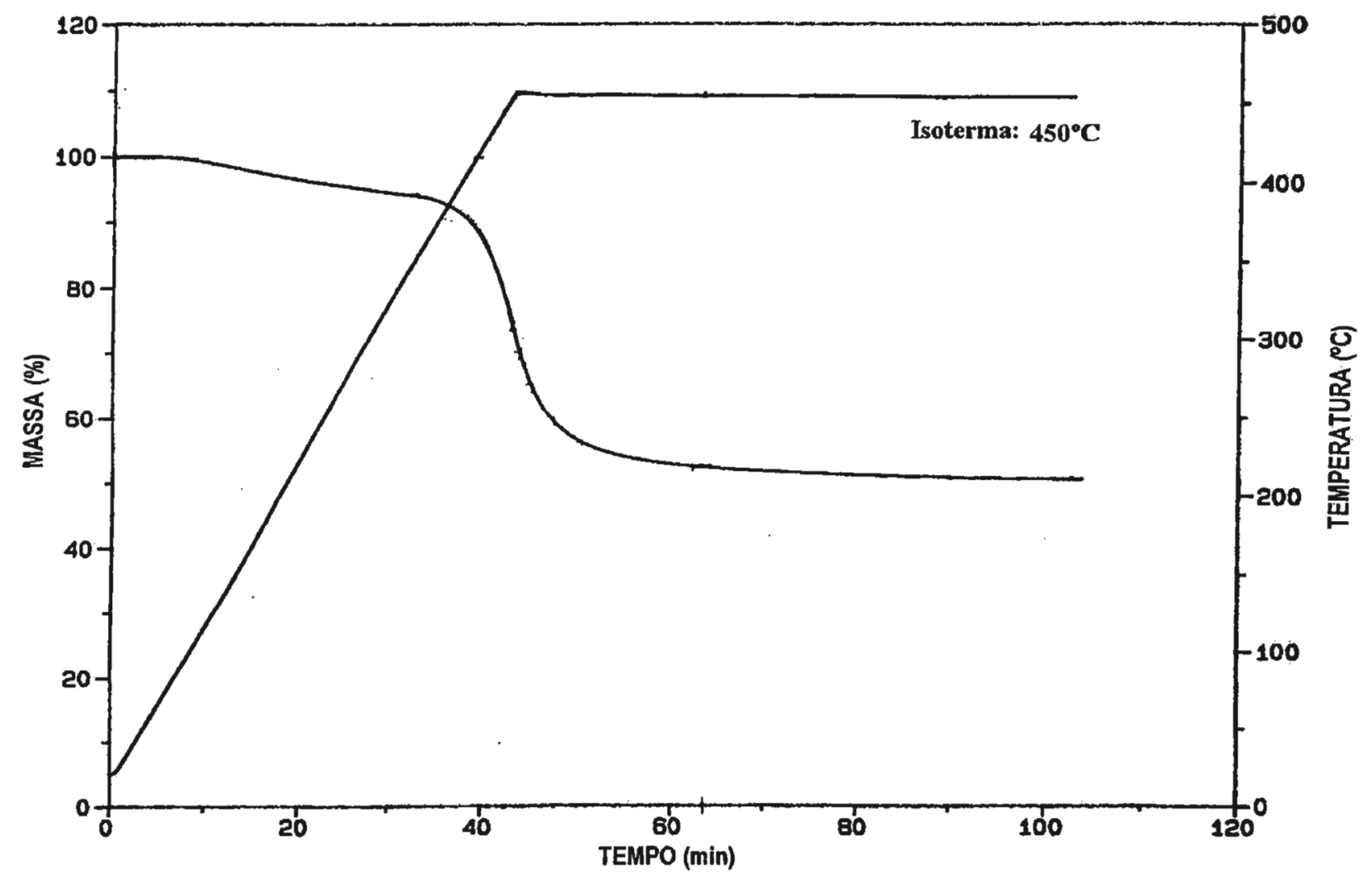

Figura A 7 - Curva de TG na isoterma de $450^{\circ} \mathrm{C}$

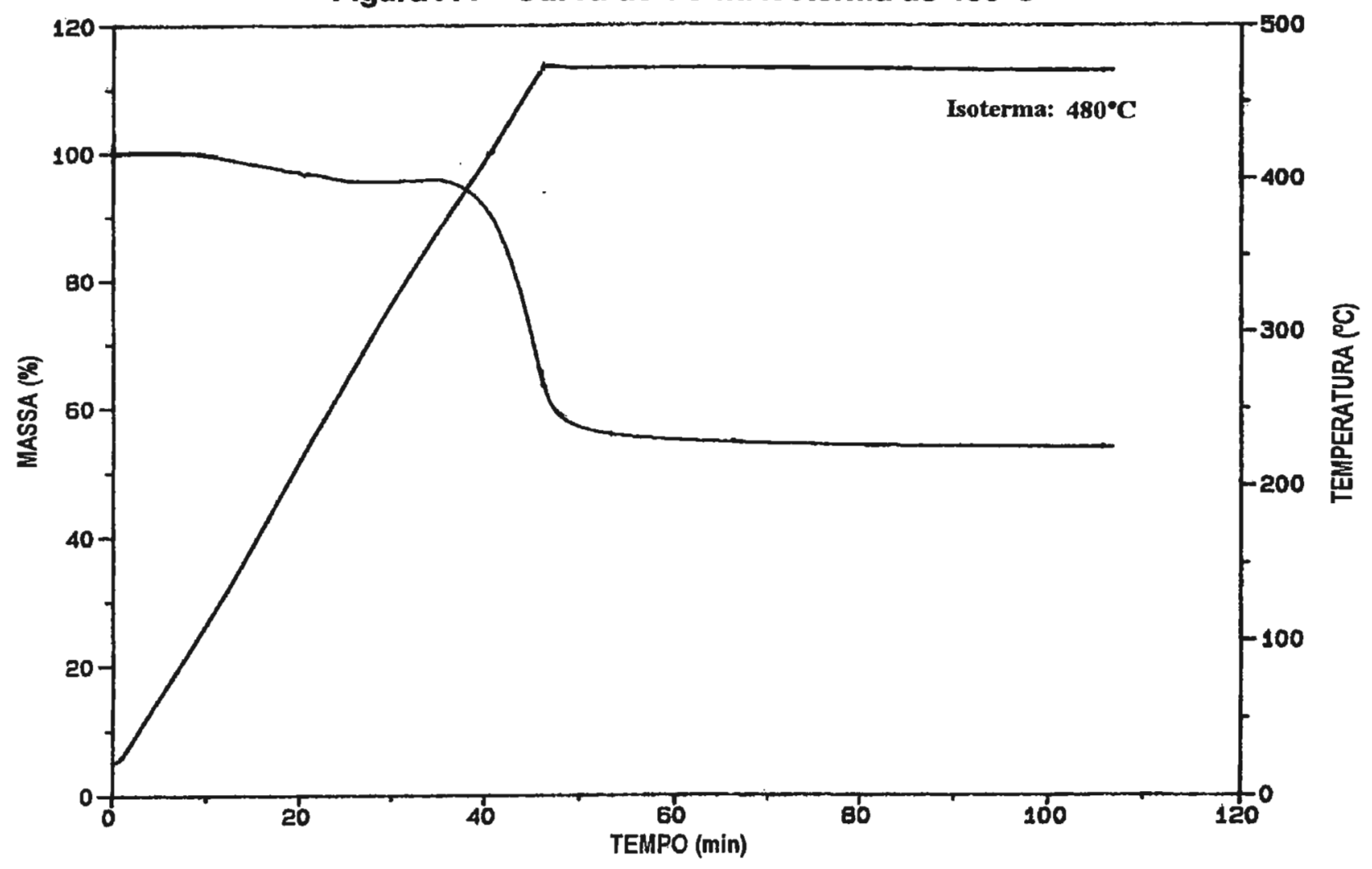

Figura A 8 - Curva de TG na isoterma de $480^{\circ} \mathrm{C}$ 


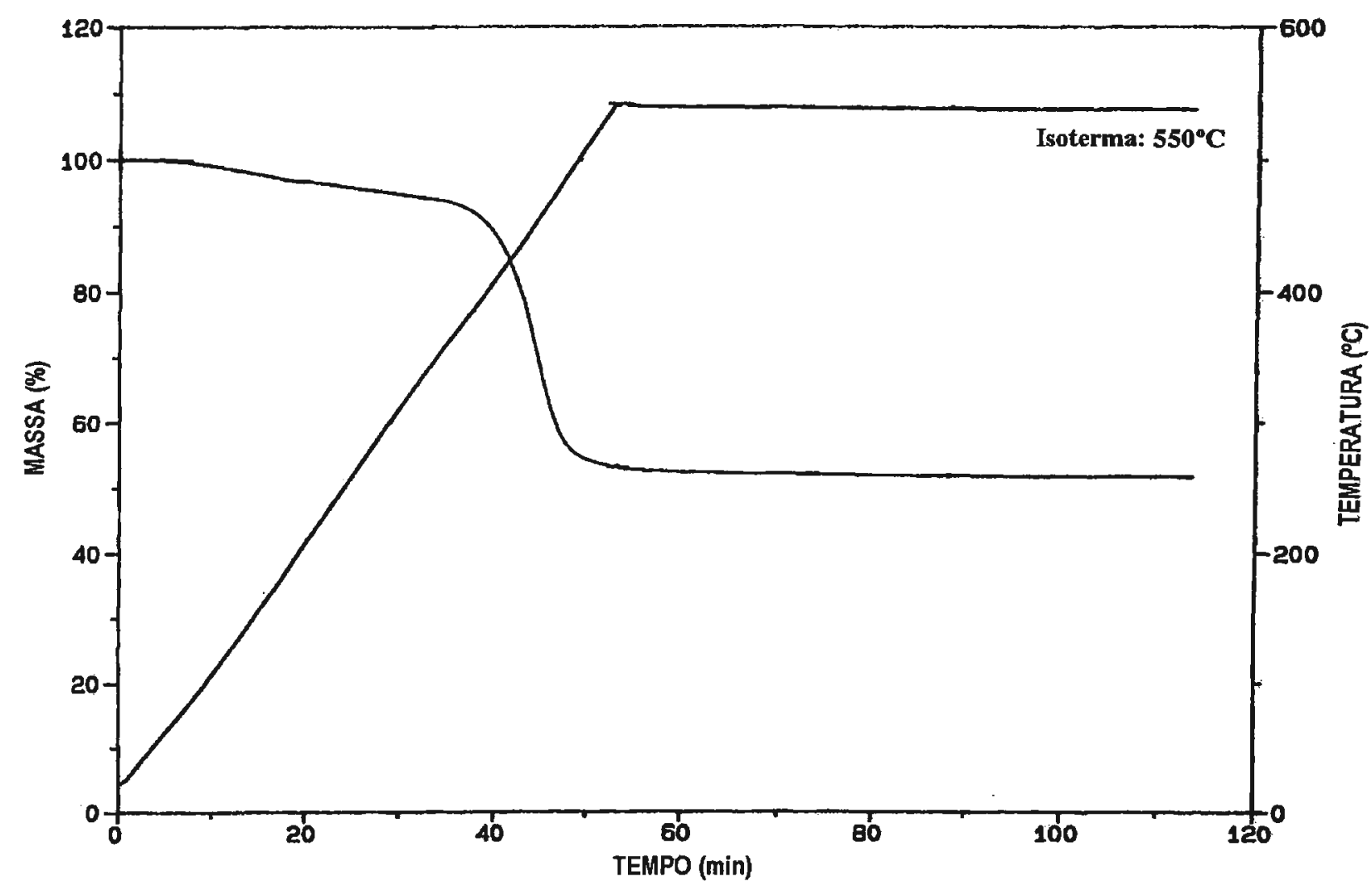

Figura A 9 - Curva de TG na isoterma de $550^{\circ} \mathrm{C}$

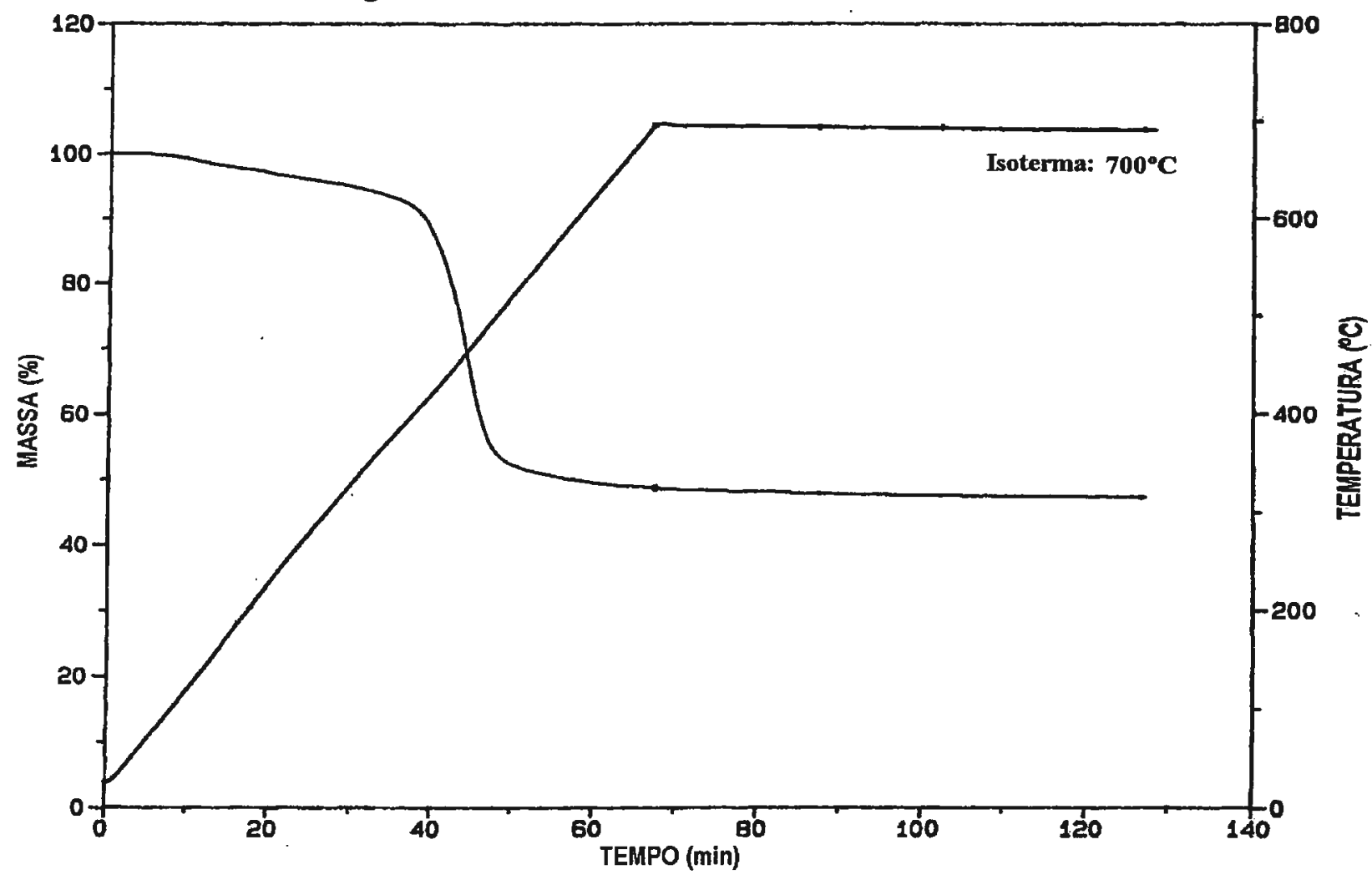

Figura A 10 - Curva de TG na isoterma de $700^{\circ} \mathrm{C}$ 
Anexo 3 - Espectros de absorção no infravermelho dos produtos sólidos da decomposição térmica dos asfaltenos obtidos em forno tubular: PSDT $-320^{\circ} \mathrm{C}$, PSDT $-380^{\circ} \mathrm{C}$, PSDT $-450^{\circ} \mathrm{C}$ e PSDT$550^{\circ} \mathrm{C}$ 


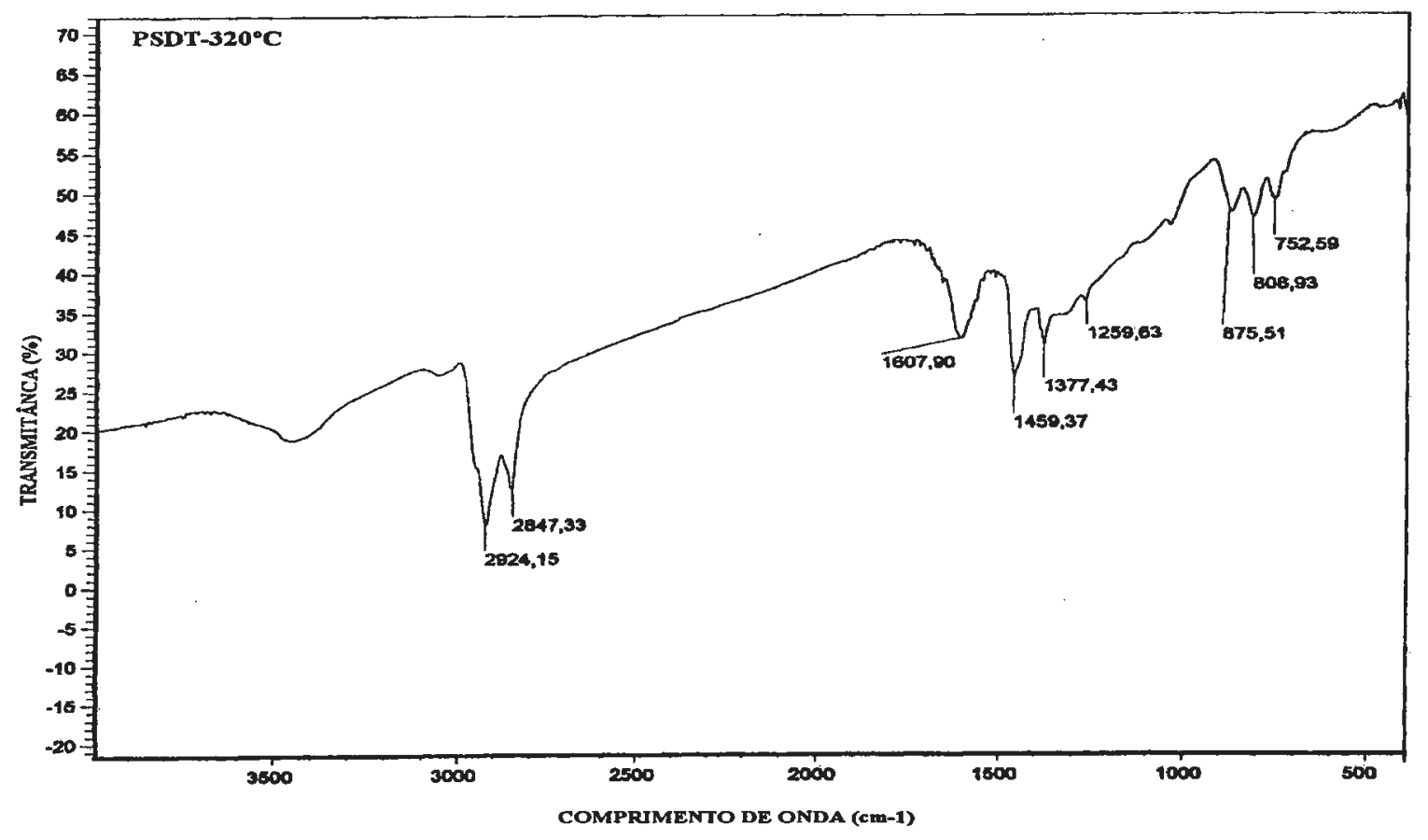

Figura A 11 - Espectro de absorção no infravermelho do PSDT- $320^{\circ} \mathrm{C}$

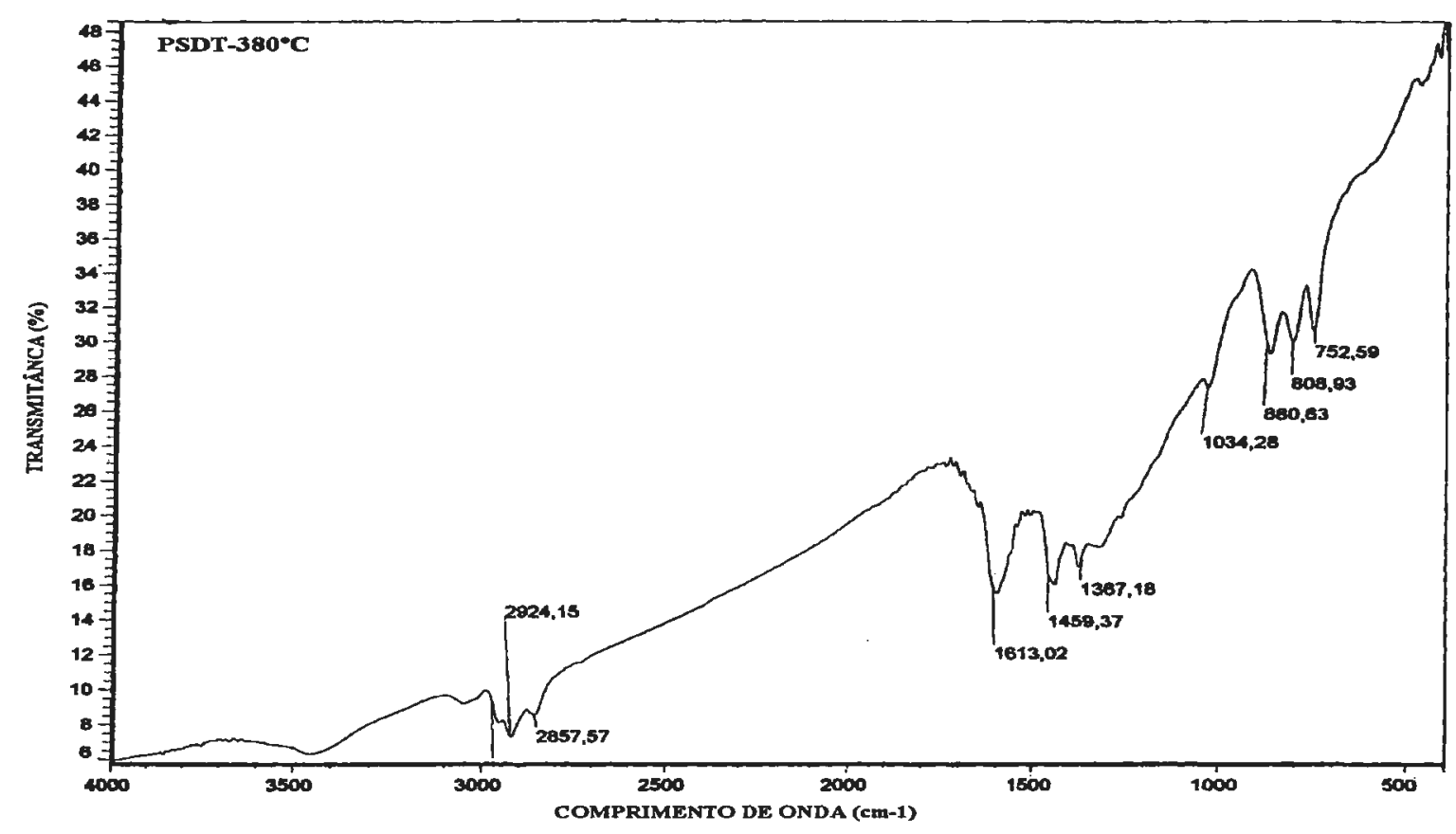

Figura A 12 - Espectro de absorção no infravermelho do PSDT- $380^{\circ} \mathrm{C}$ 


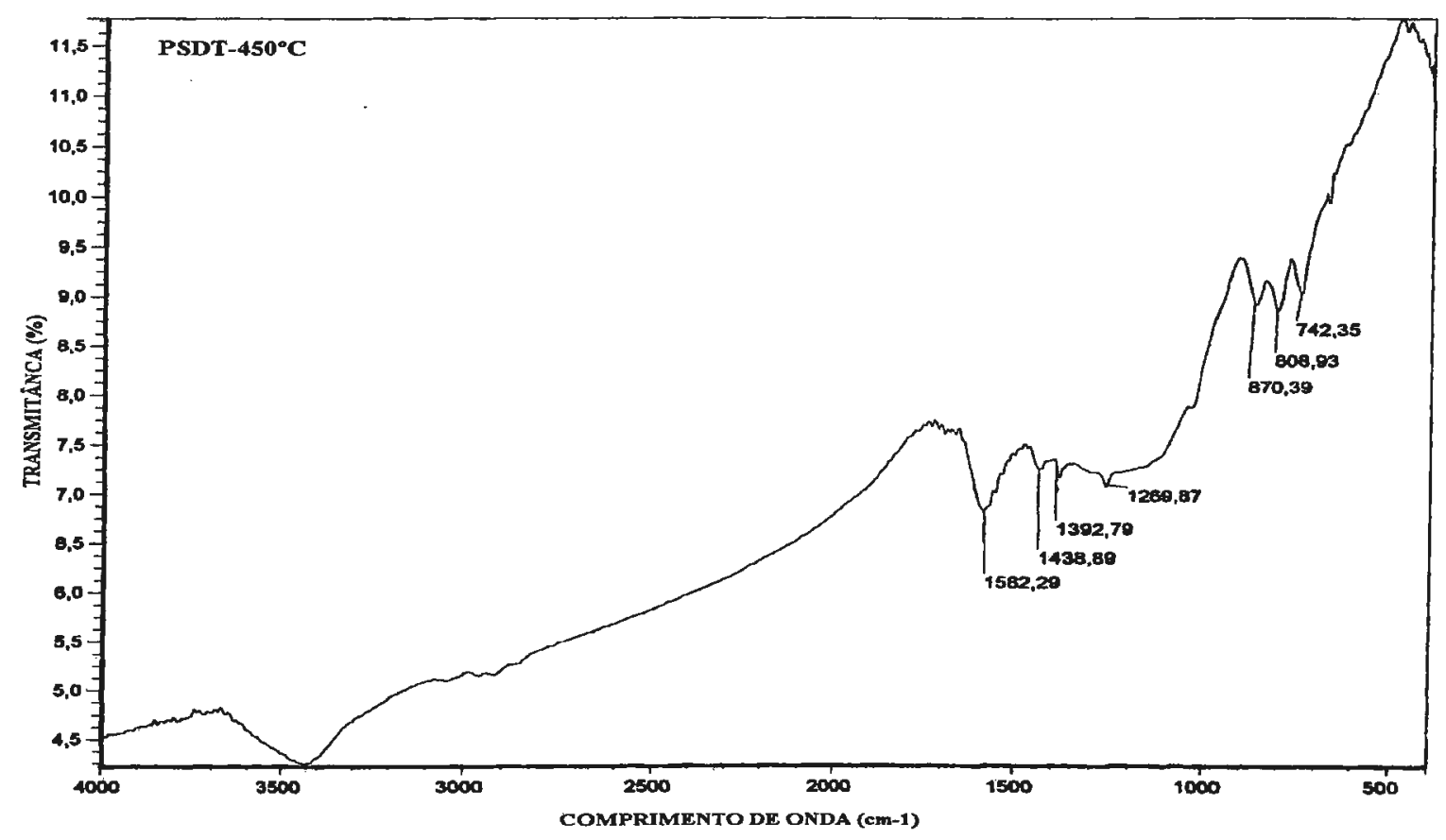

Figura A 13 - Espectro de absorção no infravermelho do PSDT $-450^{\circ} \mathrm{C}$

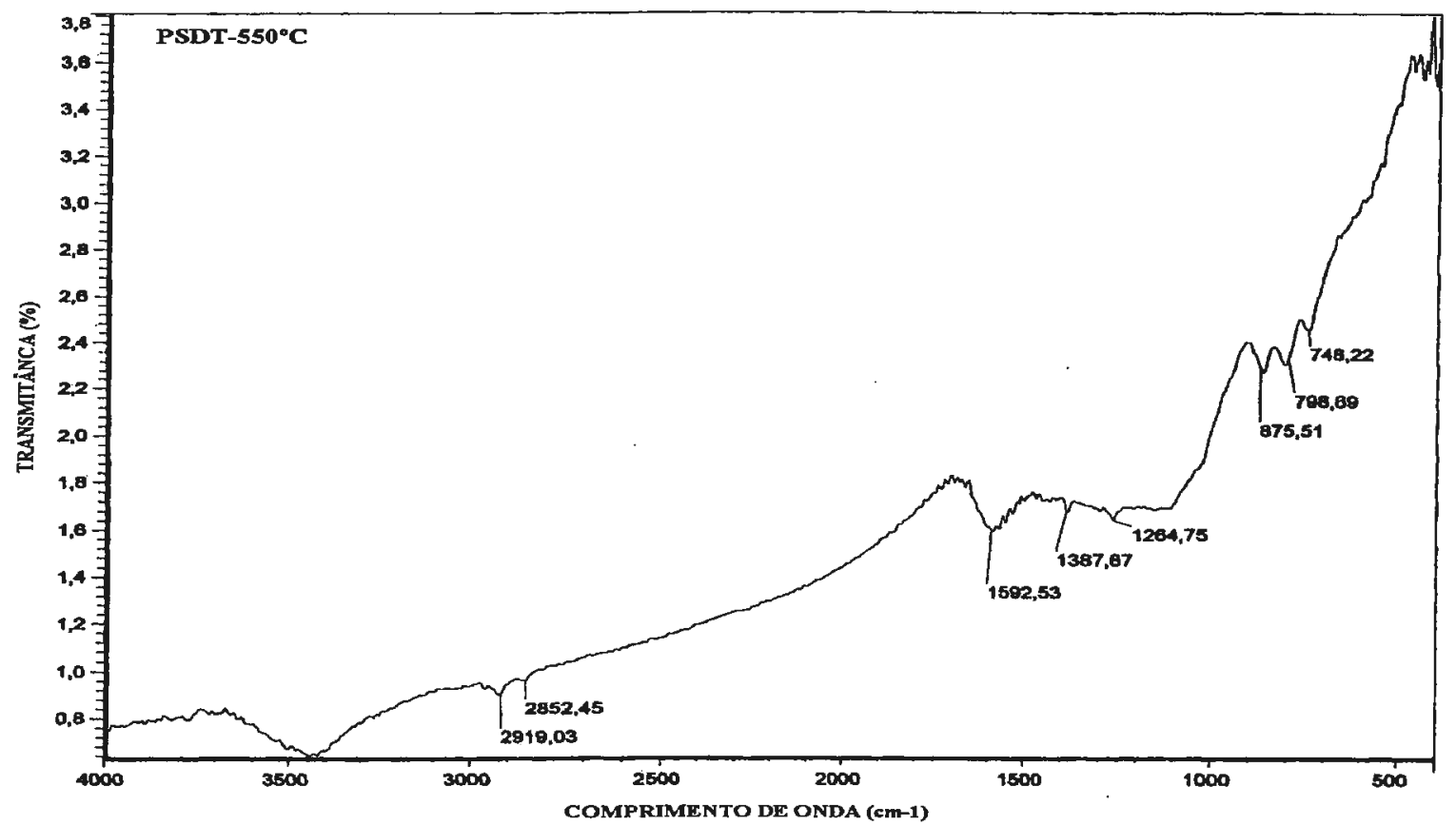

Figura A 14 - Espectro de absorção no infravermelho do PSDT-550 ${ }^{\circ} \mathrm{C}$ 
Anexo 4 - Espectros de $\mathrm{RMN}^{13} \mathrm{C}$ no estado sólido dos asfaltenos e seus produtos sólidos de decomposição térmica gerados no forno tubular PSDT $-320^{\circ} \mathrm{C}, \mathrm{PSDT}-380^{\circ} \mathrm{C}$, PSDT $-450^{\circ} \mathrm{C}$ e PSDT$550^{\circ} \mathrm{C}$ 


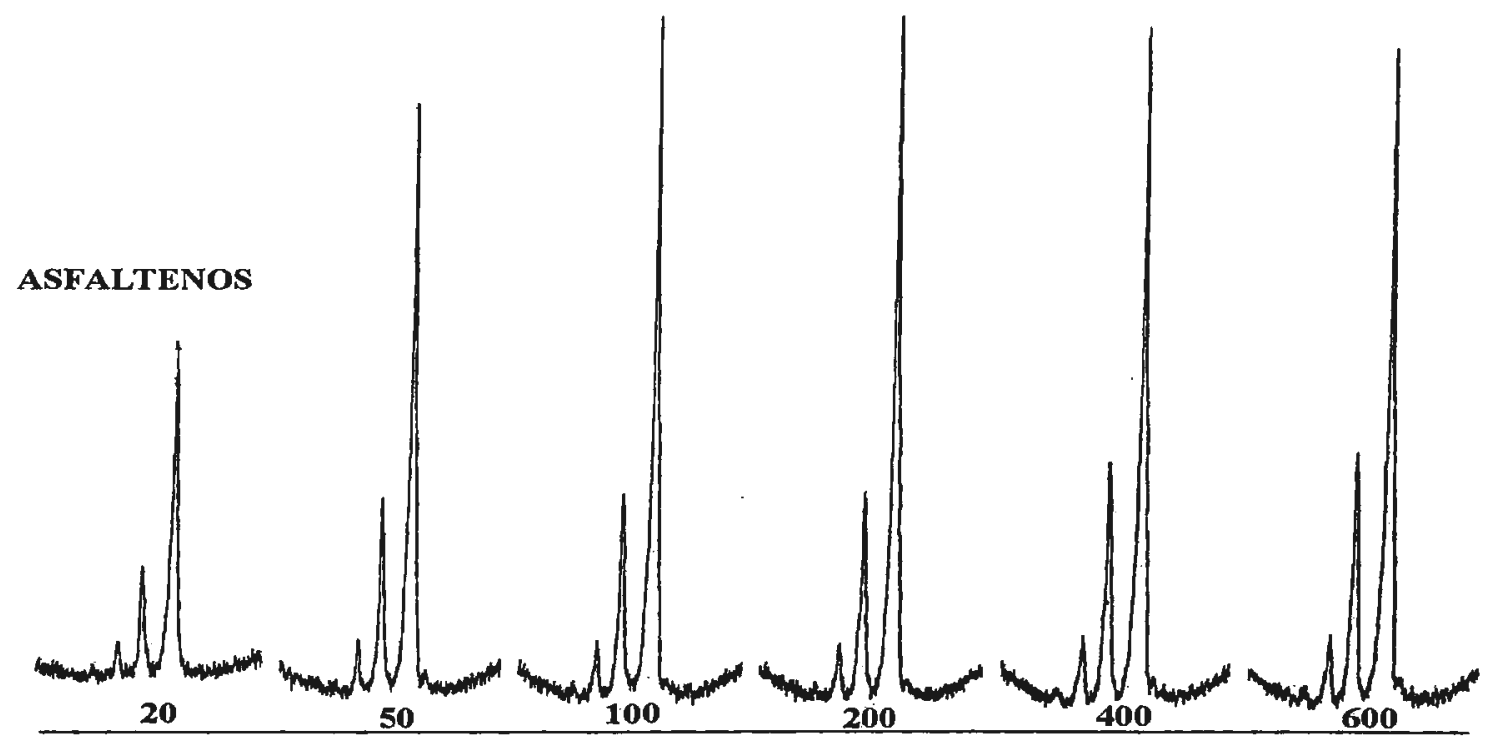

Figura A 15 - Espectro de $\mathrm{RMN}^{13} \mathrm{C}$-CP/MAS com varredura do tempo de contato dos asfaltenos

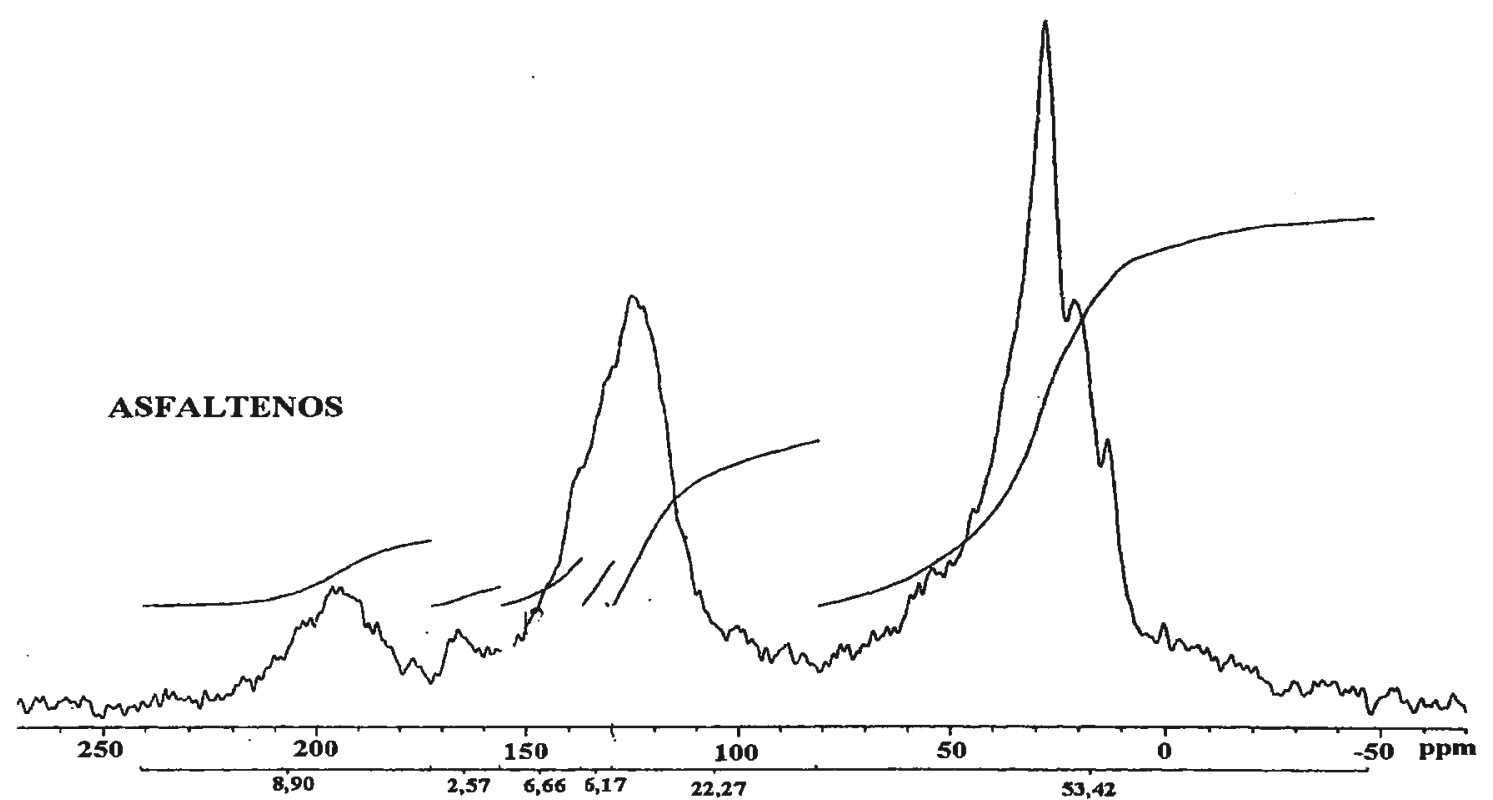

Figura A 16 - Espectro de $\mathrm{RMN}^{13} \mathrm{C}$-MAS dos asfaltenos 


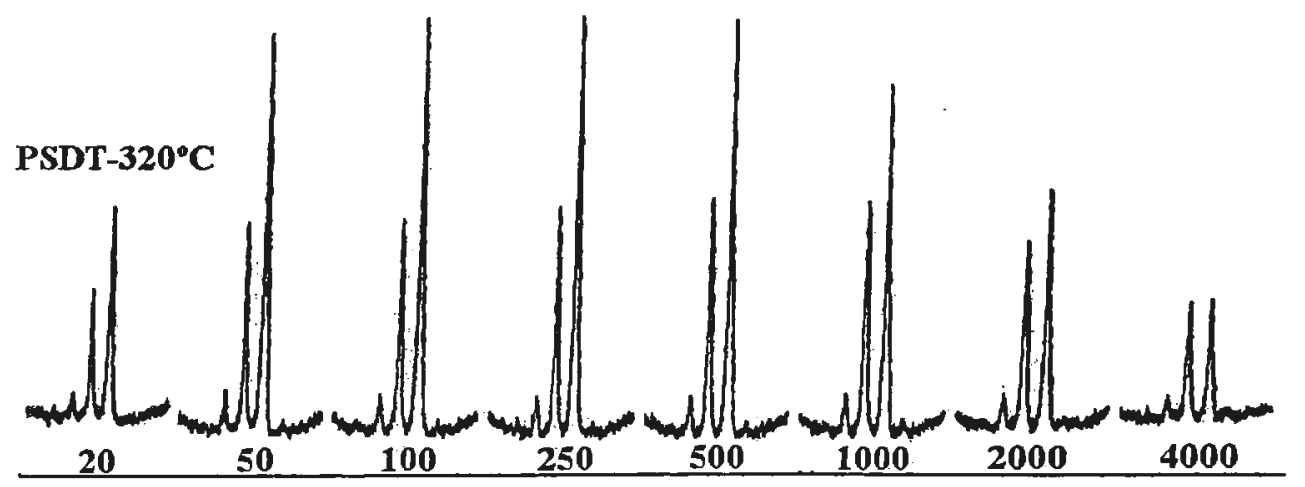

Figura A 17 - Espectro de $\mathrm{RMN}^{13} \mathrm{C}$-CP/MAS com varredura do tempo de contato do PSDT $-320^{\circ} \mathrm{C}$

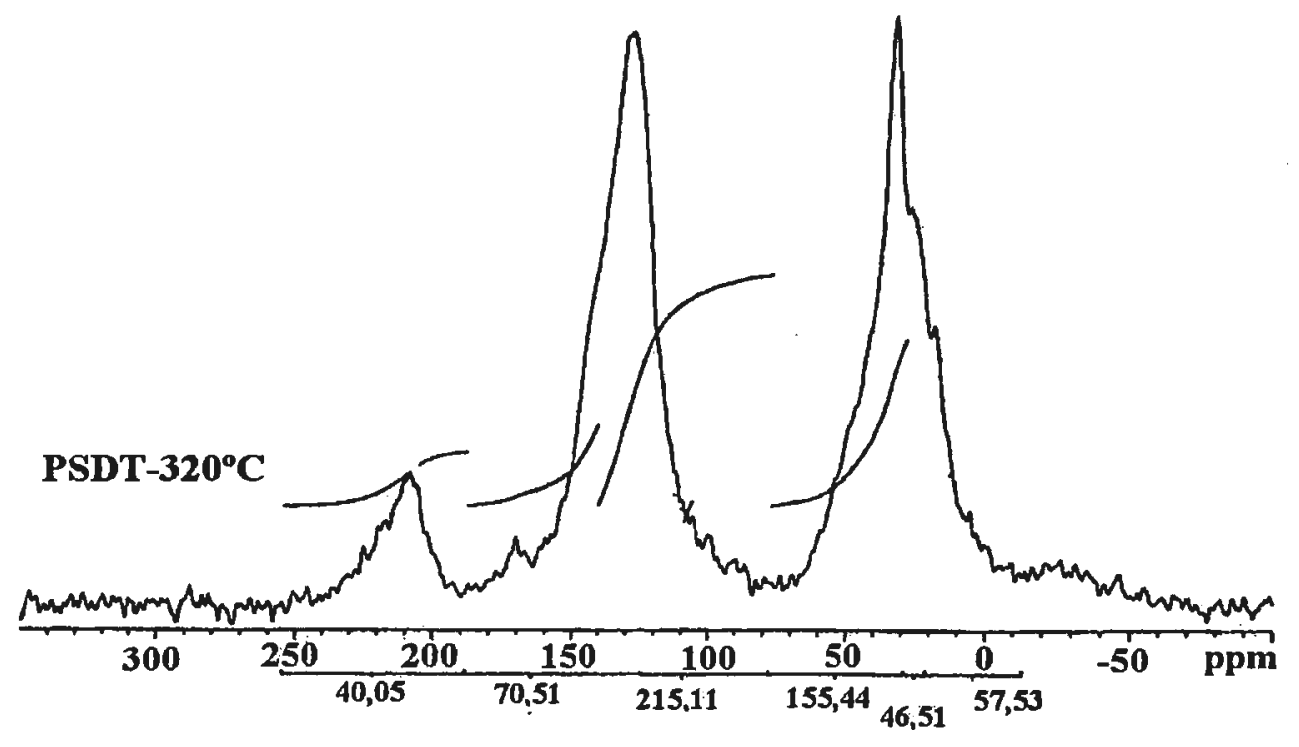

Figura A 18 - Espectro de RMN $^{13} \mathrm{C}$-MAS do PSDT $-320^{\circ} \mathrm{C}$ 


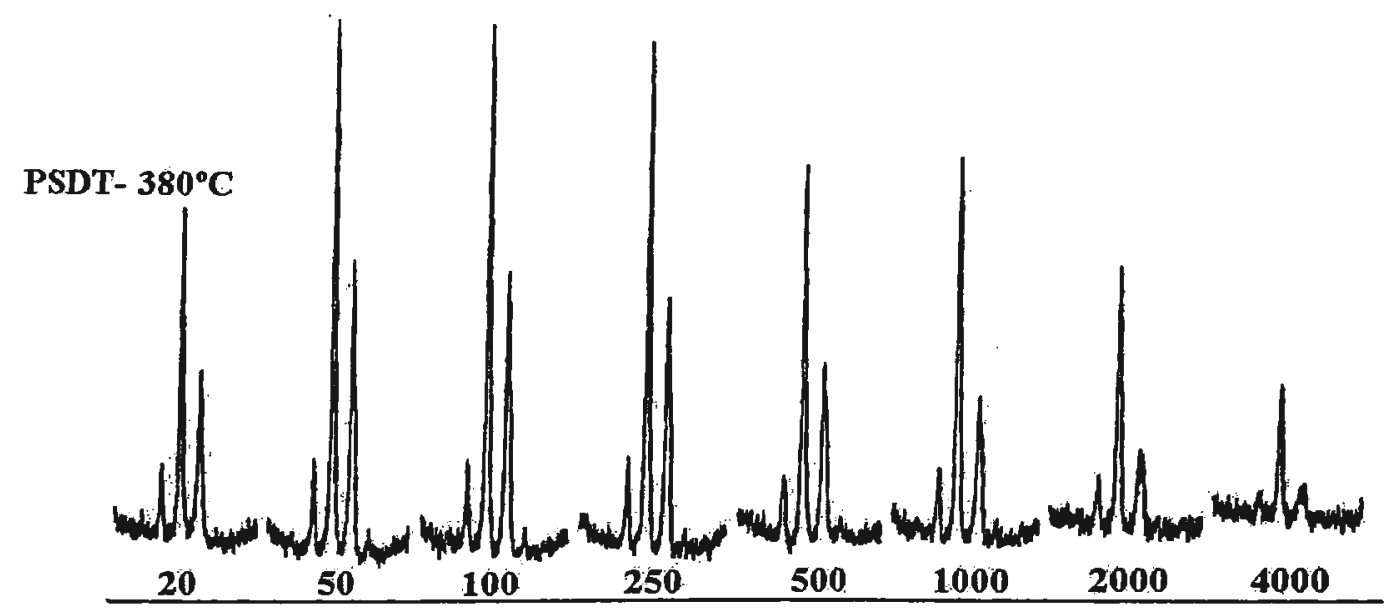

Figura A 19 - Espectro de RMN ${ }^{13} \mathrm{C}$-CPIMAS com varredura do tempo de contato do PSDT $-380^{\circ} \mathrm{C}$

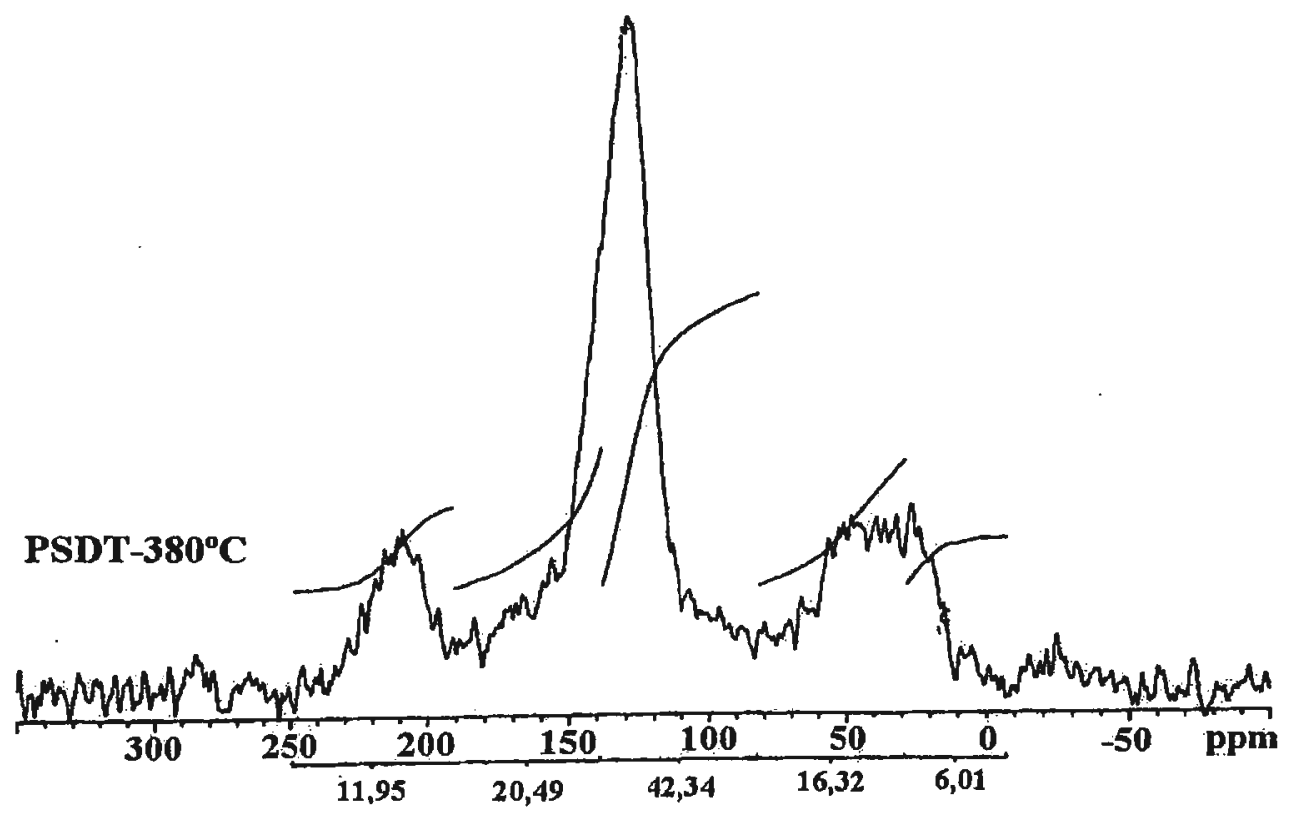

Figura A 20 - Espectro de $\mathrm{RMN}^{13} \mathrm{C}$-MAS do PSDT- $380^{\circ} \mathrm{C}$ 
129

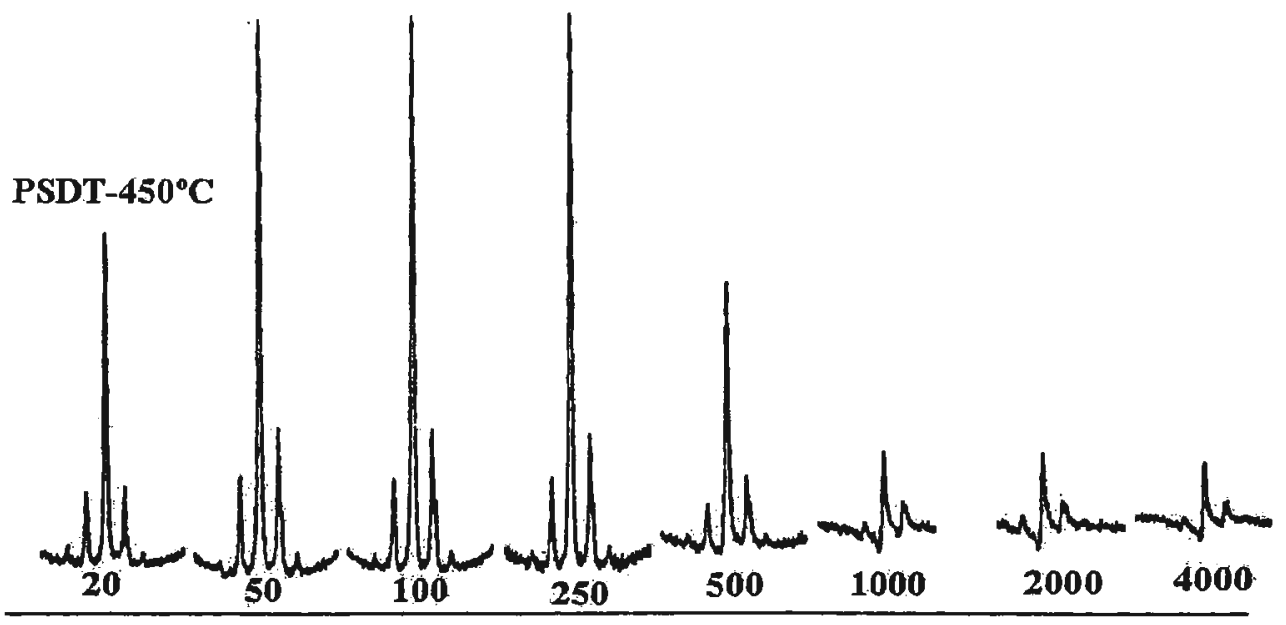

Figura A 21 - Espectro de $\mathrm{RMN}^{13} \mathrm{C}$-CP/MAS com varredura do tempo de contato do PSDT $-450^{\circ} \mathrm{C}$

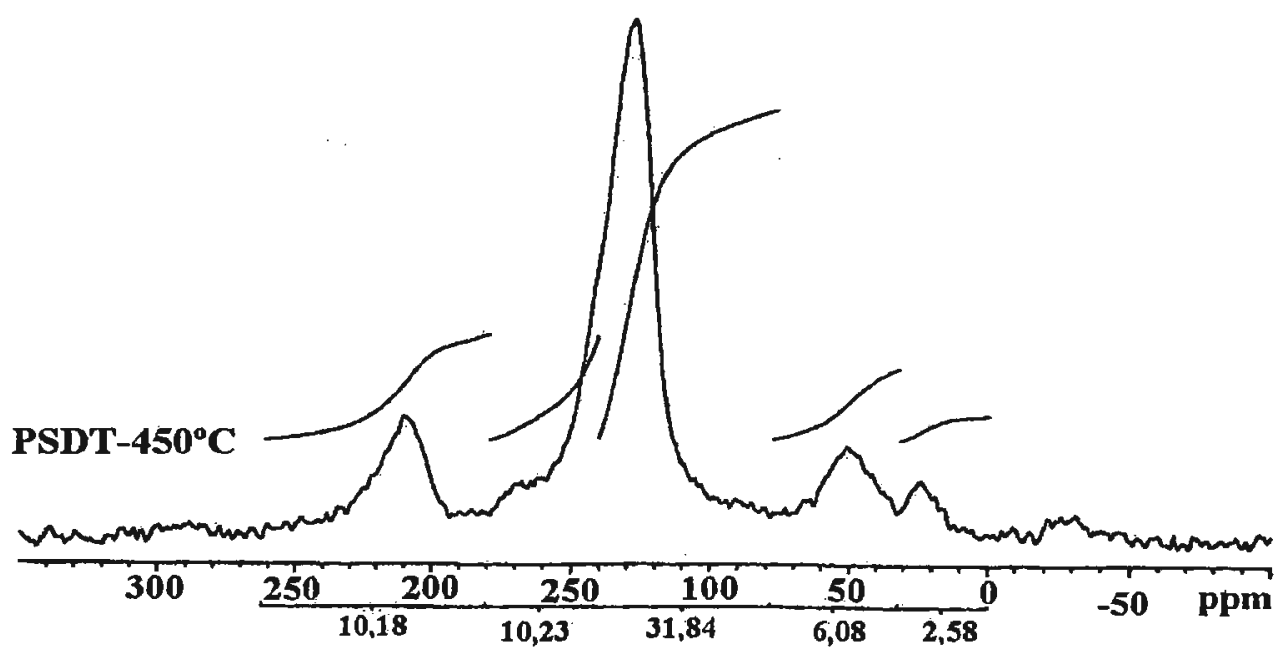

Figura A 22 - Espectro de $R M N^{13} \mathrm{C}-M A S$ do PSDT $-450^{\circ} \mathrm{C}$ 
130

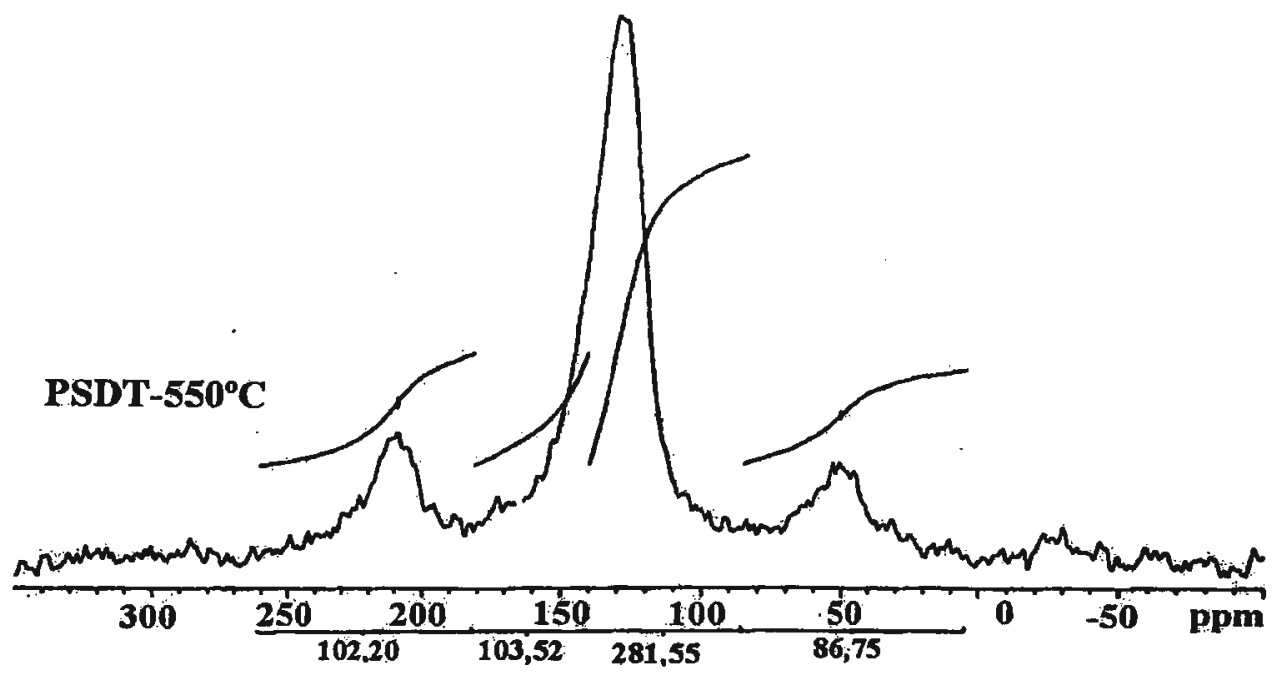

Figura A 23 - Espectro de $\operatorname{RMN}^{13} \mathrm{C}$-MAS do PSDT-550 ${ }^{\circ} \mathrm{C}$ 
Anexo 5 - Espectros de absorção no IV dos ácidos gerados na reação $\mathrm{RICO}$ com os asfaltenos, PSDT- $320^{\circ} \mathrm{C}$, PSDT $-380^{\circ} \mathrm{C}$, PSDT$450^{\circ} \mathrm{C}$ e PSDT $-550^{\circ} \mathrm{C}$ 

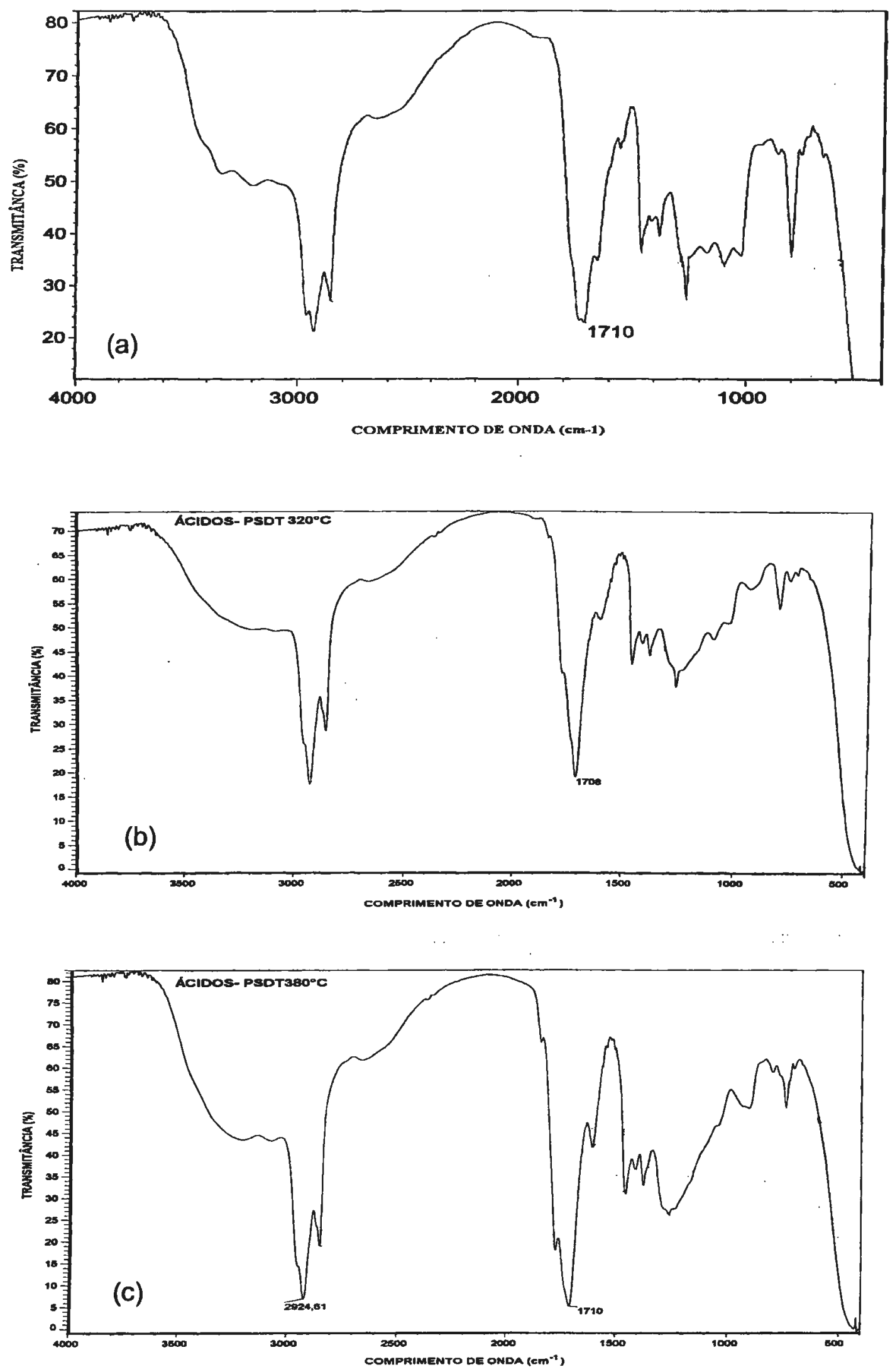

Figura A 24 - Espectros de absorção no IV dos ácidos gerados na reação RICO com: a) asfaltenos; b) PSDT $-320^{\circ} \mathrm{C}$; e c) PSDT $-380^{\circ} \mathrm{C}$ 

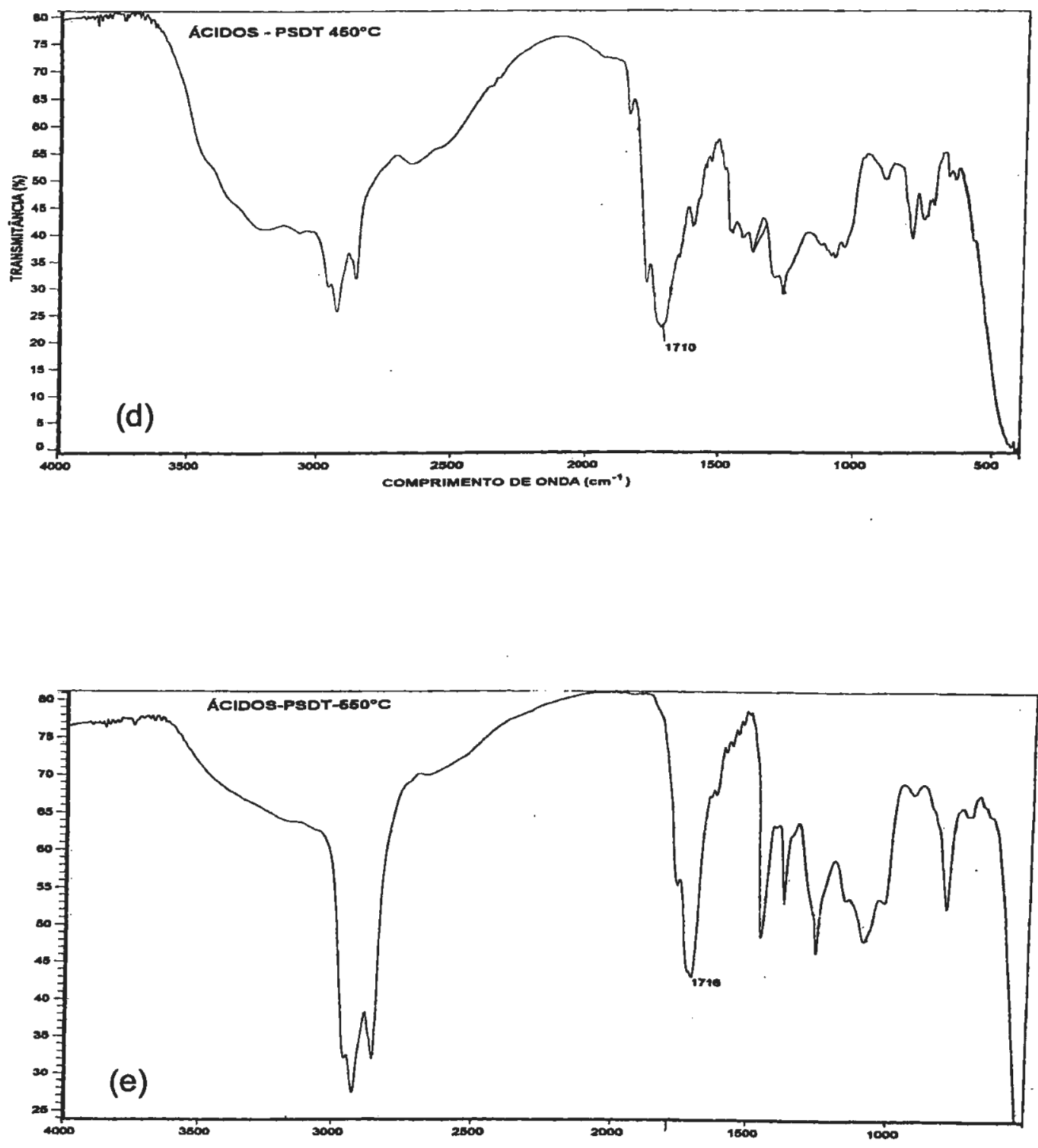

Figura A 25 - Espectros de absorção no IV dos ácidos gerados na reação RICO com: d) PSDT $-450^{\circ} \mathrm{C}$; e e) PSDT $-550^{\circ} \mathrm{C}$ 
Anexo 6 - Espectros de absorção no IV dos ésteres metílicos dos ácidos gerados na reação RICO com os asfaltenos e seus produtos sólidos de decomposição térmica no forno tubular: PSDT $-320^{\circ} \mathrm{C}, \mathrm{PSDT}-380^{\circ} \mathrm{C}$, PSDT $-450^{\circ} \mathrm{C}$ e PSDT $-550^{\circ} \mathrm{C}$ 

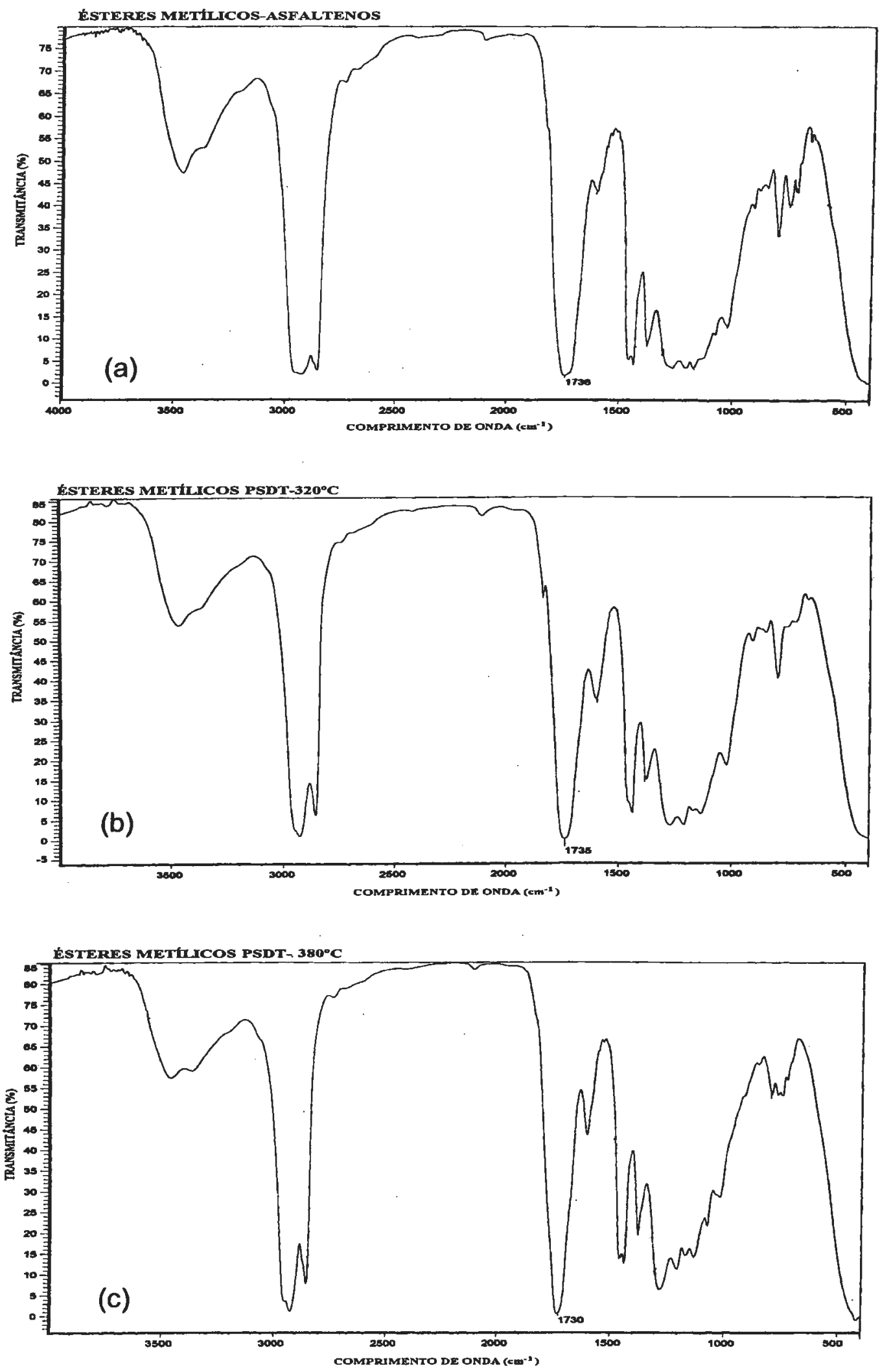

Figura A 26 - Espectros de absorção no IV dos ésteres metílicos dos ácidos gerados na reação RICO com: a) asfaltenos; b) PSDT $-320^{\circ} \mathrm{C}$; e C) PSDT $-380^{\circ} \mathrm{C}$ 

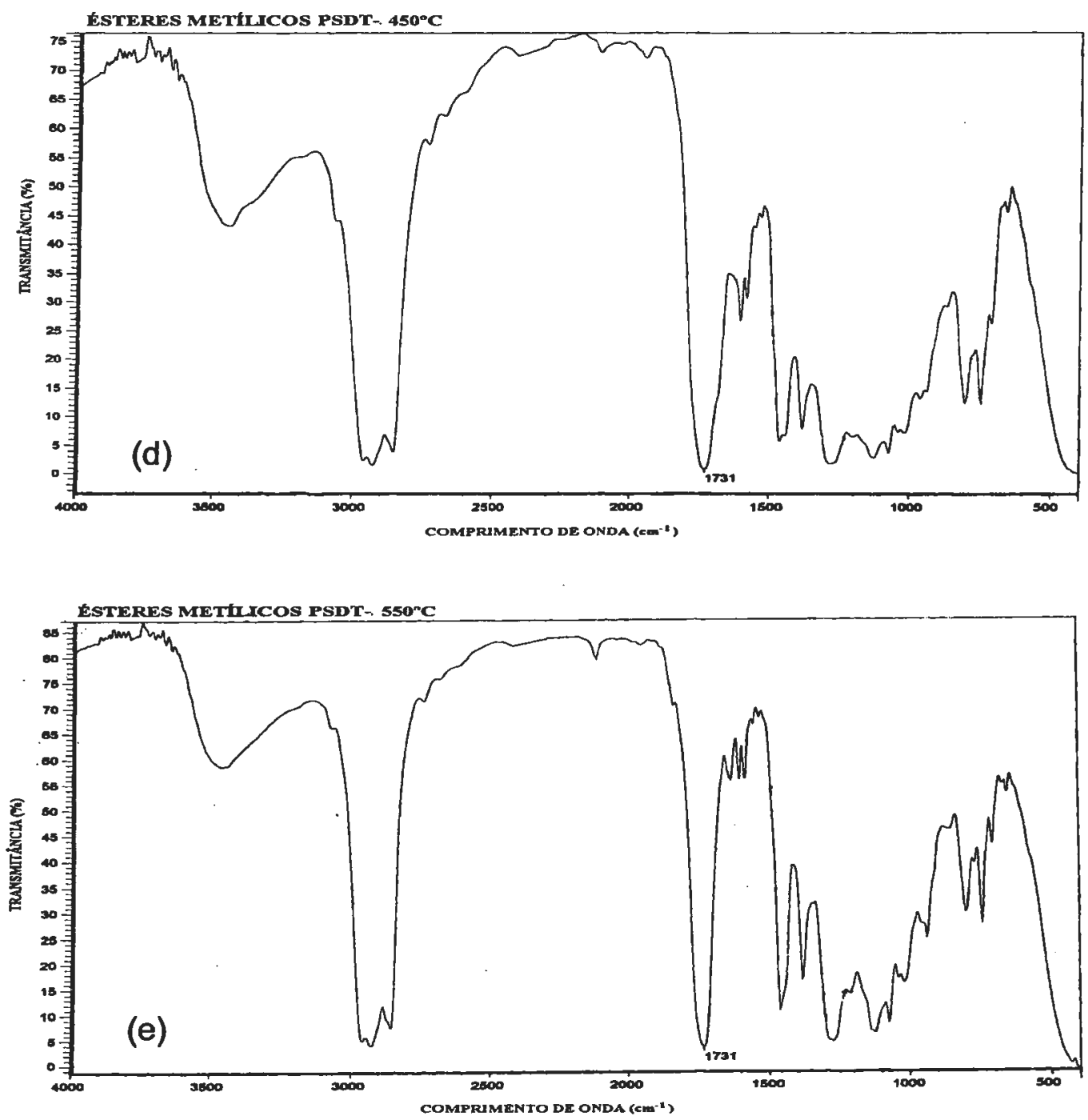

Figura A 27 - Espectros de absorção no IV dos ésteres metílicos dos ácidos gerados na reação RICO com: d) PSDT $-450^{\circ} \mathrm{C}$; e e) PSDT $-550^{\circ} \mathrm{C}$ 
Anexo 7 - Cromatogramas totais de íons da mistura de ésteres metílicos dos ácidos gerados na reação RICO com os asfaltenos e seus produtos sólidos de decomposição térmica obtidos no forno tubular: PSDT $-320^{\circ} \mathrm{C}$, PSDT $-380^{\circ} \mathrm{C}$, PSDT $-450^{\circ} \mathrm{C}$ e PSDT$550^{\circ} \mathrm{C}$ 
$\stackrel{\infty}{\stackrel{0}{0}}$

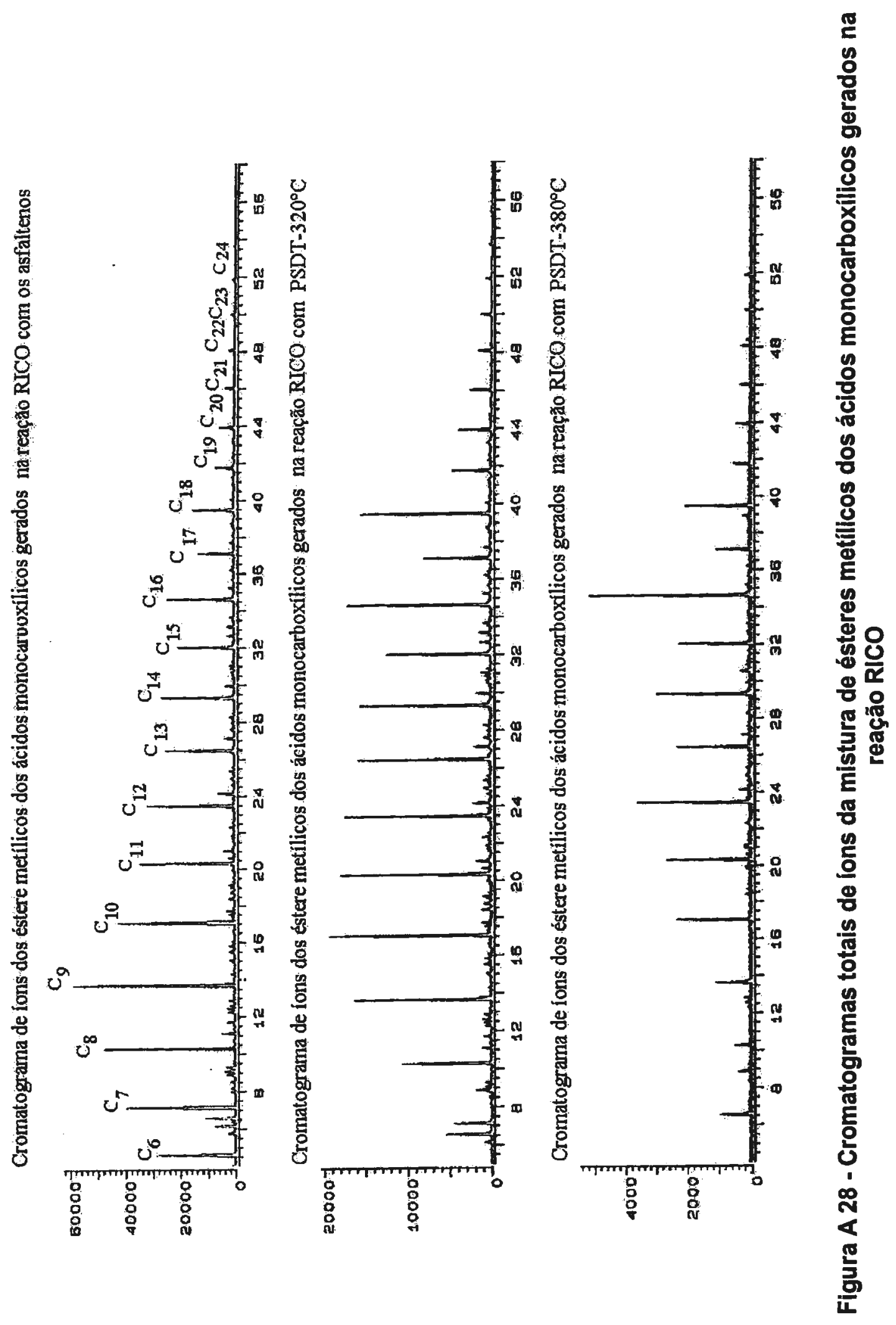


m

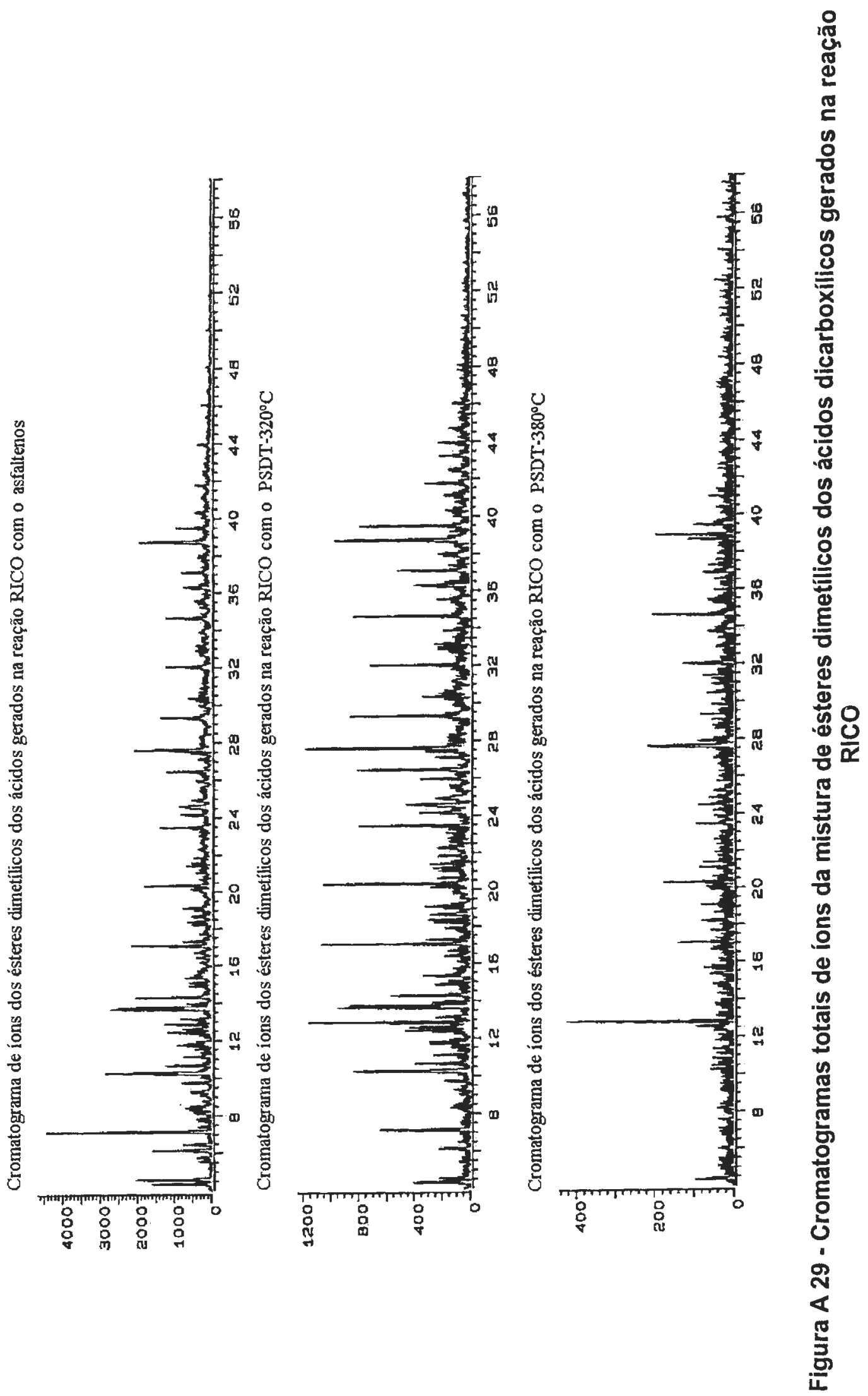


Anexo 8 - Curvas de controle da temperatura do forno do TGA-

951 na obtenção dos produtos sólidos da decomposição térmica dos asfaltenos: $\mathrm{PSDTa}-320^{\circ} \mathrm{C}, \mathrm{PSDTa}-380^{\circ} \mathrm{C}, \mathrm{PSDTa}-400^{\circ} \mathrm{C}$, PSDTa $-440^{\circ} \mathrm{C}, \mathrm{PSDTa}-480^{\circ} \mathrm{C}$, PSDTa $-550^{\circ} \mathrm{C}$ e PSDTa $-580^{\circ} \mathrm{C}$ 
$\bar{z}$
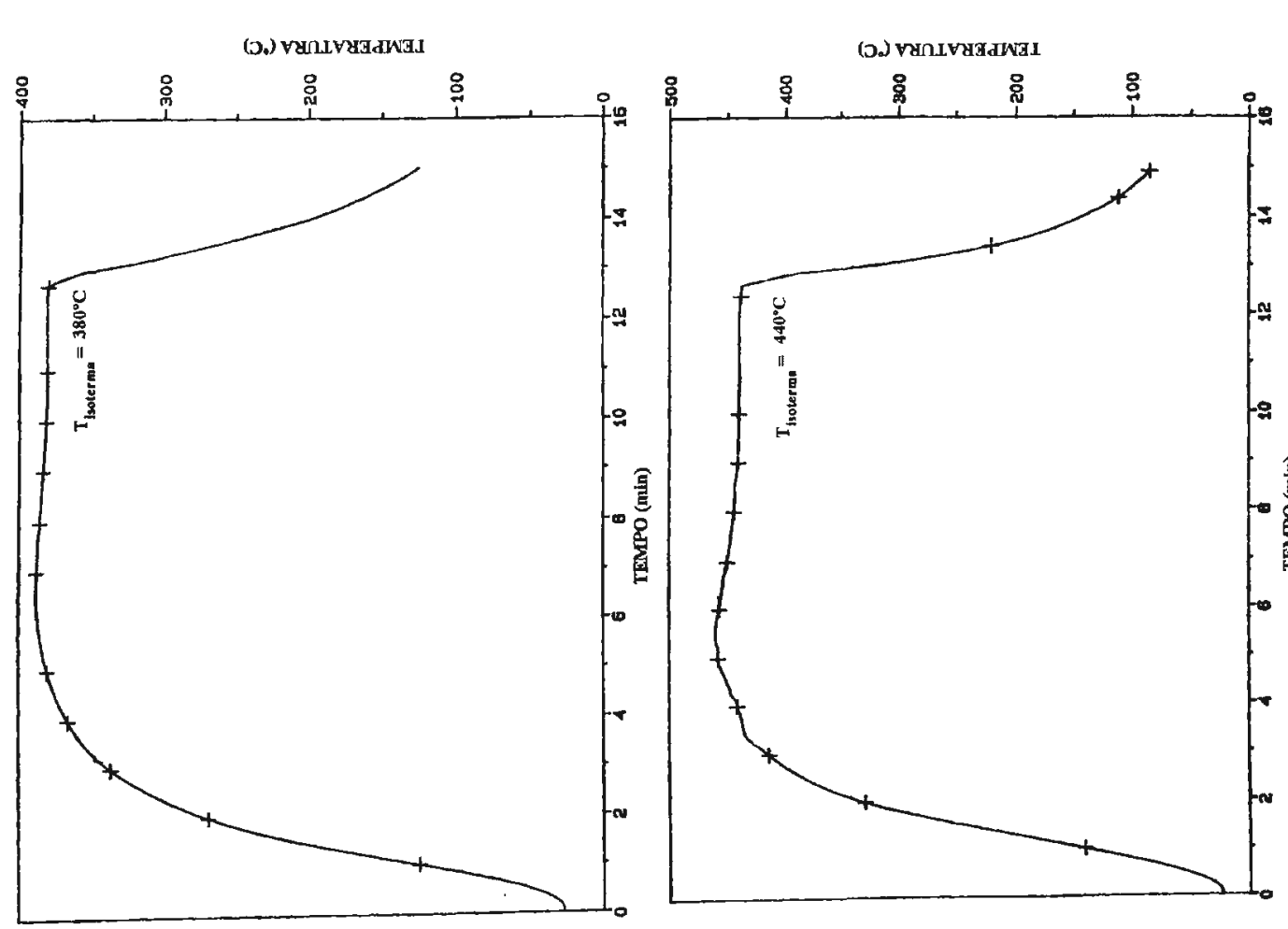

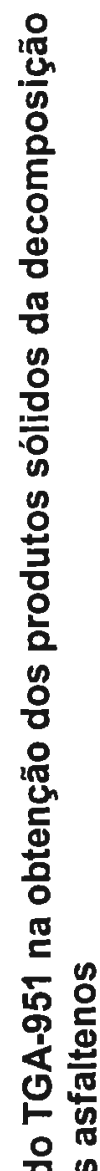

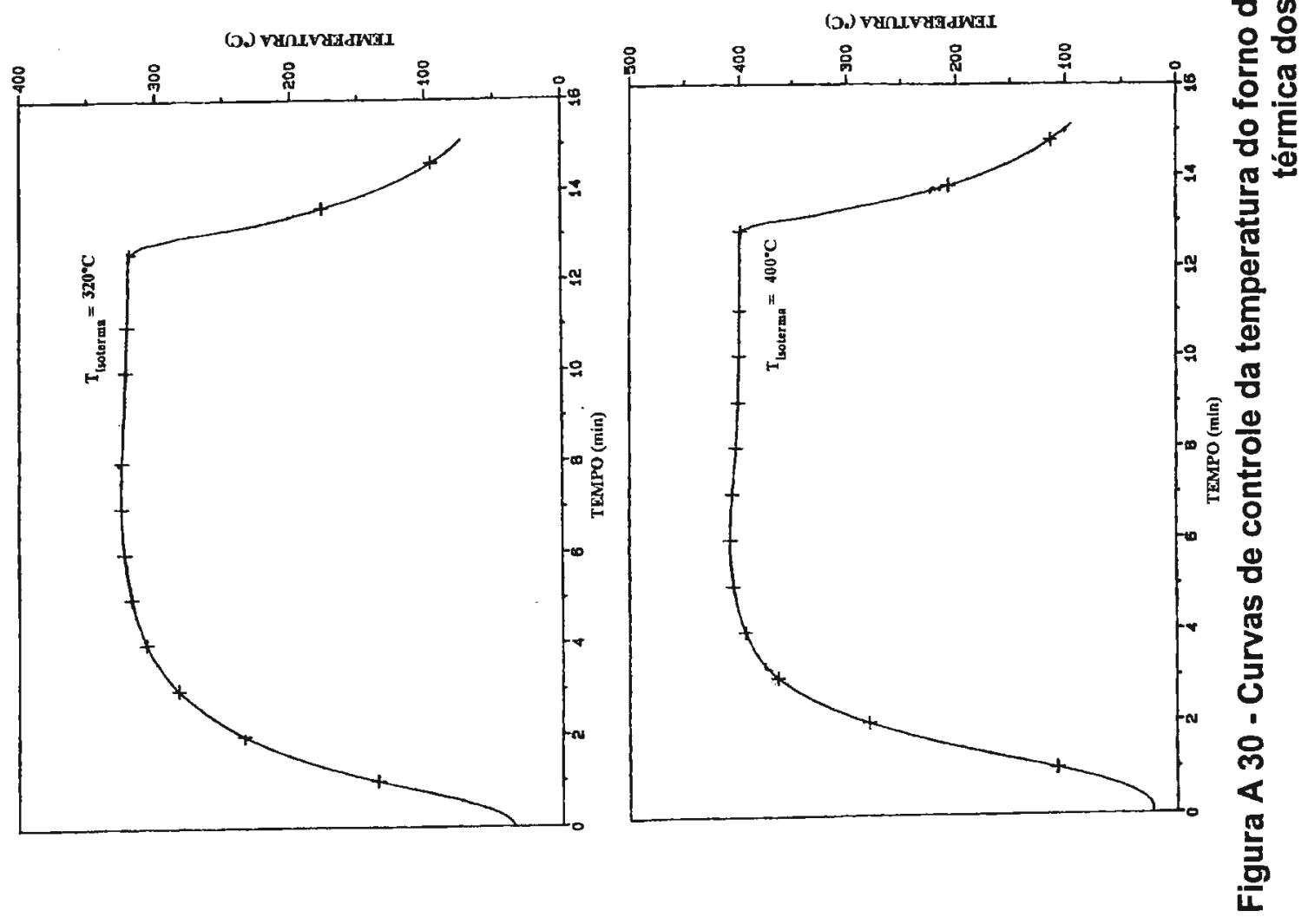



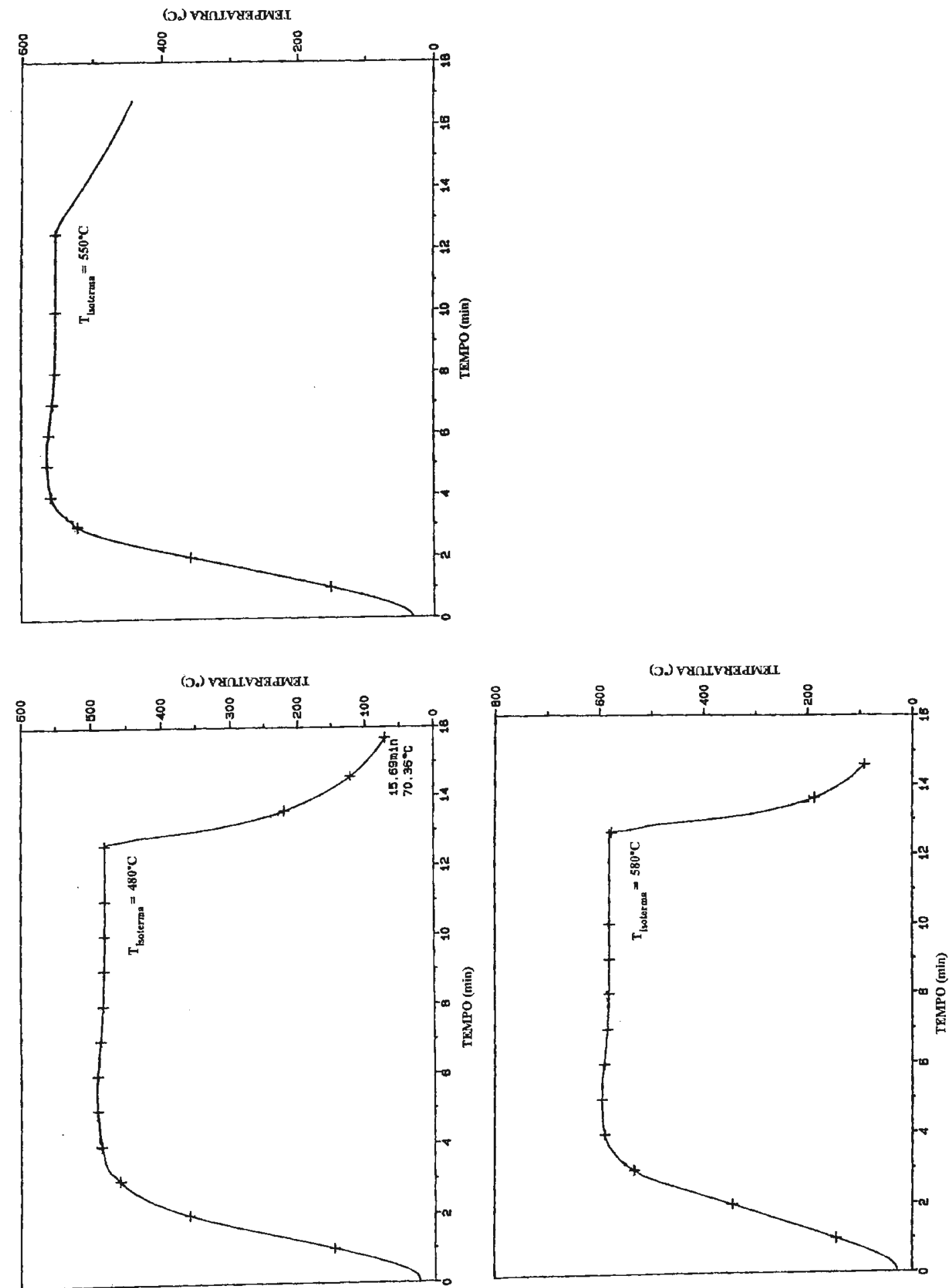

을 
Anexo 9 - Curvas de TG/DTG dos produtos sólidos gerados na decomposição térmica dos asfaltenos em forno do TGA-951: PSDTa $-320^{\circ} \mathrm{C}$, PSDTa $-380^{\circ} \mathrm{C}, \mathrm{PSDTa}-400^{\circ} \mathrm{C}$, PSDTa $-440^{\circ} \mathrm{C}$, PSDTa$480^{\circ} \mathrm{C}, \mathrm{PSDTa}-550^{\circ} \mathrm{C}$ e PSDTa $-580^{\circ} \mathrm{C}$ 


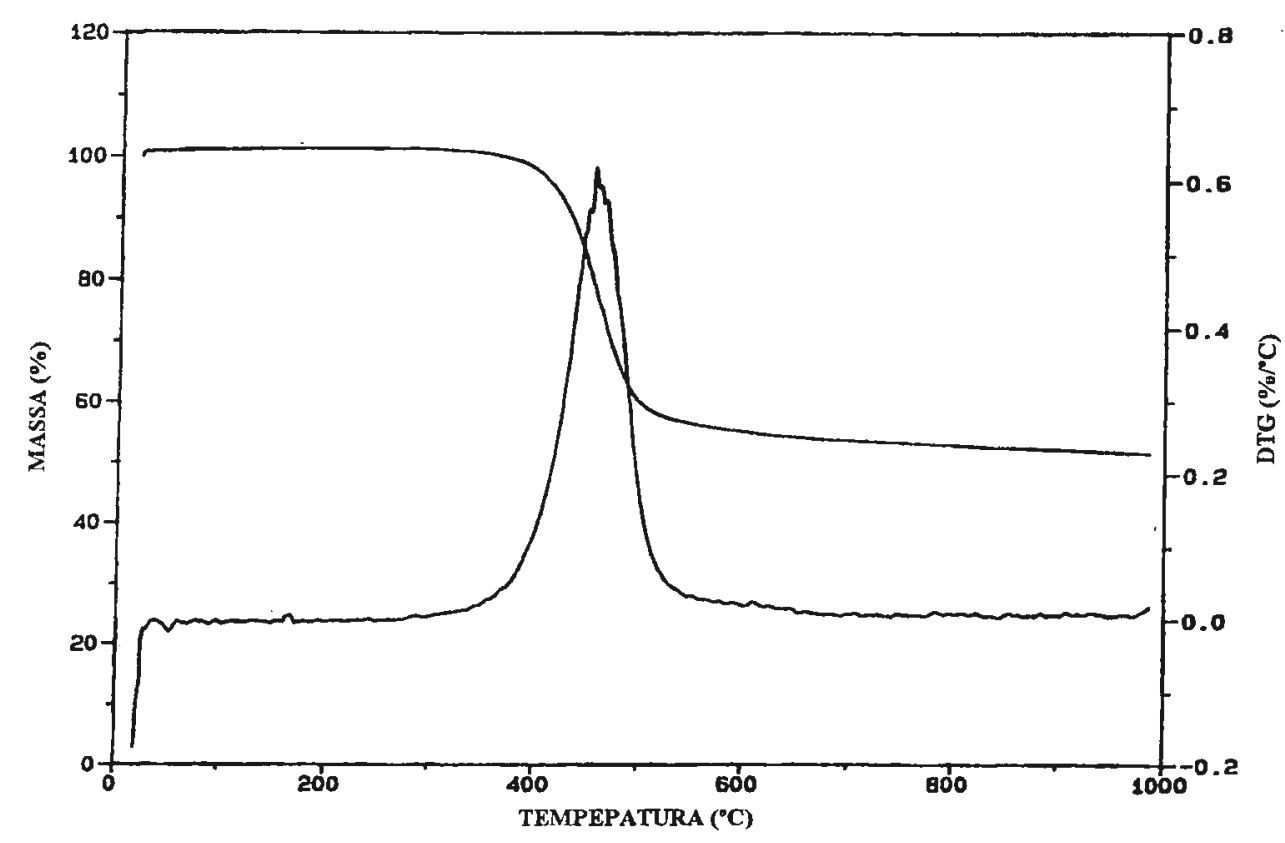

Figura A 32 - Curva de TG/DTG do PDST- $320^{\circ} \mathrm{C}$

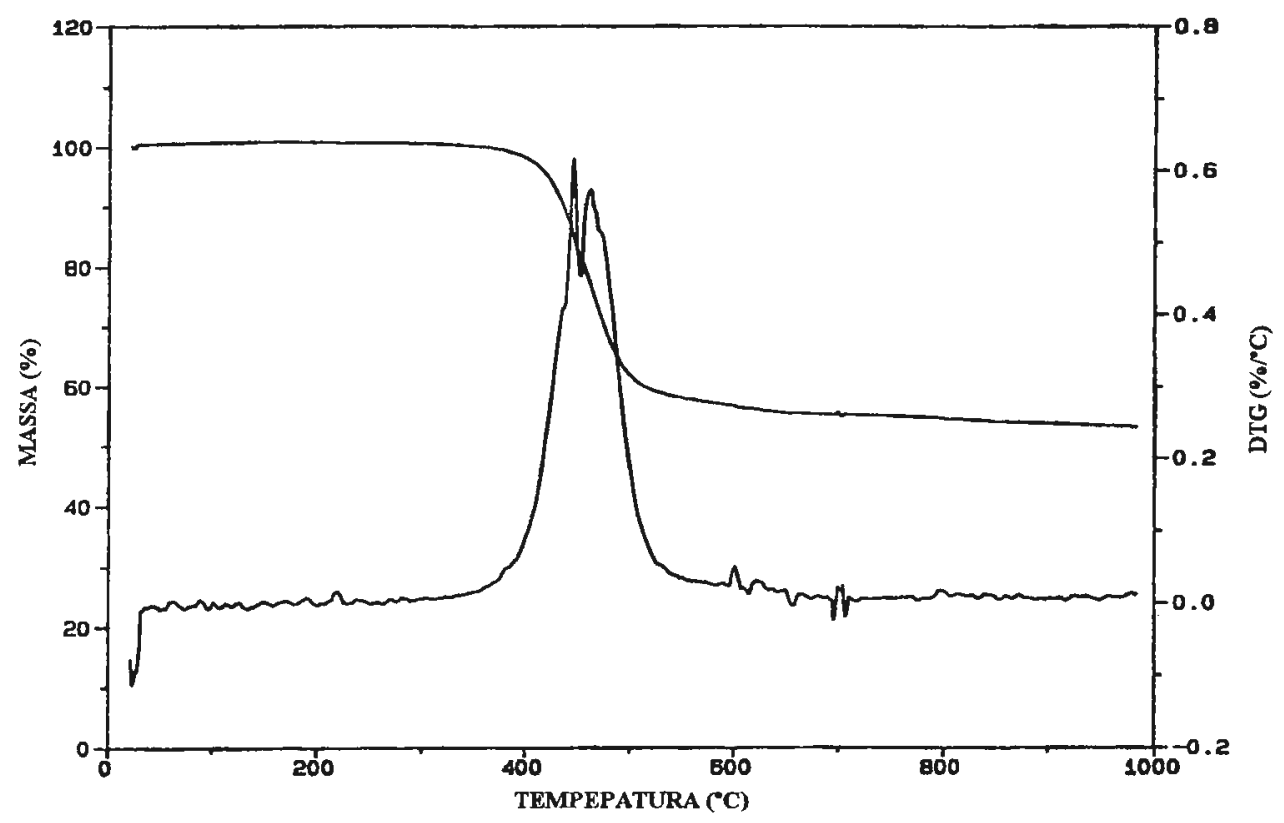

Figura A 33 - Curva de TG/DTG PSDT- $380^{\circ} \mathrm{C}$ 


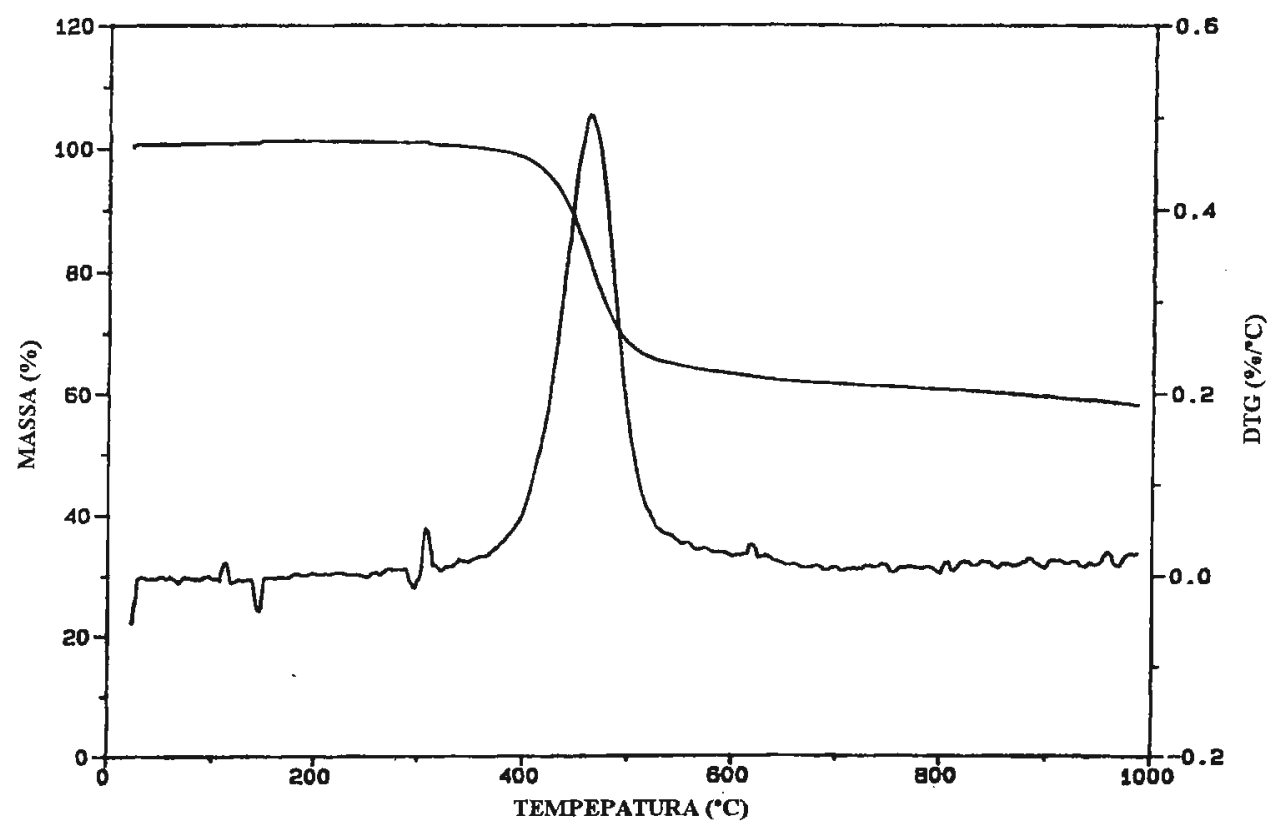

Figura A 34 - Curva de TG/DTG do PSDT $-400^{\circ} \mathrm{C}$

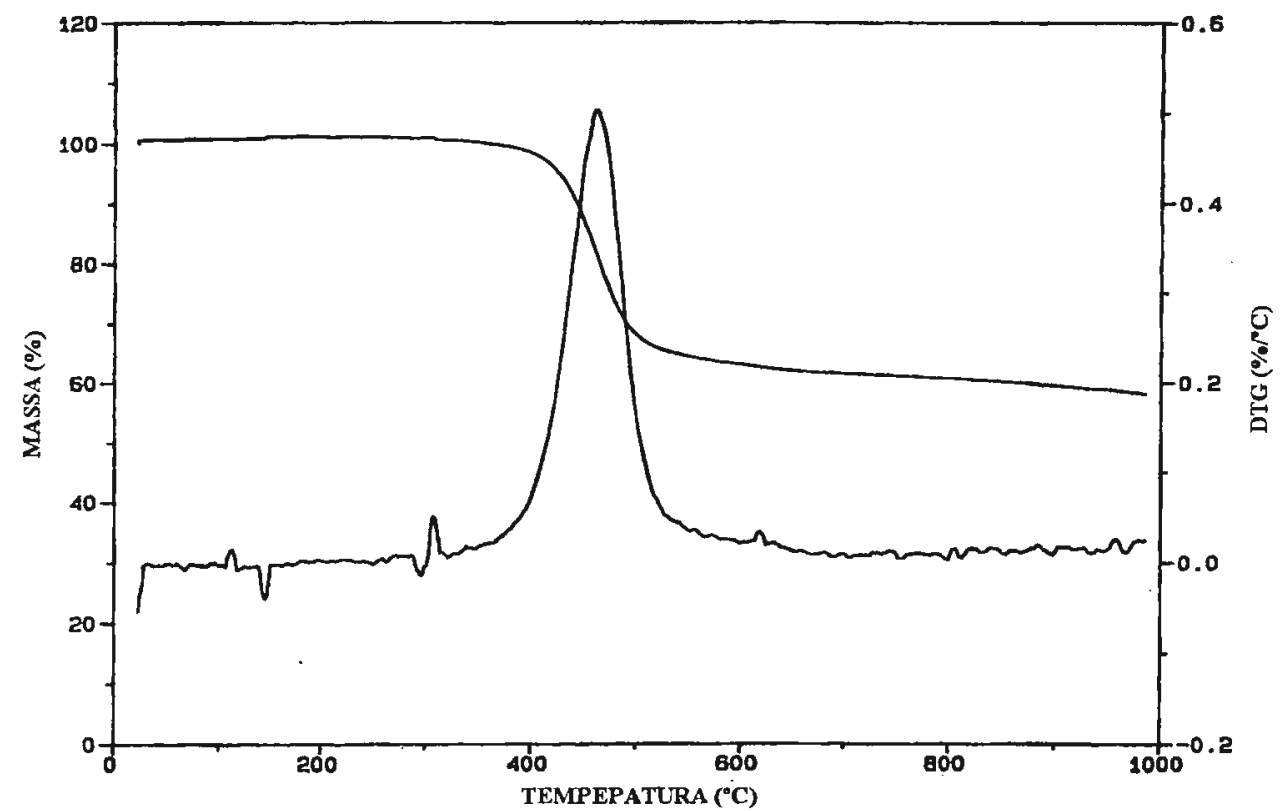

Figura A 35 - Curva de TG/DTG do PSDT $-440^{\circ} \mathrm{C}$ 


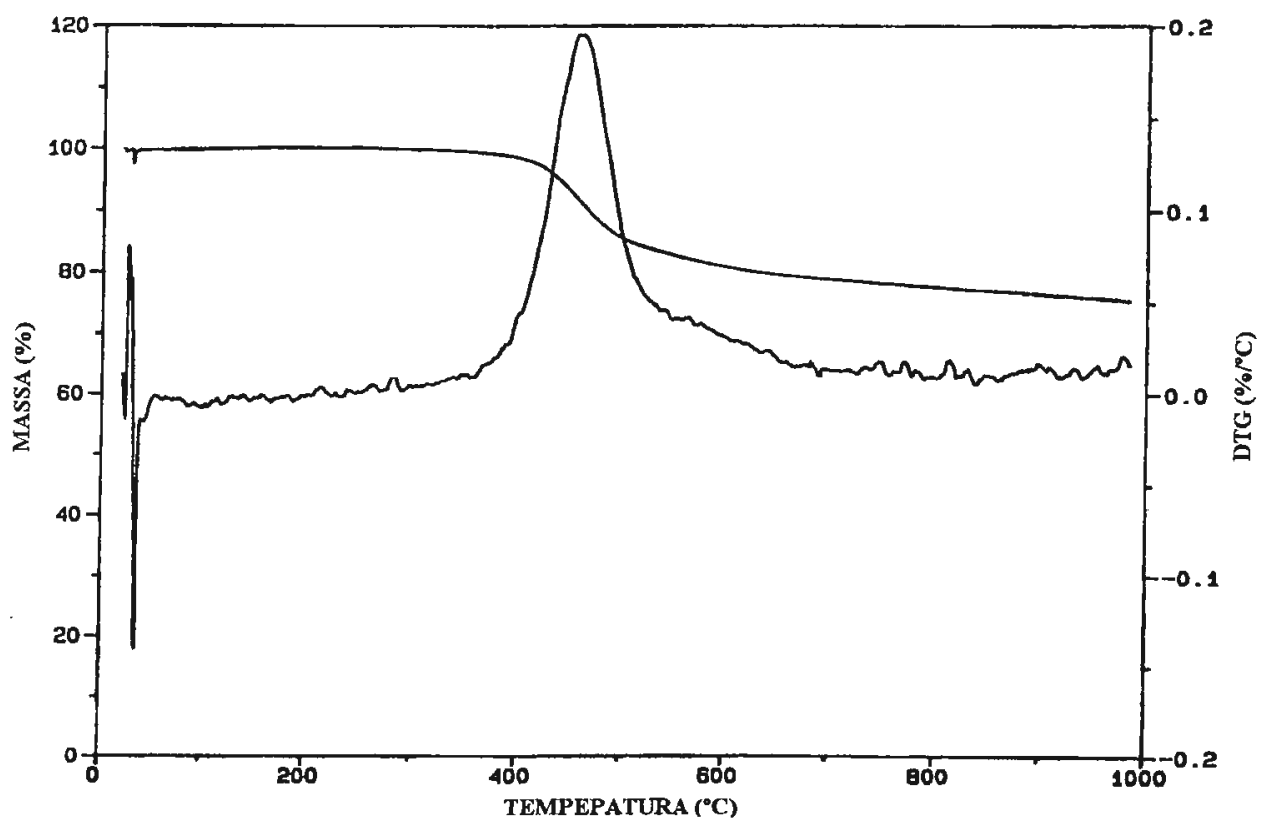

Figura A 36 - Curva de TG/DTG PSDT- $480^{\circ} \mathrm{C}$

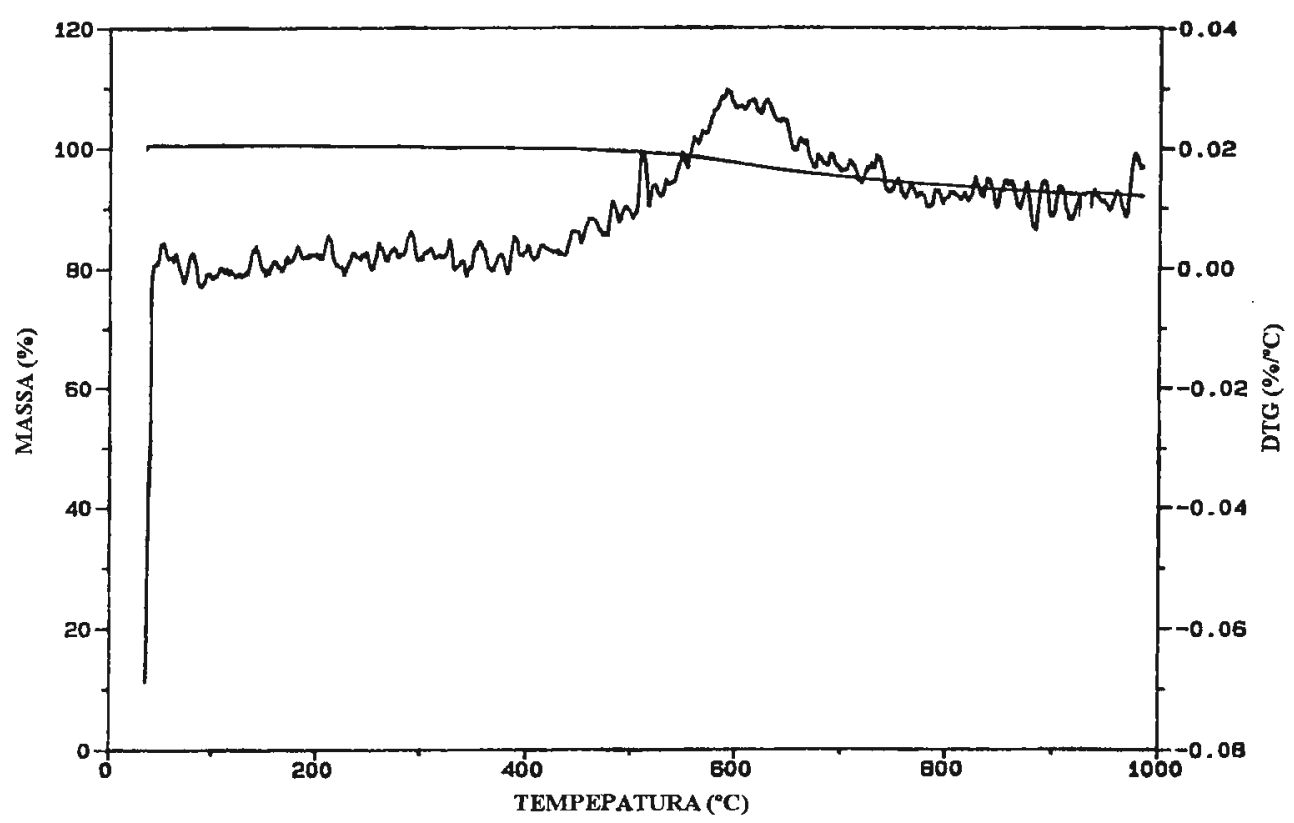

Figura A 37 - Curva de TG/DTG PSDT-550 ${ }^{\circ} \mathrm{C}$ 
Anexo 10 - Espectros de absorção no IV dos produtos sólidos gerados na decomposição térmica dos asfaltenos no forno do TGA-951: PSDTa- $320^{\circ} \mathrm{C}$, PSDTa- $380^{\circ} \mathrm{C}, \mathrm{PSDTa}-400^{\circ} \mathrm{C}, \mathrm{PSDTa}-$ $440^{\circ} \mathrm{C}, \mathrm{PSDTa}-480^{\circ} \mathrm{C}, \mathrm{PSDTa}-550^{\circ} \mathrm{C}$ e PSDTa-580 $\mathrm{C}$ 

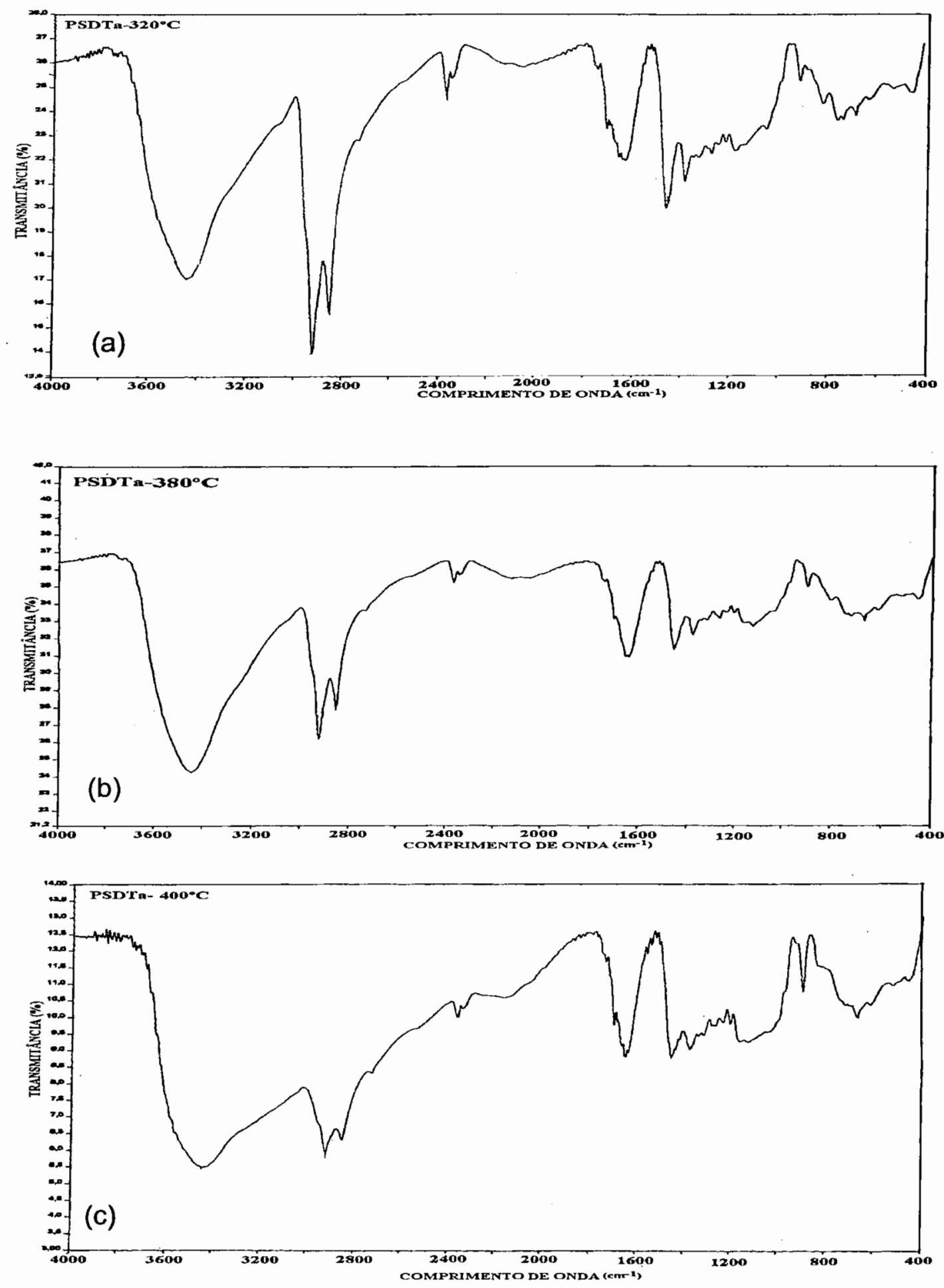

Figura A 38 - Espectros de absorção no IV dos PSDT gerados no forno do TGA-951: a) PSDTa-320 $\mathrm{C}$; b) PSDTa- $380^{\circ} \mathrm{C}$; e c) PSDTa- $400^{\circ} \mathrm{C}$ 

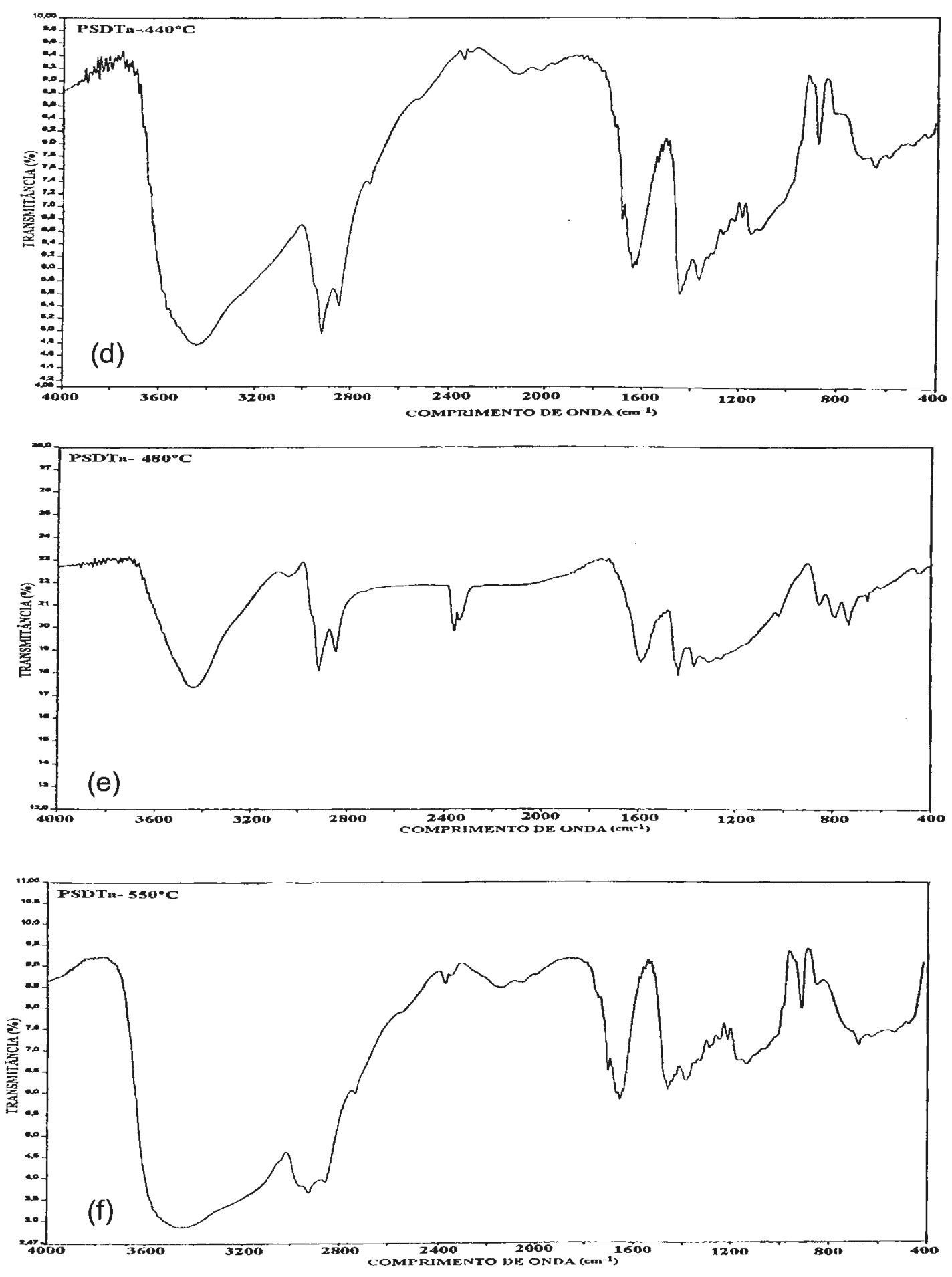

Figura A 39 - Espectros de absorção no IV dos PSDT gerados no forno do TGA-951: d) PSDTa- $440^{\circ} \mathrm{C}$; e) PSDTa- $480^{\circ} \mathrm{C}$; e f) PSDTa- $550^{\circ} \mathrm{C}$ 


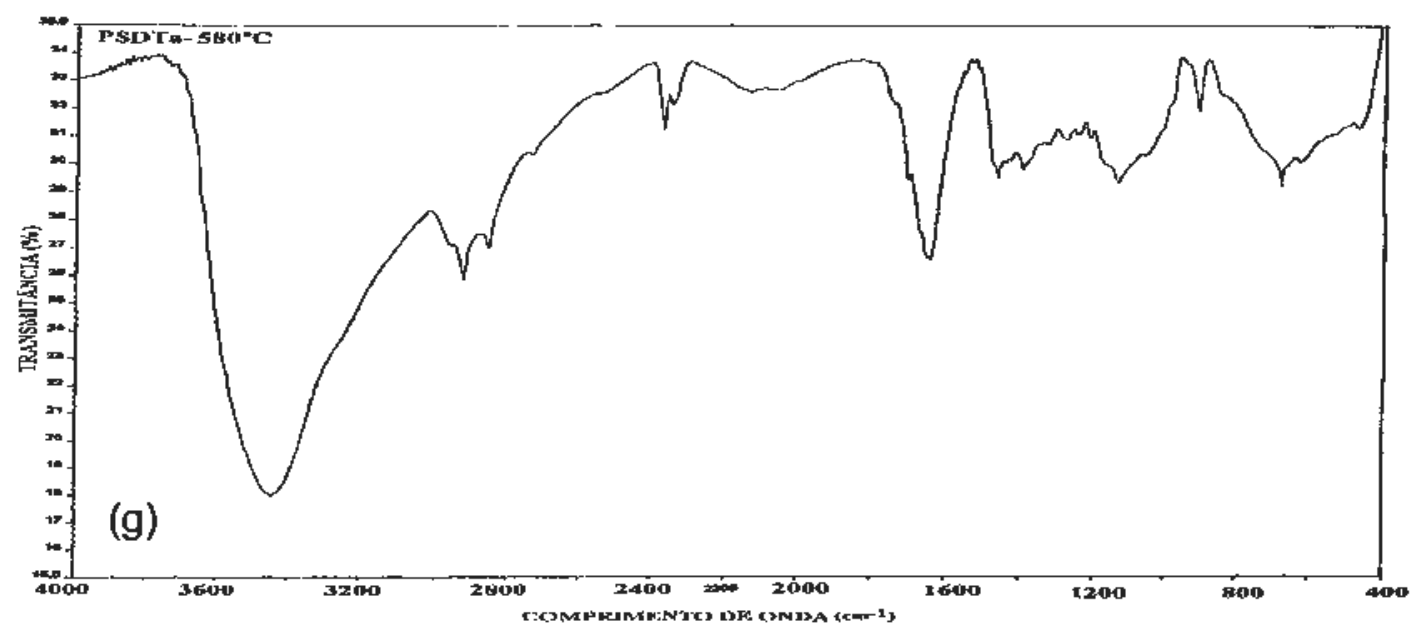

Figura A 40 - Espectros de absorçāo no IV dos PSDT gerados no forno do TGA-951: g) PSDTa-580 $\mathrm{C}$ 
Anexo 11 - Espectros de $\mathrm{RMN}^{13} \mathrm{C}$ dos produtos sólidos da decomposição térmica dos asfaltenos no TGA-951: PSDT-320 ${ }^{\circ} \mathrm{C}$, PSDT $-380^{\circ} \mathrm{C}, \mathrm{PSDT}-400^{\circ} \mathrm{C}, \mathrm{PSDT}-440^{\circ} \mathrm{C}, \mathrm{PSDT}-480^{\circ} \mathrm{C}, \mathrm{PSDT}-550^{\circ} \mathrm{C}$ e PSDT $-580^{\circ} \mathrm{C}$ 


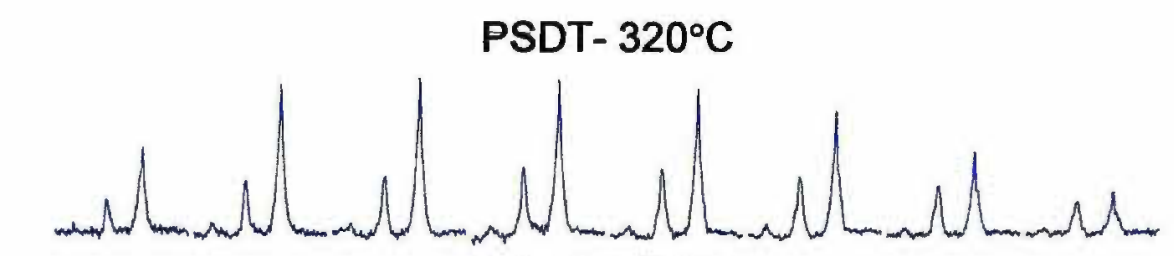

PSDT $=380^{\circ} \mathrm{C}$

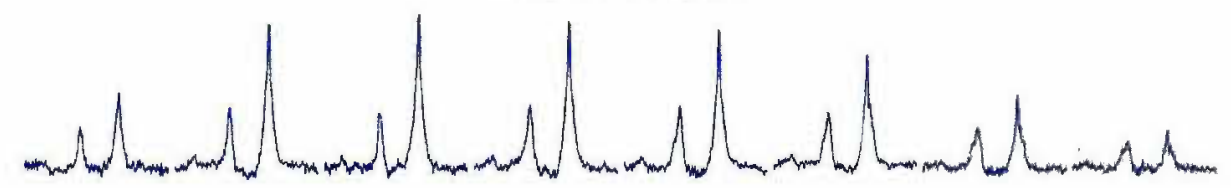

PSDT $-400^{\circ} \mathrm{C}$

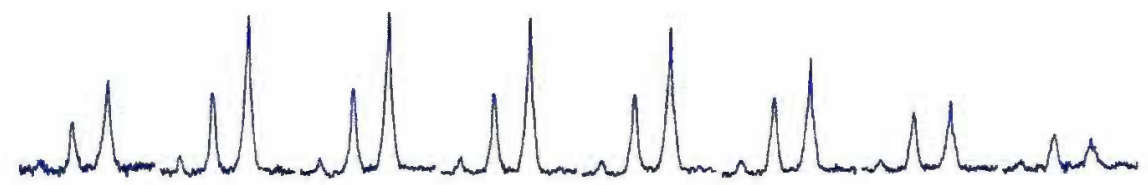

PSDTT- $440^{\circ} \mathrm{C}$

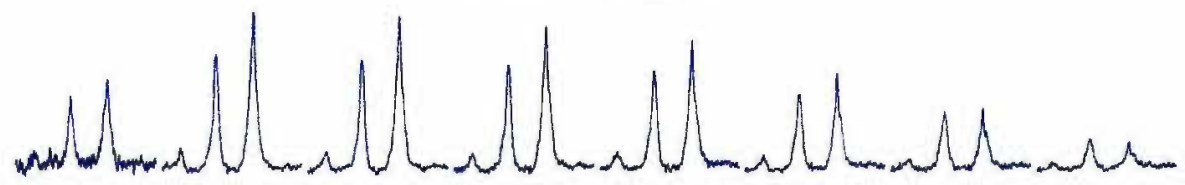

PSDT $-480^{\circ} \mathrm{C}$

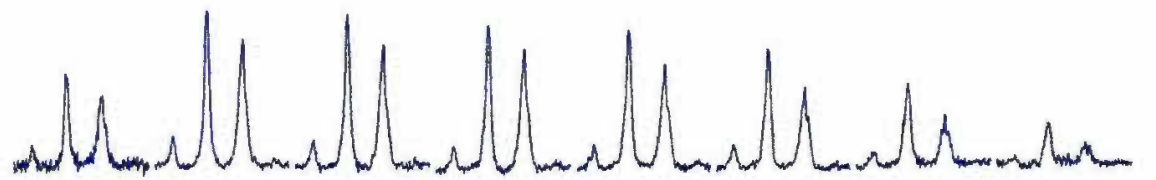

PSDT $-550^{\circ} \mathrm{C}$

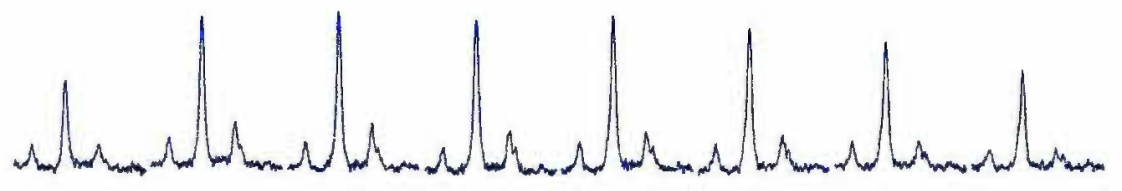

PSDT $-580^{\circ} \mathrm{C}$

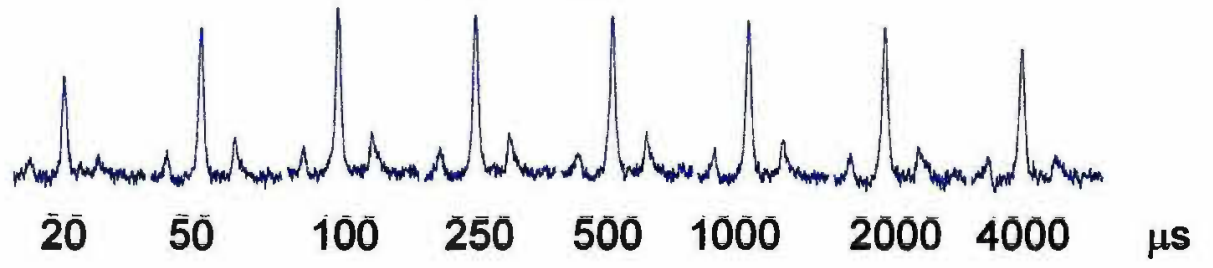

Figura A 41 - Espectros de RMN ${ }^{13} \mathrm{C}$ - CP/MAS com varredura do tempo de contato 
(a)

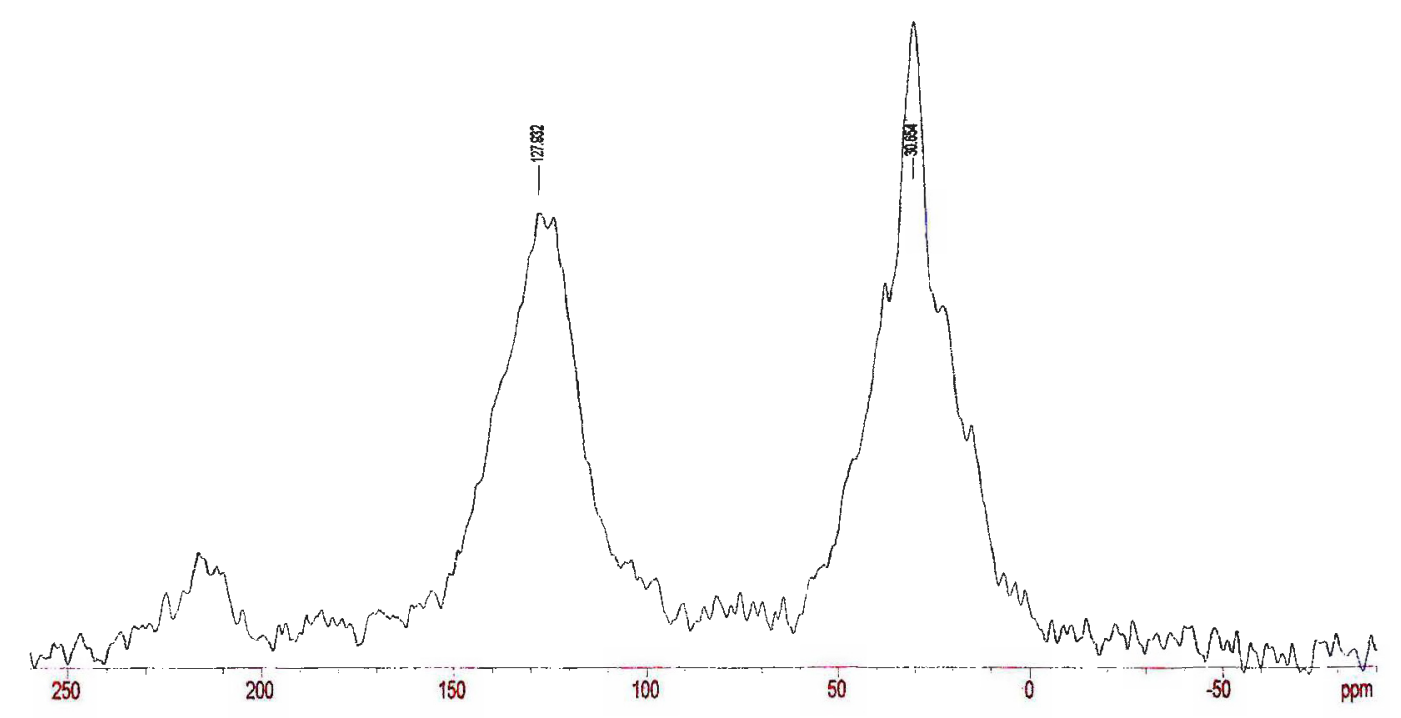

(b)

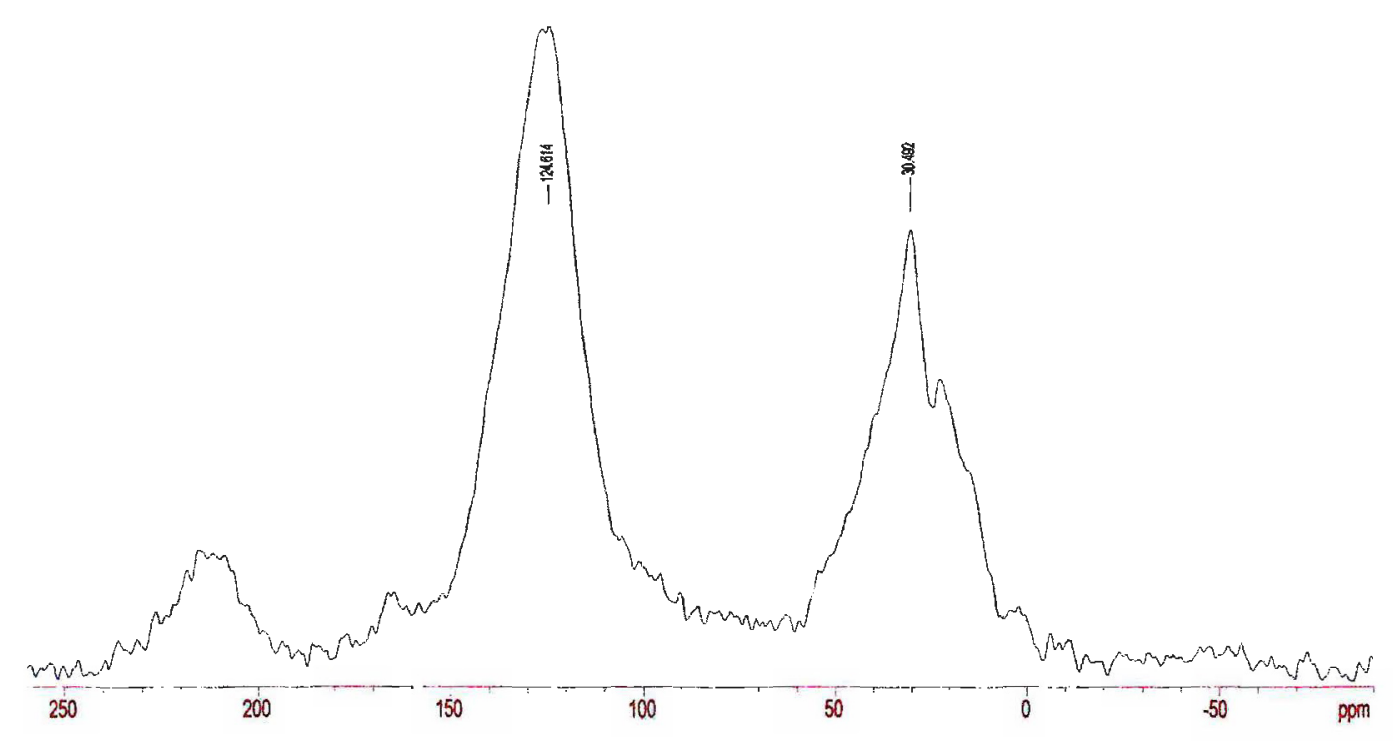

Figura A 42 - Espectros de RMN ${ }^{13} \mathrm{C}$ - MAS dos: a) PSDT-320 ${ }^{\circ} \mathrm{C}$ e b) PSDT$380^{\circ} \mathrm{C}$ 
(c)

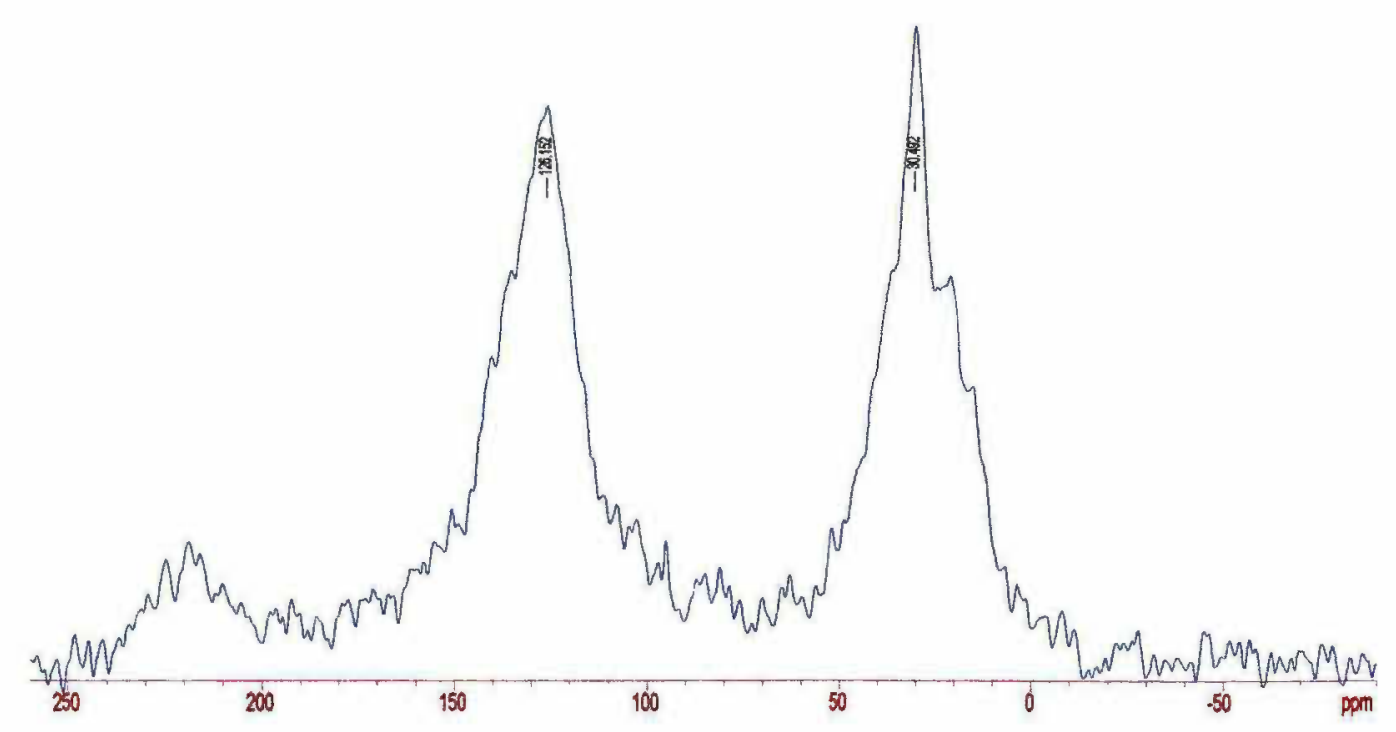

(d)

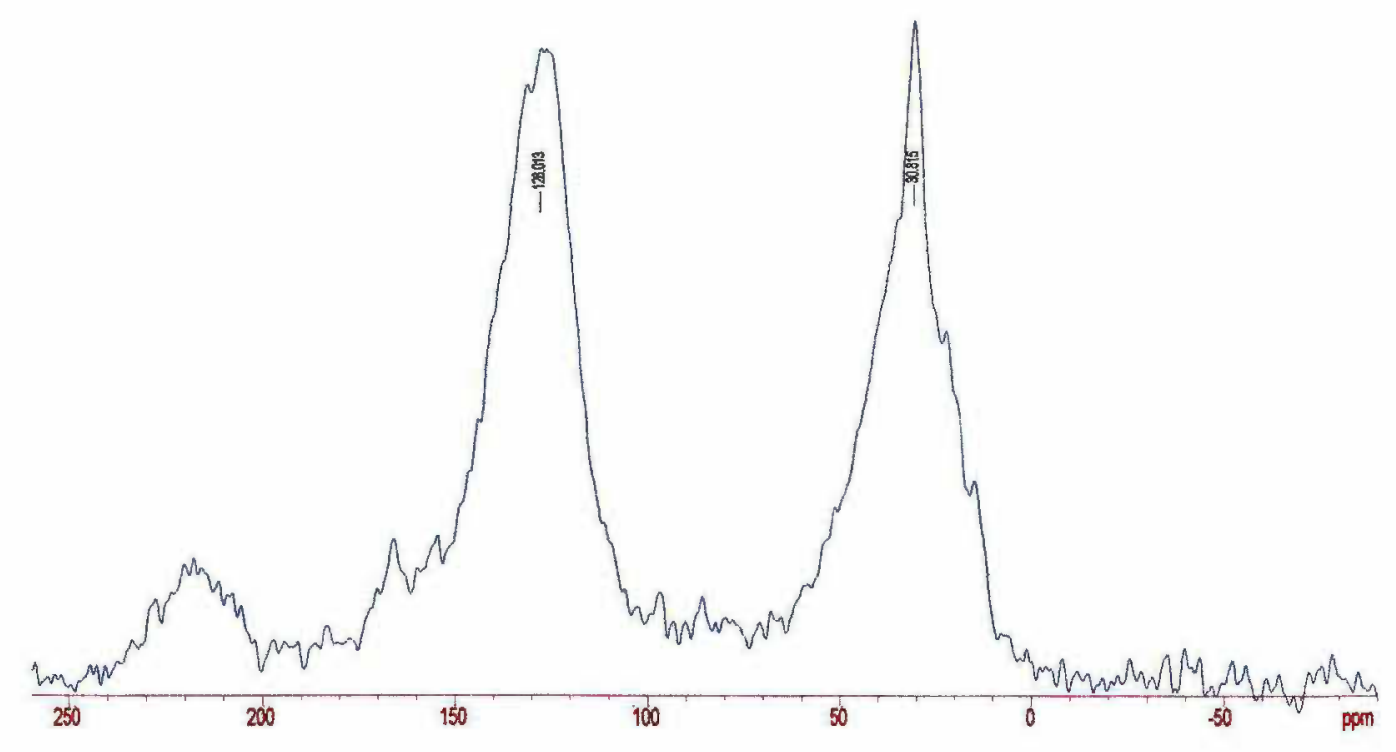

Figura A 43 - Espectros de RMN ${ }^{13} \mathrm{C}$ - MAS dos: c) PSDT-400 ${ }^{\circ} \mathrm{C}$ e d) PSDT$440^{\circ} \mathrm{C}$ 
(e)

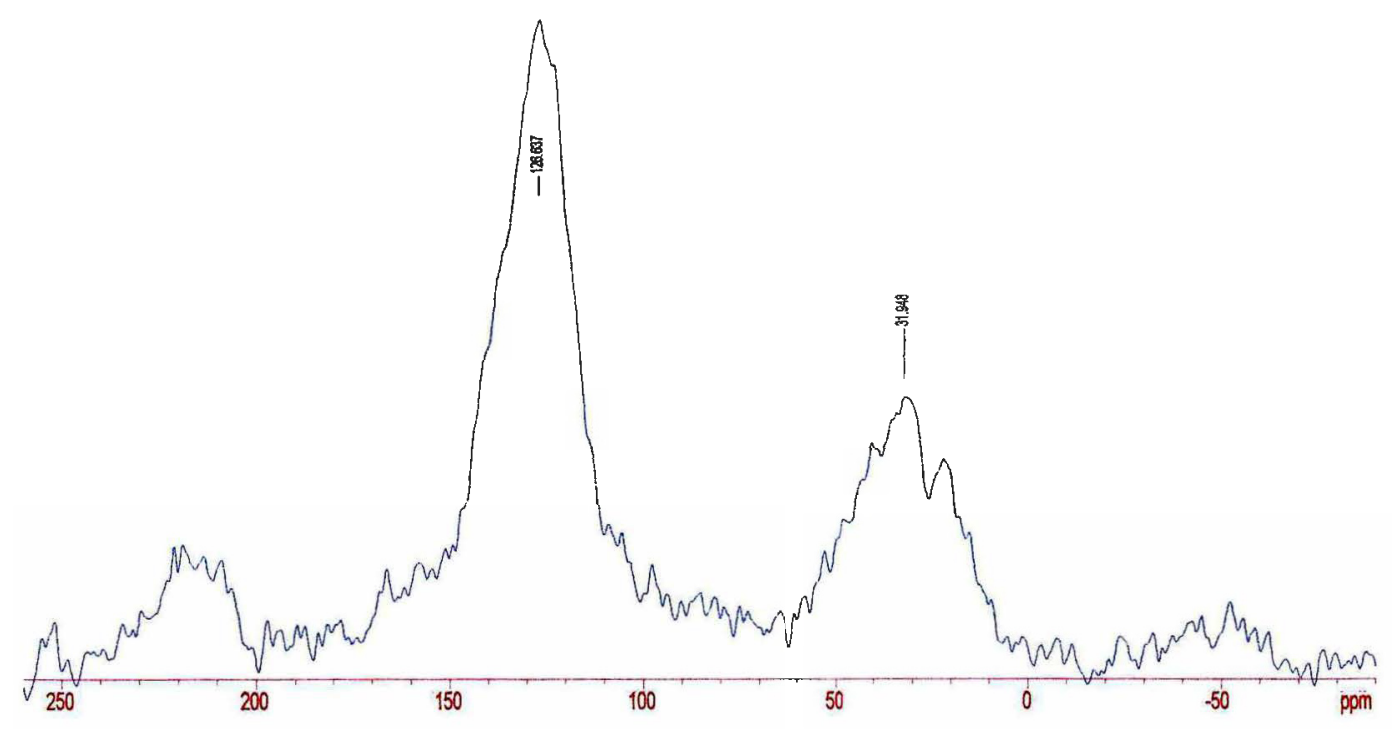

(f)

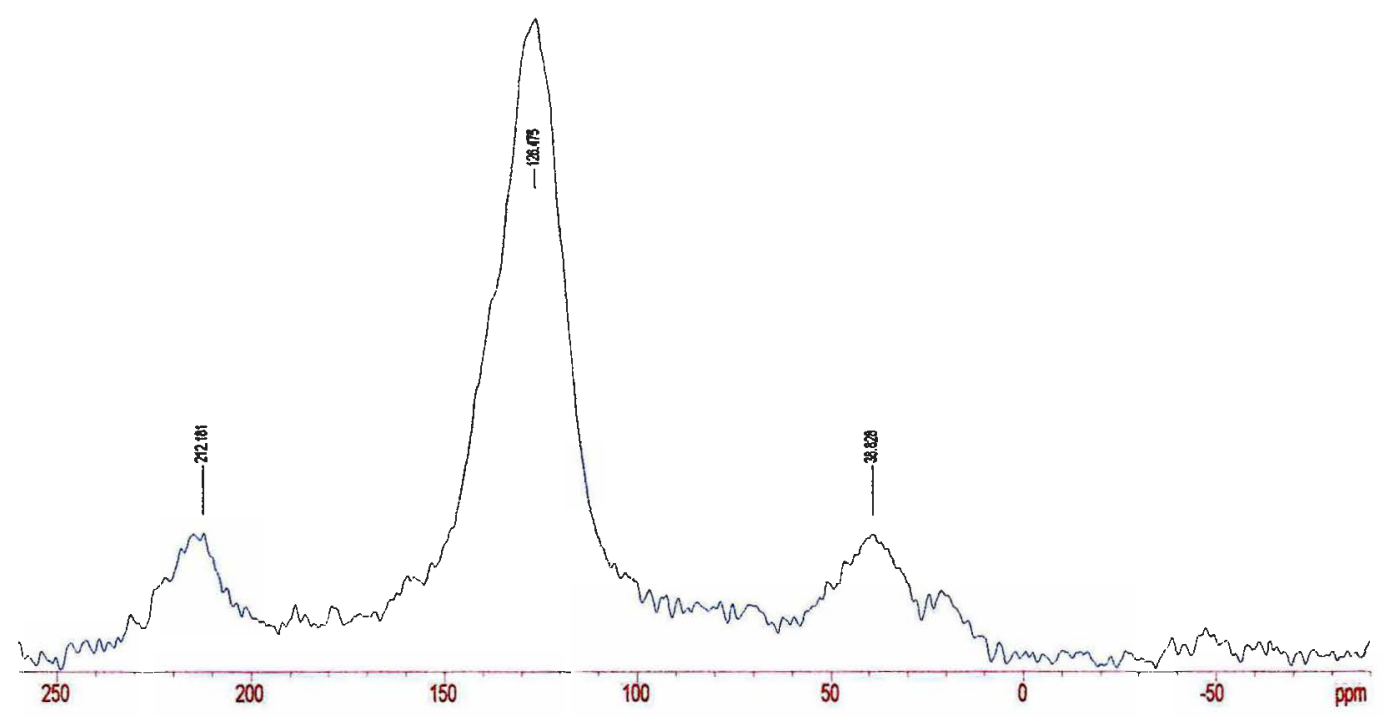

Figura A 44 - Espectros de RMN ${ }^{13} \mathrm{C}$ - MAS dos: e) PSDT- $480^{\circ} \mathrm{C}$ e f) PSDT$550^{\circ} \mathrm{C}$ 
(g)

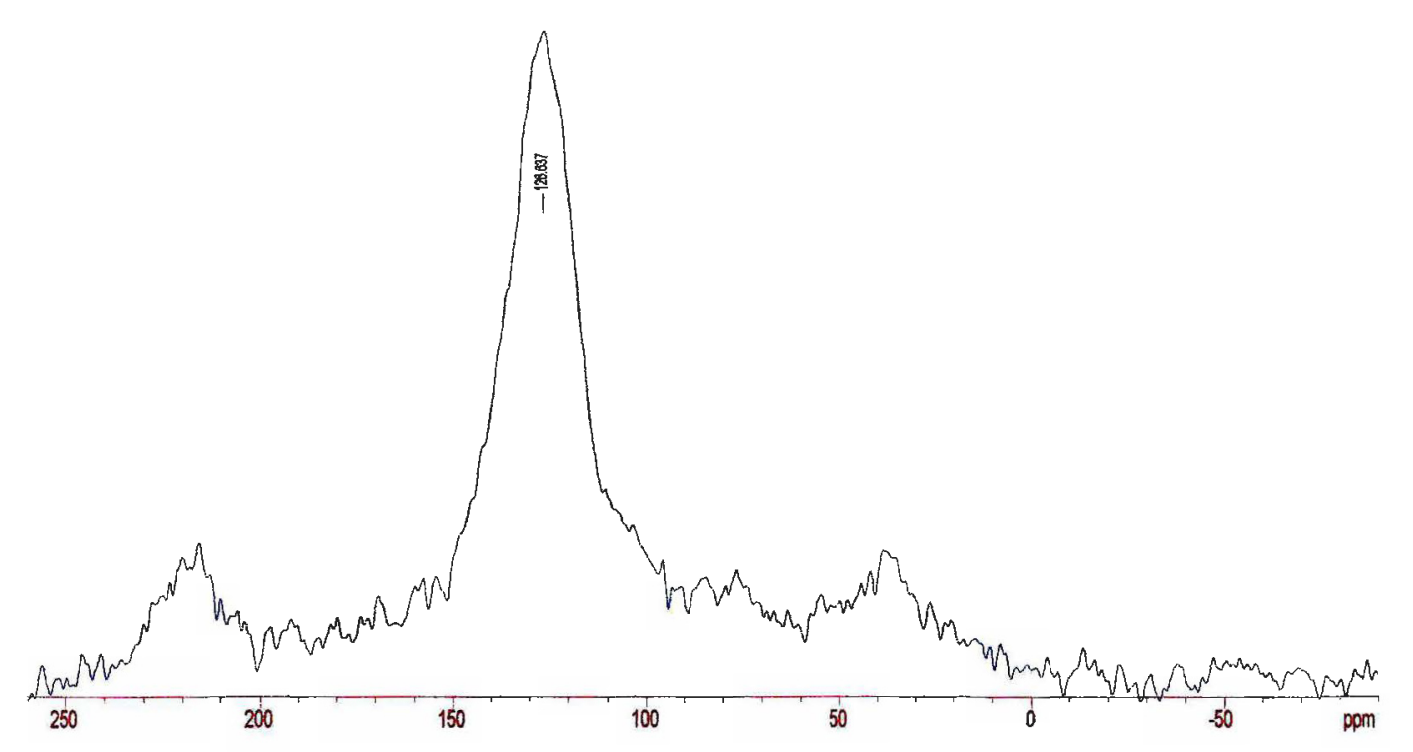

Figura A 45 - Espectro de RMN ${ }^{13} \mathrm{C}$ - MAS do: g) PSDT-580 ${ }^{\circ} \mathrm{C}$ 
Anexo 12 - Cromatograma de íons relativos a cada classe de ésteres dimetílicos gerados na reação RICO com os asfaltenos PSDTa $-400^{\circ} \mathrm{C}$ 
$\stackrel{\infty}{\stackrel{\circ}{\rho}}$

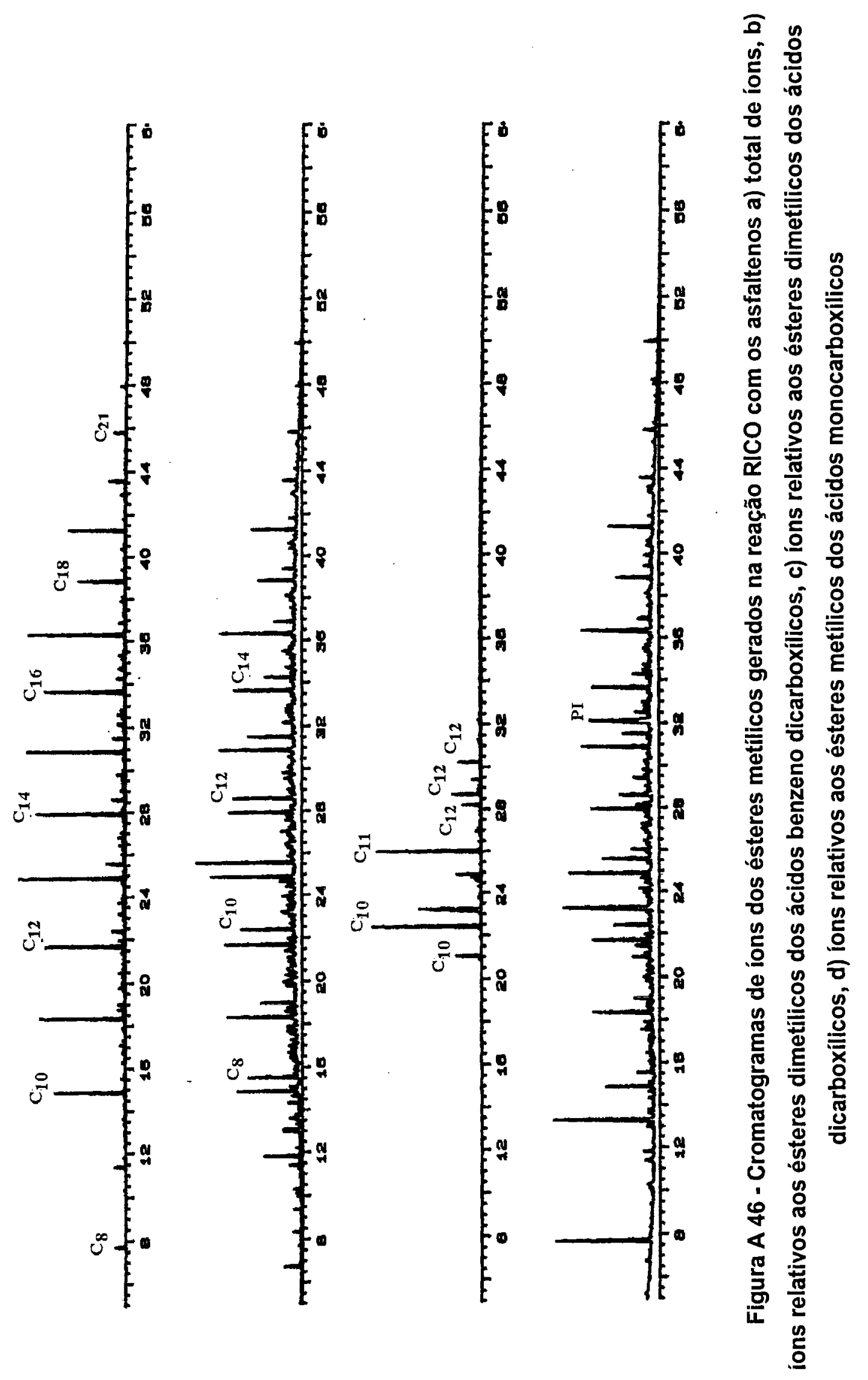


욤

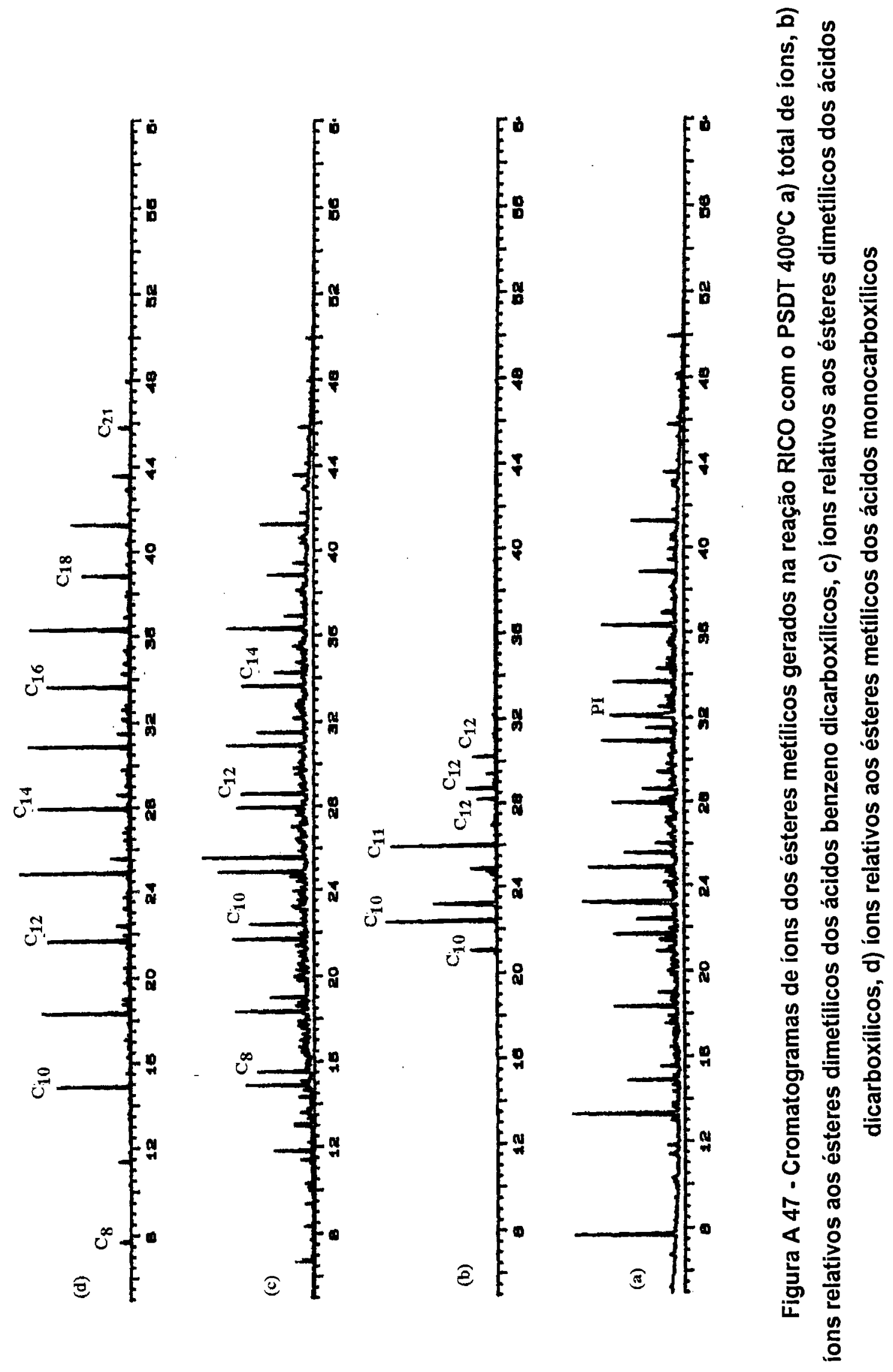

